\title{
Filles éveillées: Programme pour les adolescentes employées de maison-Guide du mentor
}

Population Council

Follow this and additional works at: https://knowledgecommons.popcouncil.org/departments_sbsr-pgy

Part of the Family, Life Course, and Society Commons, Inequality and Stratification Commons, and the Migration Studies Commons

How does access to this work benefit you? Let us know!

\section{Recommended Citation}

Population Council. 2011. "Filles éveillées: Programme pour les adolescentes employées de maison-Guide du mentor." New York: Population Council. 


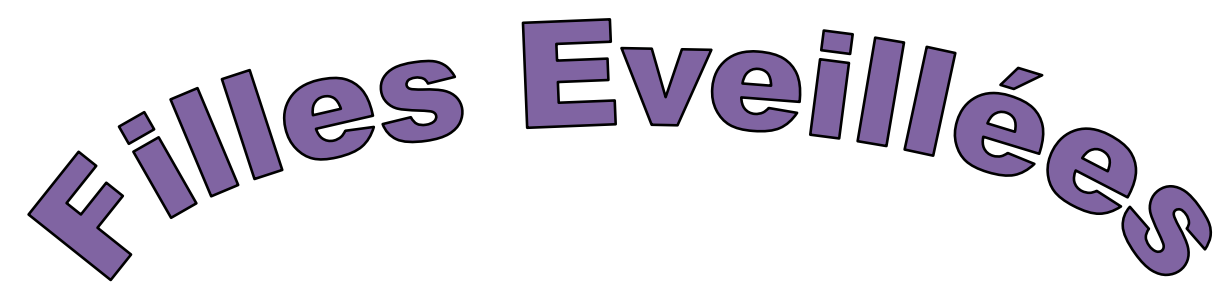

\section{PROGRAMME POUR LES ADOLESCENTES EMPLOYÉES DE MAISON}

\section{GUIDE DU MENTOR}
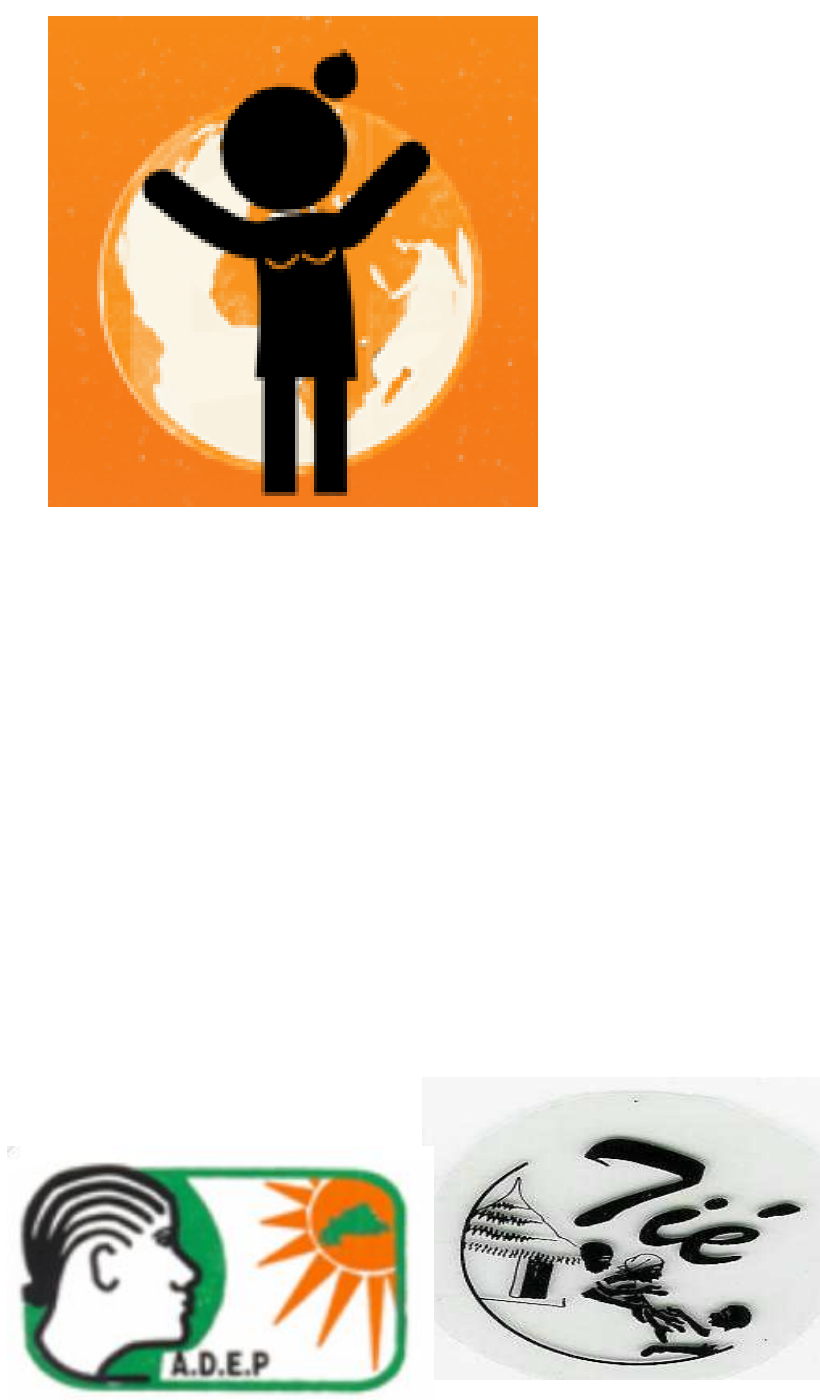


\section{(P) Population Council}

Population Council est une ONG internationale à but non lucratif dont le but est d'améliorer le bienêtre et la santé de la reproduction des générations actuelles et futures du monde entier et d'aider à atteindre un équilibre humain, équitable et durable entre les personnes et les ressources. Population Council mène des recherches dans trois domaines : VIH/SIDA ; Pauvreté, genre et jeunesse ; et Santé de la reproduction. Crée en 1952, Population Council a un conseil d'administration international. Son siège de New York appuie un réseau mondial de bureaux régionaux et nationaux.

Droits d'auteur $@ 2012$ - Population Council

Le présent document peut être reproduit totalement ou partiellement sans l'autorisation de Population Council à condition que la source soit citée en intégralité et que la reproduction ne soit pas à but commercial.

Citation suggérée : Population Council. «Filles Éveillées : Programme pour les adolescentes employées de maison. Guide du mentor. " $2^{\text {ème }}$ Ed. New York. 2012.

Pour plus d'informations, veuillez contacter : 


\section{Remerciements}

Ce Curriculum est l'œuvre de Sarah Engebretsen, Gisèle Kaboré, et Kate Barker de Population Council. Son contenu est largement inspiré de plusieurs curricula existants, y compris le document de Population Council, intitulé Life Skills: Psychosocial and Interpersonal Skills for Adolescent Girls in Urban Ghana ; le Biruh Tesfa Program for Adolescent Girls in Ethiopia ; le Girl-Centered Program Design: A Toolkit to Develop, Strengthen, and Expand Adolescent Girls Programs (Conception d'un programmes centré sur les filles : Une boîte à outils pour l'élaboration, le renforcement et l'expansion des programmes destinés aux adolescentes); et le «It's All One Curriculum» (Un Seul Programme). Nous y avons également intégré des adaptations de Tuko Pamoja: Adolescent Reproductive Health and Life Skills; Microfinance Opportunities et Freedom from Hunger's Young Women: Your Future, Your Money (les adaptations de Burundi et Kenya); les manuels de formation de Right to Play intitulé Live Safe Play Safe and Red Ball Child's Play manuals; AED Center for Gender Equality's Girls' Success: Mentoring Guide for Life Skills; et le Canadian Public Health Agency. Enfin, nous avons integré les supports visuels de le boîte d'images "Le conseil en planification familiale" de Marie Stopes International.

Nous adressons nos remerciements à Théodora Yaméogo pour la traduction minutieuse de ce document en français ainsi qu'à nos partenaires Association d'Appui et d'Eveil Pugsada (ADEP), Association Tié, et les mentors de la première phase du programme pour leurs précieuses contributions à l'amélioration de ce curriculum. Nos remerciements vont également à Leah Jarvis pour la révision du curriculum, et à l'endroit de Jacobs Foundation pour son appui à la réalisation de ce travail important. Merci aussi à la communauté de Bobo Dioulasso et de Ouagadougou et aux employeurs pour leur coopération et appui au programme. Enfin, un merci spécial aux adolescentes de Ouagadougou et de Bobo-Dioulasso qui prennent part à notre programme pilote. Nous apprécions l'énergie et l'enthousiasme que vous mettez à apprendre des compétences importantes et nécessaires pour une vie d'adulte saine.

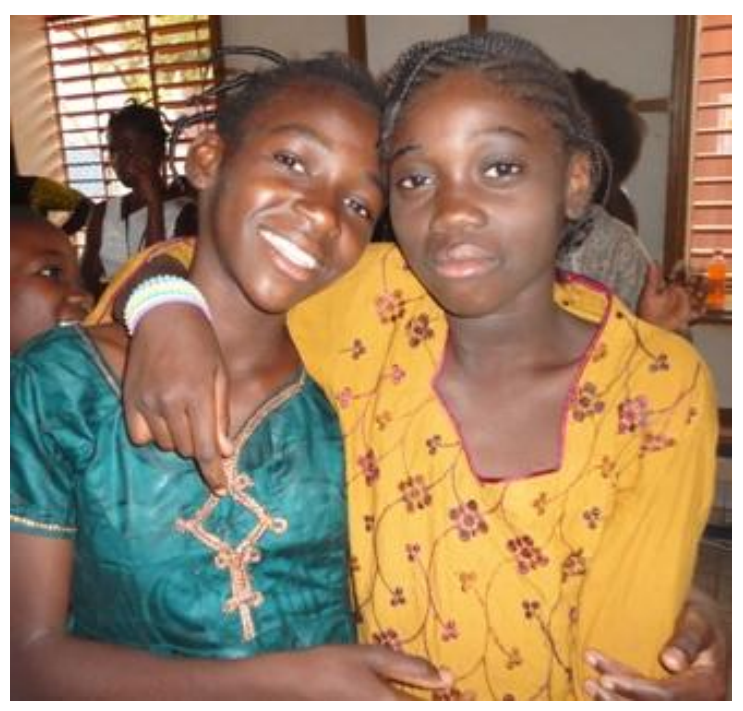

Photo: Association Tié

\section{Merci !}

\section{Introduction}


Ce curriculum est une composante du programme "Filles Éveillées » de renforcement des compétences et de création d'espaces sûrs pour les adolescentes migrantes engagées comme employées de maison dans les zones urbaines du Burkina Faso. L'approche du programme consiste à donner aux filles, un espace sûr qui leur est spécialement dédié et où elles peuvent rencontrer des amies et apprendre des sujets importants sous la direction d'un mentor de sexe féminin. Les adolescentes en milieu urbain sont confrontées à un large éventail de facteurs de risque, et font souvent montre d'un talent, d'une énergie et d'une résilience incroyables. Une gamme complète de programmation leur offrira les meilleures opportunités pour devenir des jeunes femmes fortes, confiantes et sages.

Le Curriculum comprend 30 sessions, allant de 60 à 90 minutes. La plupart des sessions devrait durer environ 75 minutes. Les séances sont conçues pour être réalisées dans l'ordre indiqué, en commençant par les compétences de vie courante, avant de passer aux capacités financières, puis à la santé et l'hygiène, et enfin à la santé sexuelle et de la reproduction. Chacune de ces sessions devrait être exécutée au cours d'une journée, et le programme Filles Éveillées devrait être mis en œuvre selon une séance hebdomadaire sur une période de 8 mois.

Les activités dans ce guide sont destinées aux adolescentes de 11 à 18 ans. Ce curriculum adopte une approche interactive, en utilisant divers jeux, jeux de rôle, activités en petits groupes, et discussions pour améliorer l'apprentissage et le renforcement des compétences des participantes. Beaucoup d'activités partent de l'hypothèse que les participantes ont un faible niveau d'instruction, de sorte que la majeure partie du travail de rédaction incombe au Mentor. Cependant, s'il y a des filles du groupe qui savent lire, le mentor peut modifier les activités afin que les filles puissent lire et/ou écrire davantage. 


\section{Qu'est-ce qu'un mentor?}

Dans ce programme, les mentors sont des femmes modèles issues de la communauté et qui dirigent les sessions hebdomadaires avec les filles. Un "modèle» est quelqu'un que les filles peuvent admirer parce qu'elle mène une bonne vie. Les mentors ont autrefois été des filles - ressemblant beaucoup aux filles qui sont maintenant sous leur mentorat - qui ont pris de bonnes décisions qui leur ont permis de réussir dans la vie. Les filles apprennent en écoutant les expériences des mentors.

Un mentor aide les filles à développer leurs capacités à opérer de bons choix. II s'agit entre autres d'aider les filles à voir différentes options ou façons de relever les défis et de prendre ensuite les meilleures décisions possibles. Les mentors posent des questions

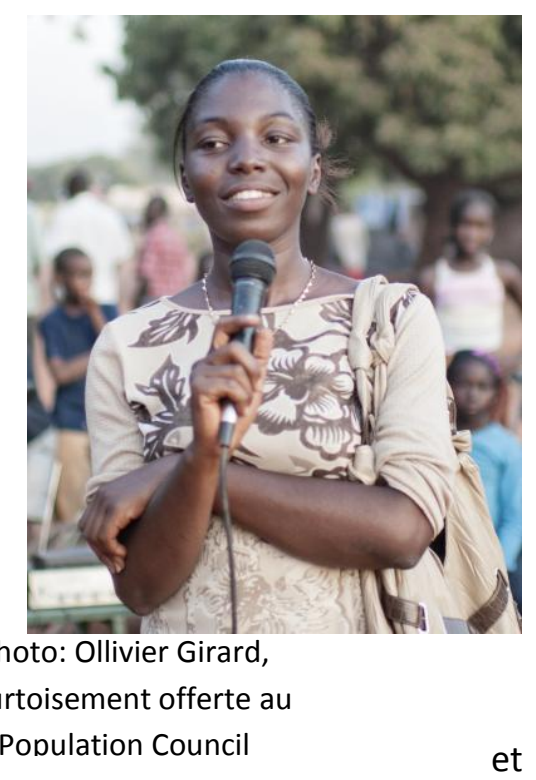
aident les filles à réfléchir sur des problèmes importants, à prendre des bonnes décisions et à réussir dans la vie. Un mentor encourage les filles à avoir des aspirations pour elles-mêmes. Un mentor se préoccupe réellement des jeunes femmes de la communauté. Elle renforce la confiance. Elle parle avec sagesse et écoute attentivement. Elle prévoit des sessions et activités de mentorat. Un mentor est disposé à faire de son mieux pour aider les filles à réussir.

Le mentorat offre aux filles la chance de passer du temps avec un adulte de confiance qui les accepte pour ce qu'elles sont. Un mentor encourage les filles à donner le meilleur d'elles-mêmes et les aident à réussir.

II n'est pas difficile d'être un bon mentor si l'on suit quelques règles importantes :

* Écouter! Un bon mentor sait bien écouter. Elle écoute et aide les filles à se sentir suffisamment à l'aise pour parler ouvertement. Une personne qui sait écouter n'interrompt pas ou ne juge pas les propos des filles. Elle accorde de la valeur aux sentiments et idées des filles, ce qui contribue à renforcer la confiance. Un mentor pose des questions pour encourager les filles à s'exprimer. Un interrogatoire minutieux aide les mentors à connaître les pensées des filles.

* Partager! Un bon mentor partage également des histoires sur ses expériences. Ces histoires ne doivent pas seulement porter sur des réussites, mais aussi sur les difficultés et les défis. En étant ouvertes et honnêtes avec les filles, les mentors gagnent la confiance et le respect de ces dernières. Les filles apprennent davantage des mentors lorsqu'elles comprennent que même les modèles ont des hauts et des bas comme tout le monde.

* Ne pas juger ou choisir des favoris! En ne jugeant pas les filles, un mentor aide les filles à se sentir en sécurité pour partager de nouvelles idées sans crainte de faire des erreurs. Un mentor ne montre pas sa préférence pour une fille par rapport à une autre, mais montre à toutes les filles qu'elles ont de la valeur et sont importantes.

* Féliciter! Un mentor doit donner un feedback aux filles et les féliciter pour leurs efforts de partage d'expérience, d'exécution des activités et de pratique de nouvelles compétences. II doit se rappeler 
que l'apprentissage de toutes ces compétences n'est pas aisé pour les filles, et qu'elles prennent leur temps libre pour participer au programme. Il doit reconnaître leurs efforts.

* Renforcer la confiance! Il est très important que les mentors ne partagent pas les informations privées de certaines filles avec les autres. Garder pour soi des informations privées permet de créer la confiance entre un mentor et les filles. Cependant, il peut arriver qu'un mentor puisse sentir une fille en danger ou exposée à des abus. Elle peut en ce moment partager des informations privées avec un autre adulte de confiance pour tirer cette fille du danger.

* Anticiper! Le mentor devrait prévoir que les jeunes femmes de son programme peuvent avoir une expérience limitée sur un sujet. Des simulations ou histoires peuvent remplacer l'expérience réelle.

* S'engager! Le mentor doit s'assurez qu'il y a tout au long de la session, une opportunité pour réfléchir, agir et ressentir.

* Ne pas attendre de cadeaux! Un bon mentor ne doit jamais demander de l'argent ou des cadeaux aux filles, aux familles des filles, ou tout autre membre de la communauté. Cela envoie un très mauvais message.

* Être fiable! Un mentor est fidèle dans l'exercice de ses fonctions de mentorat. Les filles doivent être en mesure de compter sur les mentors pour tenir leurs promesses, y compris les engagements à assister régulièrement aux rencontres, la ponctualité aux réunions, et le suivi de ce que les mentors promettent de faire.

- Donner des conseils sages! Un bon mentor donne des orientations claires aux filles. Elle ne choisit pas pour les filles ou ne leur dit pas quoi faire. Par ses conseils, un mentor peut aider les filles à opérer de meilleurs choix pour elles-mêmes. Un mentor n'est pas tenu d'avoir une réponse à tout. Elle est cependant assez sage pour savoir quand rechercher plus d'informations auprès des autres.

* Amusez-vous! Un bon mentor prend plaisir à faire du mentorat et à passer du temps avec les filles. Les filles sauront par son discours et ses actions qu'elle est contente de passer du temps avec elles. Encourager l'humour et utiliser des jeux interactifs afin de rendre les sessions dynamiques et amusantes! 


\section{Comment utiliser le présent guide?}

La description de chaque session commence par un encadré contenant les informations suivantes:

* Objectifs de la session - Connaître les objectifs de la session

- Matériel nécessaire - Ce dont vous avez besoin pour réaliser les activités prévues pour la session

* Plan de la session - Une liste des activités prévues pour la session, y compris la durée approximative de chacune d'elle

* Durée totale - Une estimation du temps nécessaire à la réalisation des activités de la session

Utilisez les durées indiquées pour chaque activité à titre indicatif. En fonction des participants, chaque activité peut prendre plus ou moins de temps ; ne soyez donc pas surpris.

Certaines activités exigent du mentor un peu de préparation avant la session. Regardez l'icône de cette check-list (liste de contrôle) qui indiquera si vous devez préparer certains travaux à l'avance. II est toujours bon de relire chaque session à l'avance pour s'assurer qu'on est prêt.

Beaucoup de descriptions de la session ont une section NOTES D'INFORMATION, qui comprend des informations à lire à l'avance par le mentor, pour s'assurer d'avoir une bonne compréhension du sujet. Vous pouvez également vous référer aux informations dans cette section pour vous aider à répondre aux questions que les filles peuvent avoir.

Chaque activité comporte des INSTRUCTIONS, étape par étape, pour vous guider dans l'animation de la session. Certaines des activités utilisent des documents de cours ou autres matériels que vous trouverez à la fin de la description de chaque session. Ces supports et le numéro de page figureront dans l'encadré, au début de la description de la session sous le point Matériel nécessaire. Une liste complete de matérieux nécessaires est en Annexe 1, à la page 191. Chaque support porte le nom de l'activité pour lequel il est écrit, à l'extrémité de la partie supérieure droite.

\section{Certaines sessions se terminent avec un TRAVAIL DE MAISON et qui sera} indiqué dans un encadré comme celui-ci.

Ces activités constituent une occasion pour les jeunes filles de prendre les leçons qu'elles ont apprises et de les appliquer à leur vie quotidienne. Elles impliquent souvent des conversations avec des amis ou des personnes dans la communauté. Certaines sessions commencent par un récapitulatif du TRAVAIL DE MAISON confié au cours de la dernière session. 
Termes

module.

2 à la
Clés dans ce Module: Ceci dénote les termes clés identifiés dans chaque Ces termes ont été traduits en Dioula et en Mooré et se trouvent en Annexe page 193 du Guide.

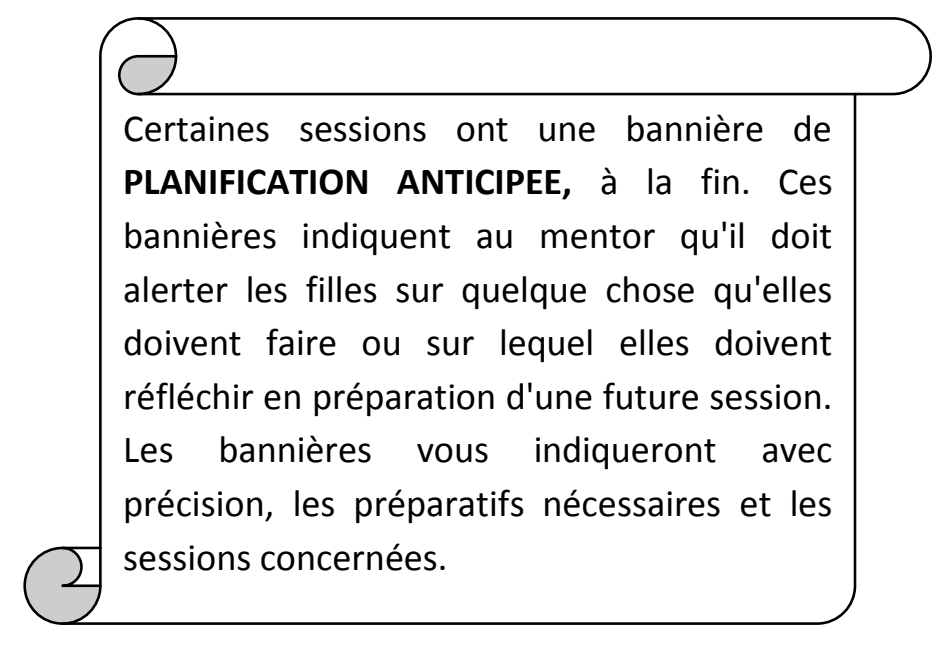

\section{Bonne chance et Amusez-vous bien!}




\section{TECHNIQUES DE FORMATION}

Les techniques de formation sur le curriculum Filles Éveillées ont été minutieusement choisies. Le principe de base a consisté à sélectionner les techniques qui servent d'outils de transformation, et qui ne sont pas simplement basés sur la mise à disposition d'informations ou la sensibilisation. Le dossier comprend des méthodes destinées à accroître la conscience et la sensibilité des participants; à développer leurs compétences ; à favoriser le changement d'attitude et à les motiver davantage. Il est important de se rappeler que la plupart des participants au programme sont analphabètes. II y a plusieurs sessions qui demandent au mentor d'écrire sur un flipchart. Le fait d'écrire sur le flipchart sert d'aide mémoire pour le mentor. Le mentor doit toujours lire à haute voix ce qui est écrit sur le flipchart. Une brève description de chaque technique de formation utilisée dans ce manuel est fournie ci-dessous :

Remue-méninges : Le remue-méninge est une méthode utilisée pour recueillir rapidement des opinions et des informations et générer des idées de façon créative et rapide. Chaque session devrait normalement y consacrer cinq ou dix minutes. Les règles du remue-méninge sont les suivantes : tout le monde participe; il y a un débat d'idées; et la discussion se fait rapidement. Des flipcharts ou un tableau blanc seront généralement utilisés au cours d'une session type de remue-méninge. Le mentor écrit les mots ou expressions clés des participants sur un thème ou un sujet donné et cela lui sert d'aide mémoire. II les relit à haute voix pour les filles vu que la plupart est illétrée.

Histoires : Les histoires utilisent les situations «réelles» pour illustrer différents aspects de la vie des filles. Des études de cas décrivent les situations et montrent comment la situation peut être comprise de façon éclairée

; analysée ; utiliser la résolution de problèmes et changer les attitudes. Ils expliquent également les processus, les réussites, les défis, les contraintes et les leçons en vue d'améliorer la compréhension des participants sur des questions spécifiques. Assurez-vous de lire ces histoires avant de les livrer, de manière à raconter ces histoires d'une manière vivante, sans lire la page. À certains moments, les mentors peuvent demander aux participants de proposer elles-mêmes, un scénario adapté.

Images : Une autre façon de rendre les sessions d'apprentissage plus vivantes et plaisantes est d'inclure des images. Les images ont été incluses dans ce guide de formation et peuvent être utilisées pour susciter des échanges entre les participants. Une autre option serait d'utiliser des objets réels à la place des images. Lorsque c'est possible, l'explication de la session doit insister sur les images, vu que la plupart des filles sont analphabètes.

Travaux ou discussions de groupe : C'est un outil efficace pour l'apprentissage par les pairs, l'enrichissement mutuel des idées et le partage d'expériences. Habituellement, les participants sont invités à former des groupes de cinq ou six, à discuter d'un thème donné avec des questions spécifiques pendant 20 à 30 minutes et ensuite à faire un rapport au groupe élargi. Le groupe choisit un leader pour diriger les débats. Le groupe devrait aussi décider de la personne qui va présenter les résultats de leur réflexion en session plénière. Après que le groupe ait présenté son point de vue au cours de la session plénière, des réponses peuvent être apportées aux questions du public par l'un ou l'autre des membres.

Mini-exposé: II s'agit d'un exposé formel, structuré et ordonné sur un sujet spécifique. Les mentors doivent utiliser des supports visuels tels que les affiches, les schémas et les flipcharts. Même si les conférences ont tendance à être la forme la moins plaisante de la formation, elles sont souvent, au même moment, les outils 
les plus efficaces, à condition que les participants soient intéressés et écoutent. Pour rendre les conférences plus intéressantes, il faut poser des questions et vérifier la compréhension que les participants ont de l'exposé. II est également essentiel de vérifier que tous sont «au même niveau». Avant de passer à un nouveau sujet, demandez aux participants ce qu'ils savent ou sentent par rapport au sujet précédemment abordé. Demandez également si un participant souhaite partager son expérience avec l'ensemble du groupe.

Exercices ou jeux de rôles: Les jeux de rôle et autres jeux sont souvent les parties les plus agréables d'un programme de formation. Lorsque les participants ont quelque chose à faire, plutôt que de s'asseoir, d'écouter ou de parler, cela peut être très stimulant pour le processus d'apprentissage. Les participants se souviennent souvent de la sensation d'avoir joué un rôle ou un jeu plus vivant que du contenu des informations données au cours d'une conférence. Ces techniques sont particulièrement utiles pour aborder :

- Les compétences: Même si d'autres techniques de formation peuvent augmenter les connaissances, les compétences sont normalement acquises par la pratique;

- Les émotions : Les participants font l'expérience de l'empathie avec les personnages dans le jeu de rôle et apprennent «directement »;

- Les attitudes: La technique aide les participants à réfléchir sur leurs propres attitudes par rapport au sujet;

- L'utilisation de ces techniques permet de manière interchangeable d'avoir une formation vivante et divertissante pour les participants et augmente l'acquisition des connaissances et compétences.

Visiteurs suggérés : Quelques sessions constituent un moment idéal à faire précéder ou suivre de la visite d'une ou des femme(s) de la communauté locale. Cependant, nous suggérons d'inviter chaque fois que cela est pratique et possible, un conférencier extérieur. Les filles tireront toujours profit de la rencontre et du fait d'apprendre auprès des femmes auxquelles elles s'identifient et qui peuvent servir d'exemples positifs et/ou de modèles.

\section{Formation de pairs}

1. Former des pairs en divisant le nombre total des participants par deux. Demandez aux participants de compter jusqu'au nombre correspondant à la moitié du total. Par exemple, si vous avez 20 participants, ils compteront jusqu'à 10 avant de recommencer à 1 . Les deux personnes ayant les mêmes numéros, sont des partenaires (les 1, 2, 3, etc.).

2. Demandez aux participants de se tourner vers la personne située à leur droite (ou gauche). Cette personne est leur partenaire.

\section{Moyens de formation des groupes}

1. Comptez. Par exemple, demandez aux participantes de compter par 4. Un par un, chaque participant donnera un nombre (le premier participant dira «1», le second " 2 », et au tour du cinquième participant, il recommencera à 1). Quand tout le monde a compté, demandez aux participantes de former des groupes avec les personnes qui ont le même numéro qu'elles. En fin de compte, vous aurez 4 groupes. 
2. Faites de simples puzzles avec 3-5 morceaux chacun. Distribuez les pièces du puzzle aux participantes et leur demander de trouver tous les autres qui ont des pièces pour compléter leur puzzle. Veillez à n'utiliser que des puzzles simples et à avoir le même nombre de pièces de puzzle que de participants.

3. Affectez des couleurs, des symboles ou des images au hasard. Demandez aux participants de trouver tous les autres qui ont la (le) même couleur, symbole ou image.

4. Placez les noms de 4 étoiles bien connues de la culture pop à différents endroits de la salle et demandez aux participants de se tenir à côté de leur étoile favorite. Si tout le monde va vers la même étoile, vous devrez ajuster l'exercice de sorte à vous retrouver avec plus d'un groupe. Par exemple vous pouvez demander aux participants de se déplacer vers leur deuxième star préférée. 


\section{Plan des sessions}

Session 1 : Introduction au programme et attentes du groupe .......................................................

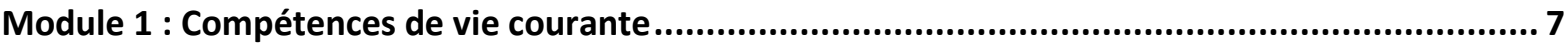

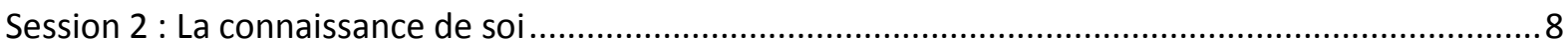

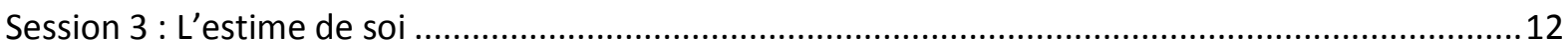

Session 4 : La fixation d'objectifs et le développement des plans ......................................................15

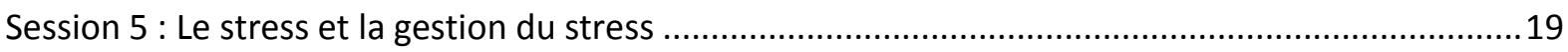

Session 6 : Les valeurs et comment elles influencent notre comportement ......................................22

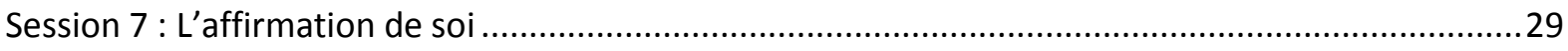

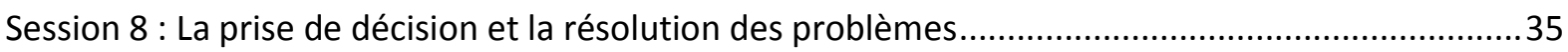

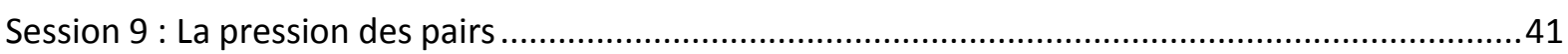

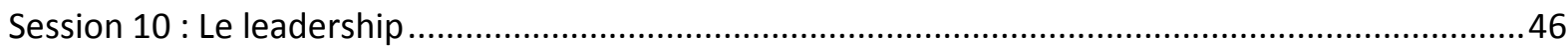

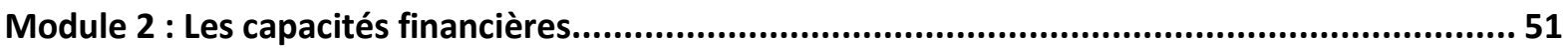

Session 11 : Introduction aux capacités financières et à l'argent ........................................................52

Session 12 : Épargner, objectifs d'épargne, et plans d'épargne........................................................57

Session 13 : Les méthodes et lieux sécurisés pour garder l'argent ..................................................64

Session 14 : Les façons de dépenser de l'argent ..........................................................................70

Session 15 : Emprunter prudemment et obtenir une grosse somme d'argent..................................76

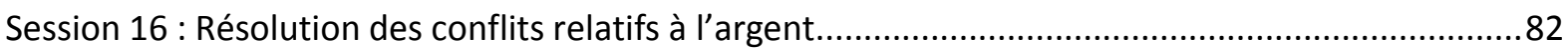

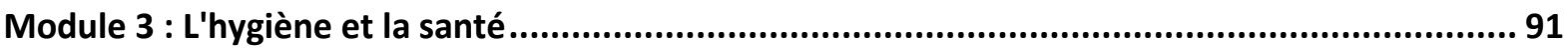

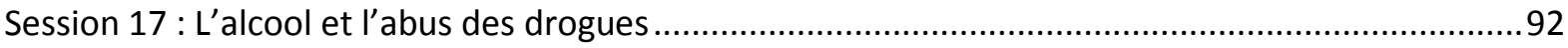

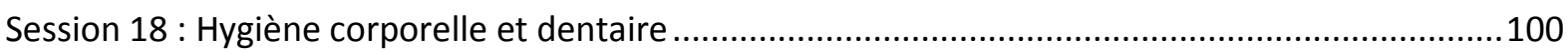

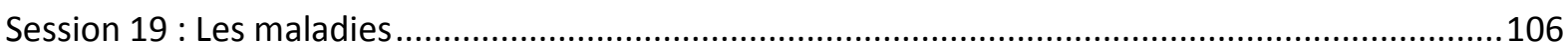

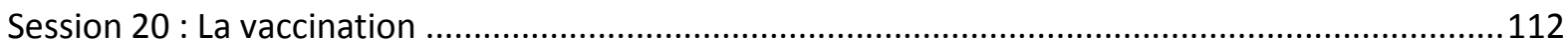

Session 21 : La fréquentation des services de santé par les adolescentes......................................118

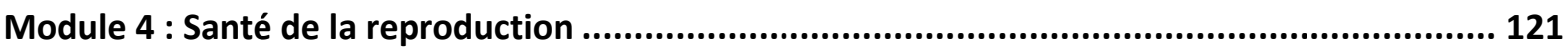

Session 22 : La période d'adolescence et les systèmes reproductifs des hommes et des femmes...122

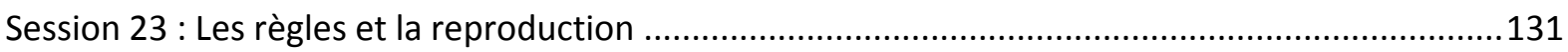

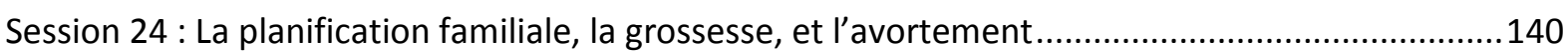

Session 25 : Gestion de la grossesse et accouchement, fistule obstétricale et excision.....................151

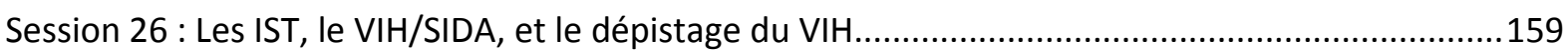

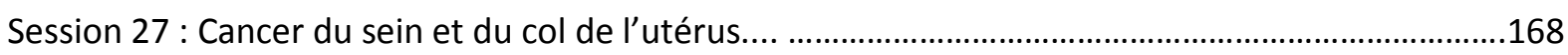

Session 28 : Information et communication sur la sexualité et sur la santé de la reproduction ........173

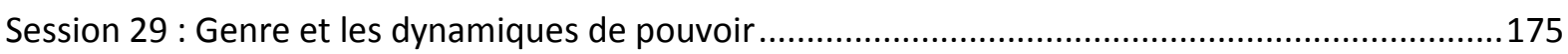

Session 30 : Le harcèlement sexuel, la violence de genre et sexuelle, l'abus ..................................182

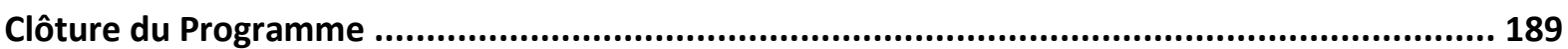

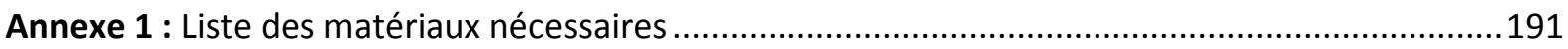

Annexe 2 : Traduction des mots clés du curriculum en Mooré et en Dioula ....................................194 


\section{Session 1 : Introduction au programme et attentes du groupe}

\section{Objectifs de la session :}

À la fin de cette session, les filles seront capables de :

- Identifier leurs mentors comme leaders du groupe

- Nommer et décrire d'autres filles dans leurs groupes

- Décrire la vie d'une fille dans leur communauté

- Expliquer les objectifs et les attentes du programme

\section{Matériel nécessaire:}

- Balle

- Papier flipchart et marqueurs

- Un appareil photo

Plan de la session:

- Présentation du mentor et du programme (10 minutes)

- Présentation des filles (15 minutes)

- L'importance d'avoir une pièce d'identité officielle (CNIB) (10 minutes)

- Une journée dans la vie d'une fille (20 minutes)

- Définition des attentes du groupe (15 minutes)

- Photographies individuelles pour les cartes d'identité du programme (qui aura lieu pendant les sessions «Une journée dans la vie d'une fille» et «Définition des attentes du groupe»)

- Choix d'un nom pour ce groupe spécifique (10 minutes)

- Services disponibles pour remédier à la violence (10 minutes)

Durée totale: 90 minutes

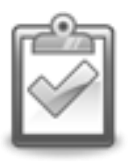

AVANT LA SESSION : Collectez des informations sur les services médicaux, juridiques, psycho-sociaux et foyers de refuge sécuritaires dans la communauté en utilisant le document fourni à la fin de cette session. Faites des copies de la liste des services et informations de contact et donner une copie à chaque fille.

\section{NOTES D'INFORMATION}

Les filles peuvent ne pas se connaître et être habituées à être membre d'un groupe. Elles pourraient être très calmes et timides. Essayez de les faire sortir de leur coquille, mais si elles semblent très mal à l'aise, n'en faites pas trop. Nous voulons que les filles se sentent à l'aise afin de continuer à prendre part au programme. 


\section{INSTRUCTIONS}

\section{$\rightarrow$ Présentation du mentor et du programme (10 minutes)}

1. Demandez aux filles de s'asseoir en forme de cercle où elles peuvent se voir les unes des autres.

2. Présentez-vous aux filles, en donnant votre nom, votre origine, et dites leur quelque chose d'inhabituel sur vous pour aider les filles à s'en souvenir.

3. Expliquez que le programme Filles Éveillées est destiné aux filles comme elles qui ont émigré, qui vivent à Ouagadougou ou à Bobo-Dioulasso et qui travaillent dans des domiciles. Ce programme sera l'occasion pour elles de rencontrer d'autres filles de leur âge, d'acquérir des connaissances et des compétences importantes, d'en apprendre davantage sur les nouvelles opportunités et d'avoir un environnement de confiance où elles peuvent poser des questions à leurs mentors. Expliquez les raisons du choix de "Filles éveillées " comme nom du programme : une fille qui a des compétences de vie courante, qui peut faire face à des situations qui se présentent à elle, qui est respectueuse, qui tient aux valeurs sociales, etc.

4. Décrivez votre rôle en tant que mentor, ou leader : pour organiser le groupe, diriger les sessions, partager des connaissances, enseigner des compétences, et servir de ressource pour les filles.

5. Décrivez la structure et les domaines d'intervention du programme :

- 30 sessions

- Une réunion chaque dimanche

- Domaines à aborder au cours du programme : compétences de vie courante, capacités financières, santé et hygiène, et santé sexuelle et de la reproduction.

6. Dites aux filles que c'est important de participer à toutes les sessions, et qu'à la fin du programme les filles qui sont venues au moins à 20 sessions recevront des certificats de mérite. Expliquez aux filles qu'à la fin du programme elles vont identifier de commun accord deux filles qui ont présenté les charactéristiques et les qualités d'un leader. Elles vont voir de façon plus approfondie ce que signifie un leader dans la session 10.

\section{Présentation des filles (15 minutes)}

1. Demandez aux filles de se tenir debout et de former un cercle.

2. Expliquez que chaque fille doit donner certaines informations lorsqu'elle se présente (vous pouvez ajouter "quelque chose de différent ou de spécial sur vous-mêmes» aux informations habituellement fournies, y compris le nom, la nourriture préférée, ou les intérêts principaux).

3. Puis lancez une balle molle (ou une chaussette enroulée ou une pelote de laine) à quelqu'une dans le cercle pour qu'elle se présente.

4. Après s'être présentée, elle lance la balle à quelqu'une d'autre dans le cercle.

5. Le jeu continue jusqu'à ce que tout le monde ait pu se présenter. 


\section{$\rightarrow$ L'importance d'avoir une pièce d'identité officielle (10 minutes)}

1. Demandez aux filles de lever la main si elles ont un extrait de naissance. Maintenant, demandez aux filles de lever la main si elles ont une pièce d'identité officielle, une Carte Nationale d'Identité Burkinabé (CNIB) par exemple.

2. Demandez aux filles s'il est important pour un individu comme elle d'avoir une pièce d'identité officielle, et pourquoi? Si elles sont timides, vous pouvez donner des exemples :

- Pour s'inscrire à l'école

- Pour obtenir le certificat d'étude primaire

- Pour voter

- Pour obtenir un permis de conduire

- Pour ouvrir un compte à la banque

- Pour retirer de l’argent à la banque

- Pour voyager

3. Expliquez aux filles que pour obtenir une pièce d'identité oficielle, il faut avoir un extrait de naissance. Si elles ont un extrait de naissane, c'est une bonne idée de l'avoir avec elles en ville pour pouvoir établir une pièce d'identité, avec l'aide du mentor si c'est necessaire.

Si elles n'ont pas d'extrait de naissance, expliquez aux filles que c'est possible de se faire établir un jugement supplétif, qui est un document officiel qui remplace l'extrait de naissance. Il faut le faire avec les parents et avec un témoin à la préfecture ou à la mairie du lieu où elles sont nées.

\section{Une journée dans la vie d'une fille (20 minutes)}

* N.B. : La séance photo des participantes devrait avoir lieu lors de cette activité et la prochaine, sous la direction d'un chargé de programme)

1. Divisez les filles en petits groupes.

2. Demandez à chaque groupe de réfléchir à la vie d'une adolescente comme elles dans leur communauté, et de discuter les activités que font les filles comme elles dans la journée (10 minutes).

3. Faites le tour de la salle et demandez aux filles de décrire une journée type de la vie d'une fille (donnez-lui un nom) dans leur communauté. Imaginez l'emploi de temps journalier de cette fille. II importe aussi de procéder à cet exercice à la troisième personne, pour que les filles parlent d'une «fille typique» et pas directement d'elles-mêmes. Cette approche les aide à s'ouvrir et à parler plus librement.

4. Regroupez les filles et demandez à chaque groupe de partager ses idées et de décrire la vie d'une fille dans sa communauté. Engagez la conversation, en posant les questions suivantes: (15 minutes)

- Qu'est-ce qu'elle aime dans le programme de sa journée ?

- Qu'est-ce qu'elle n'aime pas ?

- En quoi sa journée diffère-t-elle de celle de son frère ? De sa sœur aînée ? Et de sa petite sœur?

- Où va-t-elle pendant la journée, et avec qui ? 
- Quels sont les problèmes ou difficultés typiques qu'elle risque de rencontrer pendant cette journée?

- Si elle pouvait changer une chose dans sa journée, qu'est-ce qu'elle chagerait ? Comment pourrait-elle s'y prendre?

\section{$\rightarrow$ Définition des attentes du groupe (15 minutes)}

1. Expliquez au groupe que l'apprentissage est facilité dans un environnement où tous les participants et le mentor conviennent d'un ensemble d'attentes comportementales à suivre par tous, tout au long de la formation. Il s'agit par exemple du « respect mutuel», de la «ponctualité» ou autres.

2. Demandez aux participants d'exprimer leurs opinions sur le programme et de proposer des règles et attentes éventuelles. Écrivez les suggestions sous deux rubriques : "Attentes des participants» et «règles de base». Les règles de base peuvent inclure: (i) la participation régulière; (ii) la ponctualité ; (iii) la participation à toutes les sessions; (iv) le fait de parler avec tout le groupe -pas de discussions en aparté parmi les participants; ( v) le fait de parler honnêtement, de façon à optimiser l'apprentissage sur la base de discussions franches; (vi) le respect des points de vues des uns et des autres; (vii) la discussion sur les problèmes et non sur les personnes qui les ont soulevés et ainsi de suite.

3. Après quelques minutes de remue-méninges, revoyez les points abordés afin de déterminer s'ils doivent figurer sur la liste finale.

4. Les mentors doivent également ajouter les points qu'elles jugent importants pour maintenir un environnement positif.

\section{$\rightarrow$ Photographies individuelles pour les cartes d'identité}

\section{* N.B. : Cette activité devrait avoir lieu au cours des deux activités précédentes}

1. Demandez à chaque fille la permission de prendre sa photo pour une carte d'identification au programme.

2. Photographiez chaque fille individuellement. Demandez-lui de sourire!

3. Demandez son nom complet, son lieu d'origine, son lieu de résidence actuel, et sa date de naissance, si elle le sait.

\section{$\rightarrow$ Choisissez un nom pour le groupe (10 minutes)}

1. Expliquez que le programme est appelé «Filles Éveillées » et concerne plusieurs groupes comme le leur qui se réunissent une fois par semaine. Chaque groupe doit choisir un nom pour s'identifer.

2. Réfléchissez sur des noms de groupe possibles et enregistrez-les tous. Relisez la liste entière. 
3. Demandez aux filles de fermer leurs yeux. Expliquez aux filles que chacune d'elles peut voter pour un nom en levant la main. Commencez le vote.

4. Partagez le nom choisi par le groupe spécifique.

\section{$\rightarrow$ Services disponibles pour remédier à la violence (10 minutes)}

1. Expliquez aux filles que la plupart des filles employées de maison sont des migrantes, qui vivent dans la famille d'accueil, elles sont souvents confrontées à des problèmes divers. II est important qu'elles aient des informations sur des lieux et services qu'elles peuvent contacter en cas de problème. Expliquez aux filles qu'elles peuvent se référer à vous ou contacter les services concernés.

2. Présentez les informations et les adresses des services disponibles pour remédier à la violence que vous avez collectée à l'avance. Donnez la parole aux filles pour les questions. Donnez des réponses appropriées. Distribuez la liste des adresses à chaque fille et les invitez à contacter ces services en cas de besoin.

3. Remerciez les filles pour leur participation au programme, et dites-leur que vous avez hâte de les revoir la semaine prochaine et toujours.

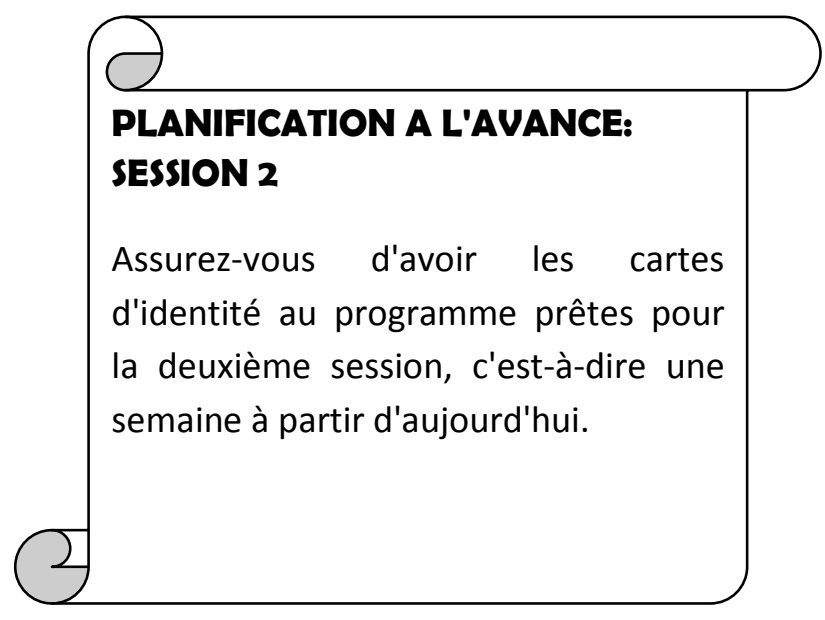




\section{Liste des services disponibles pour remédier à la violence}

(Activité: Réagir à la violence sexuelle et de genre)

\begin{tabular}{l|l|}
\hline ADRESSE PHYSIQUE & \\
\hline TRANSPORTS PUBLICS & \\
\hline NUMÉRO DE TÉLÉPHONE & \\
\hline COÛT & \\
\hline SERVICES ASSURÉS & \\
(contraception d'urgence/prévention de grossesse. & \\
dépistage et traitement des infections sexuellement & \\
transmissibles, prévention PPE-VIH, traitement de la & \\
douleur, collecte de données, conseil) & \\
\hline
\end{tabular}

\begin{tabular}{|c|c|}
\hline ADRESSE PHYSIQUE & \\
\hline TRANSPORTS PUBLICS & \\
\hline NUMÉRO DE TÉLÉPHONE & \\
\hline COÛT & \\
\hline $\begin{array}{l}\text { SERVICES ASSURÉS } \\
\text { (contraception d'urgence/prévention de grossesse, } \\
\text { dépistage et traitement des infections sexuellement } \\
\text { transmissibles, prévention PPE-VIH, traitement de la } \\
\text { douleur, collecte de données, conseil) }\end{array}$ & \\
\hline
\end{tabular}

Appellez le 17 (la police)

Appellez le 18 (sapeurs pompiers) 


\section{Module 1}

\section{Compétences de Vie Courante}

Session 2: La connaissance de soi

Session 3: L'estime de soi

Session 4: La fixation d'objectifs et le développement des plans

Session 5: Le stress et la gestion du stress

Session 6: Les valeurs et comment elles influencent notre comportement

Session 7: L'affirmation de soi

Session 8: La prise de décision et la résolution des problèmes

Session 9: La pression des pairs

Session 10: Le leadership

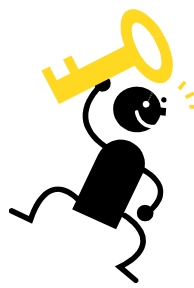

Termes Clés dans ce Module: affirmation de soi, agressivité, choix, compétences de vie courante, comportement, connaissance de soi, conséquences, défi, développement de plans, estime de soi, fixation des objectifs, leader, leadership, plan, pression des pairs, prise de décision, programme, résolution des problèmes, sentiment, stress, valeurs. 


\section{Session 2 : La connaissance de soi}

\section{Objectifs de la session:}

À la fin de cette session, les filles seront capables de:

- Expliquer le concept de la connaissance de soi

- Identifier leurs sentiments

- Identifier leurs propres caractéristiques, goûts, dégoûts, craintes et forces

- Reconnaître leur identité en tant qu'individu et un participant au programme à travers leurs nouvelles cartes de participante

\section{Matériel nécessaire:}

- Flipchart et marqueurs pour le tableau intitulé «A propos de moi et moi-même»

- Cartes d'identité individuelles

\section{Plan de la session:}

- Comprendre la connaissance de soi (5 minutes)

- Identifier nos sentiments dans différentes situations (30 minutes)

- «Moi et moi-même» (40 minutes)

- Distribution des cartes d'identité du programme (15 minutes)

Durée totale: 90 minutes

AVANT LA SESSION : Ecrivez la liste intitulé "A propos de moi et moi-même» dans le flipchart pour utilisation dans l'Activité \#3 (page 10).

\section{NOTES D'INFORMATION}

II pourrait être difficile pour certaines des participantes de parler d'elles-mêmes et de leurs caractères. Encouragez-les en disant que nous avons tous des qualités positives et négatives. Rappelez-vous en tant que mentor que vous voulez créer un environnement convivial dans lequel les filles se sentent à l'aise pour s'exprimer.

La connaissance de soi implique la compréhension de sa propre personnalité, de ses forces, de ses faiblesses, de ses pensées, de ses croyances, de ses émotions et motivations. La connaissance de soi peut aider une personne à développer de bonnes relations avec les autres, à vivre de manière productive, à aimer, à s'accepter et à renforcer sa confiance. Elle peut aussi aider une personne à identifier et à améliorer ses faiblesses. Les faiblesses ne devraient pas empêcher une personne de s'accepter telle qu'elle est. Sans la connaissance de soi, une personne peut être trop dépendante des réactions des autres.

À mesure qu'une personne développe sa connaissance d'elle-même, elle arrive à opérer des changements dans ses pensées et interprétations. Ce type de flexibilité est une caractéristique importante de l'intelligence émotionnelle et une étape essentielle dans la maîtrise des émotions et du comportement. 


\section{INSTRUCTIONS}

$\Rightarrow$ Comprendre la connaissance de soi (5 minutes)

1. Partagez la définition fournie pour «la connaissance de soi» dans la section «Notes d'informations».

2. Dites aux filles qu'elles apprendront aujourd'hui, à être plus conscientes de qui elles sont et comment cela affecte leur perception d'elles-mêmes et leurs interactions avec les autres.

\section{$\rightarrow$ Identifier nos sentiments dans différentes situations (30 minutes)}

1. Expliquez aux répondants que la connaissance de soi est en partie, le fait de savoir comment l'on réagira dans différentes situations. Contrairement à la douleur physique ou la privation où il y a une réaction physique automatique, nos réponses à de nombreux événements et circonstances de notre vie peuvent varier considérablement en fonction de nos perceptions et croyances par rapport à la situation.

2. Invitez les filles à analyser leurs sentiments dans les situations suivantes :

\section{Scénario 1}

a. Vous marchez dans la rue et vous voyez votre petit ami parlant, souriant et riant avec une fille que vous n'avez jamais vu auparavant.

Demandez aux filles d'énumérer leurs sentiments, y compris l'agacement, la colère, la jalousie, l'irritation et la frustration. Écrivez-les sur un papier flipchart.

b. Vous découvrez ensuite le cousin de votre copain visiter la ville et présenter la fille autour de lui. Comment vous sentez-vous maintenant?

\section{Scénario 2}

a. Vous êtes informé par votre employeur que vous pouvez rentrer chez vous en fin juin aider votre famille dans les travaux champêtres pendant la saison des pluies. Votre employeur vous dit ensuite que vous ne pouvez pas partir avant la fin du mois de juillet.

Écrivez les sentiments des filles sur le flipchart.

b. Vous découvrez que la fille de votre employeur est morte et qu'il pourrait avoir besoin d'une aide supplémentaire pour le ménage.

Comment vous sentez-vous maintenant?

\section{Scénario 3}

a. Vous marchez dans la rue et voyez une jeune fille de votre village et son amie parler à un garçon que vous ne connaissez pas. Elle sourit et rit avec lui. 
Écrivez les sentiments des filles sur le flipchart.

b. Vous découvrez qu'elles ne faisaient que parler au neveu de son employeur qui est venu lui rendre visite. Comment vous sentez-vous maintenant?

3. Animez un débat en posant les questions suivantes :

- Qu'est-ce-qui a changé du scénario «a» au scénario «b» dans chaque exemple?

- Pourquoi vos sentiments diffèrent-ils dans les différents exemples?

- Pouvez-vous penser à d'autres situations où vos sentiments ou réactions face à ces situations auraient pu être différentes si vous aviez eu plus d'informations sur ces situations?

\section{$\rightarrow$ «Moi et moi-même» (40 minutes)}

1. Demandez aux participantes de se diviser en petits groupes de quatre ou cinq.

2. Donnez aux participants quelques minutes pour compléter cette déclaration dans leurs têtes : J'ai plus peur de . Les participants doivent ensuite partager leurs craintes avec les autres dans le groupe.

3. Ramenez les participants dans le groupe élargi et animer un débat général sur les similitudes et les différences observées dans leurs groupes respectifs. Expliquez-leur qu'il est normal d'avoir des craintes et donnez leurs quelques suggestions sur la façon de les gérer (par exemple, en parlant avec quelqu'un, en y faisant face, en priant, etc.)

4. Dites aux participantes que vous voulez que chacune d'elle pense à elle-même et à ses traits de caractère. Lisez le tableau intitulé "À propos de moi et moi-même», à haute voix. Demandez-leur de I'utiliser comme guide pour renforcer leur connaissance de soi.

À propos de moi et moi-même

1) J'aime :

2) Je n'aime pas:

3) Mon rêve :

4) Je peux faire :

5) Je veux :

6) me rend heureuse et détendue.

7) m'attriste.

8) De toutes les choses que j'aie, je préfère

9) Au nombre des choses que j'ai bien faites et reçu des félicitations d'autres personnes, figurent :

10) Mes forces:

5. Divisez les filles en petits groupes et demandez-leur de partager les unes avec les autres.

6. Regroupez les filles et expliquez-leur l'importance de la connaissance de soi. 
Distribution des cartes d'identité du programme (15 minutes)

1. Expliquez-leur qu'elles viennent juste d'étudier certains de leurs traits de caractère dans le cadre de la connaissance de soi. La connaissance de soi est une partie importante de notre façon de nous identifier.

2. L'identité est également importante pour nous aider à accéder à des services. Expliquez que chaque fille recevra une carte d'identité du programme avec son nom, sa photographie, et d'autres informations d'identification pour montrer qu'elle fait partie du programme "Filles Éveillées ».

3. Distribuez les cartes d'identité et montrez-leur le type d'informations qui y figure.

4. Expliquez-leur qu'il est très important de prendre soin de cette carte d'identité dont elles pourraient avoir ultérieurement besoin pour accéder à des services. Invitez les filles à les avoir avec elles à chaque fois qu'elles viennent à la session. Réfléchissez avec les filles aux services pour lesquels une carte d'identité est nécessaire. 


\section{Session 3 : L'estime de soi}

\section{Objectifs de la session:}

À la fin de cette session, les filles seront capables de:

- Définir l'estime de soi

- Identifier comment l'estime de soi affecte la prise de décisions futures

- Comprendre comment accepter les compliments avec grâce

\section{Matériel nécessaire:}

- Flipchart et marqueurs

\section{Plan de la session:}

- Cercle de partage positif (20 minutes)

- Comprendre l'estime de soi (20 minutes)

- Répondre aux compliments (20 minutes)

Durée totale: 60 minutes

\section{INSTRUCTIONS}

\section{$\rightarrow$ Cercle de partage positif (20 minutes)}

1. Demandez aux filles de se lever et de former deux cercles, l'un dans l'autre, avec environ la moitié des jeunes filles dans un cercle extérieur et l'autre moitié dans un petit cercle à l'intérieur du grand cercle. Demandez aux filles dans le petit cercle de fermer les yeux, de mettre les bras les unes autour des autres, et de baisser la tête. Demandez aux filles du grand cercle de marcher autour de celles du petit cercle et pendant qu'elles tournent en rond dans le cercle, lisez les instructions suivantes :

Donnez une tape sur le dos de quelqu'un qui prend ses propres décisions et qui s'y tient.

Touchez la tête de quelqu'un d'amical et de compréhensif.

Donnez une tape sur le bras de quelqu'un qui travaille bien avec les autres.

Touchez l'épaule de quelqu'un qui est reconnu et respecté dans sa communauté.

Touchez l'épaule de quelqu'un qui nous fait nous sentir en confiance.

2. Après quelques minutes, procédez à un changement de place et les membres du grand cercle prennent la place de ceux du petit cercle et vice versa. Continuez l'activité jusqu'à ce que vous puissiez vous assurer que tout le monde a été touché d'une certaine façon par quelqu'un d'autre. Si vous voyez qu'une fille n'a pas été touchée, vous pouvez lister d'autres qualités jusqu'à ce que quelqu'une la touche, ou vous pouvez la toucher vous-même pour éviter que celles qui n'ont pas été touchées ne soient frustrées. À la fin, demandez aux filles comment elles se sont senties quand les autres camarades du groupe les ont touchées? Comment vous vous êtes senties quand quelqu'un vous a donné une tape dans le dos? (Contente, bien, fière, en confiance). 


\section{$\rightarrow$ Comprendre l'estime de soi (20 minutes)}

1. Demandez aux filles de réfléchir à ce qu'elles savent de l'estime de soi. Écrivez leurs mots sur un flipchart, en formulant les définitions et les idées avec elles sur l'estime de soi.

Vérifiez les informations avec elles en disant :

Dans cette activité, nos amis ont identifié nos forces. Nous devrions reconnaître que nous avons des forces et des valeurs dont nous devrions être fières. Il est également bon de reconnaître que nous avons certaines faiblesses que nous pouvons améliorer.

2. Expliquez-leur que l'estime de soi est la connaissance et la valorisation de soi. Donnez-leur la définition de l'estime de soi.

L'estime de soi : Décrit comment les gens se sentent par rapport à eux-mêmes. La manière dont les gens se sentent par rapport à eux-mêmes influence leurs actions envers les autres et ce qu'ils accomplissent dans la vie.

3. Expliquez que l'estime de soi est très importante pour les adolescentes. Les adolescents se soucient fréquemment de leur identité et de ce que d'autres personnes,surtout leurs pairs, pensent d'eux. Les changements physiques et émotionnels affectent la façon dont ils se sentent et pensent à eux-mêmes. Beaucoup de jeunes aspirent à avoir une bonne estime d'eux-mêmes, mais ne savent comment y parvenir.

4. Demandez aux filles de dire pourquoi l'estime de soi est importante et comment on l'apprend. Expliquez que l'estime de soi est importante car la façon dont les gens se sentent, influence ce qu'ils accomplissent dans la vie. Si les gens croient en eux-mêmes et en leurs capacités, alors ils sont capables de travailler dur, d'atteindre les objectifs fixés et d'accomplir ce qu'ils avaient prévu de faire. Demandez aux filles de réfléchir à ce que le fait de bien se sentir ou d'avoir une bonne estime de soi peut nous permettre de faire. Certaines des réponses devraient inclure :

Accepter de nouveaux défis et essayer de nouvelles activités

Être plus à l'aise avec les autres, et développer des relations plus étroites et saines

Croire que nous pouvons réussir

Avoir la confiance en soi

Être la personne que nous voulons être

S'affirmer et refuser d'être entraîné dans ce en quoi nous ne croyons pas

\section{Répondre aux compliments (20 minutes)}

1. Expliquez que dans le cercle de partage positif, les autres filles ont dit quelque chose de positif sur chacun de nous. Ces remarques positives sont connues comme des compliments.

2. Demandez aux filles comment elles se sont senties lorsque d'autres filles leur ont fait des compliments. 
Les réponses possibles sont :

$$
\begin{aligned}
& \text { - contente } \\
& \text { - satisfaite } \\
& \text { - gênée }
\end{aligned}
$$

3. Expliquez-leur que ce n'est pas toujours évident qu'on accepte les compliments, mais qu'il est important de le faire. Demandez à un membre du groupe de vous faire un compliment. Soyez un exemple en exprimant votre propre satisfaction par rapport à leurs commentaires et ce, en disant merci, en souriant, et en les regardant dans les yeux.

4. Demandez à une fille de venir devant; expliquez-lui que trois personnes différentes lui feront des compliments et qu'elle s'essayera d'accepter ces remarques avec grâce.

5. Changer les filles et recommencez. 


\section{Session 4 : La fixation d'objectifs et le développement des plans}

\section{Objectifs de la session:}

À la fin de cette session, les filles seront capables de:

- Expliquer le but de la fixation des objectifs

- Décrire le processus de définition et de réalisation des objectifs

- Fixer des objectifs clairs

Matériel nécessaire:

- Support: Photo de l'équipe de football du Burkina Faso

- Flipchart et marqueurs pour lister cinq amis et types d'objectifs

\section{Plan de la session:}

- Comprendre la fixation des objectifs et buts (10 minutes)

- Objectifs à court et à long termes (20 minutes)

- Cinq amis d'un bon objectif (15 minutes)

- Définir des objectifs pour nous-mêmes (30 minutes)

Durée totale: 75 minutes

AVANT LA SESSION : Préparez un poster avec la liste des cinq amis ; préparez des affiches avec les types d'objectifs (personnels, familiaux, professionnels, amis, santé, financier).

\section{NOTES D'INFORMATION}

Un but est une réalisation et un accomplissement vers lequel nos efforts sont orientés. Ça peut être quelque chose à faire, un endroit où aller, ou quelque chose à avoir. Les objectifs nous donnent quelque chose à rechercher et peuvent nous donner de la motivation et de l'énergie. Pour définir un objectif, nous devons recueillir des informations, prendre des décisions et opérer des choix. Nous devons en apprendre davantage sur ce que nous voulons réaliser. Les objectifs doivent être précis, concrets, et avoir une échéance. Les objectifs devraient être raisonnables et gérables. Quelque chose de réaliste et facile à gérer rend la réalisation plus facile et crée la confiance pour passer à d'autres objectifs plus grands. Réfléchir aux avantages attendus peut être motivant. Pour aider à atteindre un objectif, il est utile d'avoir un plan avec les étapes nécessaires à l'atteinte de l'objectif, et aussi de réfléchir à d'éventuelles difficultés et à la manière de les surmonter.

\section{INSTRUCTIONS}

\section{$\rightarrow$ Comprendre la fixation des objectifs et buts (10 minutes)}

1. Montrez la photo de l'équipe de football du Burkina Faso "les Étalons». Posez la question suivante : 
- Quel est le but d'un match de football? (Pour gagner)

- Comment y parvenir ? (Marquer des buts)

- Comment est-ce qu'une équipe marque des buts ou fonctionne? (Elle a un plan, elle pratique et elle joue en équipe)

2. Discutez sur le fait que la vie ressemble à cela. Nous devons avoir un but - voici nos objectifs. Un but est une réalisation et un accomplissement vers lequel nos efforts sont orientés.

3. Posez la question suivante :

- Quels sont les exemples d'objectifs?

- Pourquoi les gens fixent-ils des objectifs?

4. Expliquez que la session d'aujourd'hui portera sur la manière dont nous fixons des objectifs et faisons des plans pour les atteindre.

\section{$\rightarrow$ Objectifs à court et à long termes (20 minutes)}

1. Dites aux filles: "Parfois, nous fixons des objectifs à court terme, ou des objectifs que nous espérons atteindre dans un futur immédiat, et d'autres fois nous fixons des objectifs à plus long terme. Un objectif à court terme peut être de finir à temps toutes les corvées cet après-midi afin de rendre visite à un logeur. Un objectif à long terme pourrait être de retourner au village et de se marier. "

2. Expliquez que vous allez lire un but, et les filles décideront s'il s'agit d'un objectif à court ou à long terme. S'il s'agit d'un objectif à court terme, elles marcheront vers une extrémité de la salle; si c'est un objectif à long terme, elles iront vers l'autre bout de la salle. Lisez la liste suivante :

- Finir la vaisselle ce soir

- Acheter du poisson au marché demain

- Nettoyer la maison cette semaine

- Visitez ma famille plus tard cette année

- Achever une formation ce mois

- Me marier

- Avoir des enfants

- Démarrer ma propre entreprise de retour dans mon village

- Acheter un tissu pour coudre une nouvelle robe

- Économiser suffisament d'argent pour mon trousseau de mariage

- Économiser une petite somme d'argent chaque semaine

- M'affirmer davantage

- Etre alphabétisée

- Aller à un cours d'alphabétisation la semaine prochaine

3. Demandez aux filles d'expliquer pourquoi il s'agit d'un objectif à court ou à long terme.

4. Expliquez que de bons objectifs sont des objectifs spécifiques, mesurables, réalistes et limités dans le temps. 


\section{$\rightarrow$ «Cinq amis» d'un bon objectif (15 minutes)}

1. Dites au groupe que nous allons maintenant étudier comment définir des plans clairs.

2. Introduisez les «cinq amis» d'un bon plan. Levez votre main et listez l'un des amis sur chaque doigt :

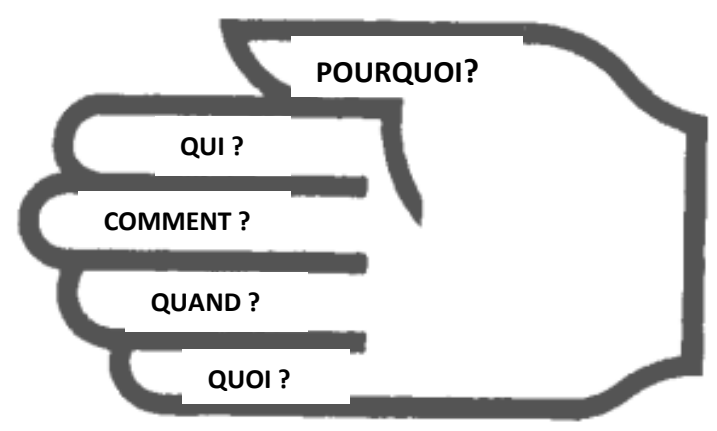

POURQUOI? Les raisons de travailler vers un but

QUI? La personne qui va exécuter le plan

COMMENT? Les actions requises, étape par étape

QUAND? Le délai dans lequel chaque étape sera réalisée et l'objectif atteint

QUOI? Les ressources nécessaires à la réalisation de l'objectif

3. Faites un jeu de mémoire pour apprendre les «cinq amis». Demandez à toutes les filles de se mettre debout et de lever une main devant elles. Faites le tour du cercle et demandez à chaque fille, de donner le nom des "cinq amis» avec ses doigts. Celles qui réussissent à les nommer correctement peuvent s'asseoir. Les autres tenteront encore jusqu'à ce que tout le monde ait énuméré les «cinq amis» correctement.

\section{Définir des objectifs pour nous-mêmes (30 minutes)}

1. Expliquez que chaque fille va élaborer un plan d'action individuel en utilisant les "cinq amis». Elles peuvent choisir parmi plusieurs objectifs :
a. Personnel
b. Familial
c. Professionnel
d. Amis
e. Santé
f. Financier

2. Rappelez-leur que tout objectif qu'elles espèrent réaliser doit énoncer clairement les «cinq amis» à savoir "pourquoi, qui, comment, quand et quoi » et devraient être spécifiques, mesurables, réalistes et limités dans le temps. Donnez aux filles 5 minutes pour réflechir seules.

3. Divisez les filles en petits groupes. Demandez-leur de présenter leurs plans les unes aux autres dans leur petit groupe. Une fois les plans présentés, demandez aux filles un feedback et des suggestions les unes pour les autres.

4. Regroupez l'ensemble du groupe et animer une discussion en posant les questions suivantes :

- Quelles difficultés avez-vous dans l'élaboration de vos plans?

- Avez-vous des questions sur les «cinq amis» et l'élaboration d'un plan?

- Comment les «cinq amis» vous aideront-ils à atteindre vos objectifs?

- Comment les «cinq amis» peuvent-ils être utiles dans votre vie?

- Avoir des objectifs est-il important dans la vie? Pourquoi ou pourquoi pas? 


\section{Photo de l'équipe de football du Burkina Faso}

(Activité : Comprendre les objectifs et la fixation des objectifs)

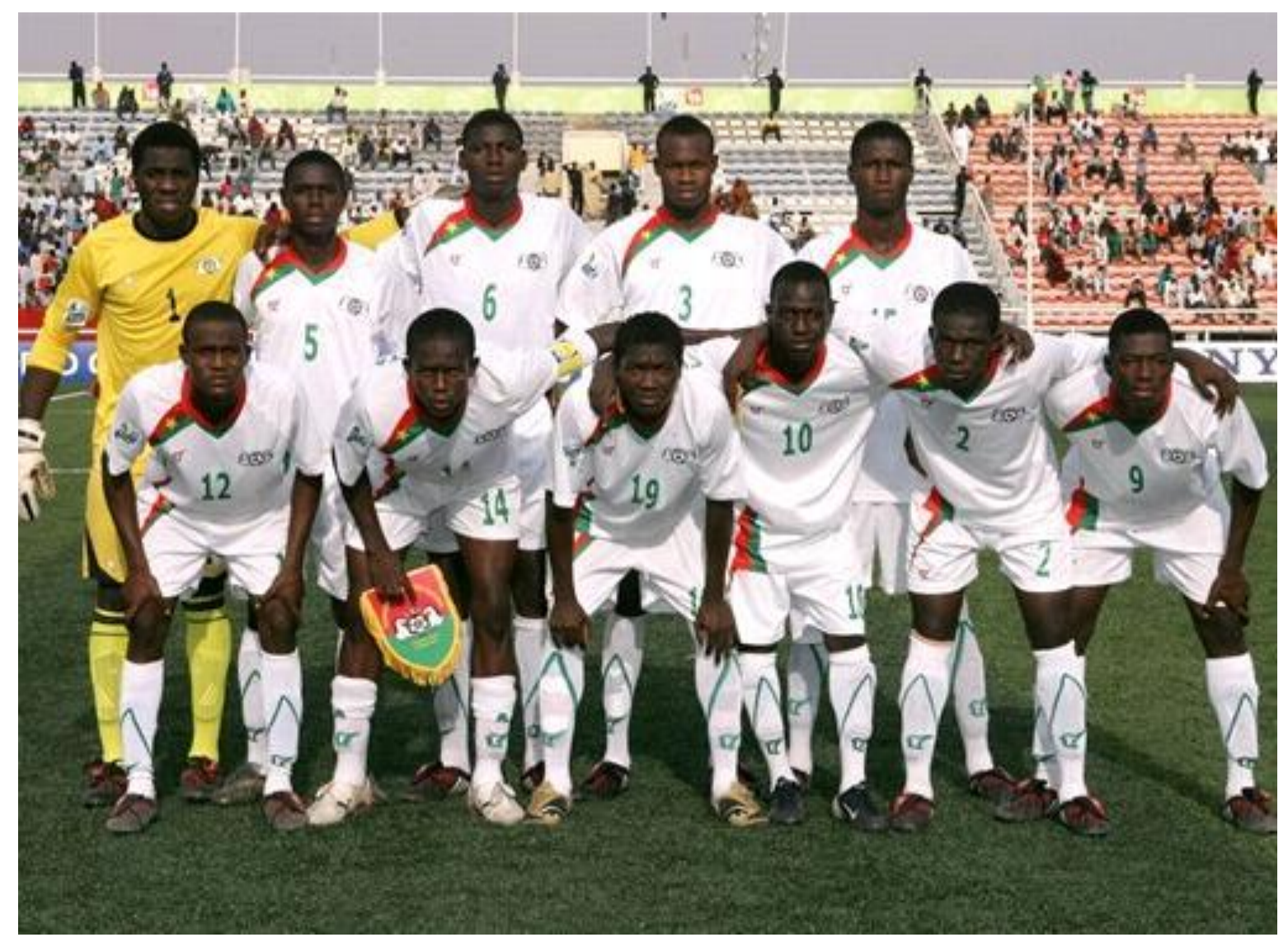




\section{Session 5 : Le stress et la gestion du stress}

\section{Objectifs de la session:}

À la fin de cette session, les filles seront capables de:

- Identifier le stress et les symptômes du stress

- Acquérir des compétences en gestion du stress

\section{Plan de la session:}

- Comprendre le stress (25 minutes)

- Reconnaître le stress; I'histoire de Ghislaine (15 minutes)

- Les facteurs de stress dans notre propre vie (25 minutes)

- La pratique d'une technique de gestion du stress (10 minutes)

Durée totale: 75 minutes

AVANT LA SESSION : Voyez l'espace disponible et si les filles pourront se coucher ou non dans le cadre de l'exercice sur «la pratique d'une technique de gestion du stress».

\section{NOTES D'INFORMATION}

Les filles du programme peuvent avoir beaucoup de stress parce qu'elles vivent en dehors de la famille et/ou à cause de leurs conditions de vie. Tout au long de la session, encouragez-les à partager des histoires sur les facteurs de stress dans leur vie.

\section{INSTRUCTIONS}

\section{Comprendre le stress (25 minutes)}

1. Demandez aux filles de fermer les yeux et de penser à une époque où elles s'inquiétaient d'une situation. Expliquez-leur qu'elles peuvent avoir ressenti du stress. Le stress est le résultat de la pression qui survient lorsqu'un ensemble de problèmes ou de préoccupations survient dans la vie d'un individu.

2. Demandez aux filles d'imaginer des situations qui peuvent être source de stress pour des filles comme elles. Voici des exemples possibles:

- La mort d'un ami ou d'un membre de la famille

- La séparation des parents

- Les problèmes de santé (personnels ou de personnes qu'on aime)

- La charge de travail

- La solitude

- Lorsque quelqu'un vous ménace d'avoir des rapports sexuels avec vous

- Une situation financière difficile 
3. Expliquez que parfois notre corps a des problèmes quand nous sommes dans une situation stressante. Demandez aux filles de réfléchir aux symptômes du stress. Entre autres exemples possibles figurent: les maux de tête, la fatigue, les maux de ventre, les problèmes de peau, la tristesse, les troubles du sommeil, la perte d'appétit.

4. Expliquez aux filles qu'elles peuvent gérer leur stress grâce à une variété de méthodes telles que :

- L'expression des sentiments et des désirs

- La relaxation ou le fait de faire certaines choses qui nous rendent heureux, comme chanter, lire et être avec des amis ou la famille

- Les techniques de relaxation comme la respiration profonde

- Les pensées positives et le fait d'éviter les personnes négatives.

- La recherche d'aide auprès de la famille, des amis ou des professionnels. II n'y a aucune honte à demander l'aide des autres lorsqu'on a des problèmes.

- S'efforcer d'avoir une alimentation équilibrée, un sommeil suffisant et de faire des exercices pour rester en bonne santé.

- Affronter vos peurs et considérer les échecs comme des occasions d'apprentissage

- Apprendre à apprécier les petits succès dans la vie. Ne pas se punir parce qu'on n'est pas parfaite.

\section{Reconnaître le stress ; I'histoire de Ghislaine (15 minutes)}

1. Racontez l'histoire de Ghislaine à haute voix aux participantes

\section{L'histoire de Ghislaine}

Ghislaine est venue à Ouagadougou avec sa tante pour obtenir un bon travail bien remunéré et aller à l'école. Cependant, après leur arrivée à Ouaga, non seulement sa tante ne lui a pas trouvé d'emploi mais ne l'a pas envoyé à l'école non plus. Ghislaine s'est donc retrouvée à aider sa tante avec les tâches ménagères. Sans autre alternative, Ghislaine a continué à servir sa tante avec diligence. Mais, la tante de Ghislaine crie sur elle à chaque fois qu'elle ne parvient pas à terminer ses tâches et Ghislaine a peur que sa tante ne la chasse de sa maison. Un jour, Ghislaine a reçu un message de ses parents par l'intermédiaire d'un autre parent venu rendre visite à sa tante. Il a dit à Ghislaine que son père était malade et ne pouvait plus travailler au champ. Par conséquent, sa mère et ses plus jeunes sœurs étaient confrontées à des difficultés financières. Le parent dit qu'il serait bon que Ghislaine envoie un peu d'argent au village. Ghislaine avait peur et ne savait pas comment demander à sa tante un salaire ou de l'aide pour trouver un autre emploi où elle pourrait gagner un salaire. Elle était aussi très inquiète pour la santé de son père. Ghislaine n'a pas eu le courage de demander à sa tante de l'aide, de peur que celle-ci ne la jette hors de la maison. Cette situation a été très stressante pour Ghislaine. À mesure que le temps passait, Ghislaine est devenue dépressive, a perdu son appétit et a commencé à avoir des maux de tête persistants. Après trois semaines, son parent est revenu et lui a rappelé qu'elle devait apprêter de l'argent d'ici la semaine suivante. Ghislaine lui a expliqué son dilemme. Il était peiné pour Ghislaine et a promis qu'il leur donnerait de l'argent et lui trouverait un autre emploi. Ghislaine a été soulagée et heureuse d'entendre ces nouvelles. 
2. Demandez aux participantes de discuter des questions suivantes :

- Quelle était la cause du stress de Ghislaine?

- Quels étaient les symptômes du stress de Ghislaine?

- Que suggérez-vous à Ghislaine pour surmonter son stress?

- Comment Ghislaine a-t-elle surmonté son stress?

- Qu'est-ce qui pourrait arriver à Ghislaine si le problème n'était pas resolu?

\section{$\rightarrow$ Les facteurs de stress dans notre propre vie (25 minutes)}

1. Dites aux filles que nous allons maintenant mettre l'accent sur les types de stress qu'elles ont dans leur vie.

2. Demandez aux filles de se repartir en petits groupes; chaque fille mentionnera 2-3 choses dans sa vie qui sont source de stress pour elle. Donnez aux groupes 10 minutes pour discuter.

3. Regroupez toutes les filles et demandez à chaque groupe de donner des exemples de quelques facteurs de stress dans leur vie. Rappelez-leur que si quelqu'un a partagé une situation personnelle, nous n'avons pas besoin de la rapporter à l'ensemble du groupe.

4. Choisissez un scénario et demandez-leur de trouver des techniques pour gérer ce stress.

5. Sélectionnez un à deux scénarios supplémentaires si le temps le permet.

\section{La pratique d'une technique de gestion du stress (10 minutes)}

1. Dites aux filles qu'elles vont s'essayer à une technique de gestion du stress connue comme la respiration profonde. Faites-leur savoir que cette technique peut être utilisée pour les aider à faire face à toute situation stressante à laquelle elles seront confrontées.

2. Demandez aux filles de s'asseoir confortablement et de fermer les yeux. Éteignez les lumières, s'il y en a.

3. Demandez aux filles de respirer lentement et profondément pendant que vous comptez jusqu'à cinq; une fois que vous atteignez cinq, dites-leur qu'elles vont maintenant expirer lentement et profondément pendant cinq secondes. Répétez l'exercice plusieurs fois.

4. Si le temps le permet et que les filles peuvent se coucher, les initier à une technique de relaxation du corps depuis leurs orteils jusqu'à leurs têtes. Par exemple, "sentez vos pieds sur le sol. Mettezvous le plus à l'aise possible et détendez-vous. Sentez chacun de vos orteils se détendre ... " 


\section{Session 6 : Les valeurs et comment elles influencent notre comportement}

Objectifs de la session:

À la fin de cette session, les filles seront capables de:

- Comprendre les valeurs

- Identifier les valeurs de la communauté

- Identifier les valeurs et croyances personnelles qui peuvent aider les filles à réussir

- Expliquer la relation entre les valeurs et les comportements

- Découvrir comment leurs valeurs vont de pair avec leurs comportements et pourquoi

\section{Matériel nécessaire:}

- Flipchart et un marqueur

Plan de la session:

- Comprendre les valeurs (10 minutes)

- Les valeurs communautaires (15 minutes)

- Les valeurs individuelles (15 minutes)

- Jeu de valeurs (25 minutes)

- Valeurs et comportements (25 minutes)

Durée totale: 90 minutes

AVANT LA SESSION : Revoir les valeurs listées dans les notes d'information pour les activités «jeu des valeurs» et "valeurs et comportements» et réfléchir pour savoir si vous souhaitez ajouter ou modifier quelques-unes des déclarations pour qu'elles correspondent le mieux aux besoins des filles de votre groupe.

\section{NOTES D'INFORMATION}

Les valeurs sont :

- Les choses qui sont importantes pour nous

- Les choses que nous défendons ou que nous ne soutenons pas (donner des exemples comme le sexe avant le mariage, le droit des filles à l'éducation)

- Les choses que nous choisissons librement (même si elles sont influencées par les familles, les enseignements religieux, la culture, les amis, les médias)

- Les choses auxquelles nous croyons et que nous sommes prêts à défendre

- Les croyances, principes ou idées qui ont de la valeur pour nous et qui permettent de définir ce que nous sommes

- Les choses qui guident notre comportement et notre vie

Les valeurs communautaires peuvent comprendre :

- Le respect des règles de la circulation

- L'honneur (des parents)

- Le respect

Les valeurs individuelles peuvent comprendre : 
- L'honnêteté

- L'abstinence des rapports sexuels avant un certain âge

- Le courage (et/ou supporter la douleur)

- La décence

Même les jeunes adolescents peuvent être très attachés à leurs valeurs personnelles et familiales, et discuter de ces valeurs peut susciter des émotions. Assurez-vous que les règles de base sont respectées en tout temps, y compris la confidentialité, le fait de ne pas porter de jugement sur les réponses, et celui de permettre à chacun de participer. Soulignez le fait que les valeurs individuelles varient et qu'il n'y a pas de «bonnes» ou «mauvaises» réponses. Permettez aux filles d'exprimer, d'expliquer et de défendre leurs valeurs. S'il y a un débat sur une question relative aux valeurs, prenez-en immédiatement la direction et demandez à chaque partie d'expliquer son point de vue. Rappelez aux filles que les valeurs des gens diffèrent et qu'il est normal d'en convenir ou non, puis passez à un autre sujet. Si la confusion et le mécontentement subsistent, le mentor peut programmer un débat formel sur la question à un autre moment.

Rappelez-vous pendant que vous suivez les filles, qu'elles n'ont pas de jugement, et que vous n'en avez pas non plus. Soyez conscient de vos propres valeurs personnelles à travers les sessions de ce programme, surtout lors des discussions sur des sujets controversés comme l'avortement, la planification familiale, ou les rapports sexuels avant le mariage. Faites attention à vos commentaires et au langage de votre corps pour éviter de soutenir une position ou une autre. Appuyez les filles afin qu'elles ne se sentent pas écrasées ou sous l'emprise des valeurs et opinions de leurs pairs. Faites bien comprendre qu'il est normal de changer d'avis sur la base de nouvelles informations ou d'une nouvelle façon de voir un problème.

Une ou deux filles vont, à l'occasion, exprimer une valeur particulière en opposition au reste du groupe. Dans ce cas, il est de votre responsabilité de soutenir le droit de quelqu'un à avoir un point de vue minoritaire. Utilisez des commentaires verbaux, le toucher ou la proximité physique pour montrer votre soutien, mais indiquez clairement que vous soutenez le comportement consistant à défendre ses valeurs, même si elles sont minoritaires, plutôt que la position.

Chaque fois qu'il y a une discussion sur un sujet et que personne dans le groupe n'exprime une position communément admise, rappelez au groupe cette position. Vous pourriez dire : «D'autres personnes pourraient dire .... et donner les raisons de cette position.

Les mentors, et autres autorités, sont souvent l'objet de questions sur leurs propres valeurs par rapport à différents sujets. Il est opportun de partager certaines de vos valeurs personnelles et de discuter des valeurs que vous avez apprises de votre famille et qui vous ont aidé à prendre des décisions positives par rapport aux objectifs professionnels ou éducatifs. Il est préférable de ne pas partager les valeurs personnelles liées à des sujets très controversés. Les mentors sont des figures importantes dans la vie des adolescentes et peuvent influencer leurs valeurs et leurs comportements. Si vous êtes invité à donner votre opinion sur un sujet controversé, dites quelque chose comme "Je m'intéresse plus à ce que vous croyez en ce moment». Si vous partagez des valeurs personnelles, clarifiez le fait que ces valeurs sont bonnes pour vous, mais pas nécessairement pour les filles. 


\section{INSTRUCTIONS}

\section{$\rightarrow$ Comprendre les valeurs (10 minutes)}

1. Lisez l'histoire suivante aux filles :

\section{Histoire de Valérie :}

Valérie est une fille de 17 ans qui travaille comme employée de maison à Ouaga. Elle adore et fait bien son travail à la grande satisfaction de son employeur. Un jour, le frère de Valérie l'informe que sa mère est gravement malade et qu'il faut 50000 FCFA pour faire face aux frais d'hospitalisation et à l'achat des médicaments. Valérie venait de commencer le travail et avait réussi à économiser seulement 25000 FCFA. Elle est angoissée de ne pas pouvoir trouver les 50000 FCFA pour les soins de sa maman. Elle en parle donc à une amie qui lui suggère deux solutions : 1) garder l'argent que son employeur lui donne pour acheter les condiments au marché et lui mentir que l'argent est perdu en cours de route, 2) demander de l'argent à leur voisin (ce dernier a fait des avances de coucher avec elle dans le passé et Valérie avait refusé l'offre).

Valérie fait comprendre à son amie, qu'elle n'exécutera aucune de ces suggestions car l'éducation qu'elle a reçue lui interdit de mentir et de vendre son corps. Elle décide de partager son problème avec son employeur. Cette dernière lui a donné un prêt et elle devra travailler pour rembourser le prêt selon des modalités acceptables.

2. Demandez aux filles :

- Quels sont les valeurs que Valérie à montré ?

- Selon vous, qu'est-ce qui représente des valeurs pour Valérie ? Pourquoi ?

- Citez d'autres exemples de valeurs.

- Qu'est-ce que une valeur de façon générale?

3. Partagez la définition suivante des valeurs :

Le mot «valeur» a différentes définitions. L'une des définitions implique un aspect personnel de la valeur, y compris l'importance de certaines croyances ou idées pour une personne. Différentes choses valent plus ou moins la peine pour différentes personnes, ce qui signifie qu'ils ont plus ou moins de la valeur. Les choses, les idées, les croyances et les principes qui ont de la valeur pour vous, façonnent vos valeurs. Nos valeurs permettent de définir qui nous sommes et nous aident à déterminer les choix que nous faisons, et qu'on appelle également notre comportement. Par exemple: un homme qui apprécie sa famille s'en préoccupe et prend soin de son épouse, de ses enfants, et de la vie familiale; une personne qui valorise la santé va essayer d'avoir une alimentation saine, d'éviter les comportements pouvant l'exposer au risque des IST; elle évite l'alcool, le tabac et autres drogues; les personnes qui valorisent l'éducation essayeront de bien étudier, d'obtenir de bonnes notes, et de réussir à leurs examens. 


\section{$\rightarrow$ Les valeurs communautaires (15 minutes)}

1. Expliquez que les sociétés ont des valeurs ou des croyances et des pratiques qui sont importantes pour elles. Quelques exemples sont : le respect des aînés, la fréquentation de l'église, et l'obtention d'un bon emploi.

2. Demandez aux filles de réfléchir à des valeurs dans leur société. Vous pouvez les inciter à réfléchir sur les valeurs relatives à la famille, la religion, le genre, la santé, les finances.

3. Notez toutes leurs réponses sur du papier flipchart. Ensuite, demandez aux filles de classer les cinq plus importantes.

4. Si les filles n'arrivent pas à être d'accord sur la classification des valeurs, expliquez que cela est normal. Expliquez que différentes sociétés et communautés ont des valeurs, croyances et pratiques qui sont importantes pour elles. Notre environnement détermine beaucoup de choses sur les valeurs de notre société. Les valeurs peuvent être differentes d'une société à autre et d'une personne à autre.

\section{$\rightarrow$ Les valeurs individuelles (15 minutes)}

1. Expliquez que chacun de nous a ses propres valeurs personnelles qui peuvent être différentes de celles de nos amis.

2. Donnez aux filles quelques minutes pour penser à leurs valeurs propres. Demandez-leur de réfléchir aux valeurs relatives à la famille, à la religion, au genre, à la santé, aux finances et à toute autre catégorie qu'elles jugent importante. Demandez à chaque fille d'identifier au moins trois valeurs importantes pour elle.

3. Demandez aux filles de lever le pouce lorsqu'elles parviennent à identifier au moins trois valeurs personnelles importantes. Demandez ensuite aux filles de les classer du plus important au moins important.

4. Echangez sur les valeurs individuelles des filles. Mettez l'accent sur les similitudes et les différences dans les valeurs. Demandez aux participantes : Était-il difficile d'identifier ces valeurs et pourquoi? Qu'est ce qui a influencé leurs valeurs?

\section{$\rightarrow$ Jeu de valeurs (25 minutes)}

1. Animez un débat sur les valeurs en posant les questions suivantes:

- Où pensez-vous que nous acquérons nos valeurs?

- Citez un exemple de valeur jugé très importante par votre famille.

- Citez un exemple d'une valeur religieuse qui vous a été enseignée.

- Laquelle de vos valeurs tire son origine de vos croyances culturelles?

- Connaissez-vous une valeur ethnique qui pourrait être moins importante dans d'autres ethnies? 
- Pouvez-vous penser à une valeur propre à quelqu'un d'autre que vous ne partagez pas? De quoi s'agit-il?

2. Expliquez aux filles qu'elles seront invitées à exprimer leurs sentiments sur des valeurs particulières. Désignez trois parties de la pièce comme suit: "d'accord», "pas d'accord», et "pas sûr»

3. Sélectionnez une dizaine des déclarations ci-dessous, et lisez chacune d'elles à haute voix. Après chaque énoncé, demandez aux filles d'aller dans la partie de la salle pour montrer qu'elles sont d'accord, pas d'accord ou pas sures. Expliquez qu'il n'y a pas de bonnes ou mauvaises réponses, et que chacun a droit à son opinion.

- Vous pouvez gagner un salaire décent sans forcément être instruite.

- Avoir un emploi que vous aimez est plus important que gagner beaucoup d'argent.

- Il est inacceptable pour un garçon ou un homme de pleurer.

- Attendre de se marier avant d'avoir des rapports sexuels est une bonne idée.

- Le travail d'une femme mariée c'est de nettoyer la maison, de cuisiner, de laver les vêtements, et de prendre soin des enfants.

- Les filles devraient être autorisées à hériter de biens.

- Les garçons et les filles doivent avoir les mêmes droits.

- Il est important de suivre les traditions peu importe lesquelles.

- Il est préférable d'avoir des enfants de sexe masculin que féminin.

- Dans une famille, l'homme devrait être responsable de l'appui financier.

- Il est normal d'avoir un enfant avant le mariage.

- Une femme est inutile si elle ne peut pas avoir des enfants.

- Il est généralement préférable de garder le silence plutôt que de s'exprimer.

- Boire peut aider à faire face au stress et aux problèmes de la vie.

- Assister à des offices religieux est important pour le bien-être spirituel.

- Si un homme demande à des filles de faire quelque chose, elles n'ont d'autre choix que d'accepter.

- Les gens devraient témoigner leur solidarité aux personnes pauvres et aux malades.

- Les adultes doivent être respectés, notamment les parents.

- L'amour est une partie importante d'une relation heureuse.

- II n'y a aucune raison de planifier puisque la vie est un jeu de hasard.

4. Après cet exercice, regrouper les filles et discutez ce qui suit :

- Avez-vous su automatiquement comment vous vous êtes senties ou aviez-vous besoin de réfléchir à chacun des points?

- Avez-vous déjà changé d'avis?

- Quelqu'un d'autre dans le groupe a-t-il influencé votre opinion?

- Qu'avez-vous ressenti par rapport aux différences de valeurs dans le groupe? 
$\rightarrow$ Valeurs et comportements (25 minutes)

1. Faites deux colonnes sur un flipchart, une pour les valeurs et l'autre pour les comportements. Listez à la fois les comportements et les valeurs sur le tableau (dans un ordre différent). Lisez à haute voix et demandez aux jeunes filles quel comportement correspond à quelle autre valeur. Entre autres exemples figurent :

Valeur : Croire au partage

Comportement : Donner de l'argent à quelqu'un qui est dans le besoin

Valeur : Ma santé est importante pour moi

Comportement : Résister à la pression des pairs pour fumer des cigarettes

Valeur : L'éducation est importante pour ma famille et moi

Comportement : Aider ma plus jeune sœur dans ses études

(Les mentors sont encouragés à penser à des exemples similaires)

2. Expliquez que parfois les gens ont du mal à agir sur leurs valeurs. Nommez quelques valeurs et pour chacune d'elle, demandez au groupe des exemples de choses que les gens font quelques fois et qui vont à l'encontre de cette valeur. Voici quelques exemples :

Valeur : Croire que l'on ne devrait pas avoir d'enfants avant le mariage

Comportement : Avoir des relations sexuelles non protégées avant le mariage

Valeur : Estimer qu'il est important d'aider à faire les travaux dans la maison

Comportement : Ne pas faire vos corvées pour pouvoir passer du temps avec des amis

Valeur : Croire qu'on doit aller à l'église chaque semaine

Comportement : Laissez tomber l'église pour aller au cinéma

(Les mentors sont encouragés à penser à des exemples similaires)

3. Expliquez que vous allez lire plusieurs déclarations, suivies d'une série de questions. Elles ne doivent pas répondre aux questions à voix haute, mais y penser. Chaque déclaration reflète une valeur. Les questions porteront sur les comportements qui appuient ou ignorent la valeur.

4. Lisez à haute voix les déclarations et questions suivantes (ou les remplacer par vos propres déclarations et questions) :

(a) Votre santé est importante pour vous.

- Faites-vous des exercices réguliers?

- Mangez-vous des aliments sains?

- Êtes-vous un non-fumeur?

- Évitez-vous de consommer de l'alcool et autres drogues?

(b) Les hommes et les femmes devraient jouir d'une égalité de chances.

- Encourageriez-vous une amie à s'inscrire à l'école ?

- Encourageriez-vous un ami à prendre des cours de couture?

(c) Il est important de se faire de l'argent

- Voulez-vous beaucoup d'argent? 
- Voudriez-vous vous faire de l'argent par des moyens illégaux en falsifiant par exemple les factures et les pièces justificatives?

- Accepteriez-vous un pot-de-vin?

5. Demandez aux filles de réfléchir à leurs réponses aux questions pendant quelques minutes, puis de réfléchir ensemble à une fin pour la phrase suivante :

Quelques fois, les jeunes ne se comportent pas selon leurs valeurs parce que ...

6. Résumez la relation entre valeurs et comportements en couvrant les points suivants :

- Les gens disent aux autres les valeurs qui sont importantes pour eux.

- Les gens font ce que leurs valeurs leur dictent, et ne font pas ce qui est contraire à leurs valeurs.

- Les gens prennent des décisions en fonction de leurs valeurs.

- Les gens défendent leurs valeurs.

- Les gens se sentent coupables lorsqu'ils se comportent de manière contraire à leurs valeurs.

7. Animez un débat autour des questions suivantes :

- Comment se sent-on lorsqu'on défend des valeurs non partagées par nos amis?

- Que se passe-t-il lorsque le comportement des jeunes va à l'encontre des valeurs de leurs parents? (Les réponses pourraient être : les parents et les enfants se disputent ; les enfants peuvent mentir à leurs parents ; les enfants et les parents peuvent éviter d'en parler)

- Qu'est-ce qui se passe si leur comportement va à l'encontre des valeurs religieuses ou spirituelles qui leur ont été enseignées? (Réponses possibles : ils peuvent arrêter d'assister aux offices religieux ou éviter les leaders religieux parce qu'ils se sentent coupables, gênés ou en colère)

- Qu'est ce qui influence les gens à adopter des comportements conformes à leurs valeurs? Donnez un exemple. (Les réponses pourraient être : I'on se sent bien en suivant ses propres valeurs; les parents et autres adultes récompensent les comportements qui reflètent les valeurs qu'ils enseignent)

- Qu'est ce qui influence les gens pour qu'ils se comportent de manière contraire à leurs valeurs? Donnez un exemple. (Les réponses pourraient être : les gens peuvent vouloir faire une expérience ; la pression des pairs ; la possibilité d'un gain personnel ; pour se rebeller ; pour attirer l'attention)

- Vos valeurs changent-elles ou demeurent-elles les mêmes à mesure que vous prenez de l'âge?

- Si vos valeurs et comportements sont différents, lesquels changeriez-vous? Vos valeurs ou votre comportement?

- Quelles sont les conséquences de l'adoption de mauvaises valeurs et de comportements répréhensibles? 


\section{Session 7 : Affirmation de soi}

\section{Objectifs de la session:}

À la fin de cette session, les filles seront capables de:

- Faire la distinction entre affirmation de soi, agressivité et passivité

- Comprendre les caractéristiques du comportement d'affirmation de soi

- Faire preuve de capacités efficaces d'affirmation de soi

- Comprendre que la prise de parole est un élément important de l'affirmation de soi

\section{Matériel nécessaire:}

- Une affiche énumérant les «six règles d'or» de l'affirmation de soi

- Flipchart et marqueurs

\section{Plan de la session:}

- Comprendre la différence entre affirmation de soi et agressivité (10 minutes)

- Définir le comportement passif, l'agression directe, l'agression indirecte et l'affirmation de soi (20 minutes)

- Les six règles d'or de l'affirmation de soi (15 minutes)

- Utiliser des phrases commençant par «Je» dans vos communications (15 minutes)

Durée totale: 60 minutes

AVANT LA SESSION : Énumérez les Six Règles d'Or de l'Affirmation de Soi (p. 34) sur un poster à afficher sur le mur.

\section{NOTES D'INFORMATION}

L'affirmation de soi est une compétence essentielle dans nos interactions avec les autres. S'affirmer, c'est se défendre. S'affirmer c'est être franc et honnête avec soi et avec d'autres personnes sur ce dont nous avons besoin et ce que nous voulons. L'affirmation de soi peut vous aider à vous protéger des situations dangereuses et à faire face à la pression des pairs pour vous amener à faire des choses pour lesquelles vous n'êtes pas à l'aise.

Les gens qui ne s'affirment pas sont souvent très passifs et soumis. Même s'ils sont maltraités, ils ne se défendent pas. Les gens qui ne s'affirment pas manquent souvent de confiance et d'auto-estime pour défendre leurs propres besoins et protéger leurs sentiments ou leur corps contre les blessures. Dans de nombreuses cultures, l'affirmation de soi n'a aucune valeur chez les filles, d'où les difficultés qu'elles ont à défendre leur cause.

L'affirmation de soi diffère énormément de l'agressivité. Les gens qui sont agressifs, sont grossiers et méchants. Ils ne se soucient pas des sentiments des autres. Être trop agressif n'est pas très bon pour votre santé émotionnelle, car, au fond, vous vous sentirez mal pour avoir été méchant. 


\section{INSTRUCTIONS}

\section{Comprendre la différence entre affirmation de soi et agressivité (10 minutes)}

1. Lisez les histoires de vie d'Azara et de Bintou à haute voix en demandant aux filles d'être attentives car à la fin elles diront lequel des cas constituent une affirmation de soi et lequel fait référence à une agression.

\section{$\underline{\text { L'histoire d'Azara }}$}

Azara est une fille de 16 ans qui a quitté son village pour la première fois pour venir à Bobo à la recherche d'un travail. Arriver à Bobo elle est hébergée par un logeur (c'est un oncle du village), le temps de trouver quelque chose à faire. Après une semaine d'attente sans aucune proposition de travail, Azara apprend qu'il y a une association dans le quartier qui forme des jeunes filles en hôtellerie pour une durée d'un an; Elle voit donc une occasion d'apprendre un métier car cela peut lui offrir des opportunités plus grandes. Elle décide de s'inscrire pour participer à la formation et en parle à son oncle (le logeur). Celui-ci ne perçoit pas l'intérêt pour Azara de faire une formation surtout qu'elle dure une année; Il essaye de convaincre Azara de travailler comme employée de maison pour gagner rapidement de l'argent. Sans frustrer son oncle, Azara reste sur sa position et elle explique à son oncle les avantages du programme et les raisons pour son choix. Après des échanges avec son oncle, elle a réussi à le convaincre de la pertinence de son choix.

\section{L'histoire de Bintou}

Bintou est une fille employée de maison de 15 ans qui participe au programme "Filles Eveillées 》. Elle a intégré le programme parce qu'elle veut développer ses compétences en santé, en capacités financières et apprendre à lire et à écrire en français car elle n'a pas eu la chance d'être scolarisée. Le programme offre des possibilités aux filles intéressées de suivre des cours du soir. Alors Bintou décide de s'inscrire à l'école et en parle avec son employeur. Celui-ci dit à Bintou qu'il ne veut pas qu'elle s'inscrive à l'école parce qu'elle va abandonner les travaux domestiques pour y aller et que c'est inutile parce qu'elle est trop âgée pour pouvoir apprendre quelque chose. L'employeur a donné une série de raisons pour la décourager de s'inscrire à l'école. Face à cette situation, Bintou se fâche et taxe l'employeur d'égoïste et de méchant.

2. Démandez aux filles :

- Laquelle des deux filles a montré l'affirmation de soi ? (Azara)

- Laquelle des deux filles a manifesté l'aggressivité ? (Bintou)

- Qu'est-ce que Bintou pourrait dire pour s'affirmer, au lieu d'être aggressive? (Elle peut expliquer l'importance de l'éducation pour elle et aussi pour l'employeur et le rassurer qu'elle prendra des dispositions pour exécuter tous les travaux domestiques de la journée avant de se rendre à l'école.)

3. Demandez aux filles d'échanger des points de vue sur ce qu'elles entendent par les termes "affirmation de soi» et "agressivité». Assurez-vous que leurs définitions sont similaires à celles qui sont ci-dessous. Demandez-leur d'énumérer les différences entre "affirmation de soi» et «agressivité» : 
Affirmation de soi : exprimer les pensées, les sentiments et les croyances de façon directe, honnête et appropriée.

Agression : un sentiment d'hostilité qui pourrait conduire à des attaques ou une action violente non provoquée.

4. Assurez-vous que les filles comprennent les deux termes en expliquant :

L'affirmation de soi consiste à défendre ce en quoi vous croyez et ce que vous voulez. Les jeunes sont souvent tentés de céder aux désirs d'autrui, soit en raison de la pression des pairs ou de quelque chose qui a été idéalisé dans les médias. Cependant, si nous disons ce que nous voulons ou ressentons et expliquons pourquoi nous avons choisi une certaine décision ou une action, nous pouvons alors faire ce que nous voulons vraiment sans blesser une autre personne. L'affirmation de soi fait partie d'une communication efficace. Lorsque vous avez de l'assurance, vous pouvez prendre la parole sans hésiter, vous pouvez dire NON sans vous sentir coupable, demandez de l'aide quand c'est nécessaire, évitez d'argumenter, exprimez votre désaccord sans vous mettre en colère, et mieux vous sentir dans votre peau.

Être agressif consiste à rabaisser, blâmer ou critiquer d'autres personnes.

\section{$\rightarrow$ Définir le comportement passif, l'agression directe, l'agression indirecte et l'affirmation de soi (20 minutes)}

1. Expliquez-leur qu'elles ont déjà entendu parler des différences entre le comportement agressif et celui d'affirmation de soi. Elles vont maintenant en apprendre davantage sur un troisième type de réaction, connue sous le nom de «passivité».

Passivité : Céder à la volonté d'autrui - l'espoir d'obtenir ce que vous voulez sans avoir à le demander- laisser aux autres le soin de deviner ou de décider pour vous. Être soumis, parler doucement, être nerveux, glousser, baisser le regard ou fuir celui des autres, affaisser les épaules, éviter les désaccords, et se cacher le visage avec les mains.

2. Expliquez aux filles qu'elles entendront maintenant parler d'un scénario et de réactions différentes. Lisez le scénario suivant :

Juliette était tellement contente d'avoir une journée libre le dimanche. Elle avait eu une semaine de travail chargée et avait hâte de rencontrer ses amis, au kiosque d'à côté, pour manger quelque chose. Elle avait juste assez d'argent pour acheter un soda et des chips. Elle les a acheté et est allée s'asseoir avec ses amies. Juste au moment où elle s'apprêtait à manger, Lydia est arrivée derrière elle et en a pris un. "Elles sont bonnes ces chips» dit-elle, "Puis-je en avoir encore»? Avant que Juliette n'ait répondu, son amie Caroline lui dit : "Puisje en avoir moi aussi?» "J'ai encore si faim» et elle en prend quelques-uns. Puis, une autre amie lui dit, "Si tu t'assoies ici, tu dois partager ta nourriture avec nous", et elle prend d'autres chips à Juliette. 
3. Lisez les réactions de Juliette.

Réaction 1 : Juliette s'excuse auprès de ses amis pour n'avoir pas partagé ses chips et les laisser manger tout.

Réaction 2 : Juliette prend les chips et leur dit qu'elle va tout manger.

Réaction 3 : Juliette permet, en silence, à ses amies de manger les chips, et ensuite elle les ignore afin qu'elles sachent qu'elle est en colère contre elles.

Réaction 4 : Juliette explique à ses amies qu'elle avait envie de manger des chips toute la semaine et qu'elle peut partager quelques-uns avec elles tant qu'elles lui en laisseront assez.

4. Demandez aux filles de faire correspondre chaque réaction avec le terme approprié.

5. Utilisez ce qui suit pour expliquer les réponses correctes :

Réaction 1 : Passif: Les amies de Juliette lui ont dit ce qu'elles voulaient, mais Juliette ne leur a pas dit ce qu'elle voulait. Les gens passifs peuvent croire que les autres leur disent toujours ce qu'il faut faire et ils jouent le rôle de la victime. Ils permettent aux autres de violer leurs droits. Une réponse passive n'est pas toujours dans votre meilleur intérêt. Mais, il y a des situations où une réponse passive est la plus appropriée. Demandez aux filles de donner quelques exemples.

Réaction 2 : Agression directe : Juliette dit ce qu'elle veut de façon menaçante et offensante pour les autres. Cette réponse n'est généralement pas dans votre meilleur intérêt et est souvent cause de conflits.

Réaction 3 : Agression indirecte : Juliette prétend que tout va bien, mais ensuite, elle agit de manière hostile vis-à-vis de ses amis. Parce que vous n'avez pas exprimé vos sentiments, vous laissez vos amis deviner ce qu'ils ont fait de mal, ce qui laisse vos amis et vous-même dans la frustration.

Réaction 4: Affirmation de soi : Juliette sait ce qu'elle veut et l'exprime franchement. Quand vous êtes sensible aux sentiments de vos amis, vous vous sentez bien dans votre peau et vos amis savent à quoi s'en tenir avec vous. C'est une solution qui satisfait tout le monde.

6. Demandez aux filles d'imaginer que l'agressivité, l'affirmation de soi, et la passivité sont comme une bascule. La personne agressive est à la tête, regardant les autres du haut de son perchoir. La personne qui s'affirme est parfaitement équilibrée au milieu et très à l'aise avec elle-même et avec les autres. La personne passive est en bas, regardant le sol et se sentant mal.

\section{Les six règles d'or de l'affirmation de soi (15 minutes)}

1. Passez en revue les Six Règles d'Or de l'Affirmation de Soi qui sont inscrits sur le poster, en utilisant des informations supplémentaires pour mieux élaborer chaque règle. Clarifiez toutes les questions. 
2. Animez ensuite un petit débat en posant les questions suivantes.

- Quelles sont les règles les plus importantes pour s'affirmer?

- Quelles sont les règles les plus faciles à suivre?

- Quelles sont les règles les plus difficiles à suivre?

\section{Utiliser des phrases commençant par «Je» dans vos communications (15 minutes)}

1. Expliquez que l'expression assurée de vos sentiments implique l'utilisation de phrase commençant par «je». Ces phrases commencent par une personne qui exprime la façon dont elle se sent honnêtement, avant de dire quand ou dans quelles circonstances elle se sent ainsi et pourquoi, et ensuite ce dont elle a besoin ou aimerait changer. Rédigez la phrase suivante sur un flipchart.

Je sens lorsque vous parce que et j'aimerais/souhaiterais

Partagez un ou deux messages commençant par «je» en utilisant le format que vous avez écrit sur le papier. Voici quelques exemples :

- Je me sens vexé et en colère quand tu me traites de stupide et je voudrais que tu arrêtes de me donner des noms.

- Je me sens mal à l'aise lorsque tu essaies de faire pression sur moi pour que j'aie des rapports sexuels parce que j'ai fait le choix personnel de ne pas avoir des rapports sexuels et j'aimerais que tu arrêtes de faire ça.

2. Demandez aux filles de retourner dans les groupes et de se prêter à un jeu de rôle sur la situation suivante. Rappelez-leur d'utiliser les «je» pour les aider à communiquer efficacement leurs sentiments à leurs amis.

Vous êtes en conversation avec vos amies. La plupart d'entre elles ont eu des expériences sexuelles et se moquent de vous parce que vous n'en avez pas eu. Puisque l'une de ces filles a dit quelque chose qui blesse vos sentiments, vous décidez de lui dire ce qu'elle vous a fait ressentir.

3. Demandez à un ou deux groupes de présenter leurs jeux de rôles à l'ensemble du groupe, et attirez leur attention sur les phrases commençant par «je» qui ont été utilisées.

\section{TRAVAIL DE MAISON}

Demandez aux filles de réfléchir sur un ou deux buts d'affirmation de soi sur lesquels elles vont travailler au cours de la semaine prochaine. Cela pourrait se faire en utilisant plus de déclarations commençant par «je» au moment d'expliquer leurs sentiments à quelqu'un d'autre ou pourrait provenir des objectifs personnels des filles.

Demandez aux filles d'observer leur comportement au cours de la semaine prochaine et de noter une situation où elles ont agi de manière passive, agressive ou avec assurance, et comment elles se sont senties en réagissant ainsi. 


\section{Les six règles d'or de l'affirmation de soi}

(Activité : Les six règles d'or de l'affirmation de soi)

1. Définissez ce que vous ressentez ou voulez et dites-le.

2. Maintenez le contact visuel.

3. Ne présentez pas d'excuses.

4. Ne recherchez pas l'approbation des autres.

5. Ne vous laissez pas tromper par les arguments de l'autre personne.

6. Rappelez-vous que vous avez le droit de changer d'avis.

\section{INFORMATIONS SUPPLEMENTAIRES :}

\section{Définissez ce que vous ressentez ou voulez, et dites-le.}

N'ayez pas peur d'être honnête sur vos sentiments. Avoir confiance en vos propres sentiments encouragera d'autres à les respecter aussi. Quelqu'un qui vous aime réellement ne voudra rien faire qui puisse vous rendre malheureux.

\section{Maintenez le contact visuel.}

Contact visuel (regarder quelqu'un dans les yeux) est une partie importante de l'affirmation de soi. II fait savoir à l'autre personne que vous êtes sérieux au sujet de ce que vous dites et que vous êtes attentif au fait qu'il soit ou non en train de vous écouter. Le contact visuel n'est pas encouragé dans de nombreuses cultures, et dans certains endroits, il peut être considéré comme impoli. Une façon de traiter ce problème est de suivre les coutumes traditionnelles qui montrent le respect, tout en conservant un contact visuel quand vous avez besoin de vous affirmer.

\section{Ne présentez pas d'excuses.}

Vos sentiments sont les meilleures raisons. Par exemple, si vous ne vous sentez pas prêt pour des relations sexuelles, mais que votre copine ou copain fait pression sur vous, évitez d'utiliser d'autres personnes comme des excuses. Dites ce que vous ressentez vraiment.

\section{Ne recherchez pas l'approbation des autres.}

Si vous ne voulez pas faire quelque chose, dites-le clairement et ne demandez pas si c'est correct. Montrez aux autres personnes que vous vous connaissez et ne recherchez pas leur approbation.

\section{Ne vous laissez pas tromper par les arguments de l'autre personne.}

Continuez à répéter ce que vous voulez ou ne voulez pas. Tenez bon et ne cédez pas.

\section{Rappelez-vous que vous avez le droit de changer d'avis.}

Peut-être que vous et votre ami avez parlé de sexe il y a quelques jours et vous lui avez dit que vous auriez des relations sexuelles avec lui. Mais vous avez eu quelques jours supplémentaires pour y penser, et maintenant vous sentez que le moment n'est pas opportun, que vous n'êtes pas prête pour la relation. II dit : «Mais tu avais accepté d'avoir des relations sexuelles.» Dites-lui : "J'ai changé d'avis; j'ai décidé que je n'étais pas prête.» S'il vous aime réellement, il respectera votre droit de changer d'avis et attendra que vous vous sentiez prête. 


\section{Session 8 : La prise de décision et la résolution des problèmes}

\section{Objectifs de la session:}

À la fin de cette session, les filles seront capables de:

- Citer les trois étapes de la prise de décision

- Appliquez les trois étapes de prise de décision dans des situations différentes

- Utiliser une méthode de résolution des problèmes en quatre étapes

\section{Matériel nécessaire:}

- Poster avec la liste des trois étapes de prise de décision

- Flipchart et marqueurs

Plan de la session:

- Trois étapes dans la prise de décision (25 minutes)

- Quatre étapes pour la résolution de problèmes (40 minutes)

Durée totale: 65 minutes

AVANT LA SESSION : Écrivez les trois étapes de prise de décision sur un poster à afficher sur le mur :

1. Décrivez le DÉFI (ou décision) qui se pose à vous

2. Citez trois CHOIX que vous avez

3. Analysez les CONSÉQUENCES positives et négatives de chaque choix

\section{RECAPITULATIF DU TRAVAIL DE MAISON}

Demandez à des volontaires de partager leurs objectifs d'affirmation de soi et ce qu'elles font pour atteindre lesdits objectifs. Demandez-leur comment elles se sentent lorsqu'elles font preuve d'assurance.

Rappeler aux jeunes filles qu'il peut être difficile d'agir avec assurance, mais si elles continuent à pratiquer, cela deviendra plus facile.

\section{NOTES D'INFORMATION}

Une décision est un choix que nous faisons entre deux ou plusieurs pistes d'action possibles. Nous prenons tous des décisions tous les jours. Nous aurons besoin de prendre de plus en plus de décisions à mesure que nous avançons dans la vie et certaines de ces décisions nous affecteront pour le restant de nos vies.

Une des parties les plus importantes de la prise de décision est de penser à l'avenir et de voir ce qui pourrait arriver si vous faites quelque chose. C'est ce qu'on appelle la prédiction des résultats ou la 
compréhension des conséquences. Mieux vous prédirez les résultats, mieux vous prendrez des décisions qui se traduiront en des résultats ou des conséquences souhaités. Comprendre les conséquences éventuelles de nos décisions nous permet de faire face à des choix que nous avons à faire par rapport à nos vies.

Les étapes clés dans la prise de bonnes décisions comprennent :

- Décrire le problème, la situation, ou la question pour lequel ou laquelle une décision s'impose.

- Rechercher plus d'informations si vous avez des questions sur la situation.

- Réfléchir aux conséquences ou résultats éventuels de chaque action.

- Penser aux valeurs personnelles et familiales, et aux actions allant de pair avec ces valeurs.

- Penser aux façons dont votre décision peut affecter d'autres personnes.

- Choisir la décision qui semble la plus appropriée en fonction de vos connaissances, valeurs, morales, éducation religieuse, et objectifs présents et futurs.

- Réexaminer la décision et vos sentiments à ce sujet - si vous sentez que vous avez soigneusement examiné toutes les alternatives et que vous êtes à l'aise avec le choix que vous avez opéré.

\section{INSTRUCTIONS}

\section{$\rightarrow$ Trois étapes dans la prise de décision (25 minutes)}

1. Expliquez que prendre des décisions et connaître les conséquences sont des compétences importantes dont les jeunes ont besoin. Expliquez qu'il existe trois étapes pour une prise de décision active. Parfois, cela se fait avec précaution, d'autres fois très rapidement. Certaines décisions peuvent prendre quelques jours, d'autres des années, tandis que d'autres sont prises instantanément. Présentez les Trois Étapes de Prise de Décisions à partir du poster.

2. Expliquez que les filles sont confrontées à de nombreux défis, surtout à mesure qu'elles prennent de l'âge et deviennent plus indépendantes. Donnez aux filles 2-3 minutes pour réfléchir à une décision grave qu'elles-mêmes ou leurs amies ont dû prendre par rapport au mariage, à la famille, à leur santé, ou à leur travail.

3. Demandez à quelques filles de partager leurs exemples, et en tant que groupe, sélectionnez l'un des scénarios décrits. Ensemble, réfléchissez à tous les choix que la jeune fille a dans ce scénario. Notez sur le flipchart, les choix mentionnés par le groupe.

4. Rappelez aux filles qu'il y a des conséquences liées à leurs décisions. Demandez-leur de penser à d'éventuelles conséquences négatives et positives pour chacun des choix et notez ceux-ci par écrit. Ajoutez les conséquences évidentes que le groupe peut occulter, surtout celles qui sont négatives. Soulignez le fait que le nombre de choix ne devrait pas déterminer le meilleur choix. Vous devez noter l'intensité ou le poids de chaque choix.

5. Demandez aux filles de regarder les choix et les conséquences et de faire un choix ensemble. Essayez de trouver un consensus ou de procéder à un vote pour déterminer le résultat. Clarifiez le 
fait que la prise de décision se fait généralement seule, mais les gens peuvent demander l'avis d'autres personnes avant de prendre une décision.

\section{Quatre étapes pour la résolution de problèmes (40 minutes)}

1. Demandez à chaque fille de penser à un problème qu'elle a ou a eu récemment.

Exemple : Une jeune fille marche dans la rue avec son ami, et un homme la touche de manière à la mettre mal à l'aise.

Demandez au groupe :

- Quelles émotions ressentent les gens lorsqu'ils sont confrontés à un problème?

- Ces émotions nous ont-ils déjà averties que nous avons un problème? De quelles façons?

Ces questions nous orientent vers la première étape de résolution des conflits :

Reportez-vous à l'affiche sur les quatre étapes de résolution des problèmes et expliquez chacune des quatre étapes

PREMIÈRE ÉTAPE
S'ARRETER \&
RECONNAÎTRE

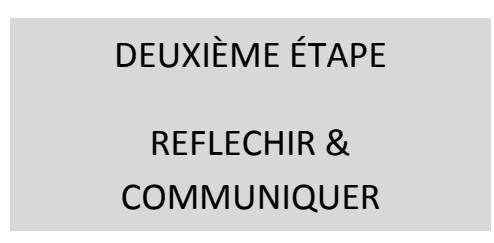

2. Informez les filles que réfléchir, c'est séparer les faits et les croyances. Demandez aux filles d'exprimer leur compréhension des concepts en posant les questions suivantes :

- Qu'est-ce qu'un fait?

- Exemple à partir du problème ci-dessus : L'homme a touché la fille.

- Qu'est ce qu'une croyance/ opinion?

- Exemple à partir du problème ci-dessus : Les hommes sont des brutes.

Clarifiez le fait que pour identifier un problème et y réfléchir, nous devons voir clairement les faits et les croyances/opinions.
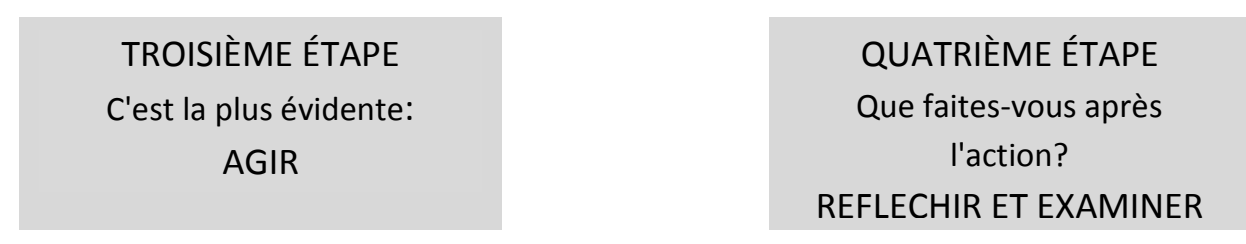

3. Divisez les filles en petits groupes et expliquez à chaque groupe, un scénario à partir de la liste de scénarii de résolution de problèmes suivante. Demandez aux groupes de discuter des problèmes, et de la manière de résoudre les problèmes en utilisant les quatre étapes de résolution des problèmes.

1. Vos amies veulent que vous voliez un pagne avec elles et disent que vous êtes faible si vous ne vous joignez pas à elles.

2. Les gens avec qui vous vivez, détestent vos amis et vous demandent de cesser de les voir.

3. Un ami vous a emprunté un habit, mais ne l'a pas retourné. Vous voulez qu'on vous rende votre habit. 
4. Vous vous sentez mal depuis quelques temps et votre employeur ne veut pas vous laisser quitter le travail pour aller au centre de santé.

5. Vous et vos amis jouez à la Marelle dans un parc situé à proximité /un terrain vide et maintenant une bande de garçons plus âgés l'utilisent au même moment.

6. Une fille que vous connaissez avoir un mauvais comportement, est en train de parler à votre frère.

4. Demandez à des volontaires dans chaque groupe de se prêter à un jeu de rôle sur l'un des problèmes qu'elles ont choisi afin de montrer comment elles résoudraient le problème. Après le jeu de rôle de chaque groupe, laissez l'ensemble du groupe évaluer le jeu de rôle selon les directives suivantes.

5. Animez un débat en posant les questions suivantes.

- Quel est le problème dans la situation?

- Quelles ont été les différentes solutions proposées pour résoudre le problème?

- Quelles ont été les conséquences de ces solutions?

- Quelle solution a été choisie?

- Pensez-vous que c'est la meilleure solution? Pourquoi ou pourquoi pas?

- Qu'est-ce qui se passe dans la vie si les problèmes ne sont pas résolus?

\section{TRAVAIL DE MAISON}

Demandez aux filles d'utiliser les Trois Étapes de prise de décisions qu'elles prendront au cours de la semaine prochaine. Demandez-leur de prêter une attention particulière à la façon dont elles se sont débrouillées face au défi, aux choix et aux conséquences pour prendre leur décision. 


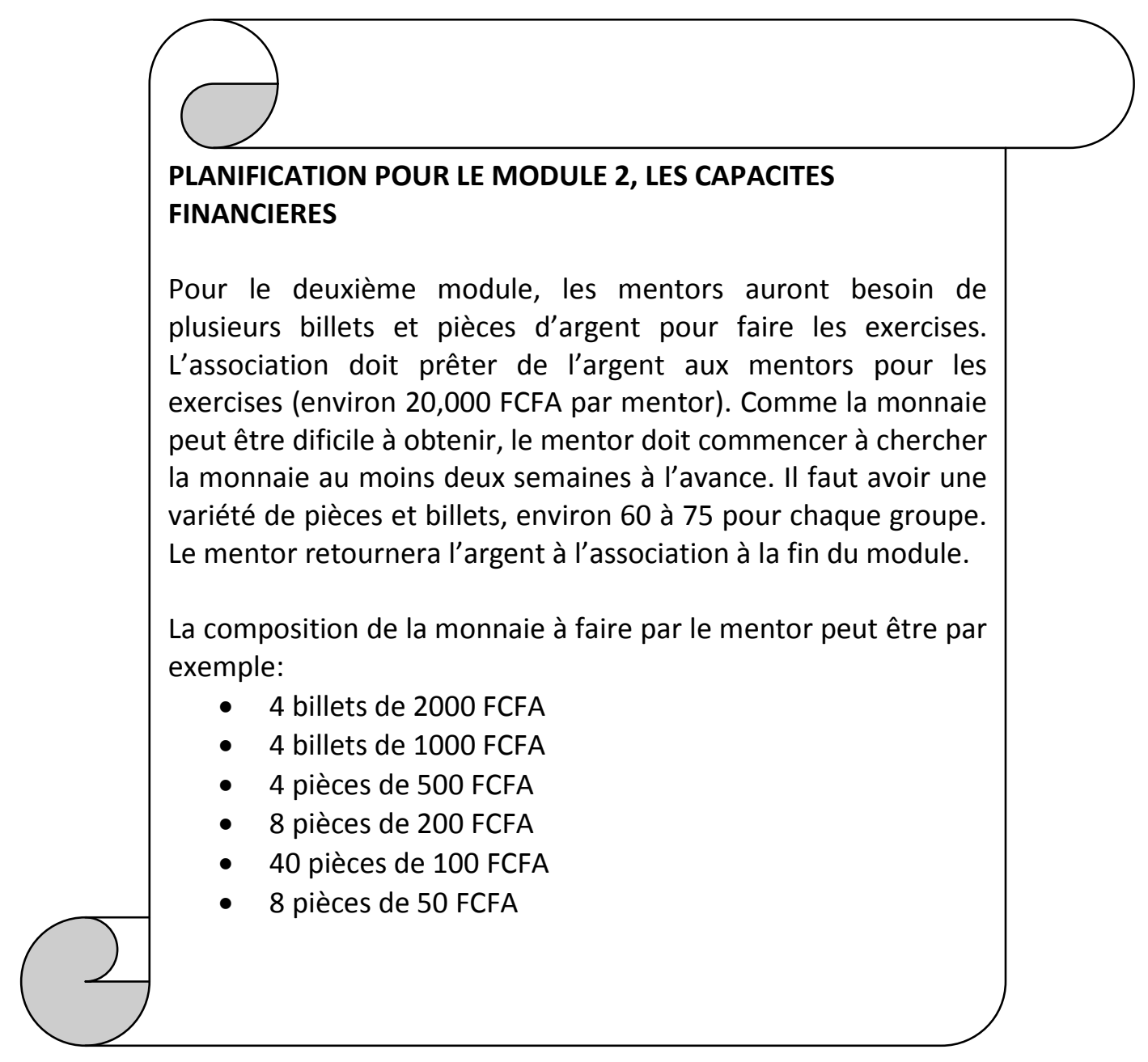




\section{Quatre étapes de résolution des problèmes}

(Activité : Quatre étapes de résolution des problèmes)

\section{S'ARRETER \& RECONNAITTRE}

- Ai-je un problème?

- Quel est mon problème?

- Comment mon corps est-il affecté?

- Quels sont les sentiments que je montre?

- Quels sont les sentiments que je garde pour moi-même?

2. REFLECHIR \& COMMUNIQUER

- Qu'est-ce que je veux voir arriver?

- Qui sont les autres personnes impliquées dans la situation?

- Quels sont les faits de la situation?

- Quelles sont mes perceptions et valeurs par rapport à la situation?

- Ai-je observé, rassemblé et rappelé tous les faits?

- Ai-je clairement exprimé mes sentiments et mes pensées?

- Les autres ont-elles clairement exprimé leurs sentiments et pensées?

- Quelles sont quelques unes des différentes solutions et leurs conséquences?

- Les conséquences sont-elles sans risque ou respectueuses pour les autres?

- Ai-je consulté d'autres personnes touchées par la gamme de solutions?

- Quelle est la meilleure solution?

3. AGIR

- Choisissez la meilleure situation

- Agir

- Choisissez de revenir en arrière et «arrêtez-vous et reconnaissez» une fois de plus s'il n'y a pas de meilleure solution

4. EXAMINER

- Observez les conséquences

- S'il n'y a pas de conséquences satisfaisantes, revenir à l'étape 1 


\section{Session 9 : La pression des pairs}

\section{Objectifs de la session:}

À la fin de cette session, les filles seront capables de:

- Comprendre les différentes situations où s'opère la pression des pairs

- Reconnaître quand la pression des pairs est positive et quand elle est négative

- Comprendre comment la pression des pairs peut influencer la prise de décision

\section{Matériel nécessaire:}

- Un poster avec la liste des trois étapes de prise de décision sur la base de la dernière session

Plan de la session:

- Jeux de rôles sur la pression des pairs (45 minutes)

- Refuser ce que vous ne voulez pas (40 minutes)

Durée totale: 85 minutes

\section{NOTES D'INFORMATION}

Même si les jeunes déclarent souvent en apprendre davantage auprès des amis lorsqu'ils atteignent l'adolescence, des études ont montré que ces mêmes adolescents préféreraient connaître une variété de sujets importants auprès de leurs parents ou autres adultes bienveillants. L'influence des pairs augmente au cours des années de l'adolescence, mais l'influence des adultes bienveillants peut rester forte que si vous avez établi une relation solide au cours des années précédentes. La pression des pairs est tout aussi subtile pour les jeunes qu'elle l'est pour la plupart des adultes, d'où l'importance de pratiquer la résistance à la pression des pairs. Trouver des moyens créatifs pour refuser l'alcool, le tabac, la drogue et le sexe requiert de l'humour et beaucoup de pratique. Chaque jeune peut aider à élaborer son propre répertoire favori de commentaires «pour décliner les propositions», mais c'est votre travail de les aider à les mettre en pratique afin qu'ils ne soient pas remis en cause si l'offre est plus subtile ou plus directe par rapport aux prévisions. Ceci dépendra beaucoup de l'âge et de l'attitude de la jeune fille, et le plus important est de s'assurer qu'elle est à l'aise avec ce qu'elle veut dire. Votre travail est de les encadrer afin qu'elles utilisent un langage et des expressions qui leur permettent de résister à la pression des pairs pour les encourager à consommer des drogues, avoir des rapports sexuels, ou boire de l'alcool.

Plus la fille est jeune, plus elle aura besoin de pratique. Ceci ne peut être une session unique. Vous pourriez trouver, par exemple, qu'une fillette de 10 ans, n'a aucun mal à dire non à une suggestion faite pour qu'elle essaie une bière chez un voisin. Cependant, 3 ans plus tard, lorsque la personne de 17 ans de la porte d'à côté lui demandera si elle veut une bière, vous l'entendrez hésiter parce qu'elle n'est pas aussi sûre d'elle et de ses convictions à 13 ans comme elle l'était à l'âge de 10 ans. 


\section{INSTRUCTIONS}

\section{$\rightarrow$ Jeux de rôles sur la pression des pairs (45 minutes)}

1. Demandez aux filles de vous donner le signe du "pouce levé» si elles ont auparavant entendu parler du terme "pression des pairs». Si quelqu'un en a entendu parler, lui demander de décrire ce qu'elle croit être la définition de ce terme.

2. Expliquez que la pression des pairs, c'est quand les opinions d'autrui ont une influence sur nous et les décisions que nous prenons. La pression des pairs peut être négative et faire en sorte que nous nous sentions obligé de faire quelque chose d'incorrect pour nous, ou elle peut être positive et nous aider à être plus réactifs que nous ne l'aurions été de nous-mêmes.

3. Expliquez aux filles qu'elles vont maintenant faire une activité qui leur permet de pratiquer les trois étapes de la prise de décision (en pensant aux défis, choix et conséquences) afin qu'elles puissent s'en servir pour prendre des décisions importantes et résister à la pression des pairs.

4. Divisez les filles en quatre groupes, et attribuez à chaque groupe un jeu de rôle sur la pression positive ou négative des pairs. Demandez à chaque équipe d'utiliser le modèle en trois étapes pour les aider à nommer les défis, choix et conséquences qui se posent aux jeunes filles dans leur situation. Les groupes devraient consacrer environ 5 minutes à ce sujet, et 5 à 10 autres minutes pour pratiquer leurs jeux de rôles.

Voici quatre histoires possibles qui peuvent être expliquées à chacun des groupes. On racontera à chaque groupe son histoire, mais à l'insu des autres groupes. Les filles devraient se rappeler en préparant les jeux de rôle, d'impliquer chaque membre de leur groupe et de les traiter avec respect. N'utilisez pas une situation réelle qui pourrait embarrasser quelqu'un.

HISTOIRE 1 (Négative) : Une fille nommée Kady et qui vient de s'installer dans la communauté est arrêtée près de la route. Deux autres filles qui ont vécu dans la communauté pendant longtemps, marchent vers elle. Les filles de la communauté n'aiment pas les vêtements extravagants que porte Kady. Elles font des commentaires selon lesquels ses vêtements sont vilains et qu'elle n'est pas une des leurs. Que devrait faire Kady?

HISTOIRE 2 (Positive) : Une fille nommée Alexandrine n'a pas de copain. Elle tient beaucoup à avoir un petit ami et demande à son amie Clémentine de l'aider à en trouver un. Alexandrine dit à Clémentine qu'elles ont toutes les deux la chance d'apprendre un métier dans un centre de formation professionnelle, et qu'elles devraient se concentrer sur le travail afin de réussir. Clémentine pense que le fait d'avoir des petits amis les détournerait de leur formation. Que devrait faire Alexandrine?

HISTOIRE 3 (Positive): Aurélie veut réussir à l'école, mais ne comprend pas les leçons de l'enseignant. Aurélie n'excelle pas dans les devoirs donnés par l'enseignant. Beaucoup d'amis d'Aurélie lui disent combien il est important de poser des questions quand elle ne comprend pas quelque chose en classe. Ils conviennent aussi de poser plus de questions pour aider Aurélie à mieux se sentir par rapport à ses questions. Que devrait faire Aurélie? 
HISTOIRE 4 (Négative) : Le père de Dominique lui a donné de l'argent pour aller au marché et acheter des œufs pour sa famille. Sur le chemin, Dominique rencontre des jeunes filles qui ont de nouvelles boucles d'oreilles. Elles racontent à Dominique que leurs pères leur ont donné de l'argent pour acheter ces boucles d'oreilles. Dominique pense qu'elle devrait avoir de jolies boucles d'oreilles aussi, mais elle sait que son père serait très en colère si elle n'achetait pas les œufs pour sa famille. Que devrait faire Dominique?

(Les mentors sont encouragés à penser à des exemples similaires, ou à permettre aux filles de raconter leur propre histoire.)

2. Appelez les groupes un à un pour leurs jeux de rôle.

3. Animez un débat en posant les questions suivantes.

- Quelles histoires ont révélé une pression négative des pairs et quelles sont celles qui ont montré des pressions positives de pairs?

- Comment les filles se sont senties quand une jeune fille a subi la pression négative de ses pairs?

- Comment les filles se sont senties quand une jeune fille a été confrontée à des pressions positives de ses pairs?

- Est-il difficile de prendre de bonnes décisions? Qu'est-ce qui rend le processus difficile? (Voici des réponses possibles : I'influence de l'alcool, la pression des pairs ou d'un partenaire ou le fait de ne pas se rendre compte qu'une décision doit être prise.)

- Qu'est-ce qui le rend plus facile? (Les réponses pourraient être : savoir comment résister à la pression, être sûre de ses valeurs et objectifs.)

- En réalité, comment sont prises la plupart des décisions? (Elles ne sont pas prises sciemment, et les événements ou choses arrivent tout simplement).

- Dans le passé, avez-vous pris une décision qui a affecté d'autres personnes? Qu'est-il arrivé? Vous êtes-vous déjà laissé emportée dans une décision ou laisser quelqu'un vous entraîner dans une décision? Quelles ont été les conséquences?

\section{$\rightarrow$ Refuser ce que vous ne voulez pas (40 minutes)}

1. Dites aux filles qu'il y a deux moyens d'obtenir ce qu'on veut et ce dont on a besoin :

1) en demandant ce qu'on veut et

2) en refusant ce qu'on ne veut pas.

Expliquez que pour le reste de la session, les filles mettront en pratique les compétences en matière de refus.

2. Demandez aux filles de penser au scénario suivant :

Gisèle et Claire vont à pied à la maison après avoir fait le marché. Gisèle veut rencontrer son copain chez lui et demande à Claire de l'y accompagner. L'employeur de Claire sera très en 
colère si elle n'est pas à la maison juste après le marché. Gisèle dit à Claire qu'elle peut juste dire à son employeur qu'elles avaient une réunion du groupe des filles. Claire ne veut pas mentir à son employeur et elle ne pense pas que ce soit une bonne idée d'aller voir le copain de Gisèle parce qu'il est plus âgé et ne paraît pas être très gentil. Gisèle promet à Claire qu'elles ne resteront pas trop longtemps et aussi que l'ami de son petit ami aime Claire et veut parler avec elle.

3. Demandez si quelqu'un peut décrire ce que Claire est probablement en train de ressentir par rapport à cette situation. Écrivez les sentiments sur le tableau. Ils devraient inclure des émotions comme "sous pression», "confuse», "frustrée», «nerveuse», ou "en colère». Soulignez le fait qu'il est aussi normal d'éprouver de la colère si un ami vous met dans l'embarras en vous demandant de faire quelque chose qui n'est pas dans votre intérêt.

4. Demandez aux filles de discuter sur les conseils qu'elles pourraient donner à Claire. Mentionnez ensuite le fait que, parfois, les parents, les enseignants, les employeurs ou d'autres adultes d'une certaine autorité présentent des requêtes aux adolescents. La demande peut ne pas plaire à l'adolescent et il peut ne pas la percevoir comme étant dans le meilleur de ses intérêts. Demandezleur comment les droits d'un adolescent sont similaires ou différents, plus avec un parent qu'avec un ami. Expliquez que certains adultes, comme les enseignants, les parents et les membres de la famille, ont le droit de faire des demandes aux jeunes. À moins que l'adulte ne demande quelque chose d'illégal, de nuisible ou de très irrespectueux vis-à-vis de l'adolescent, il n'est souvent pas approprié pour un adolescent de refuser cette demande. Les adolescents ont, cependant, le droit de dire comment ils se sentent.

5. Demandez à un volontaire de jouer le rôle de Claire, pendant que vous jouez celui de Gisèle. Utilisez les exemples qui suivent pour lui mettre la pression, et dites au reste du groupe d'entraîner la volontaire afin qu'elle puisse s'affirmer face à la pression :

- «Allez viens, tu es censée être ma meilleure amie. J'ai vraiment envie de le voir et son ami t'aime vraiment.»

- "Ton employeur ne saura même pas. Nous y resterons juste pour un petit moment.»

- «Qu'est-ce qu'il y a? tu as peur? N'importe qui d'autre viendrait avec moi, si elle était ici.»

6. Après le jeu de rôle, demandez aux filles d'identifier les comportements utilisés par Claire pour s'affirmer. Si le temps le permet, demandez à deux autres volontaires de s'essayer au jeu de rôle.

7. Animez un débat autour des questions suivantes :

- Quand pourrais-tu recourir à un «coach/encadreur» face à une pression réelle de la part d'un ami ou d'un partenaire amoureux?

- Qu'est ce qui est le plus difficile, dire ce que vous voulez ou refuser ce que vous ne voulez pas? Pourquoi?

- Pensez à une situation récente dans laquelle vous vouliez refuser une demande, mais n'aviez pas pu. Quelles compétences auriez-vous pu utiliser pour refuser? 
- Vivez-vous actuellement une situation où quelqu'un fait pression sur vous pour faire quelque chose qui n'est pas dans votre intérêt? Que pourriez-vous faire pour vous affirmer davantage dans cette situation?
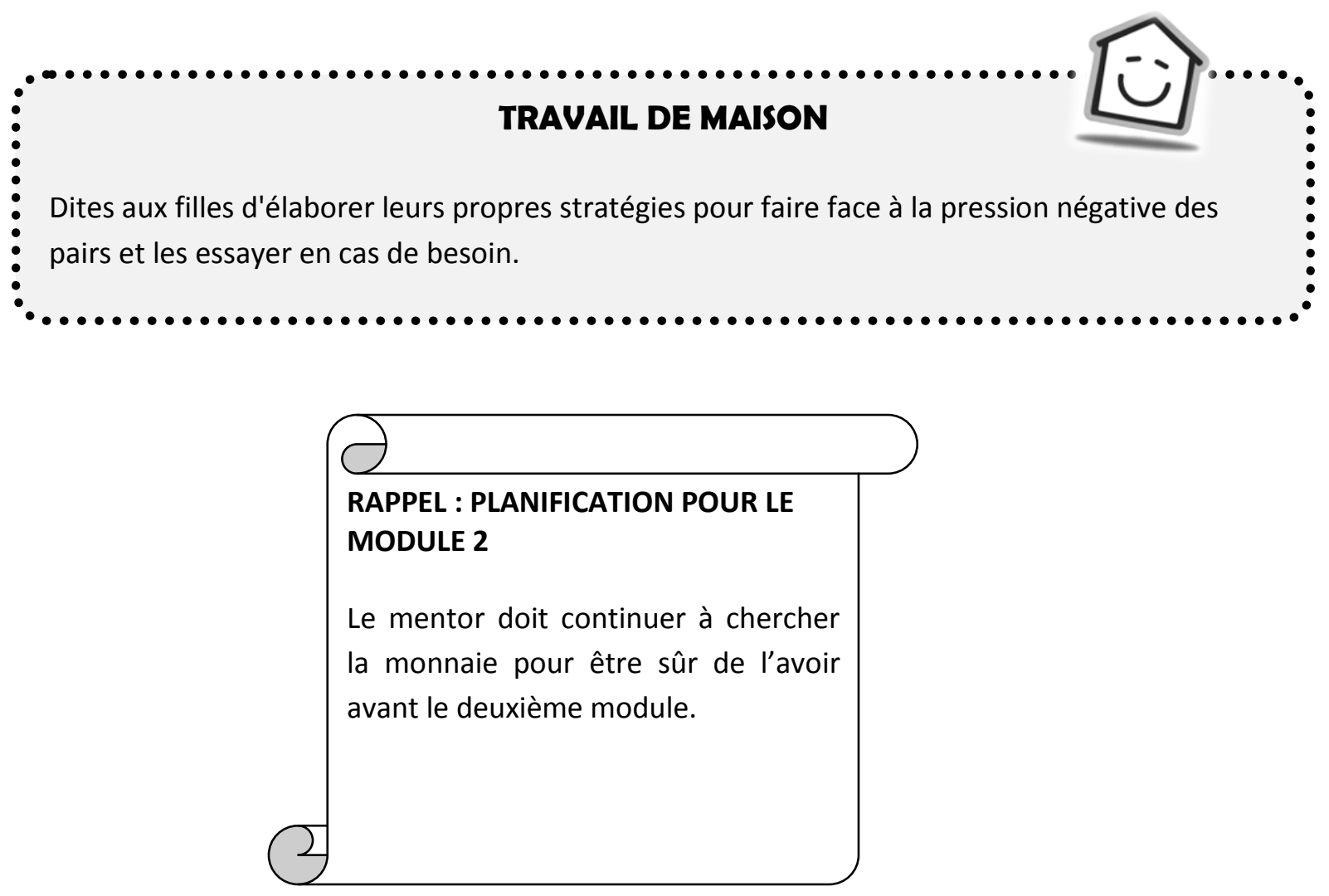


\section{Session 10 : Le leadership}

\section{Objectifs de la session:}

À la fin de cette session, les filles seront capables de:

- Identifier les femmes leaders ou des groupes de leadership dans la communauté

- Comprendre les différentes manières dont les femmes peuvent participer à la prise de décision dans la communauté

- Identifier quelques idées pour des actions dans la communauté

- Connaître et décrire les responsabilités au sein de la communauté

\section{Matériel nécessaire:}

- Flipchart et marqueurs

\section{Plan de la session:}

- Leader secret (20 minutes)

- Qualités des leaders (25 minutes)

- Femmes en tant que leaders (20 minutes)

- Mon rôle dans la communauté (25 minutes)

Durée totale: 90 minutes

\section{RECAPITULATIF DU TRAVAIL DE MAISON}

Demandez à quelques volontaires de partager les descriptions de types de pressions des pairs auxquelles elles ont été confrontées au cours de la semaine passée et comment elles ont essayé des stratégies pour résoudre cette pression des paires.

\section{NOTES D'INFORMATION}

Le leadership est très important dans la vie de tout un chacun. II y a des leaders née, et il y en a qui développent leurs compétences de leaders à travers leur vie. La stratégie de leadership en cascade est une composante importante de ce programme et consiste à développer les compétences de leadership des mentors afin que ces dernières les développent chez les adolescentes du programme. Le leadership est d'importance primordiale dans la vie d'une fille.

\section{INSTRUCTIONS}

\section{Leader Secret (20 minutes)}

1. Lancez un débat en posant les questions suivantes :

- Quelles sont certaines qualités ou caractéristiques d'un leader?

- Dans le cadre du programme "Filles Eveillées" quelles seront les qualités ou caractéristiques d'une fille leader? Noter les réponses des filles et mettez-vous d'accord sur les qualités et caractéristiques que les participantes vont retenir pour faire le choix des deux 
filles leaders à la fin du programme. Ecrivez ces qualités en grand caractère sur un papier flip-chart que vous allez coller au mur de l'espace sûr afin que les filles se rappellent de cela à chaque fois qu'elles viendront aux sessions hebdomadaires.

- Quelles sont certaines qualités ou caractéristiques d'un suiviste?

2. Demandez aux filles de former un grand cercle.

3. Demandez à un volontaire d'être la Personne qui Devine. Demandez à cette personne de quitter l'aire de jeu temporairement.

4. Expliquer que cette personne retournera au centre du cercle, et aura trois hypothèses pour identifier le Leader Secret.

5. Une fois qu'elle a quitté l'aire de jeu, choisissez tranquillement un volontaire pour être le Leader Secret.

6. Expliquez et démontrez que :

- Le Leader Secret effectuera une série d'actions différentes, tels que des battements de mains, le martèlement des pieds, le hochement de la tête, etc. Encouragez le Leader Secret à utiliser son imagination pour exécuter les différentes actions.

- Le Leader Secret changera d'action chaque fois que cela pourra se faire en toute sécurité (sans être vu).

- Chaque membre du cercle doit suivre les actions du Leader Secret en regardant la fille directement autour du cercle. Les filles ne devraient pas regarder directement le Leader Secret

- La personne qui devine retournera au centre du cercle pendant qu'une action sera en cours.

- Elle a trois chances pour indiquer la personne qu'elle pense être le Leader Secret.

- Si elle identifie le Leader Secret, elle peut choisir un volontaire pour prendre sa place au prochain tour.

- Si elle n'arrive pas à identifier le Leader Secret 3 fois de suite, elle se présentera. Elle peut choisir d'être la prochaine personne qui devine ou sélectionner un volontaire pour le rôle.

- Les actions du groupe devraient se poursuivre pendant que le devin essaie d'identifier le Leader Secret.

7. Le jeu se termine à votre discrétion.

Regardez :

- Le Leader Secret mène t-il des actions simples pouvant être facilement suivies?

- Chaque joueur regarde-t-il directement le joueur situé à l'autre côté du cercle?

8. Animez un débat en posant les questions suivantes :

- Les véritables leaders sont-ils toujours visibles?

- Est-il possible de diriger sans être remarqué par tout le monde?

- Quels sont certains moyens pour diriger dans votre famille, votre école ou communauté?

- Que signifie «diriger par l'exemple»? 


\section{$\rightarrow$ Qualités des leaders (20 minutes)}

1. Demandez au groupe de réflechir sur les leaders officiels dans leur communauté et de noter la différence entre le nombre d'hommes et de femmes.

2. Expliquez que dans la plupart de nos communautés les responsables officiels sont des hommes. Au cours de cette activité, le groupe étudiera comment les femmes peuvent être des leaders dans les communautés et participer à la politique et à la prise de décision.

3. Sur un flipchart, écrivez les mots "femmes leaders». Demandez aux filles de lister les noms de femmes leaders qu'elles connaissent. Demandez-leur d'énumérer les qualités qui font d'elles des leaders. Maintenant, écrivez les mots "hommes leaders» et demandez-leur de citer les qualités d'un bon leader de sexe masculin. Notez-les.

4. Demandez au groupe si les qualités des femmes leaders sont différentes de celles des femmes de la communauté. Quelles sont ces qualités?

5. Rayez «femmes leaders» et remplacez-le par «hommes leaders». Rayez «hommes leaders» et écrivez «femmes leaders». Demandez ce qu'elles pensent de la liste maintenant.

- Est-ce-que la première liste de qualités s'applique aux hommes et aux femmes? Pourquoi ou pourquoi pas?

- Est-ce-que la deuxième liste s'applique aux hommes et aux femmes? Pourquoi ou pourquoi pas?

- Est-il nécessaire d'être un grand orateur ou un motivateur de foules pour être un leader? Connaissez-vous des leaders "calmes» dans votre communauté?

- Qu'est ce qui empêche les femmes d'être des leaders?

N.B : Ces questions vont susciter un débat animé sur les attributs spécifiques au genre. Liez la discussion au processus de stéréotype de genre. Soulignez la nature acquise des rôles de genre.

6. Dites aux filles qu'à la fin du programme, elles vont sélectioner deux filles du groupe qui ont démontré les qualités de leadership. Vous devriez garder le papier avec les qualités de leader qu'elles ont listé pour pouvoir rapeler aux filles ces qualités pendant la session 29.

\section{Femmes en tant que leaders (20 minutes)}

1. Lisez l'histoire intitulée «Leadership des femmes dans la communauté»

\section{Leadership des femmes dans la communauté}

Aïcha vit dans un village avec son mari Moussa et leurs trois enfants dont deux garçons et une fille. Tous les trois suivaient des cours à l'école du village, mais Moussa ne voulait pas que sa fille Mariam poursuive ses études. Mariam a donc abandonné l'école.

Aïcha a été très bouleversée et a tenté de convaincre Moussa de renvoyer Mariam à l'école. Moussa n'a rien voulu entendre. II croyait qu'éduquer une fille était une perte de temps et d'argent. Par ailleurs, cela pourrait la gâter. 
Aïcha a été très déçue. Elle voulait que sa fille soit éduquée. Maintenant que Aïcha fréquentait le centre d'éducation nouvellement mis en place dans le village, elle comprenait l'importance d'éduquer une fille. Elle en a parlé aux autres femmes de sa communauté. Après plusieurs rencontres, elles ont toutes décidé que leurs filles doivent aller à l'école. Elles ont associé le leader villageois et le maître d'école dans leurs discussions. Le groupe de femmes s'est ensuite rendu dans chaque ménage et a convaincu les hommes de la nécessité d'envoyer les filles à l'école. Les hommes ont dû accepter. Ils ont commencé à envoyer leurs filles à l'école.

2. Demandez aux filles de se diviser en petits groupes et de discuter ce qui suit :

- Qu'est-ce que Aïcha a fait dans l'histoire?

- Quelles ont été certaines de ses caractéristiques de leader?

- Comment ces caractéristiques se comparent-elles avec les caractéristiques de leadership des hommes?

- Pourquoi Aïcha a été un leader efficace?

- Quelle est la différence entre ce genre de leadership et le leadership des leaders élus ou des chefs traditionnels?

3. Après des échanges de 10 minutes en petits groupes, regroupez l'ensemble du groupe. Demandez à un membre de chaque petit groupe de partager certaines idées de leur discussion.

4. Demandez aux filles de réfléchir sur leurs propres communautés :

- Qui sont certaines bonnes femmes leaders ou bons groupes de leadership?

- Pourquoi avoir choisi ces femmes ou groupes?

- Comment ces dirigeants peuvent-ils être une source de soutien dans les domaines de préoccupation des jeunes?

\section{Mon rôle dans la communauté (25 minutes)}

1. Dites aux filles que le leadership signifie que vous avez le pouvoir de provoquer le changement.

2. Divisez les filles en petits groupes de quatre ou cinq. Dites-leur d'imaginer qu'elles sont les assistantes spéciales des anciens. Elles ont le pouvoir d'apporter les changements qu'elles veulent dans leur communauté. En petits groupes, réfléchissez aux changements qu'elles voudraient apporter. Demandez à un membre de chaque groupe d'être le rapporteur et de rendre compte au groupe élargi.

3. Demandez au groupe d'identifier les changements qui sont réalistes - ceux qui pourraient s'opérer si les jeunes et les adultes conjuguent leurs efforts à cet effet. Écrivez-les sur un flipchart et encerclez les changements réalistes ou donnez des exemples. Faites remarquer que certains changements ne sont pas réalistes dans le futur immédiat - ils ne peuvent pas être faits maintenant, peu importe jusqu'à quel point quelqu'un peut désirer ces changements ou s'efforcer.

4. Demandez aux filles de retourner dans leurs groupes et de choisir un problème réaliste sur lequel elles voudraient travailler à partir de la liste des changements. Demandez aux filles de réfléchir à des stratégies pour opérer des changements afin d'éliminer le problème. Si elles se sentent bloquées, aidez-les en leur disant qu'elles pourraient faire :

- Quelque chose de mental, comme trouver une nouvelle approche ou idée 
- Quelque chose de physique, comme nettoyer, réparer ou construire

- Quelque chose de financier, comme économiser un peu d'argent chaque semaine comme contribution pour un nouveau centre communautaire

- Quelque chose de social pour aider les gens, comme le fait de visiter les malades ou les personnes âgées

- Quelque chose de politique pour changer les règles ou lois, y compris la rédaction de lettres à l'administrateur général du district, aux leaders sociaux et politiques.

5. Donnez 5 à 10 minutes, puis demandez à chaque groupe de rendre compte de ses stratégies.

6. Animez un débat en posant les questions suivantes :

- Quelqu'un a-t-il essayé de résoudre ces problèmes avant? Si oui, quel a été le résultat?

- Pouvez-vous penser à des problèmes communautaires qui ont été résolus par des jeunes comme vous? Donnez des exemples.

- Combien de temps consacreriez-vous à la résolution de l'un de ces problèmes?

- Dans quel projet de développement communautaire avez-vous été impliqué?

- Que pouvez-vous gagner en participant au développement communautaire? (Certaines idées pourraient être : quelque chose d'intéressant à faire pendant les moments libres, de nouvelles relations avec des gens intéressants ou utiles, un sentiment d'accomplissement, l'apprentissage de nouvelles compétences.)

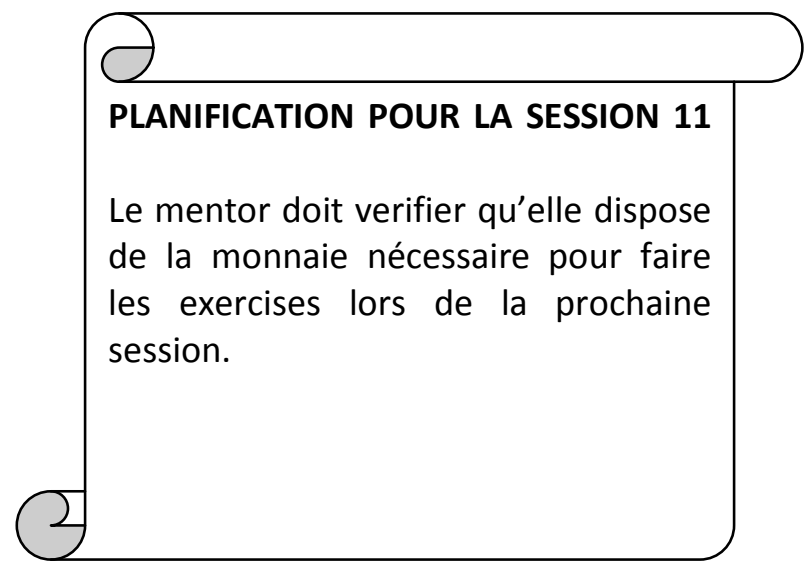




\section{Module 2}

\section{Les Capacités Financières}

Session 11: Introduction aux capacités financières et à l'argent

Session 12: Epargner, objectifs d'épargne, et plans d'épargne

Session 13: Les méthodes et lieux sécurisés pour garder l'argent

Session 14: Les façons de dépenser de l'argent

Session 15: Emprunter prudemment et obtenir une grosse somme d'argent

Session 16: Résolution des conflits relatifs à l'argent

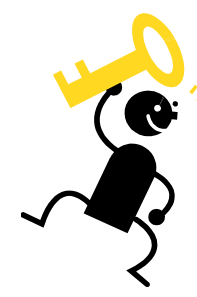

Termes Clés dans ce Module: besoins, capacité financière, désirs, emprunter prudemment, épargner, examen de l'argent, façons de dépenser l'argent, grosse somme d'argent, lieu sécurisant pour l'argent, objectif d'épargne, plan d'épargne, résolution des conflits relatifs à l'argent. 


\section{Session 11 : Introduction aux capacités financières et à l'argent}

\section{Objectifs de la session:}

À la fin de cette session, les filles seront capables de:

- Comprendre l'importance de l'éducation financière dans leur vie

- Démontrer la connaissance de la valeur des différents billets de banque et pièces

- Définir où les adolescentes obtiennent de l'argent et pourquoi elles le dépensent

\section{Matériel nécessaire:}

- Billets et pièces d'argent de différentes valeurs, avec aux moins $60-75$ pièces et billets au total

- Par exemple :

- 4 billets de 2000 FCFA

- 4 billets de 1000 FCFA

- 4 pièces de 500 FCFA

- 8 pièces de 200 FCFA

- 40 pièces de 100 FCFA

- 8 pièces de 50 FCFA

- Flipchart et marqueurs

Plan de la session:

- Introduction aux capacités financières (10 minutes)

- Examen de l'argent (20 minutes)

- Entrées et Sorties d'argent (30 minutes)

Durée totale: 60 minutes

\section{NOTES D'INFORMATION}

Les adolescentes sont au bord du chemin; elles sont en passe de devenir des adultes, avec devant elles, un avenir plein de responsabilités dont elles ne connaissent pas grand chose. Elles balancent entre la dépendance sur leurs tuteurs et l'indépendance demandée par les jeunes adultes. Elles expérimentent de nouvelles relations sociales et assument plus de responsabilités financières. Cette période tumultueuse est aussi le moment crucial où les jeunes font face à leur avenir et commencent à préparer les rôles économiques qu'ils assumeront en tant que adultes. Leur apprendre à gérer leur argent et à accumuler des actifs peut les aider à se protéger et élargir leurs opportunités. C'est le rôle de l'éducation financière.

A la base, l'éducation financière met l'accent sur les concepts de l'argent et les moyens de bien le gérer. Il favorise l'épargne régulière, les dépenses sages et les moyens de tirer le meilleur parti de ses ressources. Ces compétences servent de base pour les filles, qui transitent de la dépendance à l'indépendance dans la gestion financière. Elles passent de la dépendance du soutien familial de parents ou d'autres parents, à un stade où elles gagnent leur propre argent et prennent en toute indépendance, des décisions financières. À un niveau primaire, elles doivent savoir comment se comporter, poursuivre des opportunités de génération de revenus, couvrir leurs dépenses, et planifier leur avenir. Cependant, ces bases évoluent rapidement puisque le futur arrive à grands pas. Avec des partenariats, le mariage et la formation des ménages, elles peuvent se retrouver, toujours 
à leur jeune âge, en train de prendre des décisions conjointes. Elles assument des responsabilités supplémentaires et font face à des négociations de plus en plus complexes en ce qui concerne l'emploi, le logement, et les relations.

Ainsi, pour être prêtes à assumer les responsabilités financières des adultes, les jeunes femmes ont besoin de connaissances et de compétences pour gérer non seulement les dépenses quotidiennes, mais les besoins du cycle de vie aussi, y compris l'éducation, le mariage et les enfants. Elles ont besoin de connaissances et de compétences pour utiliser les services financiers (épargne, emprunt, assurance), qui peuvent les aider à réduire la vulnérabilité et accroître la richesse.

Ce sont des compétences dont les adolescentes et jeunes femmes ont besoin maintenant et chaque jour de leur vie d'adulte. Un investissement dans l'éducation financière des adolescentes prépare le terrain aux nombreux changements à venir. Il va augmenter leur capacité de gestion de l'argent, leur confiance et leur préparation pour l'avenir. Les connaissances financières peuvent ouvrir de nouvelles opportunités de travail, de renforcement des actifs, et d'épargne. L'accès et le contrôle sur les économies peuvent aider à protéger, atténuer et faire face aux nombreux risques liés à l'adolescence, en fournissant des ressources pouvant être utilisées en cas de besoin.

Activité: Entrées et Sorties d'argent: Cet outil aide à comprendre où les filles obtiennent leur argent et comment elles le dépensent. II peut aussi servir à cerner d'autres comportements impliquant des " entrées et sorties » de ressources, comme le type de soutien dont les filles ont besoin pour devenir des leaders et ce qu'elles peuvent apporter en tant que leaders.

Cet outil peut être utilisé pour recueillir des informations sur une question particulière qui affecte la vie des filles. II invite généralement les filles à réfléchir à deux éléments d'une question et peut s'appliquer à différents sujets. Par exemple : où les filles obtiennent leur argent et comment elles le dépensent; type de soutien dont les filles ont besoin et ce qu'elles peuvent offrir en retour au programme ou à la communauté ; défis auxquels les filles se trouvent confrontées et comportements qu'elles adoptent pour y faire face. L'outil peut aussi être concentré sur les thèmes spécifiques des responsabilités financières, des grossesses d'adolescentes, de la drogue et de l'alcool.

\section{INSTRUCTIONS}

\section{$\rightarrow$ Introduction aux capacités financières (10 minutes)}

1. Expliquez qu'on va maintenant aborder le deuxième thème du programme: les capacités financières. On espère que ce thème vous sera utile pendant toute la vie.

2. Dites: "Aujourd'hui, nous commençons la première session d'apprentissage dans notre programme d'éducation financière. Nous commencerons par l'épargne parce que c'est la clé de la sagesse en ce qui concerne l'argent. Après cela, nous parlerons aussi d'emprunt d'argent et de la façon d'être astucieuse lorsqu'il s'agit de contracter des emprunts ».

3. Dites: "Puisque la plupart d'entre nous n'avons pas assez d'argent pour payer tout ce dont nous avons besoin et tout ce que nous désirons, nous devons faire des choix au sujet de ce que nous allons acheter et ce que nous n'allons pas acheter. Nous essayons d'économiser pour les choses que nous 
désirerons à l'avenir. Nous essayons de voir comment augmenter notre argent pour couvrir les dépenses nécessaires auxquelles nous faisons face. Ceci peut être difficile ».

"Dans les prochaines sessions, nous nous concentrerons sur la valeur de l'épargne, et apprendrons certaines choses que nous pouvons faire pour aider à épargner comme la découverte d'un endroit sécurisé pour mettre notre argent et notre épargne chaque semaine, même quand c'est en petits montants. "

4. Expliquez: " Je vais formuler une série de phrases et vous demander de vous mettre débout lorsque vous estimez que la phrase est vraie ".

Levez-vous si vous:

- êtes venue à pied aujourd'hui

- portez une tenue de couleur verte

- n'avez jamais épargné de l'argent

- aimez dépenser l'argent

- savez combien vous avez dépensé en nourriture la semaine dernière

- aimeriez avoir plus d'argent

- êtes en train d'épargner pour quelque chose de spécifique que vous désirez avoir

- gardez les détails de vos dépenses

- pensez que c'est important d'épargner

- pensez que c'est difficile d'épargner

5. Demandez:

Pour ceux d'entre vous qui pensez que l'épargne est importante, pourquoi le pensez-vous?

Pourquoi est-il difficile d'épargner de l'argent?

6. Expliquez:

Gérer l'argent implique les choses suivantes:

- épargner l'argent

- dépenser l'argent

- planifier la façon dont vous aller dépenser votre argent, et

- garder les détails de la façon dont vous dépensez votre argent.

7. Expliquez que savoir mettre de l'argent de côté et économiser requiert des compétences importantes que nous allons apprendre ensemble dans les séances à venir.

\section{$\rightarrow$ Examen de l'argent (20 minutes)}

1. Distribuez des pièces et des billets à partir du lot d'argent prévu pour le jeu. Assurez-vous d'en donner à chaque fille. Expliquez aux filles que l'argent est juste pour faire des exercises et que vous allez reprendre l'argent à la fin de la session. Les filles ne peuvent pas garder l'argent. 
2. Demandez aux participantes de se tourner vers les filles à côté d'elles pour expliquer combien d'argent elles ont reçu. N'oubliez pas que certaines filles ne connaîtront certainement pas la valeur de l'argent, essayez donc de vous promener et faire un contrôle informel des connaissances financières.

3. Demandez à quelques volontaires de montrer leurs pièces et billets au groupe et de dire combien ça fait. Corrigez tout malentendu.

4. Demandez à d'autres volontaires d'expliquer ce qu'elles pourraient acheter avec l'argent qu'elles ont.

N.B: si les connaissances semblent particulièrement mauvaises, passez à l'activité 5 et mettez plutôt l'accent sur la discussion du concept des pièces et billets ayant des valeurs différentes, même si ils se ressemblent.

5. Demandez aux filles de jouer des scénarios où quelqu'un achète quelque chose. Par exemple, une fille va au marché pour acheter de la nourriture pour la famille pour laquelle elle travaille.

"Si je dois acheter de la viande à 500 CFA, et que je paie avec 1000 francs CFA, combien d'argent devrais-je récupérer? "

6. Notez les observations sur les connaissances des filles. Essayez d'avoir une idée du niveau moyen de connaissances, et accorder une attention particulière aux filles qui peuvent être moins familières que les autres avec les concepts de l'argent.

\section{Entrées et sorties d'argent (30 minutes)}

1. Dessinez au tableau l'image d'une fille dans la communauté (un dessin simple comme ceci).

2. Invitez une volontaire à donner un nom à cette fille.

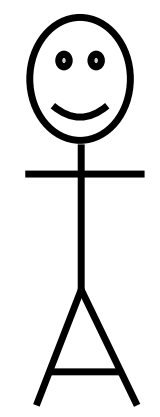

3. Tournez-vous vers la personne à coté de vous et identifiez deux sources d'argent pour cette fille et deux façons dont elle le dépense.

4. Invitez quelques volontaires à partager leurs idées avec le groupe, et écrivez toutes leurs réponses comme ça :

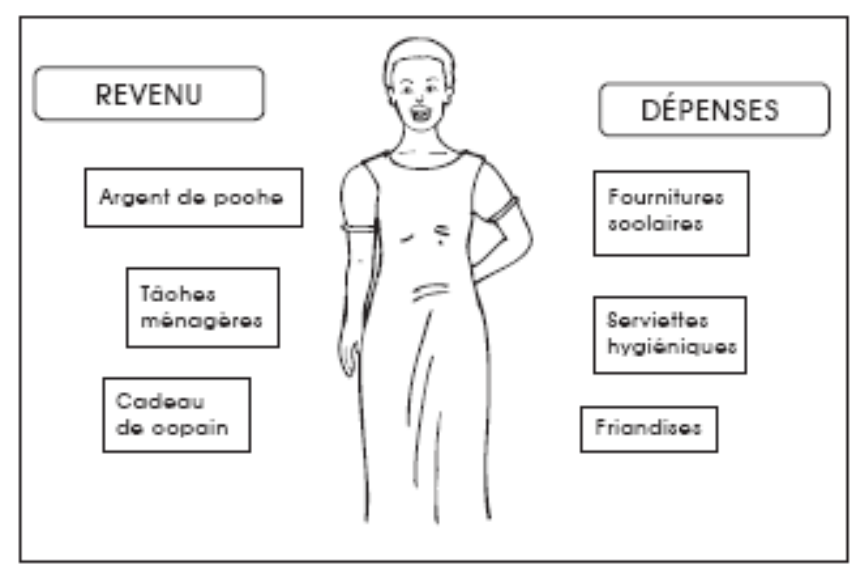


5. Si le groupe est assez avancé, essayez de classer leurs réponses par catégories (par exemple, coûts personnels, coûts de la famille, etc.). Demandez aux filles de les classer du plus important au moins important pour les revenus et les dépenses.

6. Expliquez que dans les sessions suivantes on va se focaliser sur la façon dont on gagne et dépense de l'argent.

7. Collectez les billets et pièces d'argent que vous aviez données aux filles pour l'exercice.

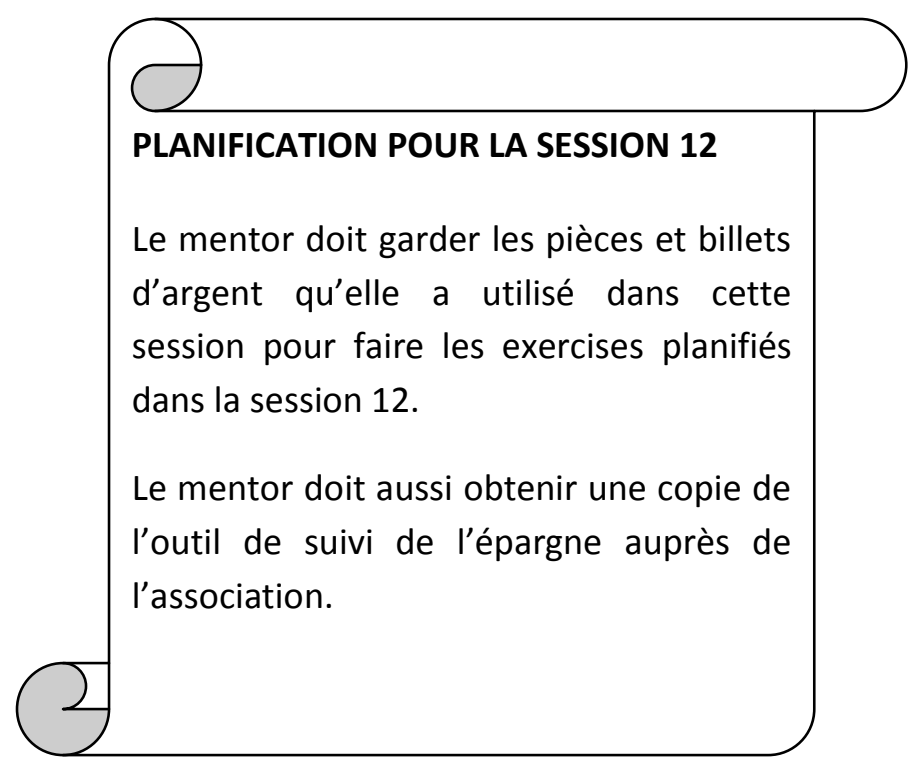




\section{Session 12: Épargner, objectifs d'épargne, et plans d'épargne}

\section{Objectifs de la session:}

À la fin de cette session, les filles seront capables de:

- Démontrer leurs connaissances en épargne

- Déterminer les éventuelles priorités en matière d'épargne

- Définir ce qu'est un objectif d'épargne

- Définir leurs propres objectifs et plans d'épargne

Matériel nécessaire:

- Une balle

- Cartes d'image

- Objets pour le comptage (pièces d'argent)

- Outil de suivi de l'épargne

Plan de la session:

- Pourquoi est-ce que nous épargnons? Passez la « balle» (10 minutes)

- Diverses raisons d'épargner: Quelles sont vos priorités? (15 minutes)

- Elaborer un exemple de plan d'épargne (30 minutes)

- Elaborer un plan personnel d'épargne (30 minutes)

Durée totale: 85 minutes

\section{INSTRUCTIONS}

Pourquoi est-ce que nous épargnons ? Passez la « balle » (10 minutes)

1. Demandez aux participantes de se lever et de former un cercle.

En premier lieu, expliquez le jeu " passez la balle ». Vous, le mentor, devrez dire une phrase qui n'est pas terminée et jeter la balle à une personne dans le cercle. Cette fille doit répéter le début de la phrase que vous avez commencée et y répondre, ou la compléter. Par exemple :

Mentor: Les filles de mon âge épargne l'argent pour

La fille : Les filles de mon âge épargne l'argent pour... acheter une chèvre

Après avoir répondu, la première fille jettera la balle à une autre fille dans le cercle, qui devra répéter le même début de phrase et fournir une fin de phrase à elle.

L'activité sera faite en 3 tours avec les trois phrases suivantes. Vous déciderez à quel moment il faut aller à la phrase suivante. Lorsque les participantes commencent à paraître ennuyées ou fatiguées avec une phrase, allez à la phrase suivante. Vous n'êtes pas obligé d'attendre que chacun ait donné une fin de phrase. C'est mieux de laisser les choses évoluer avec entrain. Utilisez les trois phrases suivantes :

Souvent, les adultes épargnent pour

Les filles de mon âge épargnent pour

Les garçons de mon âge épargnent pour 
Après les 3 reprises, résumez ce que vous avez entendu. Mettez en valeur les différences et similitudes entre les choses pour lesquelles les filles, les garçons et adultes épargnent.

\section{$\rightarrow$ Diverses raisons d'épargner : Quelles sont vos priorités ? (15 minutes)}

1. Expliquer : "Vous avez cité plusieurs raisons différentes d'épargner. La plupart d'entre elles tomberont dans l'une des catégories suivante ».

La première catégorie $c^{\prime} e s t$ :

1. Usage personnel ou familial, qui peut comprendre la nourriture, les habits, le loyer, ou les collations.

Quelles sont les autres exemples d'«usage personnel ou familial» ? [Produits pour cheveux, articles féminins, pétrole pour la lampe, etc.]

La deuxième catégorie c'est :

2. Les urgences, les événements inattendus dont nous devons nous occuper sur-le-champ. Quelques exemples sont la maladie, les accidents, ou les catastrophes naturelles.

Pour quelles autres urgences pouvons-nous épargner ? [Le vol, la mort d'animaux, une mauvaise moisson, etc.]

La troisième catégorie c'est :

3. Les futures opportunités, telles que les idées que quelques-unes d'entre vous avez pour l'avenir. Nous pouvons épargner pour atteindre ces buts. Nous pourrions acheter une chèvre à élever, suivre une formation sur une compétence ou un métier, ou investir dans un commerce.

\section{Demandez : «Pour quelles autres futures opportunités pouvons-nous épargner? 》}

3. Alors que les participantes sont encore debout, assignez une place à chacune de ces 3 catégories (si vous êtes à l'intérieur, vous pouvez utiliser un coin, la porte, une fenêtre ; si vous êtes dehors, sélectionnez ou marquez 3 endroits distincts - par exemple, près d'un arbre, d'un buisson ou d'une pierre - proche).

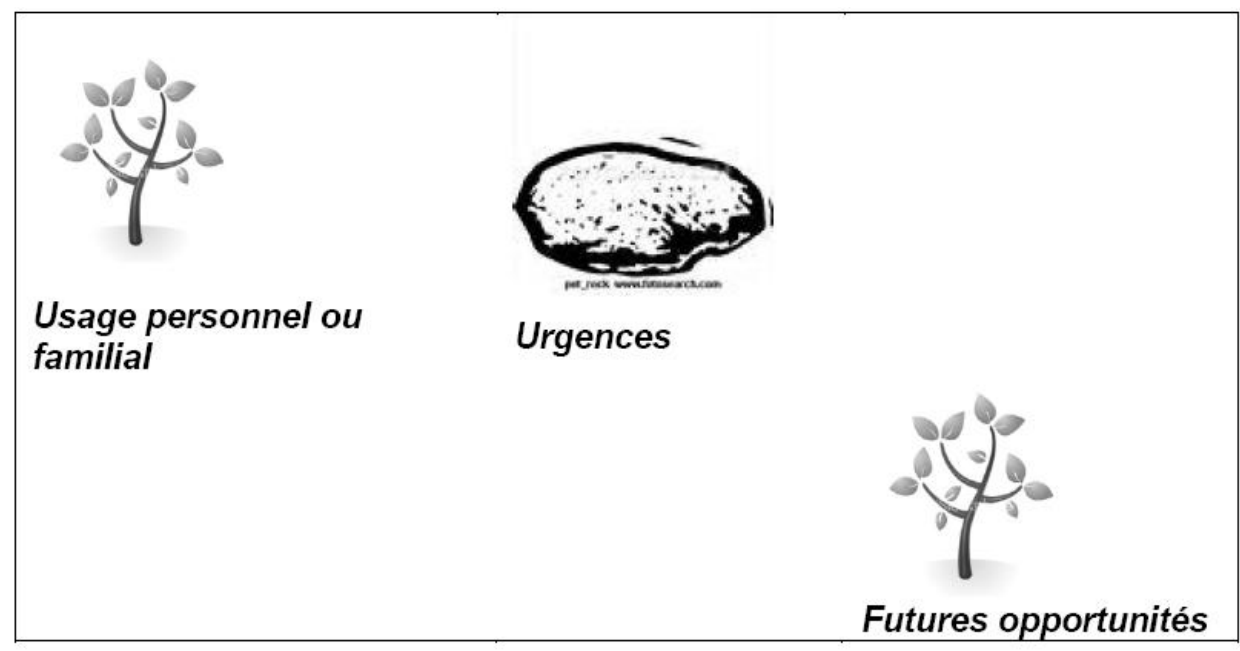


4. Demandez aux filles de rappeler quelques raisons d'épargner qu'elles avaient citées dans le dernier exercice. Pour chaque exemple, demandez aux filles de se placer au coin de la catégorie correspondante. Demandez à quelques filles sur les différents emplacements d'expliquer leur choix. Ensuite, demandez à une autre fille de donner un autre exemple.

\section{$\rightarrow$ Objectifs d'épargne (15 minutes)}

1. Expliquez : "Je vais lire une courte histoire concernant une fille de votre âge. Elle s'appelle Aminata. Pendant que vous écouter l'histoire, notez ses objectifs".

\section{L'histoire d'Aminata}

Aminata a 18 ans et elle vit dans la parcelle de sa famille. Sa grande sœur, Fatou, est mariée et vit à 2 heures de chez eux. Fatou venait juste d'avoir un bébé, et Aminata est impatiente de les visiter, de passer du temps avec le bébé et d'aider sa sœur. Aminata aura besoin d'argent pour son transport et un petit cadeau pour le bébé. Un joli petit chapeau de bébé serait parfait! Mais elle ne peut pas prendre l'argent de ses économies avec son groupe d'épargne pour ce voyage parce qu'elle économise cet argent pour acheter une chèvre. Le rêve d'Aminata est de constituer un petit troupeau de chèvres qu'elle peut vendre pour acheter une vache. Heureusement, son voisin l'embauchera pour travailler des jours supplémentaires dans sa ferme pour qu'elle puisse gagner l'argent dont elle a besoin pour son voyage.

2. Posez les questions ci-après :

- Quels sont les objectifs d'épargne d'Aminata? [le transport pour la ville où habite sa sœur, un cadeau pour le bébé, une chèvre]

- Lequel de ses objectifs d'épargne peut être accompli dans l'espace de quelques semaines ? [L'argent de transport, le cadeau pour le bébé]

- Lequel de ses objectifs d'épargne va prendre plus de temps ? [La chèvre]

3. Dites : «Maintenant: on va discuter vos objectifs d'épargne ».

4. Expliquez:

Tout comme Aminata, beaucoup d'entre vous espèrent accomplir quelque chose en épargnant. Maintenant, fermez vos yeux et pensez à un objectif d'épargne que vous avez et que vous pouvez accomplir dans un temps relativement court - au cours des deux mois prochains. Vous saisissez ? Cela sera votre premier objectif. OK - gardez-le en tête juste un moment !

Maintenant, pensez à un objectif différent, quelque chose que vous voulez pouvoir acheter qui vous prendra probablement plus de temps - 1-2 ans - d'épargne

5. Dites : «Tournes-toi vers ta voisine et partagez l'une et l'autre vos deux objectifs ». 
6. Demandez à quelques filles de partager les objectifs d'épargne de leur partenaire. Discutez des différences entre les objectifs à court et à long termes et expliquez que beaucoup de gens ont les deux types d'objectifs vers lesquels ils travaillent simultanément.

\section{Élaborer un exemple de plan d'épargne (30 minutes)}

1. Posez les questions ci-après :

- Qu'est-ce qu'un " plan » ? [Un plan est une idée sur la manière d'accomplir quelque chose, les actions à entreprendre pour atteindre un objectif]

- Quels sont les exemples de plan dont vous avez entendu parler ? Quelques exemples:

- Un fermier a un plan concernant l'endroit où il va planter chacune de ses semences ;

- Un enseignant a un plan concernant la façon de gérer sa classe chaque jour ;

- Une fille a un plan concernant la façon de terminer ses travaux ménagers à la maison de manière à avoir le temps de sortir pour voir ses amies.

- Qu'est-ce qu'un plan d'épargne d'après vous ? [Un plan d'épargne est un guide sur la manière de gérer l'argent pour atteindre un objectif d'épargne]

2. Mettez toutes les images (voir page 63) à un endroit où toutes les filles peuvent les voir.

3. Expliquez: "Aujourd'hui, nous allons apprendre comment élaborer un plan d'épargne. D'abord, sur les cartes, vous verrez une image qui montre un objectif d'épargne. Pour aujourd'hui, ce sont nos objectifs d'épargne ». Expliquez les images qui se trouvent sur les cartes. Donnez l'instruction aux filles de s'asseoir ensemble en groupes de 6 ou 7 personnes. Lorsque chacune a trouvé ses partenaires, expliquez : "Vous voyez tous les objets ici. Maintenant, vous allez choisir ensemble un de ces objets comme votre " objectif d'épargne " pour cette activité. Vous et votre/vos partenaire(s) devez répondre à 3 questions » :

- De combien d'argent avez-vous besoin pour cet objectif d'épargne?

- De combien de semaines/mois (selon l'option) pensez-vous avoir besoin pour épargner l'argent pour cet objectif ?

- Combien d'argent avez-vous besoin d'épargner chaque semaine/mois?

4. Continuez à expliquer: "Prenez une minute pour parler ensemble dans vos groupes. Pendant que vous parlez, je vais vous donner des billets et pièces. Pour le moment, ne vous souciez pas de ces billets et pièces. Je vous dirai ce que vous allez faire dans un instant ».

5. Permettez aux filles de discuter dans leurs groupes pendant 3 minutes. Pendant que les filles sont en train de converser, distribuez plus ou moins 15 billets/pièces d'argent à chaque groupe.

6. Expliquez: «Maintenant, chaque groupe a une pile de plus ou moins 15 piéces et billets. Ensemble, vous devrez:

- Décider de combien de pièces d'argent vous aurez besoin pour votre objectif d'épargne. 
- Rappelez-vous du nombre de semaines/mois dont vous avez besoin pour atteindre votre objectif.

- Divisez vos billets et pièces d'argent en parts égales, si c'est possible, en utilisant ce nombre (de semaines/mois).

7. Dites: "Rassemblez-vous autour de moi pour que nous élaborions un exemple ensemble. Par exemple, disons que mon objectif d'épargne est d'acheter un bracelet au marché. Combien coûtera-til ? ». Acceptez une réponse raisonnable, comptez le nombre correct des billets au total et montrezles aux filles.

8. Demandez: "Combien est-ce que on peut épargner chaque semaine/mois ? " Acceptez une réponse raisonnable, séparez les billets/pièces à part et montrez-les aux filles. (Par exemple, si le bracelet va coûter 2000 FCFA au total, et les filles disent qu'elles peuvent épargner 200 «francs» par semaine/mois, vous allez avoir 10 piles des pièces, chaque pile equivalent à 200 FCFA.)

9. Demandez: "Combien d'argent avons-nous besoin d'épargner par semaine/mois ? Cela prendra combien de semaines/mois pour épargner autant d'argent ?"

10. Permettez une petite discussion parmi les filles, et arrivez à un accord sur le temps qu'il faut. Séparez la pile de pièces d'argent en nombre de semaines/mois sur lesquelles vous vous êtes accordés. Les filles doivent être capables de calculer sur la base des piles de pièces d'argent que vous avez devant vous.

11. Expliquez: "Nous venons juste d'élaborer notre propre plan d'épargne pour un bracelet. Maintenant, faites de même pour l'objectif d'épargne sur la carte que vous avez choisi, avec les billets que je vous avais donnés ».

12. Pendant que les filles travaillent dans leurs groupes, allez dans chaque groupe pour répondre aux questions et vous assurer que tous les filles comprennent l'exercice.

13. Lorsque les filles ont eu 5 minutes pour créer leurs plans d'épargne avec les pièces, demandez à quelques groupes de décrire leurs objectif et plan d'épargne pour atteindre cet objectif. Demandez aux autres de commenter. Utilisez les questions suivantes pour susciter les commentaires, si tout le monde est silencieux.

- Est-ce que leur prix est réaliste ?

- Est-ce que le montant qu'elles comptent épargner chaque semaine est réaliste ?

- Doivent-elles prolonger ou raccourcir leur temps d'épargne?

14. Lorsque chacune a terminé, posez la question :

- Comment pensez-vous qu'un plan d'épargne puisse vous aider à épargner ?

15. Permettez aux filles de discuter sur le sujet. Collectez toutes les pièces que vous avez données aux filles. 


\section{$\rightarrow$ Élaborer un plan personnel d'épargne (30 minutes)}

1. Dites aux filles de rester dans leurs groupes. Dites aux filles: "Dans cette session on a discuté comment faire un plan d'epargne. Vous avez réfléchi sur les differents buts d'épargner, et vous avez réfléchi sur vos objectifs à court terme et à long terme. Maintenant je veux que chacune de vous pense à un but ou à un objectif financier réel que vous aimeriez realiser. Le but peut être à court terme, pour être atteint dans les prochains 3 ou 4 mois, avant la fin du programme, ou peut être à long terme."

Dites aux filles de penser aux quatre questions suivantes :

- Combien vous aurez besoin pour realiser votre but?

- À quelle periodicité vous allez mettre l'argent de côté (chaque jour, chaque semaine, chaque mois?)

- Combien pensez-vous qu'il est réaliste pour vous d'épargner selon la périodicité que vous avez choisie?

- Combien de temps vous devriez épargner pour atteindre votre but?

2. Si une fille n'a pas une chose précise qu'elle veut acheter, vous pouvez lui dire de penser à un but monétaire : une somme realiste d'argent qu'elle veut épargner. Si une fille ne veut pas participer, vous pouvez lui dire que ce n'est pas obligatoire mais que planifier peut l'aider à atteindre ses objectifs.

3. Donnez 10 minutes aux filles pour discuter. Après, demandez s'il y a des volontaires pour partager ses plans d'épargner avec le groupe. Pour chaque fille, notez son but et son plan sur votre outil de suivi d'épargne. Demandez à chaque fille qui a fait un plan d'épargne de le partager.

4. La fille doit dire :

- Qu'est-ce que c'est son but - un objet qu'elle veut acheter et son prix ou une somme d'argent qu'elle veut épargner

- Le nombre de semaines (ou de jours, de mois) pendant lequels elle doit épargner

- Combien d'argent elle doit épargner chaque semaine/jour/mois

5. Dites aux filles que chaque mois vous allez revoir ensemble leurs plans d'épargne et parler un peu sur les défis et succès des filles.

\section{PLANIFICATION POUR LA SESSION 13}

La session 13 porte sur les méthodes et lieux sécurisants pour de l'argent. Elaborer une liste de caisses populaires et institutions bancaires les plus proches de l'espace sûr (afin que les filles puissent s'y rendre à pieds). Préciser les horaires de travail et les jours ouvrables pour chaque caisse populaire et institution financière. Cette liste sera partagée avec les filles à la fin de la session 13 afin qu'elles puissent elles-même visiter une de ces institutions financières. Vous devriez aussi contacter un agent d'une institution bancaire pour venir à la prochaine session et faire un exposé. Il/elle peut éxpliquer aux filles les services disponsibles et les avantages de l'utilisation des banques pour les filles. 


\section{Élaborer un plan d'épargne}

(Activité: Élaborer un plan d'épargne)

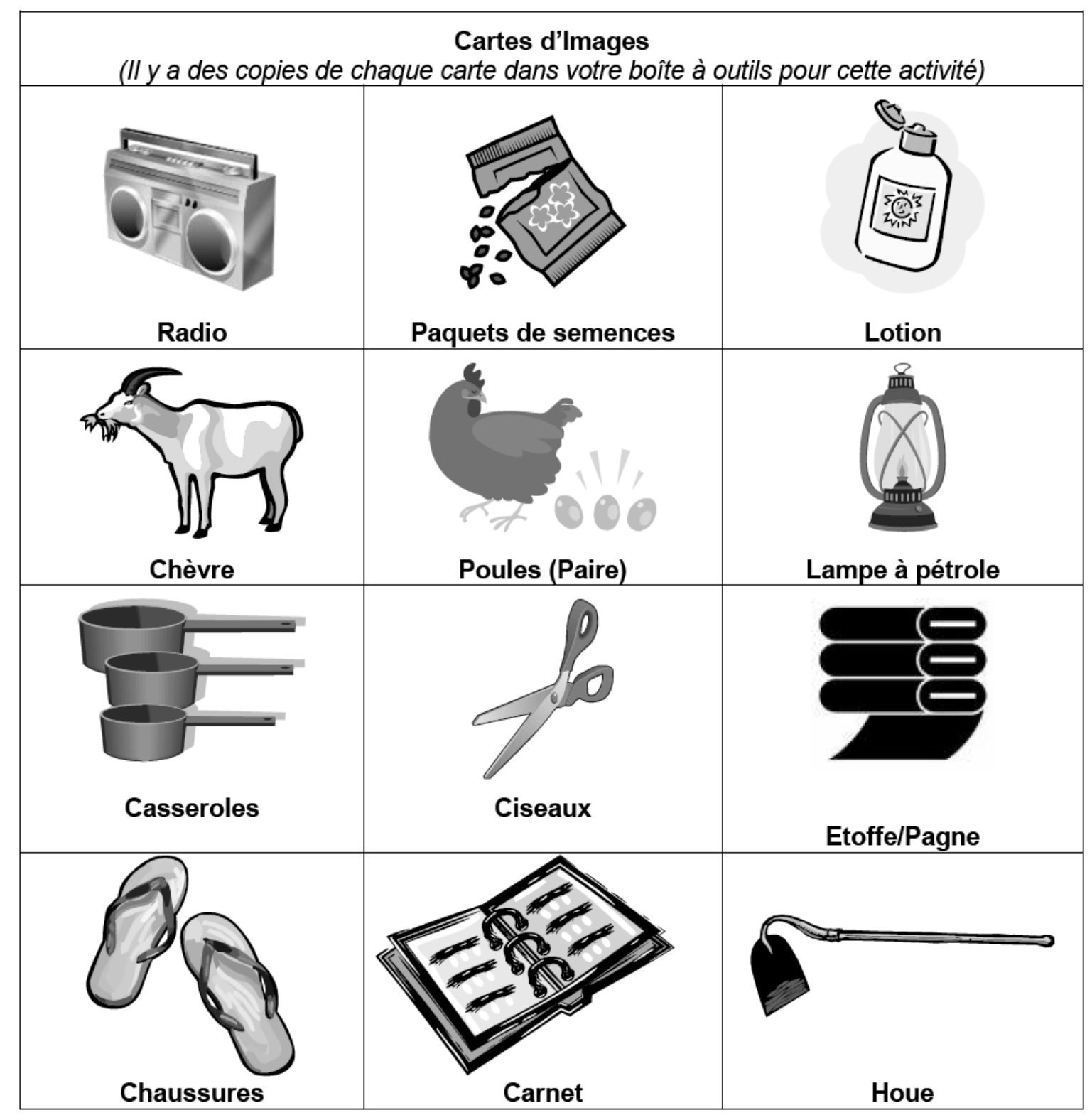




\section{Session 13: Les méthodes et lieux sécurisés pour garder l'argent}

\section{Objectifs de la session:}

À la fin de cette session, les filles seront capables de:

- Donner leur point de vue sur des situations d'épargne qui se présentent à elles

- Acquérir des capacités en matière d'épargne

- Définir la base d'une épargne régulière

- Identifier deux endroits sécurisés où économiser leur l'argent

\section{Matériel nécessaire:}

- Liste des caisses populaires

Plan de la session:

- Discussion sur les épargnes des filles employées de maison (10 minutes)

- Être d'accord ou pas d'accord (15 minutes)

- L'histoire de deux cousines qui épargnent (15 minutes)

- Épargner dans un lieu sécurisé (30 minutes)

- Exposé sur les services des institutions bancaires par un agent de banque (15 minutes)

Durée totale: 85 minutes

\section{AVANT LA SESSION}

Elaborer une liste de caisses populaire et institutions bancaires les plus proches de l'espace sûr (afin que les filles puissent s'y rendre à pieds). Cette liste, qui devait être prête au préalable, sera partagée avec les filles à la fin de la Session 13 sur Les Méthodes et Lieux Sécurisants pour de l'Argent, afin qu'elles puissent elles-même visiter un de ces centres financiers au cours de la semaine à venir. Vous devriez aussi contacter un agent d'une institution bancaire pour faire un exposé au cours de la session. Il/elle peut éxpliquer aux filles les services disponsibles et comment l'utilisation d'une banque peut être avantageuse pour les filles à l'avenir.

\section{INSTRUCTIONS}

\section{Discussion sur les épargnes des filles employées de maison (10 minutes)}

1.Demander aux filles de citer des exemples de façons d'épargner.

2. Une fois que vous obtenez une liste de 8 à 10 exemples, demandez aux filles de catégoriser ces façons d'épargner, du plus sécurisant au moins sécurisant, selon elles.

3. Une fois la liste catégorisée, demandez aux filles d'expliquez leur catégorisation. 


\section{Ôtre d'accord ou pas d'accord (15 minutes)}

1. Expliquez qu'aujourd'hui on va discuter la façon d'épargner régulièrement.

2. Demandez aux filles de former une ligne. Expliquez :

Je vais vous donner une série d'affirmations sur l'épargne. Pour chacune des affirmations que je dirais, vous devez décider si vous êtes "d'accord" ou "pas d'accord». La fin de la ligne représente la forte approbation "je suis très d'accord», (marchez jusqu'à la fin de la «ligne» pour montrer à tout le monde). L'autre bout de la ligne représente une forte désapprobation " je ne suis pas du tout d'accord ". Déplacez-vous le long de la ligne pour montrer ce que vous pensez de l'affirmation que je lirais.

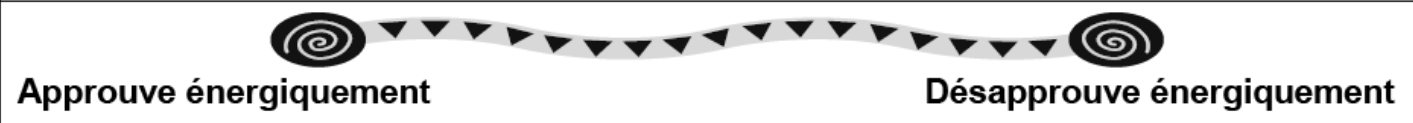

Exerçons-nous sur un exemple pour nous assurer que tout le monde comprend. Je vais lire 3 phrases. Après chacune d'elles, allez-vous placer à l'endroit de la ligne, qui montre si vous êtes " d'accord » ou " pas d'accord ». Nous allons commencer avec un exemple.

3. Dites: "Les parents ont confiance aux jeunes." Quand vous êtes certaine que toutes les filles comprennent, demandez : "Quelles questions avez-vous à poser ? " Sommes-nous prêts pour les phrases concernant l'épargne?"

4. Lisez les 4 phrases suivantes. Après chaque phrase, donnez l'instruction aux filles d'aller se placer quelque part sur la ligne qui montre ce qu'elles pensent de cette phrase. Demandez à quelques filles sur les différents emplacements d'expliquer leur choix. Ensuite, lisez la phrase qui suit.

\section{Affirmations}

- Il faut avoir une grande somme d'argent pour arriver à épargner.

- Épargner chaque semaine exige de la discipline et de la détermination.

- Je ferais mieux d'épargner le peu d'argent que j'ai au lieu de le dépenser sur les produits de beauté ou les collations.

- Epargner un tout petit peu d'argent chaque semaine résultera finalement à une grosse somme que vous pouvez utiliser pour quelque chose d'important pour moi.

5. Expliquez qu'épargner s'avère difficile lorsqu'il n'y a pas suffisamment d'argent pour payer toutes les choses dont nous avons besoin. Néanmoins, épargner peut s'avérer plus facile lorsque vous décider d'épargner régulièrement, un tout petit peu chaque semaine ou chaque mois. Même si vous pouvez épargner juste un tout petit peu, le fait d'en faire une habitude vous permettra de constituer lentement une somme d'argent et d'atteindre vos objectifs. 
$\rightarrow$ L'histoire de deux cousines qui épargnent (15 minutes)

1. Lisez l'histoire suivante et discutez-en, en utilisant les questions ci-dessous.

\section{L'histoire de Madina et Samira}

Madina et Samira sont des cousines qui vivent dans la même maison. Elles décident qu'elles peuvent se faire de l'argent en élevant des chèvres. Puisque la famille n'a pas de chèvres, les deux filles se promettent de commencer à épargner pour en acheter une. Elles savent quel type de chèvre elles veulent acheter et quel en est le prix. Elles décident d'épargner chaque semaine et, ensemble, elles s'accordent sur un montant raisonnable qu'elles croient pouvoir être capable d'épargner.

Samira est forte en math ; avec l'argent qu'elles ont promis chacune d'épargner chaque semaine, elle calcule combien de semaines elles auront à épargner avant d'être capable d'acheter la chèvre. Cela paraît être une longue durée, mais en mettant leurs épargnes ensemble, ça ira plus vite.

Pendant les premières semaines, elles ont toutes les deux fait des sacrifices pour épargner, et leur famille les a félicitées! Mais, Madina a commencé à s'intéresser à un jeune homme qui est arrivé récemment au village pour rester avec ses parents. Lorsqu'ils vont prendre du thé au kiosque, elle paie la facture pour l'impressionner. Elle commence à dépenser l'argent pour acheter des pommades et des mèches pour ses cheveux.

Lorsque Samira interroge Madina sur ses économies, Madina ne fait que hausser les épaules et dit qu'elle n'a pas les moyens d'épargner maintenant. Elle promet de remettre à Samira une somme d'argent plus grande après, quand elle aura fini de travailler à la plantation de thé. «Ne t'en fais pas» dit-elle, «je travaillerai dur et j'épargnerai beaucoup plus, le mois prochain. En fin de compte, ce sera la même chose. "

\section{Demandez :}

- Qu'est-ce qui est arrivé au plan d'épargne des filles ? [Elles n'étaient pas capables de le poursuivre lorsque Madina a trouvé d'autres choses sur lesquelles dépenser son argent.]

- Pourquoi, est-ce que Madina a du mal à épargner chaque semaine ? [Elle veut impressionner un garçon, et achète du thé.]

- Que pensez-vous de son plan de gagner un plus grand montant après? [II ne va pas marcher, et les plans des filles échoueraient alors.]

- Quelles sont les chances pour ces filles d'acheter leur chèvre ? [Elles ne sont probablement pas bonnes au regard de ce qui est arrivé à Madina.

\section{Épargner dans un lieu sécurisé (30 minutes)}

1. Dites :

Épargner peut s'avérer difficile parce qu'il y a tellement de demandes sur notre argent. Lorsque nous sommes capables d'épargner, il est important de mettre nos économies dans un endroit sécurisé, là où personne d'autre ne peut le prendre, et là où nous serons nous- 
mêmes moins tentés de le dépenser. Aujourd'hui, nous allons discuter de comment on épargne dans un lieu sécurisé.

2. Expliquez que dans cette activité, nous allons lire deux histoires.

3. Dites: "Écoutez attentivement les histoires suivantes sur la façon dont deux cousines épargnent. Après chaque histoire, nous allons nous arrêter pour parler de ce qui est arrivé. "

Yasmine, 18 ans, et Sandrine, 17 ans, sont des cousines qui habitent à Bobo-Dioulasso. Pour Noël, leur grand-mère leur a donné à chacune 10.000 francs. Les deux cousines ont projeté d'économiser cet argent pour atteindre des objectifs importants, mais elles ont choisi des trajectoires différentes.

Yasmine a décidé de se joindre à un groupe d'épargne. Sandrine a décidé de garder son argent caché à la maison. Écoutons l'expérience de Yasmine en premier lieu.

4. Racontez l'histoire suivante :

\section{Histoire 1 : Yasmine}

Yasmine est excitée à l'idée d'acheter une machine à coudre et d'être capable de commencer sa propre affaire de couture. Elle veut épargner le cadeau que sa grand-mère lui a offert et y ajouter jusqu'à ce qu'elle ait assez d'argent pour acheter la machine.

Yasmine se joint à un groupe d'épargne pour s'aider à épargner. Chaque semaine elle utilise le cadeau que sa grande-mère lui a donné pour épargner au maximum, et c'est facile. Mais, après que ses 10.000 aient été transférés dans son compte, elle a des problèmes à trouver l'argent pour son dépôt hebdomadaire. Pendant quelques semaines, au lieu de prendre l'autobus, elle va à pied à son travail de samedi comme briquetier pour pouvoir faire son versement d'épargne. C'est loin! Les autres semaines, elle se prive du déjeuner pour épargner. Elle est, soit vraiment fatiguée, ou vraiment affamée, lorsqu'elle arrive à la maison!

Quand le frère de Yasmine se marie, elle veut de nouvelles chaussures pour le mariage, mais tout son argent est avec le groupe d'épargne et elle ne peut pas le retirer avant la fin du cycle. Mais, ses économies augmentent lentement. Épargner est difficile, mais Yasmine sait qu'elle arrivera à son but.

5. Posez les questions suivantes:

- Comment le fait d'épargner avec un groupe d'épargne aide-t-il Yasmine à atteindre ses objectifs ? [Garder l'argent avec le groupe réduit les dépenses sur les «désirs» ; Yasmine peut faire un emprunt du groupe pour une opportunité de gagner de l'argent]

- Quels sont les défis à épargner avec un groupe ? [Trouver l'argent à épargner chaque semaine est difficile ; l'accès à ses économies est interdit]

6. Dites: «Écoutons maintenant ce qui est arrivé à Sandrine, la cousine de Yasmine. » 


\section{Histoire 2: Sandrine}

Sandrine veut épargner pour s'inscrire à un cours informatique, mais elle ne veut pas se joindre à un groupe d'épargne parce qu'elle a besoin de plus de flexibilité avec ses économies. Elle décide de cacher ses 10.000 francs dans une boîte métallique cachée sous un tas de vêtements sur son étagère.

Sandrine est facilement tentée par les vêtements qu'elle voit au marché, et souvent, les foulards ou les chemises qu'elle veut acheter coûtent plus qu'elle ne gagne à tresser les cheveux. Par conséquent, à peu près une fois par mois, elle sort un peu d'argent de sa boîte pour acheter quelque chose. Cela la rend si heureuse! Et quelquefois, quand elle a eu beaucoup d'affaires, elle met de l'argent dans sa boîte, très fière de sa capacité d'épargner.

Un jour, son oncle la voit ranger sa boîte, et la prochaine fois quand elle le sort, elle découvre qu'un peu d'argent manque. Une autre fois, sa sœur la supplie de lui donner l'argent du transport pour se rendre à son lieu de travail ce jour-là. Heureusement, Sandrine peut payer son transport à partir de ses économies. Mais, quand arrive le moment de payer le premier acompte pour son cours informatique, Sandrine se rend compte qu'elle n'a pas assez d'argent dans sa boîte.

7. Posez les questions ci-après :

Comment le fait de garder l'argent à la maison a-t-il fait que c'était difficile pour Sandrine d'épargner? [Garder l'argent à la maison fait que c'est plus facile de le dépenser. D’autres personnes qui ont besoin d'argent vont faire pression sur vous pour que vous le leur donniez; il peut aussi être volé.]

Pour elle, quels sont les avantages d'épargner à la maison ? [Elle a un accès facile à son argent qu'elle peut dépenser sur des choses qu'elle désire ou utiliser pour aider sa famille].

Quel endroit choisissez-vous pour épargner votre argent ? Pourquoi ?

8. Permettez aux filles de discuter de leur choix pour l'épargne de manière réaliste. II peut y avoir des raisons de choisir d'épargner à différents endroits. L'objectif de cette leçon est de les aider à comparer les options et de réfléchir sur l'endroit le meilleur et le plus sécurisé pour leurs propres économies.

\section{Exposé sur les services offerts par les institutions bancaires par un agent de banque (15 minutes)}

1. Introduire le sujet de l'exposé.

2. Donner la parole à l'agent de banque pour son exposé.

3. Demander aux participantes d'écouter attentivement.

4. Donner la parole aux filles pour poser leurs questions, puis à l'exposant pour donner les répponses 


\section{TRAVAIL DE MAISON}

Demandez-aux filles de visiter une caisse populaire ou une institution fina

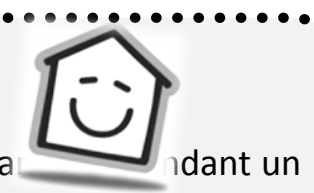
jour ouvrable, en se servant de la liste des caisses populaires et institutions financières que vous leur remettrez pendant la session. Le but de la visite est que la fille puisse se rendre à une caisse populaire ou dans une institution financière, de s'informer sur les types de services offerts, et de décider lequel serait le plus approprié pour elle même.

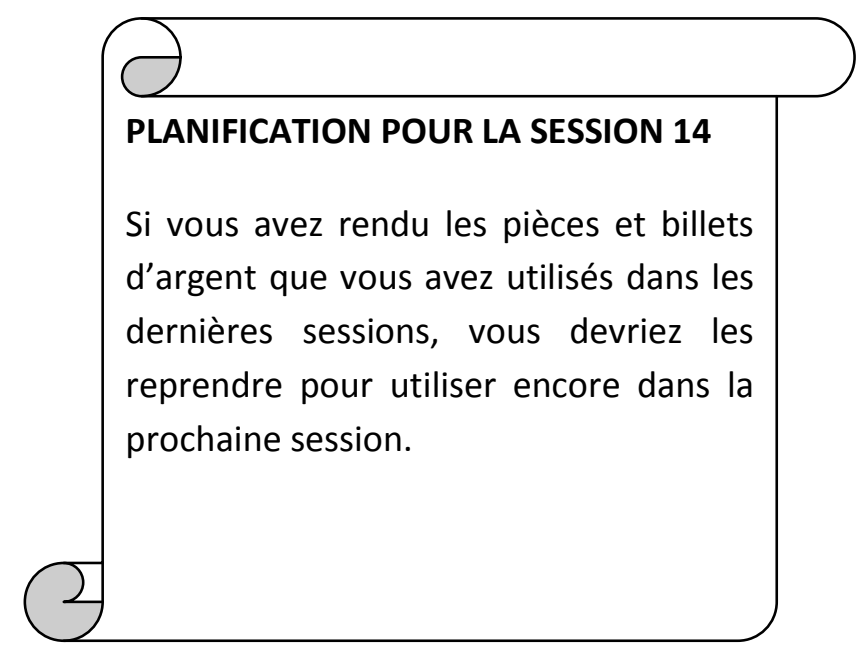




\section{Session 14 : Les façons de dépenser de l'argent}

\section{Objectifs de la session:}

À la fin de cette session, les filles seront capables de:

- Faire la distinction entre besoins et désirs

- Déterminer les priorités en matière de dépenses

- Définir ce que c'est qu'un budget et pourquoi c'est important

\section{Matériel nécessaire:}

- Corde

- Cartes d'images

- Billets et pièces d'argent

\section{Plan de la session:}

- Identifier les désirs et les besoins (30 minutes)

- Faire le marchandage (10 minutes)

- Prendre des décisions d'épargne (30 minutes)

Durée totale: 70 minutes

\section{AVANT LA SESSION}

Vous devriez avoir 4 ou 5 copies de la feuille des images «Prendre des décisions d'épargne » à la page 75 . Vous devriez couper la feuille pour séparer les images.

\section{NOTES D'INFORMATION}

L'activité première de cette session est destinée à des filles qui savent lire et écrire. Dans le cas où il y aurait des filles illettrées dans votre groupe, utilisez l'activité décrite ci-dessus au lieu des points 1 et 2 de la première activité. Après cette activité de la note d'information, suivre les étapes de l'activité « Identifier les désirs et les besoins » à partir du troisième point.

1. Sur une feuille de flipchart, dessiner des bijoux. Coller cette feuille à une extrémité de la salle.

2. Sur une deuxième feuille de flipchart, dessiner un plat de riz et de sauce. Coller cette feuille à l'autre extrémité de la salle.

3. Positionner les filles au milieu de la salle, et demander-leur de courir dans un sens ou l'autre si les éléments cités sont des désirs ou des besoins : un vélo, une montre, une nouvelle coiffure. Citer les éléments de la liste un à un, et après chaque élément, demander à une fille de chaque groupe d'expliquer (au nom du groupe) leur choix. Une fois que les filles rejoignent toutes le centre de la salle, citer le prochain mot (montre) et répéter l'exercice. 


\section{INSTRUCTIONS}

\section{$\Rightarrow$ Identifier les désirs et les besoins (30 minutes)}

1. Expliquez :

Nous dépensons l'argent sur beaucoup de choses. Certaines de ces choses sont nécessaires pour notre survie. Ces choses sont appelées les BESOINS. D'autres sont des choses que nous désirons, et quand nous les achetons, nous sommes contents. Nous appelons ces choses les DÉSIRS. Aujourd'hui, nous allons discuter de la différence entre les choses que nous désirons, et les choses dont nous avons besoin. Une partie du contrôle de nos dépenses c'est connaître la différence entre les désirs et les besoins.

Je vais faire une ligne en utilisant un morceau de corde. Un bout de cette ligne représente les BESOINS. L'autre bout représente les DÉSIRS.

2. Placez la corde en ligne et pointer cette corde vers le bout qui va représenter les besoins, et le bout qui va représenter les désirs.

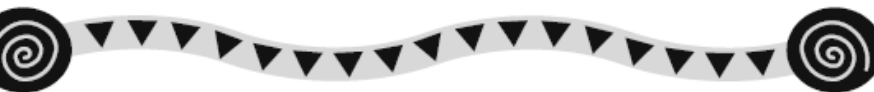

BESOINS

\section{DÉSIRS}

3. Dites: "Je vais citer une dépense, quelque chose pour laquelle on pourrait dépenser notre argent. Votre rôle est de décider si cette dépense que je cite est un besoin ou un désir ».

Je ne m'attends pas à ce que vous soyez toutes d'accord. Si vous pensez que c'est seulement un besoin, allez vous mettre debout au bout de la ligne qui représente les BESOINS. Si vous pensez que cette dépense est seulement un désir et ne peut nullement être considéré comme un besoin pour qui que ce soit, placez-vous au bout de la ligne qui représente les DESIRS. Mais si vous n'êtes pas sûr, ou si vous pensez que dans certains cas, la dépense pourrait être soit un désir, ou un besoin, placez-vous quelque part au milieu de la ligne.

Par exemple, si je dis «beignet», et vous pensez que c'est plus un désir qu'un besoin, vous pouvez vous tenir ici sur la ligne.

4. Démontrez en vous mettant debout plus près du bout de la ligne relatif aux desirs. Dites :

"Cependant, si je dis "médicaments», et vous pensez que "médicaments» est en définitif un besoin, vous vous mettrez ici sur la ligne. »

5. Démontrez en vous mettant debout tout au bout de la ligne relatif aux besoins.

6. Lisez chacune des dépenses suivantes, une dépense à la fois. Après chaque dépense, donnez aux filles le temps de se placer le long de la ligne : besoins/désirs.

- L'eau

- Une deuxième paire de chaussures

- La nourriture 
- Le loisir (de maison)

- Les bonbons

- Les produits pour les cheveux

7. Après que les filles se soient placées le long de la ligne, demandez à quelques-unes à différents emplacements d'expliquer pourquoi elles se sont placées là où elles sont.

8. Expliquez:

Vous pouvez remarquer que les besoins et les désirs ne sont pas les mêmes pour tout le monde. Mais, pour bien gérer notre argent, nous devons décider personnellement quels sont nos besoins et quels sont nos désirs, et décider ce dont nous pouvons nous passer. La clé de l'épargne c'est prendre des sages décisions de dépenses. Si vous pouvez réduire vos dépenses suffisamment pour épargner même un tout petit peu, vous allez en fin de compte atteindre votre objectif d'épargne. Votre perte à court-terme peut devenir à long-terme votre gain.

\section{Dites:}

L'objectif de l'histoire suivante est d'aider les filles à faire la distinction entre les besoins et les désirs, avec un exemple.

10. Lisez l'histoire d'Adeline et de Safiatou en montrant les images qui l'accompagne. Posez des questions aux filles pour vous assurer que tout le monde comprend I'histoire.

\section{L'histoire d'Adeline et de Safiatou}

Adeline et Safiatou travaillent ensemble dans un salon de coiffure. Les deux filles gagnent environ 30.000 francs par mois. Adeline dépense tout son argent chaque mois. Cependant, Safiatou épargne 3.000 francs chaque mois dans son groupe d'épargne. Tout le monde pense qu'Adeline gagne plus d'argent que Safiatou parce qu'Adeline porte plus de nouveaux habits et de chaussures. Elle prend souvent les taxis-motos quand Safiatou part à pied. Et elle prend le jus ou le thé quand Safiatou boit de l'eau à la maison.

Après un an, Safiatou a épargné 36.000 francs et c'est suffisant pour acheter un petit moulin. Elle a toujours son travail au salon mais elle loue aussi son moulin aux femmes dans la ville. Avec le moulin, elle gagne 5.000 par semaine. Maintenant, elle commence à dépenser tout son argent du salon de 30.000 et elle épargne les 20.000 qu'elle gagne par mois avec le moulin. Elle continue à épargner et à investir cet argent pour encore augmenter son revenu. Maintenant elle a son salaire du salon, les revenus du moulin, et elle a acheté aussi plusieurs animaux pour faire l'élevage. Elle porte souvent de beaux habits et chaussures et elle peut acheter les choses qu'elle veut. Cependant, Adeline continue de ne pas épargner. Elle n'a que son salaire du salon à dépenser.

11. Demandez aux filles :

- Qu'est-ce que Safiatou a fait avec son argent ? [Elle a épargné avec un groupe]

- Comment est-ce que la petite somme que Safiatou a mis de côté l'a aidé ? [Elle a épargné assez d'argent pour acheter un moulin. Ensuite, elle a loué le moulin aux autres, et gagné encore plus d'argent. Enfin, elle a acheté des animaux pour faire l'élevage.] 
- Qu'est-ce que Adéline a fait avec son argent ? [Elle a tout dépensé.]

- À votre avis, quelle est la leçon de cette histoire ? [Même si on a une petite somme d'argent à épargner, avec la patience c'est possible de faire de grandes choses !]

\section{$\Rightarrow$ Faire le marchandage (10 minutes)}

1. Lisez I'histoire suivante à haute voix :

\section{L'histoire de Mariam}

Mariam est une fille employée de maison de 15 ans. Elle est arrivée à Ouaga il y a 8 mois de cela et elle s'apprête à retourner au village aider les parents à cultiver parce que la saison des pluies vient de commencer. Pour préparer son retour, elle est allée au marché pour acheter des effets personnels et des cadeaux pour ses petits frères restés au village. Après avoir acheté beaucoup de choses, Mariam s'est rendu compte qu'elle a oublié de payer le foulard que sa mère lui avait demandé et un bonnet pour son père. Elle a presque tout dépensé et il lui restait que 2000 FCFA. Chez tous les commerçants que Mariam abordait, les articles coûtaient trop chers. Finalement Mariam va voir un commerçant chez qui les prix sont plus abordables pour acheter les deux articles et celui-ci lui dit que le foulard coûte 1500 FCFA et le bonnet 1000 FCFA. Elle ne peut pas non plus ne pas acheter les choses que ses parents lui ont demandées car elle leur avait fait une promesse et elle y tient.

2. Demandez à deux voluntaires de faire un jeu de rôle. La première fille joue le rôle de Mariam et la deuxième joue le rôle du commerçant qui vend les articles. Mariam doit essayer de convaincre le commerçant pour obtenir le foulard et le bonnet à 2000 FCFA.

3. Quand les filles ont terminé le jeu de rôle, posez les questions suivantes au groupe :

- Pourquoi est-il important de marchander les prix des articles qu'on veut acheter?

- Quel est le difference entre acheter quelque chose dans une alimentation et dans un marché ?

\section{- Prendre des décisions d'épargne (30 minutes)}

1. Demandez aux filles de s'asseoir en cercle ou de se rassembler de façon à ce que tout le monde puisse se voir. Prenez une copie du «jeu de dépense», et expliquez en quoi il consiste et comment le jouer.

Chaque article de dépense a une image. Faites d'abord la révision des articles de dépense pour vous assurer que tout le monde comprend ce que représente chaque image.

*N.B: Si les objets qui sont représentés sur les cartes d'image sont disponibles, utilisez-les au lieu des images.

2. En deuxième lieu, montrez aux filles les billets et pièces d'argent. Dites aux filles que chaque billet ou pièce peut acheter un seul article. 
3. Expliquez:

Vous avez à la fois de l'argent et une liste des choix sur lesquels vous pouvez «dépenser» cet argent. Vous devez décider comment vous voulez "dépenser» votre argent sur ces articles. Vous n'êtes pas obligé "d'acheter» chaque article, et vous pouvez dépenser plus d'argent sur un article et moins sur un autre.

4. Demandez:

Quelles questions avez-vous?

5. Lorsque vous êtes sûr que les filles comprennent, commencez le jeu. Donnez environ 10 billets ou pièces à chaque groupe.

6. Donnez aux filles 2 minutes pour prendre leurs décisions de dépense dans leurs groupes. Demandez à quelques volontaires de partager la façon dont elles ont «dépensé» leur «argent».

7. Puis expliquez :

Maintenant, je vais prendre 4 de vos billets ou pièces. Votre revenu est réduit de 4 et vous avez seulement 6 billets ou pièces à dépenser.

8. Prenez 4 billets et pièces de chaque groupe. Donnez aux filles 3 minutes pour prendre leurs décisions de dépense. Posez les questions ci-après :

- Quelles décisions avez-vous prises?

- Qu'est-ce qui était difficile ou facile en ce qui concerne la réduction des dépenses ?

- Pouvez-vous envisager d'autres manières de dépenser moins dans les semaines à venir?

9. Collectez les billets et pièces d'argent que vous avez données aux filles.

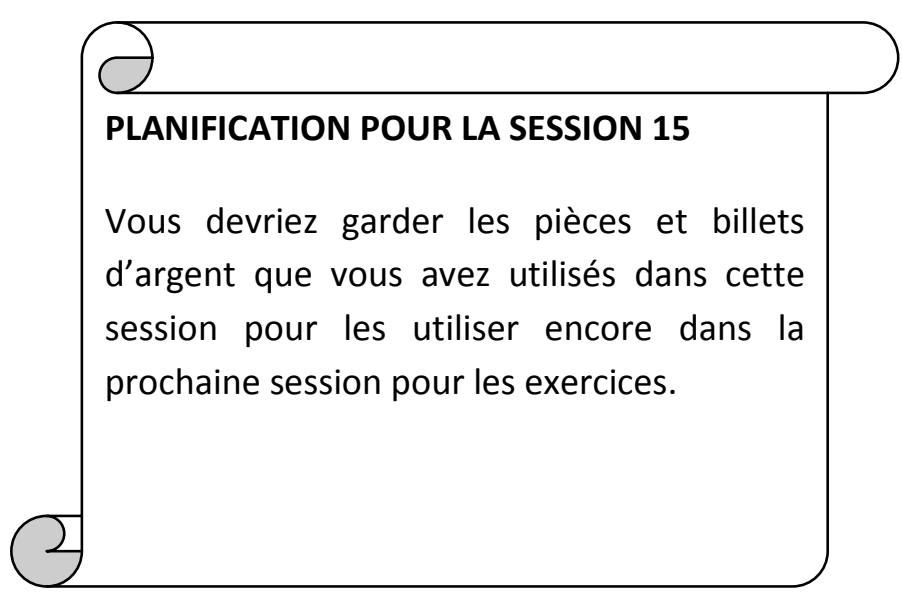


Prendre des décisions d'épargne (Activité: Prendre des décisions d'épargne)

Soda (Fanta, Coca)
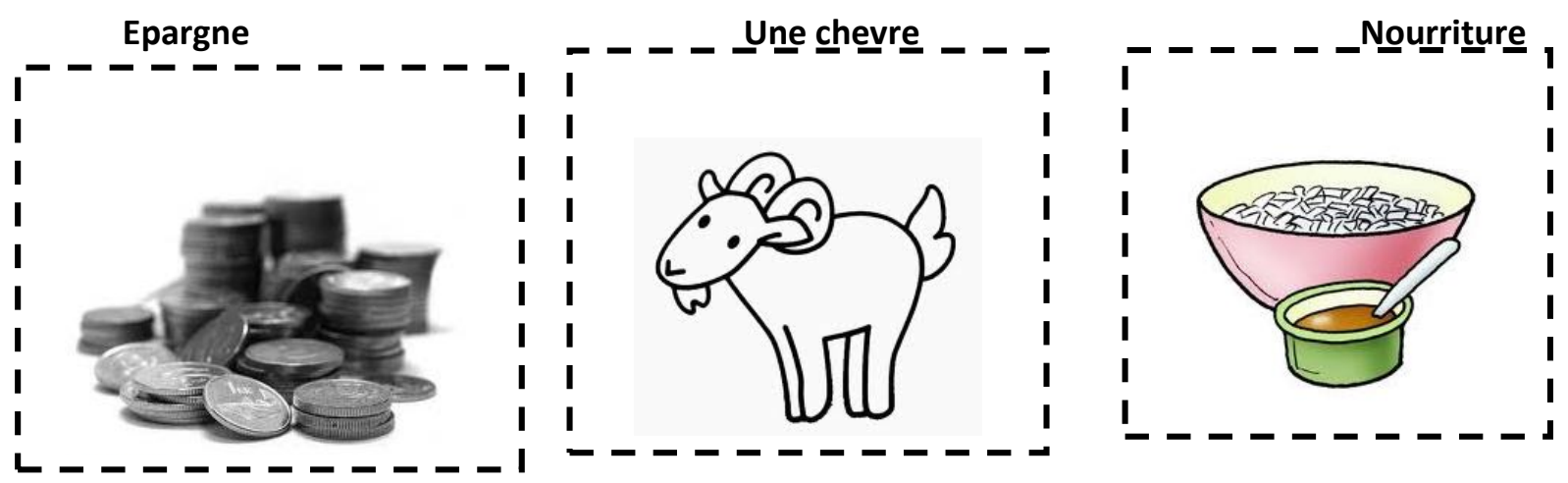

Effets pour la maison

Ecole/Cours du Soir

Transport
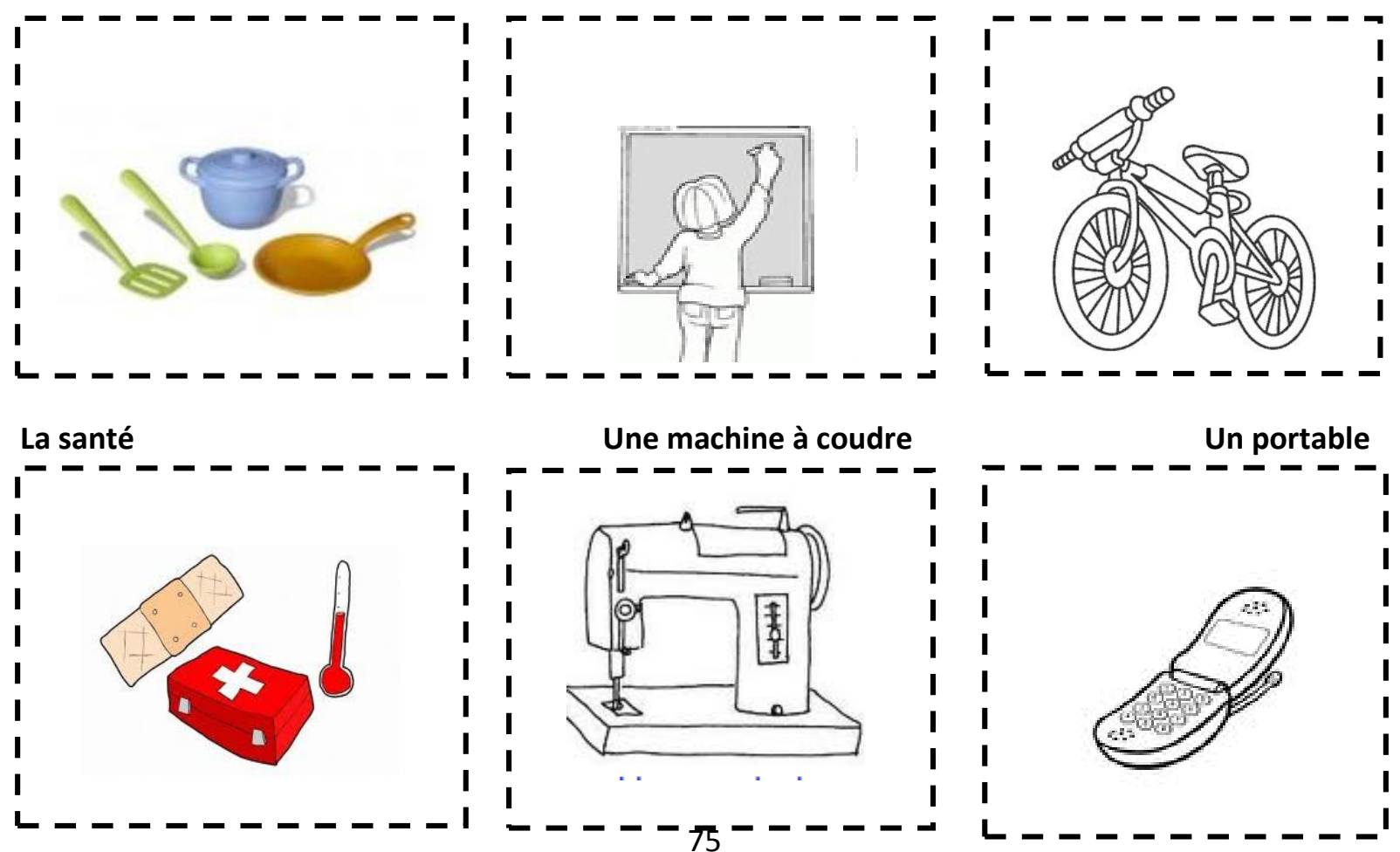


\section{Session 15 : Emprunter prudemment et obtenir une grosse somme d'argent}

Objectifs de la session:

À la fin de cette session, les filles seront capables de:

- Faire la distinction entre l'argent emprunté et l'argent propre

- Identifier les caractéristiques de l'argent emprunté

- Identifier deux moyens d'obtenir une grosse somme d'argent

- Comparer les avantages et inconvénients de l'emprunt et de l'épargne d'une grosse somme d'argent

\section{Matériel nécessaire:}

- Billets et pièces d'argent

\section{Plan de la session:}

- Faire la distinction entre l'argent emprunté et l'argent propre (10 minutes)

- Comprendre ce qu'est l'argent emprunté (20 minutes)

- Pourquoi vous avez besoin d'une grosse somme d'argent (5 minutes)

- Démontrer la différence entre l'épargne et l'emprunt (15 minutes)

- Comparer l'épargne et l'emprunt (10 minutes)

Durée totale: 60 minutes

\section{INSTRUCTIONS}

Faire la distinction entre l'argent emprunté et l'argent propre (10 minutes)

1. Demander ceci aux filles:

- Pourquoi aimez-vous emprunter de l'argent?

- Pourquoi est-ce que vous n'aimez pas emprunter?

- Quelles questions avez-vous à poser sur l'emprunt d'argent ?

2. Expliquez: "Nous allons commencer maintenant avec un nouveau thème : Emprunter prudemment de l'argent. Nous avons passé beaucoup de temps à apprendre la raison pour laquelle il est important d'épargner et la manière d'augmenter nos économies. Mais quelquefois nous empruntons aussi de l'argent. Dans cette session, nous essaierons de comprendre la différence entre l'argent que nous épargnons et l'argent que nous empruntons. "

"Commençons par former une ligne droite devant moi. Je vais lire à haute voix les descriptions montées de toute pièce des différentes sommes d'argent et leur origine. Pour chaque description, vous devez décider si cet argent est emprunté ou si c'est votre propre argent. Si vous pensez qu'il est emprunté, faites un pas à gauche. Si vous pensez que c'est votre propre argent, faite un pas à droite. " 


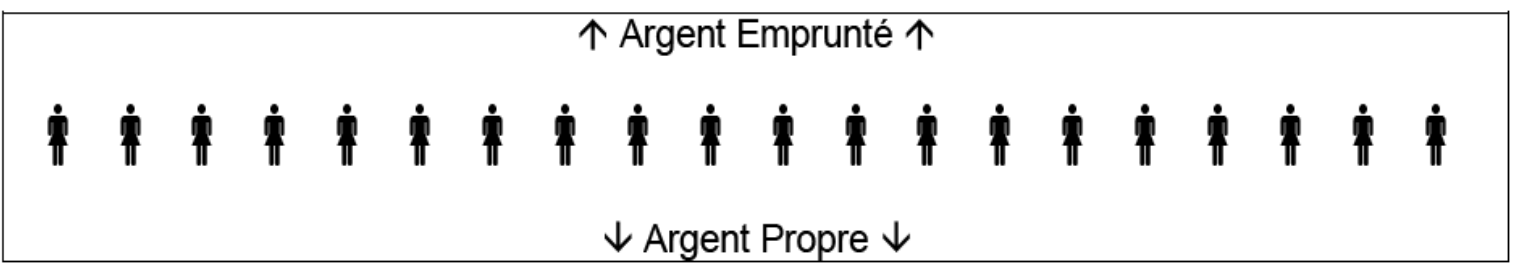

Lorsqu'il y a désaccord, discutez des différentes opinions et clarifiez toute confusion.

3. Lisez les descriptions suivantes.

- Votre mère vous donne 200 francs pour le transport

- Au magasin, le lait coûte 100 francs mais vous l'achetez à crédit

- Vous lavez le linge de votre voisin pour 200 francs

- Vous allez au centre communautaire pour voir la troupe théâtrale avec un ami et elle vous prête de l'argent pour le billet

- Vous prenez 1.500 francs de votre boîte à économies sous votre lit pour acheter des produits d'hygiène

\section{$\rightarrow$ Comprendre ce qu'est l'argent emprunté (20 minutes)}

1. Divisez le groupe en deux équipes et donnez un nom à chaque équipe (Utilisez quelque chose de familier ou d'humoristique pour les filles : noms d'animaux («les souris» ou «les poulets» ou des musiciens bien connus).

2. Expliquez :

J'ai une liste de questions au sujet de l'argent emprunté. La première question sera pour l'équipe 1. Cependant, pendant une minute, les deux équipes devraient discuter de la réponse à la question entre elles. Après une minute, l'équipe 1 donnera sa réponse. Si elle ne peut pas répondre à la question, l'équipe 2 aura une chance. La prochaine question ira à l'équipe 2; si elle ne peut pas répondre, l'équipe 1 aura une chance.

3. Posez les questions suivantes:

\section{Pourquoi l'argent emprunté est-il différent de votre propre argent?}

[L'argent emprunté doit être remboursé; avec votre propre argent, vous avez plus de flexibilité et vous pouvez le contrôler.]

Quand vous empruntez de l'argent, pourquoi est-ce que vous devez le rembourser? [Parce que l'argent ne vous appartient pas; et d'habitude la personne qui vous l'a prêté s'attend à le récupérer.]

Si vous empruntez de l'argent à un ami, est-ce que vous devez le rembourser? [Normalement, oui. Quelquefois un membre de la famille ou un ami finira par vous donner cet argent - c'est-à-dire, qu'il vous donne l'autorisation de ne pas rembourser l'emprunt. Mais vous ne devriez jamais supposer que cela se passera ainsi, et toujours projeter de rembourser ou de rendre ce que vous empruntez!] 
Quand vous empruntez de l'argent, est-ce que vous pouvez décider quand le rembourser? [Si vous empruntez de l'argent à un ami ou à un parent, ils peuvent être très flexibles concernant le moment où vous avez besoin de leur rendre l'argent. Cependant, si vous empruntez de l'argent d'une institution financière, vous aurez un programme de remboursement par des acomptes qui sont dus chaque semaine ou chaque mois jusqu'à ce que le montant total soit remboursé.]

Est-ce qu'il vous coûte quelque chose d'emprunter de l'argent? Est-ce que vous remboursez le même montant que vous empruntez? [La plupart des prêteurs vous chargent de l'argent pour utiliser leur argent; ce montant est «l'intérêt». Quand vous empruntez à un ami, il ne peut pas vous demander de payer des intérêts sur l'emprunt.]

Si vous empruntez de l'argent et qu'un voleur vous le vole alors, est-ce que vous devez tout de même rembourser cet argent? [Oui!] Pourquoi? [Parce que cet argent ne vous appartient pas]

4. Félicitez les deux équipes! La leçon tirée de ces questions est que : emprunter de l'argent est une responsabilité - le rembourser, le rembourser à temps, et le rembourser avec tout intérêt qui serait chargé.

\section{$\rightarrow$ Pourquoi vous avez besoin d'une grosse somme d'argent (5 minutes)}

1. Posez ces questions :

- Dans votre communauté, quelles sont les raisons pour lesquelles les adultes ont besoin d'une grosse somme d'argent? [Frais scolaires, terrain, loyer, vélo, travail]

- Et les filles ? Pensez à quelque chose pour laquelle vous avez besoin d'une grosse somme d'argent. Que feriez-vous avec, disons, 50.000 francs ?

2. Dites :

Il y a des raisons différentes pour lesquelles quelqu'un pourrait avoir besoin d'une très grosse somme d'argent. Certains d'entre vous voudraient une très grosse somme. D'autres parmi vous ont besoin de moins d'argent, mais c'est tout de même plus d'argent qu'elles ne possèdent présentement. Trouver une grosse somme d'argent pour atteindre vos buts peut être très difficile. Cependant, ce n'est pas impossible! Aujourd'hui, nous allons apprendre deux moyens pour obtenir une grosse somme d'argent.

\section{Démontrer la différence entre l'épargne et l'emprunt (15 minutes)}

1. Demandez à deux volontaires de venir devant. Expliquez que ces deux filles ont le même but pour lequel elles ont besoin d'argent.

Aujourd'hui, nous allons prétendre que ces billets sont notre argent. Les deux filles cherchent le moyen d'obtenir une grosse somme d'argent, disons 10 billets. Maintenant, elles ont 
besoin de cet argent pour en faire quoi? Donnons à nos deux volontaires quelque chose qu'elles veulent acheter. Qu'est-ce qu'elles veulent acheter?

2. Après quelques suggestions, demandez aux deux volontaires ce qu'elles aiment acheter. Puis concluez en disant :

Ok, nos deux volontaires veulent chacune 10 billets pour acheter un (complétez le vide par l'article qu'elles ont choisi). Maintenant la question importante est de savoir comment elles vont obtenir cette somme d'argent? Nous allons vous montrer deux moyens l'emprunt et l'épargne. Vous pourrez penser qu'emprunter et épargner sont très différents. Mais en fait, nous verrons qu'ils sont semblables en 1 point important.

3. Pour donnez la chance aux deux filles d'être choisi, prenez une pièce d'argent et dites à l'une d'elles que si la pièce tombe sur la face pile, c'est elle qui est épargnante. Si la pièce tombe sur la face, c'est elle qui sera l'emprunteuse. Lancez la pièce et décider qui est l'épargnante et qui est l'emprenteuse.

4. Dites ceci à l'emprunteuse :

Félicitations! Je suis le prêteur d'argent local et je viens de vous approuver un emprunt pour 10 billets/pièces. Mais, il ne faut pas oublier qu'il y a aussi un intérêt de 10\% pour cet emprunt.

5. Donnez à l'emprunteuse 10 billets/pièces et expliquez :

Vous avez maintenant vos 10 billets, suffisant pour acheter (complétez le nom du but sélectionné plus tôt)! C'était facile, n'est-ce pas?

6. Tournez-vous vers l'autre volontaire - l'épargnante - et dites ceci :

Vous êtes l'épargnante; vous devez juste attendre vos 10 billets/pièces. Mais! Vous êtes chanceuse parce que vous pouvez ouvrir un compte-épargne à ma banque! Nous allons prétendre que vous gagnez un revenu mensuel de 4 billets/pièces, et pour obtenir votre grosse somme de 10 billets/pièces pour acheter le (compléter le vide par le nom du but sélectionné plus tôt), vous aller épargner de votre revenu 2 billets chaque mois. Est-ce que vous pouvez réussir à en épargner 2 billets chaque mois? Bon!

7. Créez un emplacement, visible à tout le groupe, où elle peut mettre ses deux billets. Expliquez à tout le monde que cette place est son compte-épargne à la Banque (nom du mentor). Ditesleur que chaque mois l'épargnante recevra 4 billets/pièces comme revenu et en épargnera 2.

8. Tournez-vous vers "l'emprunteuse " et dites ceci :

Je suis sûre vous êtes heureuse d'avoir un emprunt de 10 billets de moi! Mais, votre premier paiement est maintenant dû. S'il vous plaît payez-moi 2 billets. Préparez-vous. Vous devez me payer 2 billets chaque mois jusqu'à ce que l'emprunt de 10 billets soit remboursé dans sa totalité avec l'intérêt de 1 billet aussi.

9. Tournez-vous vers le reste du groupe et posez ces questions: 
- Combien d'argent (l'épargnante) est-elle en train de mettre dans son compte-épargne chaque mois? [ 2 billets]

- Combien de mois devra-t-elle épargner pour obtenir sa grosse somme de 10 billets? [5]

- Combien d'argent (l'emprunteuse) est-elle en train de payer à la banque en guise de remboursement de son emprunt? [2 billets]

- Combien de paiements mensuels a-t-elle besoin d'effectuer jusqu'à ce que son emprunt de 10 billets soit remboursé ? [5, plus le paiement de l'intérêt aussi.]

10. Expliquez:

Finalement, nos deux filles obtiennent chacune leur 10 billets et sont capables de payer pour (but sélectionné plus tôt). L'une emprunte l’argent et l'autre l'épargne.

11. Posez ces questions :

- Comment les deux moyens d'obtenir une grosse somme d'argent sont-ils similaires ? [Les deux exigent de petits paiements réguliers. L'une rembourse son emprunt chaque mois, l'autre effectue des versements d'épargne chaque mois.]

- Comment les deux moyens d'obtenir une large somme d'argent sont-ils différents ? [L'emprunteuse a obtenu l'argent tout de suite et a eu à le rembourser petit à petit. L'épargnante devait attendre jusqu'à ce qu'elle puisse épargner le montant total dont elle avait besoin.]

\section{Comparer épargne et emprunt (10 minutes)}

1. Divisez le groupe en deux équipes. Assignez à une équipe la tâche d'identifier les avantages d'épargner. Assignez les avantages d'emprunter à l'autre groupe. Donnez 5 minutes à chaque équipe pour discuter. Alors demandez que chaque équipe présente, les avantages qu'elle a identifiés. Leurs réponses devraient inclure les points dans le tableau ci-dessous. Ajoutez tous les avantages qu'elles ont pu manquer.

\begin{tabular}{|l|l|}
\hline Les avantages de contracter un emprunt & Les avantages d'épargner \\
\hline $\begin{array}{l}\text { - Accès rapide à l'argent } \\
\text { - Obtenir rapidement ce que vous désirez }\end{array}$ & $\begin{array}{l}\text { - L'argent vous appartient. Vous êtes libre de } \\
\text { l'utiliser comme vous l'entendez. }\end{array}$ \\
$\begin{array}{l}\text { avantage d'une opportunité qui pourraite ne } \\
\text { pas durer très longtemps, telle qu'avoir un bon } \\
\text { prix sur quelquechose ou faire un bon } \\
\text { investissement }\end{array}$ & $\begin{array}{l}\text { - Pas de pression pour faire le remboursement; } \\
\text { vous n'aurez pas d'ennuis pour paiement tardif. }\end{array}$ \\
\hline Les inconvenients de contracter un emprunt & $\begin{array}{l}\text { pas à payer d'intérêt sur leur capital. Dans } \\
\text { certaines circonstances, la banque va payer aux } \\
\text { épargnants un intérêt sur leurs versements. }\end{array}$ \\
\hline $\begin{array}{l}\text { - Pression pour faire le remboursement } \\
\text { - Possibilité d'avoir des ennuis en cas de }\end{array}$ & $\begin{array}{l}\text { Les inconvenients d'épargner } \\
\text { paiement tardif }\end{array}$ \\
$\begin{array}{l}\text { - Paiement d'interêt sur leur capital } \\
\text { - Possibilité de ne pas pouvoir rembourser le prêt }\end{array}$ & $\begin{array}{l}\text { - Discipline et patience sont nécessaires pour } \\
\text { réussir à épargner. }\end{array}$ \\
\hline
\end{tabular}




\section{Posez la question:}

"La prochaine fois que vous avez besoin d'une somme d'argent, comment choisirez-vous de l'obtenir? Par l'épargne ou par l'emprunt ? Pourquoi ?"

N.B. Aux mentors : Vous n'auriez plus besoin de l'argent après cette session. Vous pouvez le rendre à l'association.

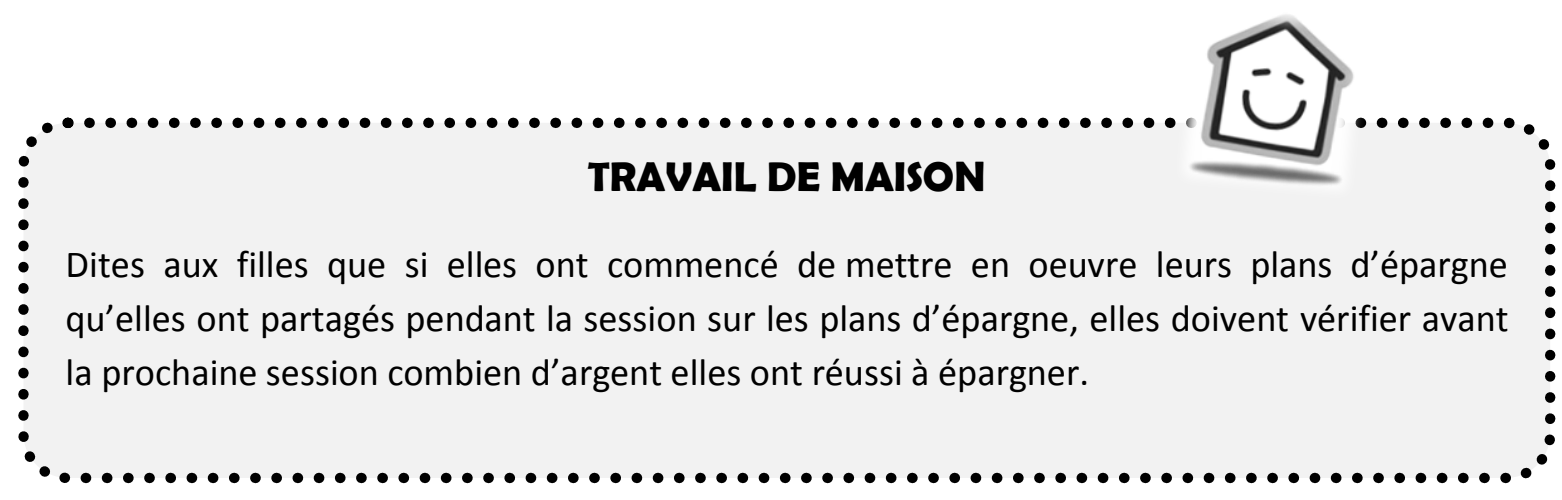




\section{Session 16 : Résolution des conflits relatifs à l’argent}

\section{Objectifs de la session:}

À la fin de cette session, les filles seront capables de:

- Donner la liste des personnes avec qui elles parlent d'argent et de quoi parlent-elles

- Décrire les résultats possibles des discussions sur l'argent

- Identifier les CHOSES À FAIRE et À NE PAS FAIRE dans une bonne communication

- Faire preuve de compétences de communication dans la résolution des conflits à travers des jeux de rôles

- Identifier plus d'une solution aux exemples de conflits

\section{Matériel nécessaire:}

- Outil de suivi de l'épargne des filles

Plan de la session:

- Suivi des plans d'épargne (15 minutes)

- Parler d'argent (30 minutes)

- Les CHOSES À FAIRE et À NE PAS FAIRE lorsqu'on parle d'argent (20 minutes)

- Jeu de rôle sur un conflit et identification d'une solution (20 minutes)

Durée totale: 85 minutes

\section{INSTRUCTIONS}

\section{Suivi des plans d'épargne (15 minutes)}

1. Expliquez aux filles qu'elles ont fait des plans d'épargne il y a de cela 4 semaines, et que maintenant on va voir leur progrès avec leurs plans.

2. Demandez aux filles une à une de dire combien elles ont réussi à épargner, et où est-ce que chacune garde son argent (chez elles, dans une caisse populaire, chez l'employeur, etc). Notez sur votre outil de suivi la situation de chaque fille. Est-ce que quelqu'une a changé son but? Si oui, le mentor doit noter le nouveau but et plan dans l'outil de suivi.

3. Demandez aux filles de partager avec le groupe leurs défis à épargner. Encouragez les autres filles à donner des idées et suggestions. Si une fille se gène de parler de ses défis au groupe, le mentor doit l'encourager à partager avec elle après la session.

\section{$D$ Parler d'argent (30 minutes)}

1. Expliquez que vous allez commencer à réfléchir à QUI vous parlez d'argent. Vous leur donnerez des exemples de personne(s), et elles devraient se lever et frapper dans leurs mains si elles parlent à cette ou ces personne(s) d'argent. Amusez-vous, et dirigez cette activité de manière vivante! Dites: 
Levez-vous et frappez vos mains si vous parlez à:

1. Votre père

2. Votre mère

3. Vos parents!

4. Vos frères

5. Vos sœurs!

6. Vos copines

7. Des commerçants!

8. Votre patron!

9. Vos amis!

10. Vos logeurs!

11. Vos employeurs!

12. Vos tantes!

13. Vos voisins!

14. Vos grands-parents!

2. Demandez aux autres groupes si elles ont d'autres exemples de PERSONNES à ajouter. Ensuite, passez à la deuxième partie du jeu.

3. Expliquez que vous allez maintenant penser à CE DONT vous parlez à ces gens par rapport à l'argent. Dites:

Levez-vous et frappez vos mains si vous parlez:

1. De choses à acheter pour la famille!

2. De la nourriture!

3. Du prix du ticket de bus!

4. Des prix des produits!

5. D'épargne!

6. D'emprunt d'argent!

4. Donnez aux filles, une chance d'ajouter d'autres exemples de CE DONT elles parlent.

5. Dites aux filles que pour la partie finale du jeu, elles vont réfléchir à ce qu'elles ont éprouvé en abordant la question d'argent. Dites:

Levez-vous et frappez vos mains si lorsque vous parlez de l'argent - vous ressentez:

1. De la confiance!

2. De la joie!

3. De la nervosité!

4. De la colère!

5. De l'espoir! 
6. Donnez à 2-3 volontaires, la possibilité d'ajouter des exemples. Dites ensuite:

Nous parlons d'argent à beaucoup de personnes dans de nombreuses situations. Cependant, l'argent peut être l'un des sujets les plus difficiles à aborder avec d'autres personnes. Même ainsi, comme nous l'avons vu dans les réponses à nos questions, nous en parlons encore avec beaucoup de gens pour de nombreuses raisons. Dans les sessions à venir, nous allons en apprendre davantage sur certains moyens d'aborder les questions d'argent afin de rendre la conversation plus aisée.

7. Dites:

Notre objectif est de trouver ensemble des façons de parler de l'argent de manière plus aisée et efficace. Nous allons commencer par identifier les résultats possibles - ou résultats - des discussions autour de l'argent.

8. Posez la question suivante:

Quand nous finissons de parler d'argent avec quelqu'un, est-ce que toutes les personnes impliquées sont toujours contentes du résultat?

Les filles répondront probablement «non». Dites:

Lorsque nous parlons d'argent, parfois les deux personnes impliquées finissent la discussion dans la joie puisque chacun obtient quelque chose qu'il veut. Parfois elles n'obtiennent rien les deux perdent. Et parfois, une personne obtient quelque chose qu'elle veut et l'autre personne non. Lorsque nous parlons d'argent, il y a des gagnants et des perdants.

9. Expliquez les résultats suivants quand on parle d'argent:

\section{Résultats possibles quand on parle d'argent}

\section{Gagnant-gagnant}

C'est le meilleur résultat de toute discussion autour de l'argent.

Les deux personnes (ou groupes) impliquées dans la discussion obtiennent quelque chose ou tout ce qu'elles veulent ou dont elles ont besoin. Elles ont toutes les deux un sentiment positif à la fin de la discussion, et sont prêtes à parler à nouveau d'argent dans le futur.

\section{Perdant-perdant}

C'est le pire résultat possible de toute discussion autour de l'argent.

Dans un résultat perdant-perdant, les deux personnes (ou groupes) ne peuvent pas s'entendre. En fin de compte, aucune des personnes (ou groupes) impliquées dans la discussion n'obtient ce qu'elle voulait. Elles peuvent ne pas être disposées à parler d'argent à nouveau dans le futur. 


\section{Gagnant-perdant / perdant-gagnant}

Dans une situation de gagnant-perdant ou perdant-gagnant, une personne (ou groupe) obtient ce qu'elle veut et l'autre, rien. Lorsque cela arrive, le perdant pourrait être moins enclin à parler au gagnant d'argent dans le futur.

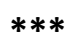

Résultat: Un résultat est l'issue de quelque chose. Lorsque nous parlons d'argent, nous utilisons les résultats en référence à l'issue de la discussion.

10. Expliquez aux filles que vous allez leur donner quelques exemples. Dites-leur que leur travail consiste à écouter et déterminer qui, dans chaque histoire, est satisfait du résultat.

11. Expliquez aux filles que vous allez leur donner quelques exemples. Dites-leur que leur travail consiste à écouter et déterminer qui, dans chaque histoire, est satisfait du résultat.

\section{Résultats de type perdant-perdant}

Lisez / racontez la Situation 1:

Une cliente discute du prix d'une jupe avec un vendeur dans le marché. Ils ne peuvent pas s'entendre sur le prix, et la cliente quitte le marché sans rien acheter au vendeur.

Posez la question suivante:

Qui a été le gagnant à la fin de cette discussion? [Personne.]

Qui a été le perdant? [Les deux personnes.]

Lorsque quelqu'un répond correctement, expliquez les résultats «perdant-perdant»:

Parfois, aucune personne impliquée n'obtient ce qu'elle veut. Ce type de résultat est appelé "perdant-perdant».

Posez la question suivante:

Quel est un autre exemple de résultat "perdant-perdant» quand on parle d'argent? [À titre d'exemple: Votre voisin et vous souhaitez acheter de la friperie et la vendre ensemble. Cependant, vous ne pouvez pas vous mettre d'accord sur la somme à dépenser par chacun de vous; vous perdez tous les deux. Aucun de vous ne peut faire cet investissement et en tirer profit. C'est une situation perdant-perdant.

12. Permettez à 1-2 filles de donner un exemple pour vérifier leur compréhension. Assurez-vous que les exemples donnés sont vraiment des situations de «perdant-perdant». Ensuite, passez aux résultats gagnant-perdant / perdant-gagnant. 


\section{Résultats gagnant-perdant / perdant-gagnant}

Lisez / racontez la Situation 2:

Honorine veut que sa sœur Lydia fasse le ménage pour elle, afin que Honorine puisse passer du temps avec son nouveau copain. Lydia demande à Honorine de la payer, mais cette dernière refuse. Lorsque Honorine menace de frapper Lydia, celle-ci cède et accepte de faire le ménage pour rien.

Posez la question suivante:

Qui a été le gagnant dans cette discussion? [Honorine]

Qui a été le perdant? [Lydia]

Lorsque quelqu'un répond correctement, expliquez les résultats «Gagnant-perdant / Perdant Gagnant»:

Souvent, une personne dans la discussion obtient ce quelle veut, et l'autre ne reçoit rien. Ces résultats sont appelés "gagnant-perdant» ou "perdant-gagnant». Dans ces situations, le perdant pourrait être moins disposé à parler à nouveau d'argent avec le gagnant!

Posez la question suivante:

Quel peut être un autre exemple de résultat "Gagnant-perdant/ Perdant-gagnant»? [À titre d'exemple: Vous avez besoin d'argent immédiatement et ne pouvez attendre. Vous empruntez de l'argent à une amie, et elle n'est disposée à vous prêter de l'argent QUE si vous acceptez de rembourser deux fois le montant initial. Dans ce cas, vous perdez parce que vous n'avez pas le temps d'attendre, et votre amie gagne puisqu'elle obtient en retour un investissement important. C'est une situation perdant-gagnant.]

13. Permettez à 1-2 filles de donner un exemple pour vérifier leur compréhension. Assurez-vous que les exemples donnés sont vraiment des situations de «gagnant-perdant/perdant-gagnant». Enfin, passez aux résultats gagnant-gagnant. 


\section{Résultats gagnant-gagnant}

Lisez / racontez la Situation 3:

Barro veut acheter un vélo. II discute le prix avec un vendeur du marché pour un vélo qui est exposé, mais ne peut pas obtenir de prix assez bas. Il est sur le point de partir quand le vendeur demande à Barro d'attendre un instant, car il vient de se rappeler d'un autre vélo, qu'il a derrière son étal. Barro l'apprécie et le prix du vélo est dans sa fourchette de prix. Barro décide d'acheter le deuxième vélo.

Qui a été le gagnant à la fin de cette discussion? [Les deux].

Lorsque quelqu'un répond correctement, expliquez les résultats «gagnant-gagnant»:

Ce résultat est une situation "gagnant-gagnant». Les deux camps ont obtenu quelque chose, sinon tout ce qu'ils voulaient ou dont ils avaient besoin. Dans les résultats "gagnantgagnant», toutes les parties ressortent avec des sentiments positifs et elles sont susceptibles de reparler les unes aux autres de questions d'argent.

Posez la question suivante:

Quel peut être un autre exemple de résultat «Gagnant-gagnant»? [À titre d'exemple: Vous voulez acheter de la nourriture chez une vendeuse, et vous négociez un bon prix ensemble. Vous êtes content de votre achat, et de vos économies, et vous recommandez à vos amis et à votre famille d'acheter des choses chez la même vendeuse. Elle fait plus d'affaires à cause de la bonne offre qu'elle vous a faite et vous avez économisé de l'argent. Vous avez tous deux gagné, et c'est une situation «gagnant-gagnant».]

14. Offrez à 1-2 filles la possibilité de donner des exemples pour vérifier leur compréhension. Posez la question suivante:

Lequel de ces trois résultats est le résultat préféré? [Gagnant-gagnant] Pourquoi? [Gagnantgagnant, parce que les deux personnes dans la situation gagnent. Elles ont toutes deux des sentiments positifs, et sont prêtes à retravailler ensemble dans l'avenir.]

\section{Les choses à faire et à ne pas faire lorsqu'on parle d'argent (20 minutes)}

1. Dites:

Une communication claire est très importante quand il s'agit de discuter d'argent et de sujets d'ordre financier. Nous ne voulons pas que nos messages soient brouillés ou modifiés ou mal compris parce que nous ne communiquons pas bien - surtout quand nous parlons d'argent, et que nous voulons atteindre un résultat gagnant-gagnant.

Sur la base de vos propres expériences: 
Qu'est ce qui peut arriver au cours d'une conversation sur l'argent pour aboutir à un résultat gagnant-perdant ou perdant-perdant? [Une personne se fâche; une ou les deux personnes refusent d'écouter l'autre; une ou les deux n'est pas flexible ou ne veut pas voir le point de vue de l'autre.]

Si nous voulons un résultat gagnant-gagnant, quelles sont les règles que nous devrions suivre lorsque nous parlons d'argent?

2. Autorisez plusieurs filles à donner leur avis. Ajoutez l'une des choses à faire qui est mentionnée cidessus et dont les filles n'ont pas fait cas. Lorsque vous avez fini avec la liste, assignez à chaque fille les choses suivantes à faire. Si vous avez un flipchart non utilisé ou un tableau disponible, préparez ces choses à l'avance. (Il y aura plus d'une fille pour chaque chose à faire.)

\section{Les choses à faire lorsqu'on parle d'argent}

- Écouter l'autre personne

- Essayer de voir le point de vue de l'autre personne

- Montrer du respect

- Être flexible

- Indiquez clairement ce que vous voulez

3. Puis demandez:

Que devriez-vous EVITER en essayant de communiquer avec succès?

4. Encore une fois, permettez aux filles de répondre. Ajoutez l'une des choses à éviter qui est mentionnée ci-dessus et dont les filles n'ont pas fait cas. Lorsque vous avez fini avec la liste, assignez à chaque fille une des choses suivantes à NE PAS FAIRE. Si vous avez un flipchart non utilisé ou un tableau disponible, préparez ces choses à l'avance. (II y aura plus d'une fille pour chaque chose À NE PAS FAIRE.)

$$
\begin{aligned}
& \text { Les choses à ne pas faire lorsqu'on parle d'argent } \\
& \text { - Se mettre en colère } \\
& \text { - Être grossier ou insulter } \\
& \text { - Rejeter les idées de l'autre personne, sans écouter } \\
& \text { - Vous enfermer dans une position }
\end{aligned}
$$

5. Finissez la session en passant à des exercices pratiques sur les " choses à faire " et les " choses à ne pas faire " pour vous assurer que chacun s'en souvient. Autorisez les filles à pratiquer d'abord les CHOSES A FAIRE qui leur ont été assignées, avant de passer aux CHOSES A NE PAS FAIRE. 


\section{$\rightarrow$ Jeu de rôle sur un conflit et identification d'une solution (20 minutes)}

1. Divisez les filles en groupes de 4. (Il y a 5 jeux de rôle. Si vous avez plus de 20 filles, vous pouvez donner les instructions du même jeu de rôle à plus d'un groupe.) Donnez l'un des scénarios suivants à chaque groupe de filles.

2. Expliquez:

Je vais confier à chaque groupe un jeu de rôle qui décrit un conflit relatif à l'argent. En premier lieu, chaque groupe doit décider ensemble d'une solution gagnant-gagnant qui permettra de résoudre votre conflit. Ensuite, vous allez faire un jeu de rôle entre les gens décrits et la solution que vous avez choisi. Au moins, l'un des personnages dans le jeu de rôle devrait tenter de faire preuve de bonnes compétences en communication.

Vous n'avez que 5 minutes pour préparer le jeu de rôle et 3 minutes pour le jouer. Bonne chance.

Jeux de rôle : Conflits autour de l'argent

1. Marie-Claude aide sa grand-mère le samedi matin dans son hôtel près du marché. Elle veut garder cet argent elle-même. Mais sa mère insiste pour que Marie-Claude lui donne tout l'argent pour l'aider avec les dépenses du ménage.

[Marie-Claude peut discuter des raisons pour lesquelles elle économise de l'argent avec sa mère, et elles peuvent convenir que Marie-Claude conserve la moitié de l'argent, et donne l'autre moitié à sa mère.]

2. Fatima reçoit de l'argent chaque semaine de ses parents pour son ticket de bus et les frais pour son programme de formation. Elle économise ce qui reste avec un groupe d'épargne. Lorsque les parents ont appris que Fatima avait un peu d'argent à économiser à la fin de chaque semaine, ils ont été mécontents. Ils ont menacé de réduire son allocation, mais Fatima veut garder un peu d'argent pour elle-même.

[Fatima peut inviter son mentor du programme d'épargne pour parler avec ses parents sur les avantages de l'épargne. Elle peut leur présenter les avantages de l'épargne, et les objectifs d'épargne qu'elle s'est fixée. Elle doit veiller à expliquer que cela permettra aux parents d'économiser de l'argent dans le long terme.]

3. Alima et Fatou sont des sœurs qui travaillent dans le même stand au marché, chaque jour. Elles obtiennent de l'argent de leurs parents pour prendre le bus pour aller au marché. Cependant, Alima veut maintenant marcher, et économiser sa part et donc diviser leur argent de transport.

[Alima peut expliquer certains des objectifs pour lesquels Fatou et elles, peuvent économiser à I'avenir et de combien d'argent elles auront besoin pour les atteindre. Alima et Fatou peuvent alors décider d'un objectif commun, et convenir de marcher de temps à autre.]

4. Ghislaine a récemment travaillé pour un voisin pendant 5 jours. Cependant, quand elle est allée chercher son argent, le voisin a dit qu'elle avait seulement travaillé pendant 4 jours. Ghislaine 
veut résoudre la situation et pouvoir récupérer ses avoirs tout de même.

[Ghislaine peut trouver quelqu'un d'autre qui a vu son travail journalier sur les 5 jours pour appuyer son histoire. Elle peut dire au voisin qu'elle est une bonne travailleuse, et qu'elle veut continuer à faire du bon travail pour lui et que pour bien le faire, elle doit être payée.]

3. Après que chaque groupe ait présenté son jeu de rôle, demandez:

- Quelles compétences de communication avez-vous remarqué chez les acteurs dans le jeu de rôle?

- Quelle a été la solution à laquelle ils sont parvenus?

- Quelles sont les autres solutions possibles à ce conflit?

4. Dites:

"Aujourd'hui, nous avons vu différentes façons de résoudre les conflits. Dans la vie réelle, ce ne sont pas toutes les discussions sur l'argent qui aboutissent à un résultat gagnant-gagnant. Bien que nous espérions tous un résultat gagnant-gagnant, parfois cela est impossible à cause des personnes impliquées ou des émotions du moment. Cependant, la communication avec confiance est le point de départ pour obtenir de bons résultats lorsqu'on parle d'argent.

Comme nous l'avons dit dans la partie des CHOSES À FAIRE OU À NE PAS FAIRE, si nous expliquons ce que nous voulons clairement et écoutons les besoins de l'autre partie, gardons notre calme, et cherchons un compromis, nous pouvons négocier notre chemin vers un résultat gagnant-gagnant le plus souvent." 


\section{Module 3}

\section{L’Hygiène et la Santé}

Session 17: L'abus des drogues et de l'alcool

Session 18: Hygiène corporelle et dentaire

Session 19: Les maladies

Session 20: La vaccination

Session 21: La fréquentation des services de santé par les adolescentes

Termes Clés dans ce Module: abus de l'alcool, carie, choléra, coqueluche, drogues, fièvre typhoïde, fréquentation des services de santé par les adolescentes, gencive, hépatite $B$, hygiène corporelle, hygiène dentaire, maladies, mythes, paludisme, pneumonie, poliomyélite, rougeole, tétanos, tuberculose, vaccination. 


\section{Session 17 : L'abus des drogues et de l'alcool}

\section{Objectifs de la session:}

À la fin de cette session, les filles seront capables de:

- Définir l'abus des drogues et de l'alcool

- Identifier certains des facteurs et situations pouvant conduire à l'abus de drogue et d'alcool

- Prendre des décisions efficaces sur la consommation des drogues et l'alcool

- Montrer leurs connaissances des mythes et réalités sur les drogues et l'alcool

\section{Matériel nécessaire:}

- Flipchart

- Marqueurs

\section{Plan de la session:}

- Définition de l'abus de drogues et d'alcool (15 minutes)

- Étude des mythes et réalités sur les drogues (20 minutes)

- Communication et prise de décision rassurantes sur les drogues et l'alcool (40 minutes)

Durée totale: 75 minutes

\section{AVANT LA SESSION}

Préparez-vous pour la troisième activité (communication et prise de décision rassurantes sur les drogues et l'alcool) en écrivant ce qui suit sur le tableau ou l'affiche :

\section{Trois étapes pour la prise de décision}

1. Décrivez le DÉFI (ou décision) qui se pose à vous

2. Citez trois CHOIX que vous avez

3. Analysez les CONSÉQUENCES positives et négatives de chaque choix

\section{NOTES D'INFORMATION}

L'abus d'alcool et d'autres drogues constitue un problème majeur de santé publique qui expose des millions d'adolescents au risque accru d'accidents liés à l'alcool et au trafic de drogues, aux pratiques sexuelles risquées, à la délinquance juvénile, et aux problèmes de croissance.

La consommation de drogue peut être définie comme l'utilisation de toute substance chimique qui provoque des dommages physiques, mentaux, émotionnels ou sociaux à un individu ou à ses proches. La toxicomanie est l'utilisation compulsive de drogues, malgré le préjudice social, émotionnel ou physique qu'elles peuvent causer à l'individu. Le caractère de dépendance vis-à-vis des drogues varie d'une substance à l'autre, et d'un individu à un autre. Certaines drogues peuvent créer plus de dépendance que d'autres, et certaines personnes sont plus susceptibles d'en dépendre que d'autres.

Une personne qui se drogue régulièrement peut devenir dépendante. Beaucoup de drogues créent une dépendance, y compris les médicaments tels que les antidouleurs, les pilules minceur et les somnifères, et 
la dépendance n'est pas toujours reconnue. II est souvent difficile ou impossible d'arrêter la prise d'une drogue quand la dépendance s'installe. Pour la vaincre, il faut détermination, volonté, confiance en soi et appui d'autrui, souvent à travers un traitement professionnel ou la participation à un programme thérapeutique.

Certaines drogues sont plus néfastes qu'autres. Par exemple, le tabac en forme de cigarette est une drogue très commune au Burkina Faso. La cigarette est très dangereuse. Environ la moitié des personnes qui consomment le tabac régulièrement meurent d'une cause associée au tabac. En opposé, le café, le thé et de nombreux sodas contiennent de la caféine, qui est un stimulant et aussi consideré une drogue. La caféine créé une dépendance; les maux de tête sont un signe commun de manque de cafeïne chez les consommateurs; cepandant la cafeïne n'est pas autant néfaste pour l'organisme comme le tabac.

\section{INSTRUCTIONS}

\section{$\rightarrow$ Définition de l'abus de drogues et d'alcool (15 minutes)}

1. Expliquez ce qu'est une drogue.

Drogue : Une drogue désigne tout produit chimique qui affecte le fonctionnement d'un corps.

2. Demandez aux filles: "Quels sont les différents types de drogues ou les substances nocifs pour l'organisme qui existent dans la communauté?» Essayez de les faire réfléchir à un minimum de cinq exemples. Écrivez leurs idées sur le flipchart. Au besoin, ajoutez d'autres exemples à partir de la liste suivante.

Dolo (bière locale), bière, Pastis; Coutoucou, whisky, Bangui, tabac, cigarette, cocaïne, solvants (dissolution, essence), morphine, cannabis, heroine, chanvre indien, marijuana

3. Décrivez la différence entre «consommation» et «abus» de drogue et d'alcool.

Abus de drogues et d'alcool : Il est important de noter que "consommation» et "abus» de drogue et d'alcool ne sont pas les mêmes. La consommation de drogues peut venir avant l'abus de drogues et ne conduit pas nécessairement à l'abus. Mais, pour la plupart des drogues, comme le tabac, le l'héroïne et les cigarettes, la consommation, même une seule fois est néfaste pour la santé. L'abus des drogues n'est pas défini par la seule fréquence d'usage des drogues, mais prend également en compte, l'âge du consommateur de drogues, les réactions physiologiques, les niveaux de dépendance, les attitudes concernant l'utilisation de substances, et les effets que la consommation de drogue a sur d'autres domaines de la vie du consommateur.

4. Demandez aux filles: "Quelles sont certaines des raisons pour lesquelles quelqu'un pourrait commencer à abuser de drogues ou d'alcool? " II peut être utile de dire aux filles de se rappeler les sessions sur la pression des pairs dans la section sur les Compétences de vie courante. Les raisons doivent inclure des exemples tirés de la liste ci-dessous :

- pour réduire leur anxiété dans les situations sociales ;

- pour paraître mûrs et sûrs d'eux ;

- pour éviter certains sentiments ou problèmes, comme l'ennui et la solitude ;

- pour s'intégrer socialement ou s'amuser ; 
- pour se stimuler l'esprit ou rester éveillés ;

- pour intensifier leurs perceptions sensorielles (« voyage »);

- pour réduire leur appétit ou ne pas manger (maigrir);

- pour se détendre ou dormir ; et

- pour faire face à un traumatisme.

5. Demandez aux filles : «Connaissez-vous quelqu'un dans votre communauté qui abuse des drogues ou de l'alcool? Comment savez-vous qu'il consomme de façon abusive de drogues ou d'alcool? Que fait-il ?» Les exemples peuvent inclure des idées de la liste ci-dessous :

Effets néfastes des drogues et de l'alcool: Pour que les problèmes liés à l'alcool ou à la drogue qui sont énumérés ci-dessous puissent indiquer un abus d'alcool et d'autres drogues, il est important de noter qu'ils doivent être extrêmes ou aller au delà de quelques jours. Si une fille mentionne quelqu'un qu'elle connaît éprouver ces symptômes, vous pouvez lui dire que la personne pourrait avoir besoin d'un dépistage supplémentaire par un professionnel. En reconnaissant les signes avant-coureurs et symptômes potentiels de l'abus d'alcool et de drogues, vous pourrez peut-être obtenir de l'aide pour un adolescent qui a besoin de traitement.

\section{Signes et symptômes d'abus d'alcool et de drogues :}

- Des changements brusques dans la personnalité sans autre cause connue

- La perte d'intérêt pour les passe-temps, sports ou autres activités favoris

- Une baisse soudaine de la performance ou de la présence au travail ou à l'école

- Des changements au niveau des amis et la réticence à parler de ses nouveaux amis

- La détérioration des habitudes personnelles consistant à soigner son apparence

- Des difficultés à prêter attention ou le manque de mémoire

- Prise de mauvaises décisions

- Agressivité soudaine ou comportement violent, irritabilité, nervosité, ou étourderies

- Réserve accrue, sensibilité accrue aux questions

\section{$\supset$ Étude des mythes et réalités sur les drogues (20 minutes)}

1. Dites aux filles: «Nous allons maintenant tester vos connaissances sur les drogues et les effets des drogues sur la santé à travers un jeu d'équipe.» Ensuite, lisez les instructions suivantes du jeu, pour les filles :

- Nous allons jouer dans deux équipes et rivaliser afin de voir quelle équipe a les informations les plus précises sur les drogues.

- Je vais lire une question ou une déclaration sur l'utilisation des drogues à une équipe. Certaines des déclarations sont vraies et sont appelées réalités (faits), d'autres sont fausses et connues sous le nom de mythes. Un mythe est un fait fictif qui est faussement reconnue par un grand nombre de personnes comme un fait réel.

- Après avoir entendu une déclaration, la première équipe aura une minute pour discuter et décider de la meilleure réponse. 
- Après une minute, une fille (une fille différente à chaque tour) de l'équipe me dira si la déclaration ou la question est un «mythe» ou une «réalité».

- Si la réponse est correcte, l'équipe gagnera un point. Si l'équipe est en mesure de fournir des informations supplémentaires sur les raisons pour lesquelles la déclaration est un mythe ou une réalité, elle gagnera un point supplémentaire.

- Ce sera ensuite le tour de l'équipe suivante.

2. Demandez aux filles de se diviser en deux équipes et d'aller aux extrémités opposées de la salle. Puis demandez-leur de donner un nom à leur équipe. Écrivez les noms des équipes sur le flipchart.

3. Lisez une déclaration pour la première équipe à partir de la fiche sur les Mythes et Réalités (ci-dessous). Demandez-leur de se concerter avec leur équipe sur la meilleure réponse, puis de demander à un membre de l'équipe de partager la réponse. Si la réponse est correcte, donnez à l'équipe un point sous leur nom inscrit sur le flipchart. Si l'équipe est en mesure de fournir des informations supplémentaires sur les raisons pour lesquelles la déclaration est un mythe ou une réalité, donnez-lui un point supplémentaire.

4. Si la première équipe ne connaît pas la réponse, demandez à la deuxième équipe si elle a la bonne réponse. Si cette dernière trouve la bonne réponse, attribuez-lui un point.

5. Si les équipes ne connaissent pas la réponse correcte, fournir des informations supplémentaires à partir de la liste des mythes et réalités. N'attribuez pas de point.

6. Encouragez la discussion sur chaque déclaration, mais ne perdez pas trop de temps pour trouver les réponses (30-60 secondes pour chacune).

7. Répétez les étapes 3 - 6 pour la deuxième équipe. Continuez de manière alternée entre les équipes jusqu'à faire le tour de toutes les participantes. Laissez l'activité se poursuivre. Notez que vous n'avez pas à lire toutes les déclarations du support ci-dessous si le temps est court. Assurez-vous que chaque participant a eu l'occasion de répondre au moins une fois pour le compte de l'équipe.

\section{Communication et prise de décisions rassurantes sur les drogues et l'alcool (40 minutes)}

1. Dites aux filles: «Nous allons maintenant parler de la prise de décisions sur les drogues et l'alcool. Certaines décisions peuvent prendre quelques jours, d'autres des années, tandis que d'autres sont prises instantanément. Mais prendre des décisions et connaître les conséquences de vos décisions sont des compétences importantes dont tout le monde a besoin. Il y a trois étapes pour la prise de décision active. Nous avons appris ceci dans la Session 8 lors du cours sur les Compétences de Vie Courante. Qui se souvient de ces trois étapes?»

2. Les filles doivent lever la main pour donner les trois étapes. Si possible, identifier une fille au fur et à mesure pour donner chaque étape (c'est à dire ne pas avoir une seule fille pour énumérer toutes les trois étapes).

3. Une fois les étapes données par les filles, vous pouvez tourner le flipchart pour aller aux Trois étapes de prise de décision (que vous avez préparée au début de la session).

\section{Trois étapes pour la prise de décision}

Décrivez le DÉFI (ou décision) qui se pose à vous 


\section{Citez trois CHOIX que vous avez}

Analysez les CONSÉQUENCES positives et négatives de chaque choix

4. Dites aux filles: «Nous allons maintenant aller à la pratique en utilisant les trois étapes de prise de décisions sur les drogues et l'alcool. Je veux que vous vous imaginiez en train de marcher vers la maison en provenance du marché avec deux de vos amies. Comme vous êtes à pied, un groupe de garçons (beaux, populaires et plus âgés) commencent à vous parler, et vous invitent à marcher vers un autre lieu - dans une direction opposée à la maison. Les garçons s'arrêtent à côté d'un arbre et ouvrent un sac contenant de la bière et vous demandent si vous en voulez.»

5. Faites passer les filles par les trois étapes de prise de décision, et réfléchissez ensemble à des idées. Quel est le défi actuel? Quels sont les trois options qu'elles peuvent avoir dans ce scénario? Quelles pourraient être les conséquences positives et négatives de chaque choix?

N'hésitez pas à laisser les filles partager leurs idées. Cependant, si la conversation est difficile, vous pouvez partager les idées suivantes pour faire avancer les choses :

Défi : Devrions-nous rester boire de la bière avec ces garçons beaux et populaires?

Choix : (1) Rester et boire de la bière ; (2) Restez, mais ne pas boire de la bière ; (3) Partir immédiatement

Conséquences : (1) Si nous restons boire de la bière : Entre autres conséquences positives, les garçons pourraient penser que nous sommes "cool»; l'une des conséquences négatives est le risque que nous courons de devenir ivres, ce qui affectera négativement notre pouvoir de décision, et pourrait nous amener à faire des choses que nous n'aurions normalement pas fait (comme des relations sexuelles).

(2) Si nous restons sans boire de la bière : Comme conséquence positive, les garçons peuvent penser que nous sommes "cool»; une conséquence négative est qu'ils peuvent continuer à nous mettre de la pression ou nous influencer à boire un autre jour.

(3) Si nous partons immédiatement: Comme conséquence positive, nous ne deviendrons pas ivres et n'agirons éventuellement pas de manière à le regretter plus tard (comme les comportements sexuels à risque); une conséquence négative peut être le fait que les garçons ne verront pas en nous des filles «cool».

6. Dites aux filles : «OK - Nous allons maintenant passer à la pratique en utilisant un jeu de rôle. Pourrais-je s'il vous plaît avoir 6 volontaires pour m'aider avec ce jeu de rôle?»

7. Demandez au 6 volontaires de venir devant. 3 filles joueront le rôle des filles qui marchent vers la maison en provenance du marché ; les 3 autres filles joueront celui des garçons.

8. Dites aux filles : «les «garçons» vont appliquer la pression des pairs sur les filles et les filles doivent réagir en se servant des trois étapes de prise de décision.» 9. Donnez aux filles 5 minutes pour ce jeu de rôle, puis demandez à un autre groupe de 6 jeunes filles de venir devant et de jouer le même rôle.

9. Ensuite, animez un débat autour des questions suivantes :

- Jusqu'à quel point est-il difficile ou aisé d'utiliser les Trois étapes pour prendre ces décisions? Quelle a été la plus difficile? 
- Quelles parties du modèle de prise de décision semblent être les plus utiles dans ce genre de situations?

- Quelles ont été les «pires conséquences» de chacune des situations?

- Quelqu'un peut-il partager une décision difficile qu'il ou elle a pris au cours des trois dernières années?

- Connaissez-vous quelqu'un qui est actuellement confronté à un problème de drogue? Comment doit-il/elle gérer sa situation?

10. Si possible, informez les filles des ressources en termes de conseils et de traitement disponibles dans leur communauté. Si les ressources en counseling ne sont pas disponibles, invitez les filles à vous rencontrer individuellement en votre qualité de mentor si elles ont des questions ou ont besoin d'aide pour parler de la consommation d'alcool ou de drogue. 


\section{Support : Mythes et realites sur les drogues et l'alcool}

L'alcool n'est pas une substance qui augmente la dépendance, c'est un médicament.

Mythe. L'alcool est une drogue, comme c'est le cas de toute substance qui affecte l'esprit ou le corps.

Un plus grand nombre d'adolescents consomment plus l'alcool que le cannabis.

Réalité. L'alcool est la substance la plus fréquemment utilisée chez les adolescents parce qu'elle est facilement disponible.

Il est rare qu'un adolescent soit alcoolique.

Mythe. Beaucoup de jeunes consomment de l'alcool chaque semaine et nombreux sont ceux qui s'y accroche.

Le tabagisme peut provoquer une dépendance.

Réalité. Plus de gens dépendent de la cigarette que de toute autre substance. Le tabagisme est une habitude dont il est très difficile de se défaire, mais il est indispensable d'arrêter de fumer pour être en bonne santé.

Beaucoup d'adultes dépendants de drogues dangereuses pensent que le fait de fumer le cannabis a été la première étape de leur dépendance.

Réalité. Le cannabis est perçu par les toxicomanes et les chercheurs comme une "drogue d'introduction», ou une drogue qui ouvre la porte à d'autres drogues.

\section{L'alcoolisme est une maladie.}

Réalité. L'alcoolisme est une maladie, tout comme le diabète ou l'épilepsie. II peut répondre au traitement, qui comprend la suppression de toute consommation d'alcool.

Les drogues aident les gens à mieux gérer leurs problèmes.

Mythe. Les drogues aident les gens à oublier leurs problèmes ou réduisent la douleur causée par les problèmes. Les problèmes ne disparaissent pas, mais s'empirent souvent.

Les inhalants sont fondamentalement inoffensifs, même si les adultes en font toute une affaire.

Mythe. L'utilisation des inhalants (comme l'essence, la laque, ou la colle) peut être extrêmement dangereuse car pouvant causer des dégâts irrémédiables aux organes comme le foie, le cerveau ou les nerfs.

Une tasse de café et une douche froide vont dessoûler un ivrogne.

Mythe. Seul le temps permettra à une personne de se dessoûler. Il faut une heure pour permettre au foie de traiter un demi-verre d'alcool pur.

\section{L'alcool affecte certaines personnes plus que d'autres.}

Réalité. Les facteurs qui influencent la façon dont l'alcool affecte l'individu comprennent : le poids corporel, la quantité d'alcool ingurgitée, la présence d'autres médicaments dans le système, la santé générale de l'individu à l'époque et la manière dont il ou elle a récemment mangé. 


\section{L'alcool est un stimulant sexuel.}

Mythe. L'alcool, comme la cocaïne et d'autres drogues, peuvent effectivement réduire les réactions sexuelles d'une personne. La drogue peut diminuer l'inhibition avec un partenaire sexuel, mais elle provoque des problèmes tels que le manque d'érection, ou la perte de la libido. En outre, l'alcool ou les drogues peuvent amener une personne à avoir un comportement sexuel contraire à ce qu'il/elle aurait fait s'il/elle était sobre.

Quand les gens arrêtent de fumer, ils peuvent renverser la tendance de certains dégâts causés à l'organisme.

Réalité. S'il n'y a pas de dégât irrémédiable au niveau du cœur ou des poumons, le corps commence à se guérir quand une personne cesse de fumer.

Le tabagisme fera mal à une femme enceinte, mais pas à son bébé.

Mythe. Fumer pendant la grossesse peut entraîner un accouchement prématuré et la naissance de bébés souffrant d'une insuffisance pondérale.

Ne boire que de la bière permettra d'éviter les problèmes d'alcool.

Mythe. L'alcool éthylique affecte les buveurs, et l'alcool éthylique est présent dans la bière, ainsi que dans le vin et les liqueurs.

\section{Fumer la cigarette de temps à autre n'est pas nocif.}

Mythe. Dès que les gens commencent à fumer, ils voient leurs dents prendre une coloration jaune, ont une mauvaise haleine et s'essoufflent vite, ce qui peut affecter leurs performances physiques. La dépendance à la nicotine est rapide. Les personnes qui fument sur une certaine période de temps ont un risque accru de cancer du poumon et autres maladies pulmonaires, de cancer de la langue et de la gorge et de maladies cardiaques.

Les drogues comme l'alcool, le cannabis et la cocaïne ne seraient pas un problème pour les adolescents si elles ne créaient pas de dépendance.

Mythe. Les drogues interrompent la croissance et le développement normal des adolescents, causent des problèmes au niveau de l'école et de leurs relations, et aboutissent souvent à des grossesses non désirées ou aux IST / VIH car leur utilisation peut conduire à des comportements à risque.

\section{La cocaïne crée de la dépendance.}

Réalité. Même si les gens ne lui associaient habituellement pas de dépendance, les recherches indiquent que la cocaïne crée certainement une dépendance psychologique. Le crack créé une forte dépendance, souvent après seulement quelques utilisations.

L'alcool ne devient un problème qu'après plusieurs années d'utilisation.

Mythe. Quand une personne prend un verre, l'alcool ralentit immédiatement les temps de réaction, affecte l'équilibre et diminue les facultés de coordination. Cela signifie qu'un athlète, un danseur, un musicien ou un pilote peut perdre ses capacités normales et voir ses performances affectées. 


\section{Session 18 : Hygiène corporelle et dentaire}

\section{Objectifs de la session:}

À la fin de cette session, les filles seront capables de:

- Définir l'hygiène corporelle et dentaire et expliquer pourquoi elles sont importantes

- Démontrer leurs connaissances sur les raisons pour lesquelles le lavage des mains est important et quand se laver les mains

- Montrer les étapes de lavage des mains

- Démontrer leurs connaissances sur les raisons pour lesquelles le brossage des dents est important et quand se brosser les dents

- Montrer les étapes de brossage des dents

\section{Matériel nécessaire:}

- Deux seaux

- Eau propre

- Savon

- Gobelet (pour prendre l'eau)

- 30 brosses à dents

- 30 pâtes dentifrices

- Copie de l'image sur le brossage des dents

- Si possible:

- une serviette propre (ou des serviettes jétables) (pour sécher les mains)

- une assiette ou un plateau propre

- Paillettes ou cendres

- Des petits gobelets ou des verres jetables

Plan de la session:

- Comprendre l'hygiène (20 minutes)

- Pourquoi le lavage des mains est important? (10 minutes)

- Démonstration du lavage des mains (20 minutes)

- Pourquoi le brossage des dents est important ? (10 minutes)

- Démonstration du brossage des dents (20 minutes)

Durée totale: 80 minutes

\section{AVANT LA SESSION}

Les démonstrations sur le lavage des mains nécessitent un seau avec de l'eau potable, du savon, un gobelet (pour prendre l'eau), et, si possible, une serviette propre. Mettre de l'eau propre dans le seau et déposez le savon, le gobelet, et la serviette à côté du seau (sur une assiette ou un plateau propre, si possible). Les démonstrations sur le brossage des dents nécessitent de l'eau potable, de la pâte dentifrice, des petits gobelets, et des brosses à dents pour toutes les filles.

\section{NOTES D'INFORMATION}

L'hygiène personnelle joue un rôle important dans une vie saine, car elle empêche la propagation des microbes. Les bonnes pratiques d'hygiène sont particulièrement importantes pour ces filles qui nettoient les maisons et préparent ensuite les repas ; ces pratiques peuvent aider les filles à rester en bonne santé et 
à garder ceux qui les entourent en bonne santé, aussi. Certains éléments de bonne hygiène corporelle peuvent comprendre :

- Le brossage des dents

- Comment se moucher

- Couverture des cheveux lors de la préparation des repas

- Se laver avec du savon au moins deux fois par journée (matin et soir)

- Séparer les objets utilisés pour la cuisine et ceux utilisés pour faire la toilette

- Entretenir les habits propres

- Eviter de partager les sous-vêtements, la brosse à dents, les habits sales, les objets utilisés pour la toilette, etc

\section{INSTRUCTIONS}

\section{$\rightarrow$ Comprendre I'hygiène corporelle (20 minutes)}

1. Expliquez la définition de l'hygiène :

Hygiène : L'hygiène est un ensemble de mesures destinées à prévenir les infections et l'apparition de maladies infectieuses. Cela signifie préserver son corps, son domicile, et son environnement propres et exempts de saleté et de maladies. L'hygiène corporelle consiste à se débarrasser des microbes et à les tenir loin du corps. L'hygiène corporelle joue un rôle important dans une vie saine, car elle empêche la propagation des microbes.

2. Demandez aux filles si elles savent ce que c'est qu'un microbe, et clarifiez le fait qu'elles connaissent le mode de propagation des microbes. Si elles ne savent pas ce qu'est un microbe, leur expliquer ceci :

Microbes : Les microbes sont de très petites bactéries ou virus qui peuvent causer des maladies et vous rendre malade. Elles sont tellement petites qu'elles ne peuvent pas être vues à l'oiel nu. Ils peuvent se propager de plusieurs façons :

- À travers l'air, par les éternuements ou la toux

- Le contact direct avec les gens (y compris les poignées de main)

- Le contact direct avec des objets ou des surfaces qui ont des germes

- Le fait de manger des aliments avec des germes

- Le fait de toucher les animaux

En fonction du temps/des ressources, vous pouvez faire une activité pour démontrer la propagation des microbes. Pour mener cette activité : (1) placez un plat contenant des cendres ou des paillettes sur le bureau ou une table; (2) demandez à une fille de mettre ses mains dans les cendres ou les paillettes et de prétendre que cette cendre ou ces paillettes sont pleines de germes ; (3) demandez à la première fille de serrer la main d'une autre fille ; (4) dites à la deuxième fille de regarder ses mains (qui devraient être couvertes de cendre ou de paillettes), et de les montrer à l'ensemble du groupe ; (5) expliquez au groupe que cette seconde fille a maintenant les mêmes germes que la première fille.

3. Demandez aux filles : "Quels sont quelques exemples des façons dont vous pouvez pratiquer une bonne hygiène?» Essayez de leur faire partager au moins cinq exemples. Si les filles ont du mal à partager des idées, vous pouvez mentionner quelques-uns des exemples suivants de bonnes pratiques d'hygiène :

- Se doucher une fois par jour avec du savon et de l'eau propre 
- Pour les filles qui ont leurs règles, il est particulièrement important de se doucher régulièrement

- Se laver les mains régulièrement avec du savon et de l'eau potable, surtout après avoir utilisé les latrines, et avant/après avoir mangé

- Le brossage ou le nettoyage des dents après chaque repas - ou au moins deux fois par jour

- Garder les cheveux propres, peignés ou tressés

- Garder les oreilles et le nez propres

- Couper les ongles des mains et des pieds régulièrement, et garder les ongles propres

- Laver les vêtements régulièrement

- Porter des vêtements propres chaque jour, notamment les sous-vêtements

- Garder la maison propre en balayant et en lavant les planchers, les tables et la literie

- Bouillir l'eau de boisson et de cuisine pour la nettoyer et la purifier des microbes

- Ne pas partager les objets personels, comme les sous-vêtements ou la brosse à dents

\section{Pourquoi le lavage des mains est important? (10 minutes)}

1. Expliquez pourquoi il est important de se laver les mains :

Il est très important de se laver les mains, car des mains sales peuvent vous rendre malade. Se nettoyer les mains vous protège des maladies. Ne pas se laver les mains ou tout simplement les essuyer avec un chiffon déjà sale peut vous rendre malade parce qu'il peut y avoir des excréments ou des germes. Si vous n'avez pas de savon, vous pouvez utiliser de l'eau simple pour vous laver les mains. Si vous ne vous lavez pas les mains avec du savon ou de l'eau, vous ou les membres de votre famille peuvent avoir la diarrhée. Se laver les mains avec du savon ou de l'eau vous permet ainsi qu'aux autres de rester en bonne santé et vous protège contre les maladies.

2. Demandez aux filles si elles ont des questions, et clarifiez toute fausse information.

\section{$\rightarrow$ Démonstration du lavage des mains (20 minutes)}

Cette activité enseigne aux filles les étapes utiles dans le lavage complet des mains et explique à nouveau l'importance de l'hygiène par le partage de bonnes pratiques avec leurs pairs. Cette activité nécessitera deux (2) seaux - un rempli d'eau propre, et un laissé vide pour recueillir l'eau sale - du savon, un gobelet (pour puiser l'eau), et, si possible, une serviette propre. Déposez à côté du seau, du savon, un gobelet et une serviette.

1. Expliquez aux filles qu'elles vont participer à cette activité comme si elles étaient des élèves du primaire. Demandez aux filles de se rappeler les étapes de l'activité, de rentrer ensuite chez elles et de les enseigner aux personnes plus jeunes avec lesquelles elles vivent.

2. Montrez les étapes du lavage correct des mains aux filles, en utilisant les étapes suivantes :

I. Demandez à une des filles de se porter volontaire et de venir devant.

II. Demandez à cette fille de prendre un gobelet d'eau propre dans le seau et de la verser sur vos mains sur le seau «d'eau sale». Dites à la volontaire de placer le gobelet sur un plateau propre ou dans le seau d'«eau propre» (plutôt que sur le sol) afin de garder le gobelet propre. 
III. Savonnez vos mains et frottez vos mains pendant 10-15 secondes, en comptant à haute voix et en veillant à nettoyer entre les doigts et sous les ongles.

IV. Ensuite, maintenez vos mains sur le seau d'«eau sale», et demandez à la volontaire de remplir le gobelet avec de l'eau propre et de la verser sur vos mains, tout en répétant cette action jusqu'à ce que tout le savon soit totalement rincé. La volontaire dépose encore le gobelet sur le plateau ou dans le seau d'ueau propre».

V. Demandez aux filles de changer de rôles et de répéter l'exercice.

VI. Après que les mains des deux filles aient été rincées, dites-leur de se débarrasser de l'excès d'eau et de sécher leurs mains avec une serviette propre. Si une serviette propre n'est pas disponible, dites aux filles de laisser leurs mains à l'air libre jusqu'à ce qu'elles séchent. Vous pouvez expliquer que c'est important d'attendre que leurs mains sèchent avant de toucher quoi que ce soit, car les mains mouillées vont ramasser plus de microbes.

3. Expliquez aux filles que c'est maintenant à leur tour de s'exercer au lavage des mains.

4. Demandez aux filles de former des pairs (groupes de deux), et choisissez un premier pair de filles pour venir devant.

5. Dites au reste des filles de s'asseoir à côté de leur partenaire et de regarder chaque pair faire la démonstration du lavage des mains. S'il y a un nombre impair de filles, vous (le mentor) pouvez travailler avec la fille supplémentaire. Permettez à chaque personne du pair d'aider l'autre à laver ses mains en suivant les étapes ci-dessous.

I. Le pair vient devant et se tient en face du seau.

II. La Fille 1 prend un gobelet d'eau propre dans le seau et la verse sur les mains de la Fille 2, sur le seau d'«eau sale». Dites à la Fille 1 de placer le gobelet sur un plateau propre ou dans le seau d'ueau propre» (plutôt que sur le sol) afin de garder le gobelet propre.

III. La Fille 2 savonne ses mains et les frotte pendant 10-15 secondes, en nettoyant entre les doigts et sous les ongles.

IV. La Fille 2 tient ses mains au dessus du seau d'«eau sale», et la Fille 1 remplit le gobelet avec de l'eau propre et la verse sur les mains de la Fille 2 jusqu'à ce que tout le savon soit totalement rincé. Elle redépose ensuite le gobelet sur le plateau ou dans le seau d'«eau propre».

V. Demandez aux filles de changer de rôles et de répéter l'exercice.

VI. Après que les mains des deux filles aient été rincées, dites-leur de se débarrasser de l'excès d'eau et de sécher leurs mains avec une serviette propre. Si une serviette propre n'est pas disponible, dites aux filles de laisser leurs mains à l'air libre jusqu'à ce qu'elles séchent. Vous pouvez expliquer que c'est important d'attendre que leurs mains sèchent avant de toucher quoi que ce soit, car les mains mouillées vont ramasser plus de microbes.

Continuer avec les étapes I - VI jusqu'à ce que toutes les filles aient terminé l'activité. Si le temps est court, les mentors peuvent également utiliser deux filles pour faire l'activité pour montrer l'exemple à l'ensemble du groupe et demandez aux autres filles de s'exercer à la maison.

\section{$\rightarrow$ Comprendre l'hygiène dentaire (10 minutes)}

1. Expliquez la definition de l'hygiène dentaire 
"Comme l'hygiène corporelle, I'hygiène dentaire est un ensemble de mesures destinées à prevenir les infections, les caries, le gengivite, et la mauvaise haleine. Cela signifie préserver sa bouche, ses dents, et ses gencives propres et en bonne santé."

2. Demandez aux filles si elles savent ce que c'est la carie dentaire, et qu'est ce qui cause la carie dentaire. Si elles n'en savent pas, donnez l'explication suivante.

"Les caries dentaires sont des petits trous dans les dents qui grandissent de jour en jour. Nos dents ont une surface dure (émaille) qui protège nos dents contre la pourriture. Donc, si vous ne brossez pas vos dents après le repas, les germes et les bactéries de la nourriture et de votre salive se collent sur vos dents, et peuvent causer la carie dentaire et la pourriture des dents. Si la carie dentaire grandit, elle est douloureuse. Si quelqu'un se plein de douleur aux dents, c'est probablement parce qu'il a des caries dentaires. La nourriture trop sucrée cause plus la carie dentaire. "

3. Demandez aux filles si elles ont des idées sur comment éviter les caries dentaires. Ecrivez leurs idées sur le flipchart. Si elles oublient de citer les points suivants, veuillez les compléter.

- Brosser les dents regulièrement (au moins deux fois par jour, et surtout après chaque repas)

- Utiliser des buchettes ou un morceau de fil pour enlever les morceaux de nourriture qui restent entre les dents. Faites attention pour ne pas blesser les gencives.

- Eviter de manger trop de nourriture sucrée.

\section{$\rightarrow$ Pourquoi le brossage des dents est important? (10 minutes)}

1. Demandez aux filles pourquoi elles trouvent que l'hygiène dentaire est importante. Pourquoi les dents sont importantes ? Pour les adultes? Pour les enfants? Laissez les filles discuter pendant cinq minutes. Lorsqu'elles finissent de donner leurs idées, expliquez pourquoi il est important de se brosser les dents.

L'hygiène dentaire est autant importante que l'hygiène corporelle. La bouche et les dents sont des parties importantes de notre corps, et elles sont nécessaires pour manger, parler clairement, et avoir une belle dentition. Nos dents sont faites pour durer toute notre vie, alors nous devons y prendre soin pour éviter qu'elles pourrissent ou soient malades.

Il est très important de brosser les dents après chaque repas, car l'hygiène dentaire peut prévenir les caries dentaires et la gengivite pour les adultes et les enfants. Le gengivite et les caries dentaires causent la pourriture des dents, ce qui peut être très douloureux et causer la chute des dents.

II n'y a pas un âge indiqué pour commencer à se brosser les dents. C'est autant important pour les enfants que pour les adultes, donc les mamans doivent aider les enfants à commencer à brosser leurs dents dès que leurs dents poussent.

2. Demandez aux filles si elles ont des questions, et clarifiez toute fausse information.

\section{Démonstration du brossage des dents (20 minutes)}


Cette activité enseigne aux filles les étapes utiles dans le brossage complet des dents. Vous aurez besoin d'eau propre, de petits gobelets pour chaque fille (vous pouvez utiliser les verres jetables), et un autre sceau pour les eaux sales. Vous devriez distribuer aux filles une brosse à dents et un tube de pâte dentifrice.

1. Expliquez aux filles que maintenant qu'elles ont appris à laver les mains proprement, nous allons apprendre comment se brosser les dents.

2. Demandez à une volontaire de venir devant le groupe et montrer comment se brosser les dents. Demandez aux autres filles du groupe de bien regarder et de faire des observations quand la fille termine de se brosser.

3. Notez les idées des autres filles sur le flipchart. Après, donnez l'information correct de comment il faut se brosser les dents. Utilisez l'image et les instructions d'appui pour expliquer.

- Il est recommendé de brosser toutes les parties des dents : dehors, à l'intérieur, et sur les dents, et dent par dent.

- Il est recommendé aussi de brosser la langue, car il y a beaucoup de bacteries.

- Le brossage doit durer deux minutes pour pouvoir nettoyer bien chaque dent.

- Eviter d'avaler la pâte dentifrice et bien se rinçer les dents avec de l'eau potable.

4. Invitez les filles à faire l'exercice. Pour se faire, divisez le groupe en deux et demander au premier groupe de venir devant pour pratiquer le brossage. Pendant ce temps, les autres filles chantent pour encourager le groupe. Le mentor doit chronométrer les deux minutes. Quand les deux minutes sont terminées, le mentor doit faire arrêter la chanson et inviter les filles à se rinçer la bouche.

5. Répétez l'exercice avec le deuxième groupe.

6. Dites aux filles de garder leurs brosses à dents et la pâte dentifrice et de se rappeler pour se brosser les dents au moins deux fois par jour (matin et soir), surtout après chaque repas.

\section{TRAVAIL DE MAISON}

- Demandez aux filles si elles ont du savon, de l'eau et des serviettes propres à la maison.

- Si elles n'en ont pas, leur demander s'il serait possible pour elles de les obtenir.

- Demandez-leur d'enseigner à d'autres enfants à la maison, comment se laver les mains, avant la prochaine session. 


\section{Session 19: Les maladies}

\section{Objectifs de la session:}

À la fin de cette session, les filles seront capables de:

- Identifier les symptômes des maladies suivantes (tuberculose, Fièvre typhoïde, choléra, paludisme, hépatite $B$ )

- Décrire les modes de transmission/causes de ces maladies

- Décrire les conduites à tenir lorsque ces maladies sont suspectées chez une personne.

\section{Matériel nécessaire:}

- Papier Flip-chart ou tableau

- Marqueurs ou craies

\section{Plan de la session:}

- Identification des maladies et leurs symptômes (15 minutes)

- Identification des symptômes des maladies (tuberculose, fièvre typhoïde, choléra, paludisme, hépatite $\mathrm{B})$ (30 minutes)

- Description des modes de transmission/causes de ces maladies (45 minutes)

Durée totale: 90 minutes

AVANT LA SESSION : Lire attentivement la note d'information pour comprendre très bien les cinq (5) maladies. Également il faudrait examiner la façon dont vous allez instruire les filles sur chacune des cinq maladies (voir le début de section «Instructions»).

\section{NOTES D'INFORMATION}

\section{La tuberculose}

La tuberculose est une maladie causée par un germe qui attaque surtout les poumons d'une personne. La tuberculose se transmet d'une personne malade à une autre personne réceptive, essentiellement par voie aérienne au travers :

- des gouttelettes de salive ou de crachats émises lorsqu'une personne malade tousse ou éternue ;

- des germes libres contenus dans l'air ambiant ou dans la poussière par exemple.

La contamination dépend de la quantité des germes à laquelle la personne est exposée et de la durée d'exposition.

Ainsi, la promiscuité d'exposition sous un même toit peu aéré et peu éclairé pendant un laps de temps et de façon répétée représente un risque important de contamination. Cette maladie est suspectée lorsque les constats suivants sont observés chez un individu :

- Une toux qui dure plus de deux (02) semaines

- Des sueurs nocturnes qui durent plus de deux (02) semaines 
- Une perte de poids d'au moins trois (03) kg pendant les quatre (04) dernières semaines

- Une fièvre qui dure plus de deux (02) semaines

- Et surtout lorsque la personne a eu un contact direct avec un tuberculeux

La tuberculose est de plus en plus répandue au Burkina Faso avec la pandémie du sida. C'est une maladie qui est grave car elle se propage rapidement et elle est mortelle. Dès que vous constatez ces comportements chez une personne, conduisez-la immédiatement dans un centre de santé pour le diagnostic et la prise en charge médicale. Il existe des médicaments éfficaces pour soigner cette maladie et le traitement est gratuit au Burkina Faso. Vous pouvez aussi vous faire vacciner régulièrement pour prévenir la maladie.

\section{Le choléra}

Le choléra est une infection diarrhéique aiguë provoquée par la consommation d'aliments ou d'eau contaminés par le bacille Vibrio cholerae. Le choléra est une maladie extrêmement virulente, dont on peut mourir en quelques heures en l'absence de traitement. Les causes de la maladie sont liées au manque d'hygiène (alimentaire et corporelle : en mangeant par exemple avec les mains sales). La contamination se fait par voie orale, à travers les matières fécales, l'eau de boisson ou des aliments souillés. Le choléra se manifeste par des vomissements, une diarrhée abondante, indolore pouvant aboutir rapidement à une déshydratation sévère et à la mort du malade, si le traitement n'est pas administré rapidement. Tout le monde peut avoir cette maladie : les enfants, les jeunes, les hommes et les femmes adultes. Au Burkina Faso, les cas de choléra sont fréquents pendant la période hivernale.

Des remèdes efficaces existent pour soigner cette maladie mais cela exige que le malade consulte un agent de santé très tôt. Il existe également des vaccins pour prévenir la maladie. Dans certains pays, le vaccin est même obligatoire. Mais retenez que la prévention du choléra consiste essentiellement en des mesures d'hygiène.

Sur le plan personnel, il convient de se laver soigneusement les mains et d'éviter la serviette collective. Il faut nettoyer et désinfecter tout ce qui a été au contact avec de la matière fécale.

Sur le plan alimentaire, il convient d'utiliser une eau saine pour l'hygiène, la boisson et le lavage des aliments.

En ce qui concerne les mesures collectives, il faut éliminer les mouches et organiser l'élimination des selles faites parfois dans la nature.

\section{Le paludisme}

Le paludisme est une maladie infectieuse due à un parasite, propagé par la piqûre de moustiques. Une personne ne peut contracter le paludisme que par une piqûre de moustique infecté ou par une transfusion sanguine d'une personne infectée. Le paludisme peut aussi être transmis de la mère au fœtus pendant la grossesse. C'est pour cette raison que les agents de santé recommandent aux femmes enceintes de faire le traitement préventif du paludisme pendant la grossesse pour éviter de contaminer leur nouveau-né. Le paludisme est une maladie grave. Elle est très répandue au Burkina Faso surtout pendant la période hivernale à cause des nombreux moustiques. 
Les symptômes du paludisme apparaissent généralement 12 à 14 jours après l'infection. Les personnes qui souffrent du paludisme présentent les symptômes ci-après :

- une douleur abdominale ;

- des frissons et des sueurs ;

- une diarrhée, des nausées et des vomissements;

- des maux de tête ;

- des poussées de forte fièvre ;

- une pression artérielle basse causant des étourdissements lors du passage à la position couchée ou assise à la position debout ;

- des douleurs musculaires ;

- une diminution de l'appétit.

Le paludisme est une maladie guérissable. Lorsque les traitements sont effectués de manière appropriée et lorsque la maladie est prise en charge rapidement, la guérison est possible. Sachant que le paludisme est transmis par les piqûres de moustiques, on peut le prévenir en limitant les possibilités de se faire piquer par ces bestioles :

- Porter, dès la tombée de la nuit, des vêtements qui protègent tout le corps, y compris les bras et les jambes. Les vêtements doivent être enduits d'insecticides.

- Utiliser une moustiquaire imprégnée de répulsif pour dormir, toutes les nuits

- Utiliser des répulsifs pour la peau et les vêtements (que vous trouverez en pharmacie) entre le coucher du soleil et l'aube.

- Pulvériser les maisons avec de l'insecticide anti-moustique

\section{La fièvre typhoïde}

La fièvre typhoïde est une maladie infectieuse. La contamination se fait par l'ingestion de boissons ou aliments souillés par les selles d'une personne infectée. Le malade est prostré (prostration, torpeur, délire) et a des signes digestifs intenses (diarrhées par exemple). Comme pour le choléra et le paludisme, le manque d'hygiène est la principale cause de cette maladie (hygiène alimentaire et environnementale surtout). Pour ce faire, la prévention passe par l'amélioration des conditions d'hygiène dans les pays endémiques et par la vaccination. Au Burkina Faso, la maladie est courante pendant la période hivernale à cause de la pluie qui peut propager l'eau contaminée à travers des inondations et de le manque d'hygiène environnementale.

La maladie se soigne et l'individu qui souffre de ce mal peut retrouver la guérison s'il est pris en charge médicalement très tôt. Pour ce faire, il est recommandé de se rendre immédiatement dans un centre de santé en cas de soupçon de cette maladie.

\section{L'hepatite B}


L'hépatite $B$ est une hépatite virale due à une infection par le virus de l'hépatite $B$ et entrainant une inflammation du foie de l'individu. La gravité potentielle de l'hépatite B est constituée par le risque d'évolution vers une hépatite chronique $B$ qui peut se compliquer en une cirrhose du foie et un cancer du foie.

La transmission du virus se fait par l'intermédiaire des liquides et sécrétions biologiques. Les principaux modes de transmission sont les rapports sexuels, les injections chez les toxicomanes, les transfusions sanguines à risques, la transmission de la mère à l'enfant lors de l'accouchement et le contact étroit avec une personne infectée.

Dans plusieurs des cas, l'hepatite B n'a pas des symptômes, donc la prévention est particulierment importante. Lorsqu'il y a des symptômes qui se manifestent, cela peut inclure

- la jaunisse (les yeux deviennent jaunes),

- la fatigue,

- la fièvre,

- la diarrhée, des nausées et des vomissements

- la douleur de l'abdomen au côté droit (l'endroit du foie)

C'est une maladie mortelle qui se soigne difficilement à travers la chimiothérapie dont le taux de réponse est très faible actuellement. Cette maladie est très courante en Afrique de façon générale et particulièrement au Burkina Faso. La seule manière de confirmer l'infection c'est d'aller chez le medecin pour faire un examen de sang. On peut prévenir l'hépatite $B$ en se faisant vacciner et en adoptant des comportements à moindre risque, comme utiliser un preservatif à tous les rapports sexuels; de ne pas partager de raisoir, d'aiguille, ou autre objet souillé par le sang; et de faire l'examen pendant la grossesse. Au Burkina Faso, vous pouvez trouver le vaccin contre cette maladie dans les services d'hygiène, les pharmacies, certains centres de santé, et certaines cliniques.

\section{INSTRUCTIONS}

\section{$\rightarrow$ Identification des maladies et leurs symptômes (15 minutes)}

1. Diviser les filles en cinq groupes.

2. Donnez le nom d'une des cinq maladies à chaque groupe. Demander aux filles de citer tout qu'elles connaissent sur la maladie et d'expliquer ce qui cause la maladie, les symptômes, et le traitement, s'il existe. Donnez aux filles cinq minutes pour discuter entre elles.

3. Demandez à une volontaire de chaque groupe de partager les connaissances du groupe. Corrigez tout malentendu et ajoutez des informations. Ce n'est pas necessaire de lire toute l'information en haut aux filles, car ça peut être trop technique pour elles, mais vous devriez partager les informations clés.

\section{- Identification des symptômes des maladies (tuberculose, fièvre typhoïde, choléra, paludisme, hépatite B) (30 minutes)}

Cette session sera abordée essentiellement sous forme de jeu de rôle. 
1. Diviser le groupe en deux équipes et demander à chaque équipe d'identifier un nom pour leur équipe (« Equipe $X$ » et « Equipe $Y$ » par exemple).

2. Organiser une compétition/jeu de questions- réponses. Chaque bonne réponse à une question vaut un point.

3. Inviter les deux équipes à mener une compétition en répondant aux questions que vous aller poser et qu'à la fin du jeu, l'équipe gagnante sera celle qui enregistrera le plus de bonnes réponses.

4. Ecrire en grand caractère sur le côté droit du flip-chart le nom choisi par la première équipe et sur le côté gauche celui de la deuxième équipe.

5. Poser les questions ci-dessous et inviter à chaque fois chacune des équipes à donner sa réponse.

- Qu'est-ce que c'est que la tuberculose ?

- Quels sont au moins deux signes de la tuberculose ?

- Qu'est-ce que c'est que la fièvre typhoïde ?

- Quels sont au moins deux signes de la fièvre typhoïde?

- Qu'est-ce que c'est que le choléra?

- Quels sont au moins deux signes du choléra?

- Qu'est-ce que c'est que le paludisme?

- Quels sont au moins deux signes du paludisme?

- Qu'est-ce que c'est que l'hépatite B?

- Quels sont au moins deux signes de l'hépatite B?

6. Enregistrer toutes les réponses de chaque équipe (qu'elles soient vraies ou fausses) dans l'espace qui lui est réservé sur le flip-chart.

7. Faire la synthèse en donnant les bonnes réponses et compléter les réponses s'il en existe d'autres (utiliser un marqueur de couleur différente pour les réponses ajoutées).

8. Attribution des points aux bonnes réponses données par chacune des équipes et faire la sommation des notes obtenues pour déterminer l'équipe gagnante.

9. Féliciter l'équipe gagnante et encourager celle qui a enregistré moins de points.

\section{Description les modes de transmission/causes et prevention de ces maladies (45 minutes)}

1. Maintenir les deux équipes.

2. Adopter la même démarche. 
3. Poser les questions suivantes et noter toutes les réponses données par chaque équipe :

- Comment se transmet la tuberculose ?

- Est-ce que la tuberculose se soigne ?

- Comment prévenir la transmission de la tuberculose ?

- Que faire si on découvre qu'on souffre de la tuberculose ?

- Est-ce qu'il y a un vaccin pour prévenir la tuberculose?

- Comment se transmet la fièvre typhoïde ?

- Est-ce que la fièvre typhoïde se soigne ?

- Comment prévenir la fièvre typhoïde?

- Que faire si on découvre qu'on souffre de la fièvre typhoïde ?

- Est-ce qu'il y a un vaccin pour prévenir la fièvre typhoïde ?

- Comment se transmet le choléra?

- Est-ce que le choléra est contagieux ?

- Est-ce que le choléra se soigne?

- Quel sont au moins deux choses que vous pouvez faire pour vous proteger du choléra?

- Que faire si on soupçonne qu'on souffre du choléra?

- Comment se transmet le paludisme?

- Est-ce que le paludisme est contagieux?

- Est-ce que le paludisme se soigne?

- Comment prévenir le paludisme?

- Le paludisme est plus courant pendant quelle saison?

- Que faire si on découvre qu'on souffre du paludisme?

- Comment se transmet l'hépatite B?

- Est-ce que l'hépatite B est contagieuse ?

- Est-ce que l'hépatite B se soigne ?

- Quel sont au moins deux choses que vous pouvez faire pour vous proteger de l'hépatite B?

- Est-ce qu'une personne infectée par l'hépatite B présente forcement des symptômes ?

4. Enregistrer toutes les réponses de chaque équipe (qu'elles soient vraies ou fausses) dans l'espace qui lui est réservé sur le flip-chart.

5. Faire la synthèse en donnant les bonnes réponses et compléter les réponses s'il en existe d'autres (utiliser un marqueur de couleur différente pour les réponses ajoutées)

6. Attribution des points aux bonnes réponses données par chacune des équipes et faire la sommation des notes obtenues pour déterminer l'équipe gagnante.

7. Répondre aux questions et conclure en faisant ressortir les similitudes de ces maladies :

- Ces maladies sont causées par le manque d'hygiène pour la plupart du temps. 
- On peut prévenir ces maladies soit à travers les vaccins ou en adoptant un mode de comportements sains.

- Dès qu'on manifeste ces symptômes, il faut se rendre le plus vite possible au centre de santé.

- Il faut eviter de faire l'auto-médication car cela est dangereux pour l'individu. II est recommendé de consulter un spécialiste (médecin ou pharmacien) avant de prendre un médicament.

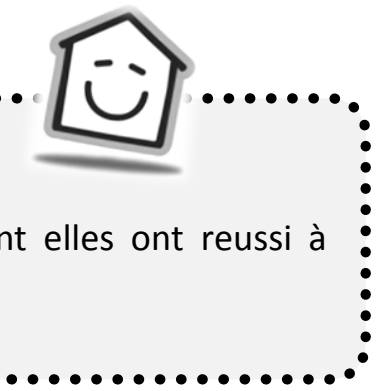

Demandez aux filles de vérifier avant la prochaine session combien d'argent elles ont reussi à épargner.

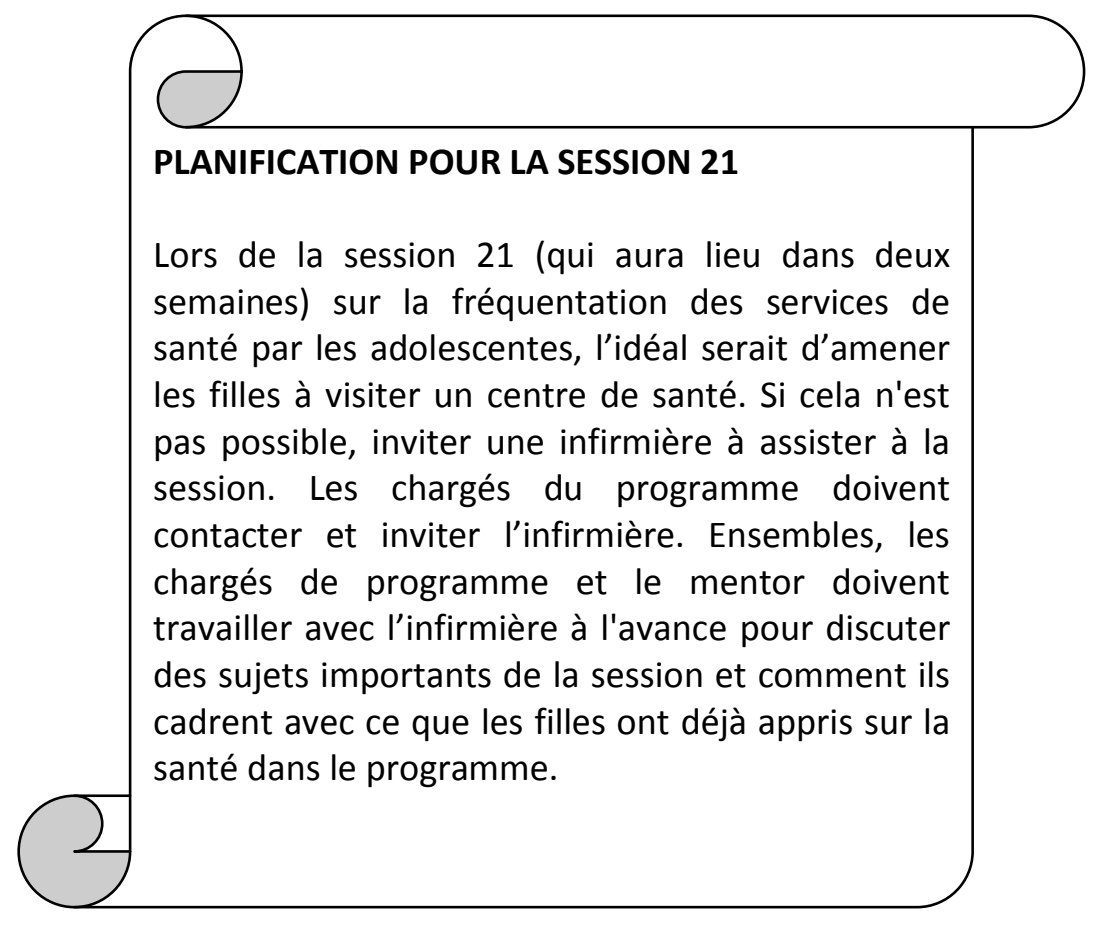




\section{Objectifs de la session:}

À la fin de cette session, les filles seront capables de:

- Déterminer l'importance de la vaccination surtout chez les femmes enceintes et les enfants

- Identifier les vaccins les plus importants chez l'individu vivant au

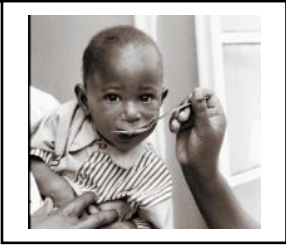
Burkina Faso

- Identifier les endroits où peux-t-on se faire vacciner

\section{Matériel nécessaire:}

- Outil de suivi de l'epargne

- Papier Flip-chart ou tableau

- Morceaux de papier collant (Post-its)

- Marqueurs

\section{Plan de la session:}

- Suivi des plans d'epargne (10 minutes)

- L'importance de la vaccination (30 minutes)

- Identifier les vaccins les plus importants chez un individu vivant au Burkina Faso (30 minutes)

- Où est-ce qu'on peut se faire vacciner (20 minutes)

Durée totale: 90 minutes

\section{NOTES D'INFORMATION}

\section{L'importance de la vaccination}

La vaccination protège les enfants contre quelques-unes des maladies infantiles les plus meurtrières. Tous les enfants sans exception, y compris les enfants handicapés, doivent être vaccinés. Un enfant est immunisé par des vaccins qui sont injectés ou administrés par voie buccale. Les vaccins ont pour but de renforcer les défenses de l'enfant contre la maladie. Le vaccin est efficace seulement s'il est administré avant que la maladie ne frappe.

La vaccination offre une protection contre plusieurs maladies dangereuses. Un enfant qui n'est pas vacciné risque davantage de tomber malade, d'être handicapé à vie, de souffrir de malnutrition et de mourir. Un enfant qui n'est pas vacciné risque d'attraper la rougeole, la coqueluche et d'autres maladies meurtrières. Les enfants qui survivent sont affaiblis, ils risquent de ne pas grandir comme il faut ou d'être handicapés à vie. Ils risquent aussi de mourir plus tard de malnutrition et d'autres maladies.

Tous les enfants doivent être vaccinés contre la rougeole, qui est l'une des principales causes de malnutrition, de retard du développement mental, ainsi que de troubles de l'ouïe et de la vue. Tous les enfants, partout, doivent être vaccinés contre la polio.

Depuis la naissance jusqu'à la fin de la vie sur terre, le corps de l'être humain a besoin de vaccins pour se protéger contre certaines agressions extérieures telles que les infections ou les maladies. Pour cela, des vaccins sont administrés au nouveau-né dès les premiers jours de sa naissance. Cette protection commence 
même déjà dans le ventre de la mère. C'est pour cette raison qu'il est recommandé aux jeunes filles et aux femmes en âge de procréer de se faire vacciner contre le tétanos. Si elles respectent la prise des doses de vaccin nécessaires, elles seront protégées pendant toute leur vie. Leurs enfants seront également protégés pendant quelques semaines après la naissance.

\section{Les vaccins les plus importants chez un individu vivant au Burkina Faso}

Le Burkina Faso est un pays sahélien en voie de développement. La situation sanitaire du pays est caractérisée par des taux de mortalité générale et spécifique également élevés. Cette mortalité est due, entre autres, aux maladies transmissibles que sont le paludisme, les maladies cibles du PEV (Programme Elargi de Vaccination), la malnutrition, les maladies diarrhéiques, les infections respiratoires aiguës. La mortalité des jeunes de 15 à 40 ans est due essentiellement au SIDA. A cela s'ajoute de nombreuses incapacités liées à l'accouchement dont les fistules.

Face à cette situation, certains types de vaccins sont recommandés chez l'individu vivant au Burkina Faso. On peut citer entre autres les vaccins contre la rougeole, la tuberculose, la poliomyélite, la méningite, le tétanos, la coqueluche, la pneumonie, I'hépatite $B$, la fièvre typhoïde, le cancer du col de l'utérus, et le choléra.

Pour chaque vaccination, il y'a un calendrier à respecter pour l'efficacité du vaccin. Les agents de santé peuvent vous donner des informations sur ce domaine. Dès que vous vous faites vacciner, l'agent de santé mentionnera sur votre carnet de vaccination ou sur votre carnet de santé la date à la laquelle le vaccin a été administré, le type de vaccin administré, la date du prochain rappel. Ce document doit être minutieusement conservé par devers vous à tout moment car c'est le témoin que vous avez été vacciné et les agents de santé peuvent $s^{\prime} y$ référer pour vous aider à suivre les dates de renouvellement de vos vaccinations. Si vous oubliez de renouveler votre vaccination dans le délai imparti, demander conseil à un agent de santé.

\section{Les endroits où on peut se faire vacciner}

On peut acheter le vaccin en pharmacie et aller se faire vacciner dans un centre de santé comme on peut aller directement dans les endroits où on fait la vaccination car certains vaccins peuvent être disponibles. Ces endroits sont entre autres :

- Dans les services d'hygiène

- Dans les centres de santé et de promotion sociale (CSPS)

- Dans les dispensaires

- Dans les hôpitaux

- Les centres de santé

- Les cliniques privées

- Auprès de certaines associations

- Avec les équipes mobiles lors des campagnes de vaccination 


\section{INSTRUCTIONS}

Suivi des plans d'épargne (10 minutes)

1. Expliquez aux filles qu'il y a 8 semaines de cela, chaque fille avait fait un plan d'épargne et que maintenant nous allons voir les progrès individuels de vos plans.

2. Demandez aux filles une à une de dire combien elles ont reussi à épargner, et où est-ce que chacune garde son argent (chez elles, dans une caisse populaire, par l'employeur, etc). Notez sur votre outil de suivi la situation de chaque fille. Est-ce que quelqu'une a changé son but? Si oui, le mentor doit noter le nouveau but et plan dans l'outil de suivi.

3. Demandez aux filles de partager avec le groupe leurs défis à épargner. Encouragez les autres filles à donner des idées et suggestions. Si une fille se gène de parler de ses défis au groupe, le mentor doit l'encourager de lui en partager après la session.

\section{$\rightarrow$ Définition de la vaccination et l'importance de se faire vacciner (30 minutes)}

1. Poser les questions, une à une, et noter chaque réponse donnée par les filles sur les morceaux de papier collant (Post-its):

\section{Questions}

- Qu'est-ce que la vaccination ?

- Pourquoi il est important de se faire vacciner ?

- Quelles sont les raisons pour lesquelles on se vaccine ?

- Quelles sont les raisons pour lesquelles certaines personnes ne se vaccinent pas?

- Connaissez-vous des gens qui sont tombés malades parce qu'ils ne se sont pas vaccinés ?Demander aux participantes de donner 3 à 4 exemples.

- Quelles sont les personnes qui sont concernées par les vaccins ? Pourquoi ?

- Est-ce que les adolescentes comme vous avez besoin de se faire vacciner ? Pourquoi ?

2. Diviser le papier flip-chart en deux parties. Ecrire en grand caractère sur le côté droit du flip-chart «REPONSE VRAIE» et sur le côté gauche «REPONSE FAUSSE»

3. Expliquer aux participantes que parmi les réponses qu'elles ont donné, certaines sont vraies et d'autres fausses, et que pour cela vous allez leur donner une dernière chance de se rattraper.

4. Relire un à un les morceaux de papier (les Post-its) et inviter les filles à dire si la réponse est vraie ou fausse.

5. Demander à une participante de vous aider à coller les feuilles sur le flip-chart.

6. Facilitez la discussion de ces résultats.

7. Corriger l'exercice fait par les filles en déplaçant les fiches incorrectes à leur bonne place puis complétez la liste des réponses s'il en existe d'autres et faire la synthèse. 


\section{$\rightarrow$ Identifier les vaccins les plus importants chez un individu vivant au Burkina Faso (30 minutes)}

1. Diviser le groupe en deux équipes (Equipe A et Equipe B)

2. Inviter les deux équipes à mener une compétition en répondant aux questions que vous aller poser et qu'à la fin du jeu, l'équipe gagnante sera celle qui enregistrera le plus de bonnes réponses.

3. Ecrire en grand caractère sur le côté gauche du flip-chart « EQUIPE A » et sur le côté droit «EQUIPE B ».

4. Poser les questions ci-dessous et inviter à chaque fois chacune des équipes à donner sa réponse.

5. Enregistrer les réponses de chaque équipe dans l'espace qui leur est réservée sur le flip-chart.

6. Faire la synthèse en donnant les bonnes réponses.

7. Comptabiliser et annoncer la note obtenue par chacune des équipes

8. Féliciter l'équipe gagnante et encourager celle qui a enregistré moins de points.

\section{Questions}

- Quels sont les types de vaccinations que vous connaissez ?

- A quel moment (âge) doit-on commencer à se faire vacciner ?

- Quels sont les différents vaccins nécessaires qu'un individu doit faire au cours de sa vie?

- Pourquoi il est important de respecter le calendrier des vaccinations?

- Que faire si vous oubliez de faire un vaccin ?

- Par quel moyen peut-on savoir si quelqu'un est vacciné ?

\section{$\partial$ Où est-ce qu'on peut se faire vacciner (20 minutes)}

1. Maintenir les deux équipes.

2. Procéder de la même que dans le jeu précédent.

3. Poser les questions ci-dessous et inviter à chaque fois chacune des équipes à donner sa réponse:

\section{Questions}

- Où est-ce qu'on peut se faire vacciner dans votre localité?

- Choisissez une fille pour expliquer au groupe comment on peut arriver au dispensaire qui offre les vaccinations.

- Est-ce qu'il est facile de se faire vacciner dans votre quartier? Pourquoi ou pourquoi pas ?

- Quelles sont les raisons pour lesquelles les gens se vaccinent?

- Pourquoi certaines personnes ne se font pas vacciner?

4. Ecrire en grand caractère sur le côté droit du flip-chart « EQUIPE A » et sur le côté gauche «EQUIPE B ». 
5. Enregistrer les réponses de chaque équipe dans l'espace qui leur est réservée sur le flip-chart.

6. Corriger l'exercice en déplaçant les fiches incorrectes à leur bonne place puis complétez la liste des réponses s'il en existe d'autres et faire la synthèse.

7. Comptabiliser et annoncer la note obtenue par chacune des équipes.

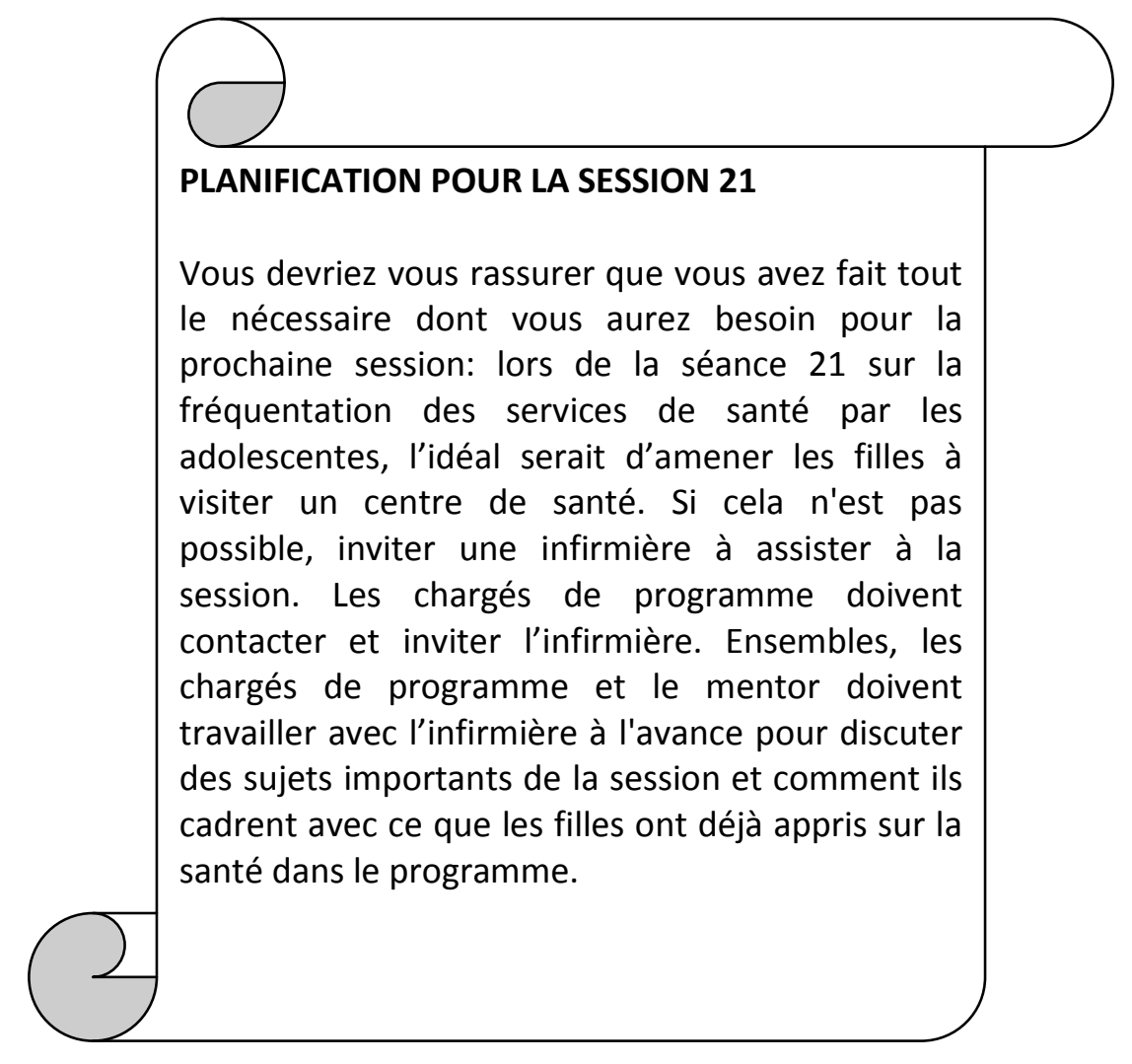




\section{Session 21: La fréquentation des services de santé par les adolescentes}

\section{Objectifs de la session:}

À la fin de cette session, les filles seront capables de:

- Expliquer l'importance de fréquenter les centres de santé

- Identifier les services offerts par les centres de santé surtout en direction des adolescentes

\section{Matériel nécessaire:}

- Papier Flip-chart ou tableau

- Marqueurs ou craies

\section{Plan de la session:}

- Partage des idées sur les types de centres de santé souvent visités par les employées de maison (5 minutes)

- Jeu de rôle sur l'importance de fréquenter les centres de santé (30 minutes)

- Exposé sur les services de santé offerts par les centres de santé (30 minutes)

- Questions-réponses sur l'exposé (15 minutes)

Durée Totale: 80 minutes

AVANT LA SESSION : Rencontrer l'infirmière et partager avec elle ce que le groupe a appris jusqu'à présent sur la santé et ce qu'ils vont apprendre dans les prochaines semaines. Planifier avec elle, comment rendre la session interactive et informative sur les services disponibles.

\section{NOTES D'INFORMATION}

A défaut de pouvoir déplacer les filles dans un centre de santé pour la session, l'associationinvitera une infirmière pour la circonstance. Le contact entre l'infirmière et les filles est très important dans cette session. De préférence, l'écart d'âge entre les filles et l'infirmière ne doit pas être très énorme dans le souci de favoriser une discussion franche et sans gène au cours de la session. La session sera co-dirigée par le mentor et l'infirmière. La session sera abordée sous forme de jeux de rôles menés par les participantes sous l'orientation du mentor suivi d'un exposé sur la fréquentation des centres de santé par les adolescentes qui sera fait par l'infirmière.

Le mentor et l'infirmière doivent se concerter avant sur le déroulement de la session. L'intervention de l'infirmière doit porter sur les points suivants : les types de centres de santé qui existent au Burkina, les services offerts en fonction des types de centres de santé, l'intérêt pour les adolescentes de fréquenter les centres de santé.

Le mentor doit identifier les candidates intéressées aux jeux de rôle auparavant et donner les instructions afin de permettre aux groupes de bien se préparer avant le jour de la session. 


\section{INSTRUCTIONS}

Partage des idées sur les types de centres de santé souvent visités par les employées de maison (5 minutes)

1. Diviser les filles en groupes.

2. Demander aux filles de partager leurs idées sur les types de centres de santé souvent visités par les employées de maison. Demandez-leur de citer les raisons pour lesquelles certaines employées de maison ne fréquentent pas les centres de santé.

\section{$\rightarrow$ Jeu de rôle sur l'importance de fréquenter les centres de santé (30 minutes)}

1. Installer les participantes en forme de $U$, puis l'infirmière et le mentor au bout, de sorte à ce que chacune puisse percevoir tout le groupe.

2. Introduire la session du jour: Expliquer aux participantes que la session d'aujourd'hui est assez particulière car vous avez l'honneur de recevoir une infirmière qui va s'entretenir avec elles sur les services offerts par les centres de santé, en direction des adolescentes surtout.

3. Demander à l'infirmière de se présenter

4. Demander ensuite aux filles de se mettre débout à tour de rôle pour se présenter (Nom et prénom, secteur d'où elle vient).

5. Demandez à 2 participantes de faire un jeu de rôle, l'une se nommera Awa et l'autre Bibata. Vous êtes des amies de longue date mais cela fait plus de 10 ans que les deux amies ne se sont pas vue parce qu'elles ne vivaient pas dans la même ville. Pendant la conversation, Awa découvre que Bibata n'est pas en bonne santé et refuse de se rendre dans un centre de santé. Alors Awa va essayer de développer des arguments pour convaincre son amie Bibata de se rendre dans un centre de santé pour se faire soigner.

6. Demander aux autres filles de suivre attentivement et de relever les raisons avancées par Awa pour expliquer la nécessité d'aller au centre de santé.

7. A la fin du jeu de rôle, demander aux autres participantes de lister les raisons avancées par Awa pour convaincre Bibata.

8. Noter les sur le papier fip-chart puis ensuite discuter la pertinence de ces raisons

\section{Exposé sur les services de santé offerts par les centres de santé (30 minutes)}

1. Introduire le sujet de l'exposé.

2. Donner la parole à l'infirmière pour son exposé. 
3. Demander aux participantes d'écouter attentivement.

\section{$\supset$ Questions-réponses sur l'exposé (15 minutes)}

1. Donner la parole aux participantes qui ont des questions à poser à l'infirmière.

2. Conclure la session et remercier l'infirmière pour son exposé.

TRAVAIL DE MAISON

A la fin de la session, le mentor demande à chacune des participantes de se rendre dans un centre de santé et de revenir rendre compte à la prochaine session. 


\section{Module 4}

\section{Santé de la Réproduction}

Session 22: La période d'adolescence et les systèmes reproductifs des hommes et des femmes

Session 23: Les règles et la reproduction

Session 24: La planification familiale, la grossesse, et l'avortement

Session 25: Gestion de la grossesse et accouchement, fistule obstetricale et excision

Session 26: Les IST, le VIH/SIDA, et le dépistage du VIH

Session 27: Le cancer du sein et du col de l'utérus

Session 28: Information et communication sur la sexualité et sur la santé de la reproduction

Session 29: Genre et les dynamiques de pouvoir

Session 30: Le harcelement sexuel, la violence de genre et sexuelle, l'abus

Termes Clés dans ce Module : abus, accouchement, avortement, blennorragie, canaux vaginaux, cancer, cancer du col de l'utérus, chancre mou, changement émotionnel, changement psychologique, changements sociaux, Chlamydia, clitoris, contraception d'urgence, coton hygénique, cycle menstruel, cycle mensuel, dépistage SIDA, diaphragme, excision, faire des cicatrices, fecondation, fistule obstétricale, genre, gestion de la grossesse, grossesse, harcèlement sexuel, herpès, hymen, identité, implant, infection sexuellement transmissible, injectable, menstruation, ovaire, ovule, pénis, période de l'adolescence et les règles, petites lèvres, pilule, planification familiale, pouvoir et impuissance, preservatif feminin, preservatif masculin, prophylaxie poste-exposition, puberté, règles, repercutions de la violence sexuelle, reproduction, réseaux sociaux, santé de la reproduction, scrotum, sexe, sexualité, spermatozoïdes, sperme, spermicide, stérilet, syphilis, systèmes reproductifs des femmes, systèmes reproductifs des hommes, tampon, testicule, trichomonas, trompes, urêtre, utérus, vagin, VIH/SIDA, violence de genre et sexuelle. 


\section{Session 22: La période d'adolescence et les systèmes reproductifs des hommes et des femmes}

Objectifs de la session:

À la fin de cette session, les filles seront capables de:

- Comprendre les changements physiques qui s'opèrent chez les garçons et les filles au cours de la puberté

- Comprendre les changements émotionnels qui ont lieu pendant la puberté

- Énumérez les principaux organes des systèmes reproductifs des hommes et la fonction de chaque organe

- Expliquez le processus de production de sperme et d'éjaculation

- Énumérez les principaux organes des systèmes reproductifs des femmes et la fonction de chaque organe

Matériel nécessaire:

- Flipchart

- Marqueurs

- Copies en grand format d'images des appareils sexuels et reproductifs

- Copie en grand format des images du corps de l'homme et de la femme

Plan de la session:

- Comprendre les Changements Physiques qui se Produisent Pendant la Puberté (20 minutes)

- Comprendre les Changements Émotionnels et Sociaux qui se Produisent Pendant la Puberté (25 minutes)

- Connaître les systèmes sexuels et reproductifs des femmes (30 minutes)

- Connaître les systèmes sexuels et reproductifs des hommes (15 minutes)

Durée totale: 90 minutes

\section{NOTES D'INFORMATION}

Quels sont les systèmes sexuels et reproductifs? Les systèmes sexuels et reproductifs partagent certains organes, mais pas la totalité des organes. Le système sexuel comprend les organes impliqués dans l'activité sexuelle et le plaisir. Chez les femmes, le système reproductif est constitué de ceux impliqués dans la grossesse et l'accouchement. Chez les hommes, le système reproductif comprend les organes qui produisent, stockent ou transportent les spermatozoïdes pour la reproduction.

Il peut s'agir d'une discussion désagréable, mais si vous prétendez que vous êtes médecin et ne partagez que des informations, il devrait être facile de discuter. Rappelez-vous que vous n'avez pas besoin de lire toutes ces informations. Assurez-vous d'encourager toutes les questions.

Description et fonction des organes de l'appareil sexuel et génital féminin (les termes suivis d'un chiffre entre parenthèse sont liés aux images de la page 129.)

La vulve inclut tous les organes génitaux externes visibles de la femme (voir l'illustration ci-dessous). 
Le clitoris $\left(n^{\circ} 1\right)$ est un petit organe en forme de bourgeon recouvert de tissu en forme de petit " capuchon ". Le rôle principal du clitoris est le plaisir sexuel de la fille ou de la femme. Le clitoris s'étire pour faciliter l'accouchement.

Les petites lèvres $\left(n^{\circ} 2\right)$ gonflent lors de l'excitation sexuelle.

Les grandes lèvres $\left(n^{\circ} 3\right)$ couvrent et protègent l'orifice vaginal.

Le vagin $\left(n^{\circ} 4\right)$ est un canal élastique menant de la vulve au col et à l'utérus. Le vagin d'une femme sexuellement excitée se mouille. Lors de rapports sexuels vaginaux, le pénis pénètre dans le vagin. Si l'homme éjacule, le sperme entre dans le vagin et remonte, jusqu'à l'utérus Le flux menstruel (le sang) quitte le corps à travers le vagin, de même que l'enfant au moment de l'accouchement. Le vagin s'auto-nettoie. II n'est pas nécessaire de le doucher et il ne faut pas y introduire de substances pour le dessécher ou le resserrer (elles peuvent être néfastes).

L'hymen (non illustré) est une fine membrane qui obstrue partiellement l'orifice vaginal. Cette membrane se déchire lorsque la femme a des rapports sexuels la premiere fois et le sang coule. Cependant, l'hymen peut se déchirer aisément lors de la pratique de sports ou d'autres activités physiques et peut se détendre si la fille utilise des tampons. Un hymen déchiré ou détendu n'indique donc pas si la fille ou la femme a eu des rapports sexuels.

Le col de l'utérus ( $n^{\circ} 5$ ) est un muscle qui separe le vagin de l'uterus.Lors de l'accouchement, le col de l'uterus se dilate pour laisser passer l'enfant.

L'utérus $\left(n^{\circ} 6\right) c^{\prime}$ est l'organ dans lequel le foetus grandit.

Les trompes de Fallope $\left(n^{\circ} 7\right)$ sont deux tubes qui transportent les ovules des ovaires vers l'uterus.

Les ovaires $\left(n^{\circ} 8\right)$ sont deux petits organes qui contiennent tous des ovules. Ils libèrent un ovule chaque mois, qui traverse les trompes de Fallope vers l'uterus.

Description et fonction des organes de l'appareil sexuel et génital des hommes (les termes suivis d'un chiffre entre parenthèse sont liés aux images de la page 130.)

* Le pénis $\left(n^{\circ} 1\right)$ remplit plusieurs fonctions. Il participe à la sensation sexuelle, correspondant en ce sens au clitoris de la femme. Le pénis peut se remplir de sang, durcir et se mettre en érection en réponse à la stimulation sexuelle. La fonction reproductrice du pénis consiste à déposer le sperme dans le vagin. Sa troisième fonction est la sécrétion d'urine. L'extrémité du pénis est recouverte d'une couche de peau appelée "prépuce ». La circoncision, ablation du prépuce, est pratiquée dans de nombreuses populations.

* Les testicules $\left(n^{\circ} 2\right)$, deux glandes en forme de boules continues dans le scrotum, produisent les spermatozoïdes.

* Le scrotum $\left(n^{\circ} 3\right)$, ou les bourses, poches de peau lâche, contient et protège les testicules. Le scrotum et les testicules sont sensibles au toucher et peuvent être source de plaisir. 
* L'urètre $\left(n^{\circ} 4\right)$ est un tube qui s'étend de la vessie à la pointe du pénis. II s'agit du conduit par lequel le sperme est propulsé lors de l'éjaculation. L'urine s'écoule aussi par ce conduit mais au même moment.

\section{INSTRUCTIONS}

\section{Comprendre les changements physiques qui se produisent pendant la puberté (20 minutes)}

1. Expliquez aux jeunes filles les changements qui s'opèrent pendant la puberté.

"Pendant l'adolescence, une personne devient sexuellement mature, ce qui signifie que le corps passe par des changements pour s'apprêter à reproduire. Tous les jeunes traversent une période de changements à la puberté et à l'adolescence : les uns de nature physique, les autres dans la manière dont ils sont traités. La puberté débute entre 9 et 16 ans. II se peut que vous grandissiez et que vous vous développiez plus rapidement que vos amis, ou plus lentement. C'est parce que vous avez votre propre horloge interne. C'est ce qui fait de vous un individu. Ces différences sont normales. Votre niveau de croissance dépend de l'hérédité, de l'environnement, de votre sexe - elle se poursuivra jusqu'à ce que vous ayez entre 18 et 22 ans. Discutons de ces questions à présent.»

\section{Divisez le groupe en 2 petits groupes.}

3. Le Groupe 1 réfléchira aux changements physiques qui s'opèrent chez les garçons; le Groupe 2 aux changements physiques au niveau des filles. Si les groupes sont bavards, leur accorder 10 minutes pour cette activité. Si les filles semblent gênées ou ne parlent pas, vous pouvez rapidement mettre fin à cette activité et passer à l'étape 4.

4. Rassemblez les deux groupes pour reformer le grand groupe.

5. Demandez à un leader/représentant du Groupe 1 de partager les idées du groupe sur les changements physiques chez les garçons. Pendant que le représentant du groupe parle, matérialisez la réponse sur l'image de l'homme. Par exemple, lorsqu'il dit que l'homme pousse une barbe, faites un dessin d'une barbe sur le menton pour indiquer cela. $S^{\prime}$ il s'agit de réponse abstrait, telle que " la voix de l'homme change ", faites une flèche au niveau du coup pour matérialiser cela.

6. Demandez à un leader/représentant du Groupe 2 de partager les idées du groupe sur les changements physiques chez les filles. Pendant que le représentant du groupe parle, matérialisez la réponse sur l'image de la femme. Les réponses peuvent être incomplètes ou indirectes. Après que le leader du groupe ait fini de parler, encouragez d'autres filles de l'autre groupe à mentionner d'autres idées. Vous pouvez utiliser les listes ci-dessous pour des idées.
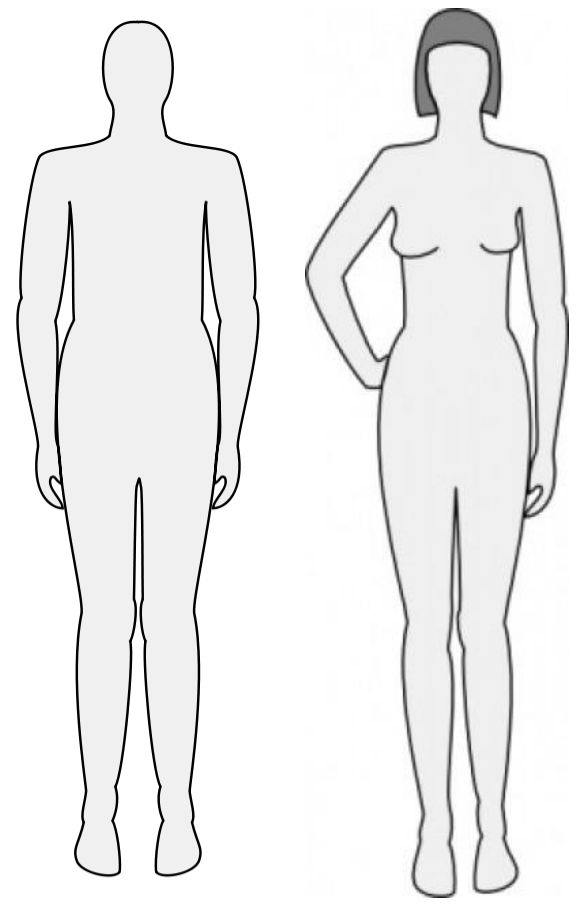
Changements physiques: Les changements physiques qui surviennent au cours de l'adolescence sont le résultat de changements hormonaux dans le corps.

- Filles et garçons: Poussée de croissance (c'est à dire que vous devenez plus grand en un temps très court) - besoin de plus de nourriture; toutes les dents permanentes sont là; la peau du visage peut devenir plus grasse et des boutons peuvent se former; les poils des aisselles augmentent et la sueur change, entraînant une odeur corporelle d'adulte; les poils pubiens apparaissent, augmentent progressivement, prennent un aspect grossier et frisé

- Filles uniquement: Les seins se développent (parfois d'un seul côté d'abord; le développement complet prend environ deux ans); les hanches s'élargissent; le tour de taille se rétrécit; les organes génitaux externes se développent; à l'intérieur, l'utérus et les ovaires se développent; l'ovulation se produit; la menstruation commence (habituellement environ deux à trois ans après le commence de développement des seins)

- Garçons uniquement: Les épaules s'élargissent; les muscles se développent; le larynx s'agrandit (de sorte que la voix devient grave); la pilosité faciale apparaît; les poils de la poitrine apparaissent; le pénis et les testicules se développent; la production de sperme commence; l'éjaculation a lieu (parfois la nuit quand ils dorment)

\section{$\rightarrow$ Comprendre les changements émotionnels et sociaux qui se produisent pendant la puberté (25 minutes)}

1. Expliquez qu'en plus de changements physiques, les adolescents passent également par des changements personnels dans leur façon de se sentir et des changements dans la façon dont les membres de la communauté peuvent les traiter.

2. Sur un flipchart, écrivez "Changements psychologiques" sur un côté et "Changements affectant la manière dont les gens vous traitent ».

3. Demandez aux filles de réfléchir sur les changements psychologiques et les changements affectant la manière dont les gens les traitent. Au fur et à mesure que les filles mentionnent un changement, écrivez-le dans la colonne "Changements emotionnels " ou celle des "Changements affectant la manière dont les gens vous traitent ». Assurez-vous de lier cette conversation à l'activité Pression des Pairs de la module sur les Compétences de Vie Courante (Session 9). Les changements suivants peuvent être mentionnés:

\section{Les changements psychologiques}

- L'identité - Les jeunes s'interrogent: «Qui suis-je?». Ils développent de plus en plus de relations amicales en dehors de la sphère familiale. Le groupe de pairs devient plus important que la famille. On note une urgence à devenir indépendant face aux parents.

- Le futur - Souvent, le jeune n'a aucune idée de ce que le futur lui réserve. L'adolescent n'a aucune idée de ce qu'il fera la semaine prochaine, encore moins pour le reste de sa vie. 
- La pression - Le groupe de pairs détermine souvent les règles concernant l'habillement, les comportements, le langage. Les comportements diffèrent souvent de ceux des parents, ce qui peut générer des conflits.

- La confusion - Le préadolescent oscille parfois entre le désir d'être un adolescent indépendant et un enfant dépendant. Son corps se développe et ressemble de plus en plus à celui d'un jeune adulte, mais il n'est pas nécessairement prêt émotionnellement à passer au stade de l'adolescence.

- La période des décisions difficiles - En plus de vivre tous les changements inhérents à la puberté, le préadolescent peut aussi être amené à prendre certaines décisions difficiles telles que les choix de cours ou de carrière, inviter un/une partenaire à une danse à l'école.

- Changements d'humeur - Des taux hormonaux fluctuants, les changements physiologiques, une perception de soi en évolution ainsi que le stress inhérent à cette période de la vie peuvent entraîner des changements d'humeur imprévus. Ce phénomène exige beaucoup de compréhension de la part de l'entourage.

- Conscience accrue d'eux-mêmes - Les jeunes filles se développent habituellement plus tôt que les garçons. Elles peuvent être embarrassées par les transformations de leurs seins ou par leurs menstruations. Les adolescents des deux sexes peuvent avoir tendance à cacher leur corps. Les jeunes se développent à des rythmes différents. Les jeunes filles ont des poussées de croissance plus tôt, ce qui peut entraîner un certain malaise lorsqu'elles se retrouvent avec des garçons plus petits. Toutefois, ces différences s'atténuent vers la fin de l'adolescence.

- Le désir sexuel - Émergence de nouvelles sensations sexuelles. Intérêt plus marqué pour la sexualité. Les préadolescents fantasment davantage sur des personnes plus âgées du sexe opposé - vedettes du cinéma, chanteur rock, instituteur, frère ou sœur d'un ami. Les parents peuvent découvrir des magazines érotiques dans la chambre de leur fils, début de nombreux amours de jeunesse; il est important de les différencier du véritable amour. Le préadolescent développe sa façon d'aborder le sexe opposé ce qui entraîne souvent malaise et gêne en sa présence.

Des changements affectant la manière dont les gens les traitent: L'acceptation et l'approbation des amis et pairs peuvent devenir très importantes pour un adolescent. Les adolescents peuvent modifier leur comportement pour s'assurer d'être acceptés par le groupe, devenir rebelles, ou faire preuve d'un désir, d'une plus grande indépendance vis-à-vis des parents et des autorités. Entre autres changements figurent:

- Plus ou moins de liberté à fréquenter l'espace public (rues, parcs, centres communautaires ou commerciaux)

- Plus de responsabilités domestiques (tâches ménagères ou soins des enfants)

- Plus grande responsabilité pour gagner de l'argent

- Plus de pression à se vêtir de manière à se couvrir ou découvrir davantage le corps

- Plus d'interaction sociale entre les garçons et les filles ou moins d'interaction sociale

- Rites de passage avec pratiques nuisibles (telles que la mutilation génitale des filles) 
- Rites de passage sans pratiques nuisibles

- Pression sociale pour acquérir une expérience sexuelle

- Pression sociale pour se préparer au mariage

- Pression sociale pour commencer à procréer

- Meilleures occasions de leadership à l'école et dans la communauté

- Pression sociale pour des performances sportives

- Risque accru de devoir quitter l'école si la famille en décide ainsi

- Exposition au harcèlement sexuel

- Pression pour se conformer aux rôles de genre en prenant des risques dangereux

- Pression pour accorder ses faveurs sexuelles en échange de cadeaux, d'argent ou d'argent pour l'école

Rappelez aux jeunes filles que ces changements, en particulier les sentiments émotionnels et sexuels, arrivent à tout le monde.

\section{$\rightarrow$ Connaître les systèmes sexuels et reproductifs des femmes (30 minutes)}

1. Afficher les images de l'anatomie des organes sexuels et reproductifs des femmes (préparé avant le début de la session selon le document ci-dessous). Dites aux filles:

Dans le corps humain, nous avons des organes internes. Chaque organe a un but précis; par exemple, nous poumons nous permettent de respirer, notre cœur fait circuler le sang dans tout le corps, et notre estomac aide à digerer la nourriture. Nous avons aussi des organes qui nous permettent de faire des rapports sexuels, d'avoir du plaisir, de tomber enceinte, et de faire des enfants. Ce sont des organes reproductifs. Les hommes et les femmes ont des organes reproductifs différents. Ces organes développent et changent pendent la période de l'adolescence. Le système reproductif est compliqué, donc, ne soyez pas désolées si vous n'arrivez pas à retenir les détails.

2. Expliquez la fonction de chaque organe en utilisant les informations dans "notes d'information » et les images de l'anatomie des organes sexuels et reproductifs des femmes

\section{$\rightarrow$ Connaître les systèmes sexuels et reproductifs des hommes (15 minutes)}

1. Affichez les images de l'anatomie des organes sexuels et reproductifs des hommes (voir supports ci-dessous) et expliquez la fonction de chaque organe.

2. Expliquez le processus de production de sperme et d'éjaculation

Lorsque le pénis est en érection, un garçon verra qu'il ne lui est pas facile d'uriner. Il faudra attendre jusqu'à ce que l'érection tombe avant de pouvoir uriner. L'éjaculation a lieu lorsque le sperme sort du pénis en érection d'un garçon ou d'un homme à la suite d'une excitation sexuelle. Un homme n'a pas à éjaculer à chaque fois qu'il a une érection. S'il attend, l'érection descendra d'elle-même sans causer de dégâts. 
3. Clarifiez les mythes ou idées fausses que les apprenants pourraient avoir (à savoir que le sperme s'accumule dans le corps, si des rapports sexuels / l'éjaculation n'ont pas lieu, ou que avoir des rapports sexuels peut résoudre le cas des règles douloureuses). Si vous ne connaissez pas certaines réponses, écrivez les questions et demandez un appui au chargé du programme pour les clarifier. Répondez aux questions à la session prochaine. 


\section{Support: Organes de l'appareil sexuel et génital féminin}

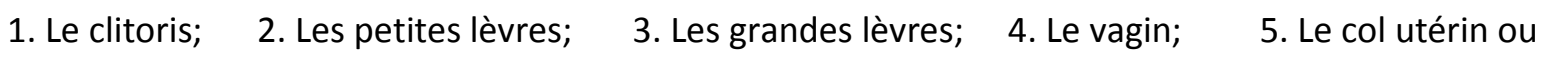
col de l'utérus; 6. L'utérus; $\quad$ 7. Les trompes de Fallope; $\quad$ 8. Les ovaires
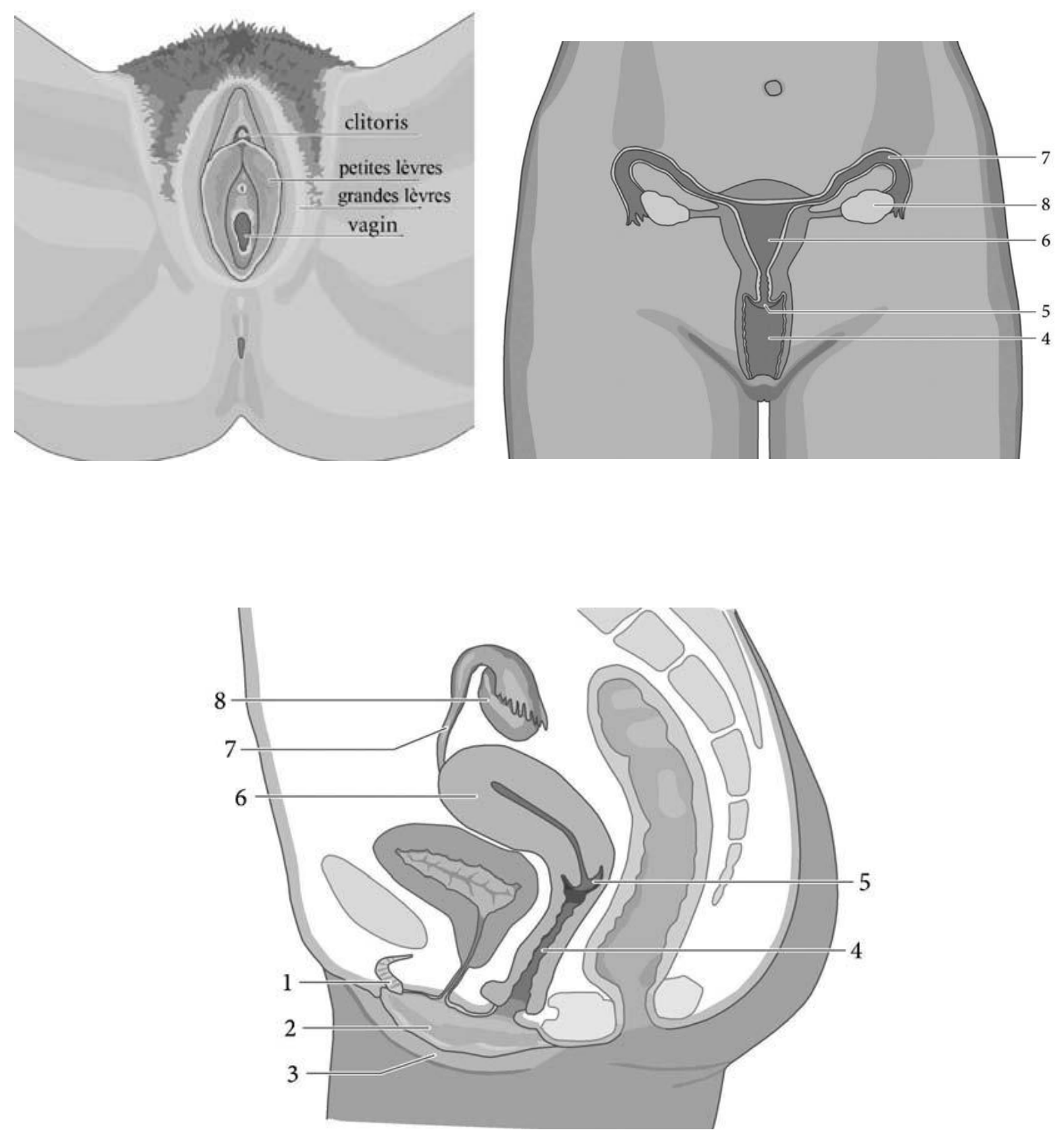


\section{Support: Des organes de l'appareil sexuel et génital masculin}
1. Le pénis;
2. Les testicules;
3. Le scrotum;
4. L'urètre
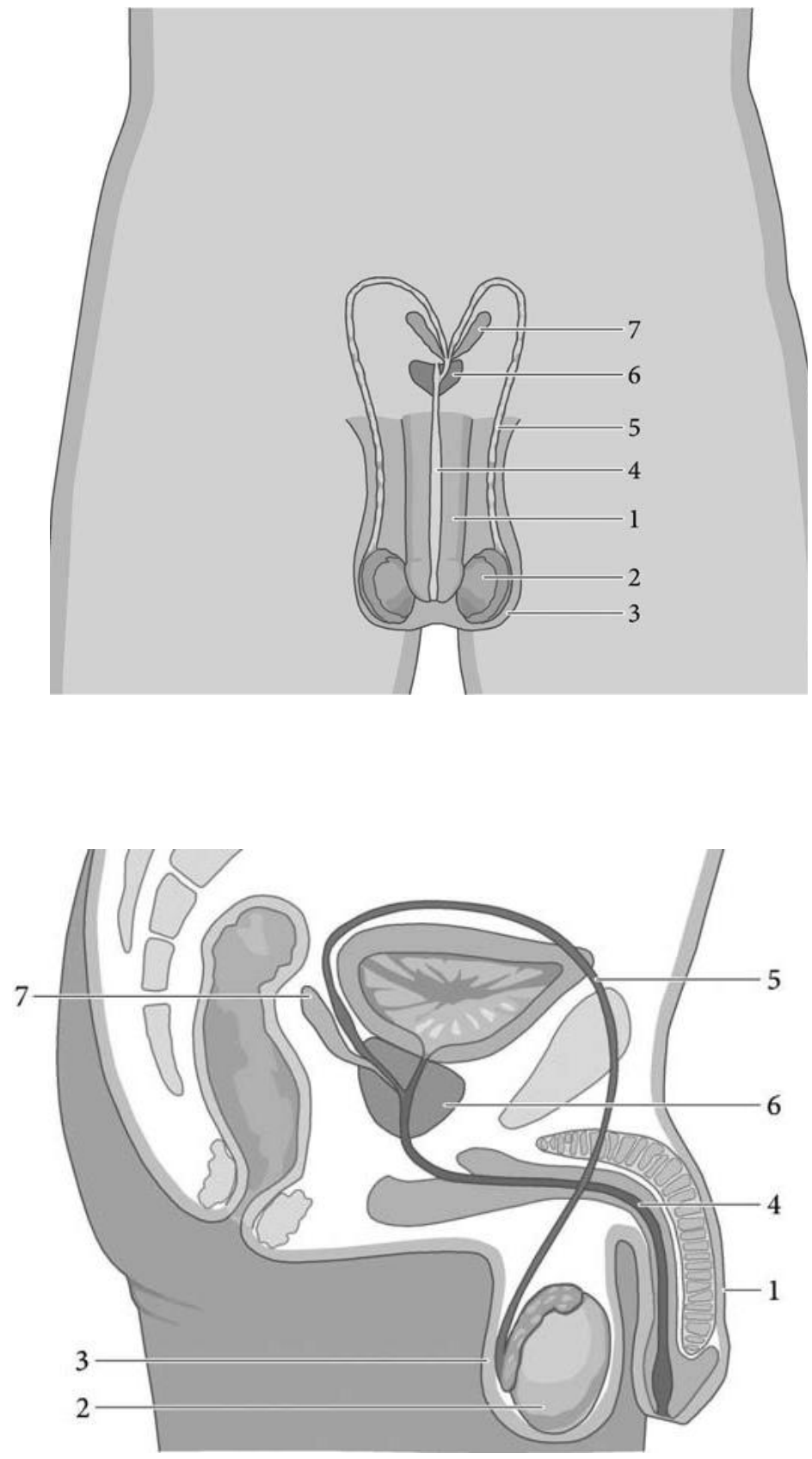


\section{Session 23: Les règles et la reproduction}

\section{Objectifs de la session :}

À la fin de cette session, les filles seront capables de :

- Comprendre le cycle menstruel et les mesures prises pour gérer la menstruation

- Distinguer les mythes et réalités autour de la menstruation

- Comprendre le processus de fécondation

\section{Matériel nécessaire:}

- Flipchart

- Marqueurs

- Matériel utilisés par une femme au cours des menstrues ('morceau de tissus,' coton hygiénique, tampons)

- Copies en grand format des supports :

- les appareils sexuels et reproductifs de la femme

- le cycle menstruel

- les rapports sexuels

- la fécondation et la grossesse

\section{Plan de la session:}

- Discussion sur la menstruation et l'ovulation (30 minutes)

- Mythes et Réalités sur la Menstruation (20 minutes)

- Comment sont conçus les bébés? Comprendre le Sexe et la Fécondation (25 minutes)

- Différences entre les Femmes et les Hommes (15 minutes)

Durée totale: 90 minutes

AVANT LA SESSION : Déposez les matériaux locaux utilisés au cours des menstrues par une femme ('morceau de tissus,' coton hygiénique, tampons) sur une table afin que les filles les regardent. Si vous le souhaitez, vous pouvez aussi dessiner l'image ci-dessous sur un flipchart avant la session pour aider à expliquer la troisième activité (Comprendre le cycle menstruel et les mesures prises pour gérer la menstruation).

\section{NOTES D'INFORMATION}

Les participants peuvent ressentir de la timidité à aborder ces sujets sensibles. Avant que les filles commencent la discussion, il peut être utile de mentionner que tout le monde passe par ces changements à mesure qu'on passe de l'enfance à l'adolescence et à l'âge adulte. Les gens connaissent différents changements physiques, émotionnels et sociaux au fur et à mesure qu'ils passent par ces étapes. Ces changements sont tout à fait normaux. II est également tout à fait normal que les filles n'aient pas encore subi ces changements; chacun fait l'expérience de ces changements à différents moments de sa vie.

\section{Le cycle menstruel}


Le cycle menstruel c'est un processus qui dure en moyenne 28 jours. Pour certaines femmes il dure plus ou moins de 28 jours. Pour certaines femmes le cycle peut ne pas être régulier, spécialement durant la puberté. Nous calculons le cycle menstruel depuis le premier jour des règles. Environ 14 jours après le début du cycle menstruel, un de ses ovaires libère un ovule, qui traverse les trompes de Fallope vers l'utérus. Ceci est appelé ovulation. Les jours avant et environ ce moment (entre 11 et 15 jours après le début des règles) sont des périodes favorables pour une femme de tomber enceinte. Si la femme a des rapports sexuels pendent cette période, ou quelque jours avant ou après, et l'ovule est fécondé par le sperme de l'homme, l'ovule deviendra un fœtus. Si elle n'a pas des rapports sexuels ou si l'ovule n'est pas fécondé, elle ne tombera pas enceinte. Dans ce cas, l'ovule s'éliminera du corps avec le sang menstruel.

C'est possible aussi d'avoir des rapports sexuels et ne pas tomber enceinte. Ceci ne signifie pas nécessairement que la femme ou l'homme n'est pas fertile. Cependant, il est aussi possible de tomber enceinte la première fois qu'une femme a des rapports sexuels avec un homme. C'est aussi possible de tomber enceinte en faisant des rapports sexuels en dehors de la période féconde. Si vous ne voulez pas tomber enceinte, il faut utiliser un contraceptif moderne régulièrement.

- La menstruation est une partie du cycle menstruel. Pendant la menstruation, l'utérus élimine sang et tissu, qui s'écoulent par le vagin. Le premier jour des règles est le premier jour du cycle. Le saignement dure généralement entre quatre et six jours. Pour la plupart des filles, la menstruation commence entre l'âge de 9 et 12 ans, mais peut commencer plus tard. Les premières menstrues d'une fille indiquent qu'elle a des capacités de reproduction; la menstruation indique également qu'une fille ou une femme n'est pas enceinte. Si au cours du mois, une femme ne voit pas ses règles, cela ne signifie pas qu'elle est forcément enceinte.

- Quelques jours avant le début d'une période menstruelle, certaines filles et femmes peuvent avoir un ou plusieurs types de malaises. Certaines filles peuvent avoir des crampes ou douleurs abdominales, de la fatigue, des nausées, les seins douloureux ou sensibles, des changements d'humeur et des envies alimentaires avant et pendant la menstruation. Boire une boisson chaude et frotter le ventre aide à soulager les crampes. Beaucoup de filles et de femmes trouvent que leur inconfort prémenstruel et leurs crampes menstruelles ont tendance à diminuer si elles font des exercices réguliers tout au long du mois.

\section{INSTRUCTIONS}

\section{$\rightarrow$ Discussion sur la menstruation et ovulation (30 minutes)}

1. Demandez aux filles de réfléchir à ce qu'elles savent de la menstruation. Donnez quelques minutes aux filles de partager ce qu'elles connaissaient. Après, expliquez la menstruation aux filles en utilisant le texte suivant :

La menstruation : La menstruation est naturelle et normale pour une fille ou une femme en bonne santé. Les premières règles peuvent marquer un événement heureux, surtout quand la fille sait à quoi s'attendre. Beaucoup vivent malheureusement l'arrivée de leurs premières règles dans l'inquiétude ou la peur parce que personne ne leur en a expliqué le sens ni la 
démarche à suivre. La menstruation fait, cependant partie des manières dont le corps se renouvele et préserve la fertilité.

\section{Expliquez l'ovulation.}

Toutes les femmes naissent avec des millions d'ovules dans les ovaires. Les ovules sont tellement petits qu'ils ne peuvent pas être vus à l'œil nu. Lorsqu'une fille commence sa puberté et ses règles menstruelles, elle commence aussi à ovuler. Ceci signifie que chaque mois un de ses ovaires libère un ovule, qui traverse les trompes de Fallope vers l'utérus. Ceci est appelé ovulation, et ça se passe environ 14 jours après le commencement des règles. Les jours avant et environ ce moment (entre 11 et 15 jours après le début des règles) sont des périodes plus favorables pour une femme de tomber enceinte. Cependant, c'est possible aussi de tomber enceinte en dehors de cette période féconde. Si elle ne tombe pas enceinte, son corps va libérer du sang qui va sortir du vagin. Ce sang est appelé règles menstruelles et cela est normal. On parlera plus sur la menstruation et l'ovulation la semaine prochaine.

3. Expliquez le cycle menstruel et la menstruation à partir des notes d'information. Utilisez l'anatomie féminine de la semaine dernière et répondez aux questions des filles.

4. Déposez sur une table les matériaux utilisés au cours de la période menstruelle d'une femme ('morceau de tissus,' coton hygiénique, tampons ou d'autres produits facilement disponibles et utilisés dans votre communauté.)

5. Demandez aux filles de réfléchir à la manière de gérer les problèmes potentiels concernant la gestion des menstrues en posant les questions suivantes:

- Pourquoi utiliser ces produits?

- Comment fonctionnent-ils?

- Combien de fois doivent-ils être changés?

- Comment s'en débarrasser ou les nettoyer?

- Où sont-ils vendus et combien coûtent-ils?

Coton hygiénique: Ils sont coupés pour s'adapter à la zone du slip en cousant plusieurs bandes de coton les unes sur les autres. Ceux-ci doivent être propres. Le coton hygiénique est à usage unique et ne doit pas être lavé.

Morceau de tissus: La femme/fille peut utiliser un paquet épais de papier hygiénique ou un morceau de pagne. Parfois, le papier hygiénique est trop rugueux, et peut irriter la peau. II peut aussi ne pas être suffisant pour absorber la quantité de sang. Le morceau de pagne doit être soigneusement lavé après usage et accroché dans un endroit privé mais ensoleillé pour sécher; C'est un matériel personnel et ne doit pas être partagé.

Tampons: Un tampon est une petite masse de coton (ou autre matière absorbante) de forme souvent semblable à celle d'un doigt, qui s'insère confortablement dans le vagin pour absorber le flux menstruel. Le tampon doit être remplacé au moins trois fois par jour. Laisser un tampon en 
place pendant plus d'un jour peut provoquer une infection grave et parfois mortelle. (L'insertion de tout objet impur dans le vagin peut causer une infection grave.)

\section{LE CYCLE MENSTRUEL}

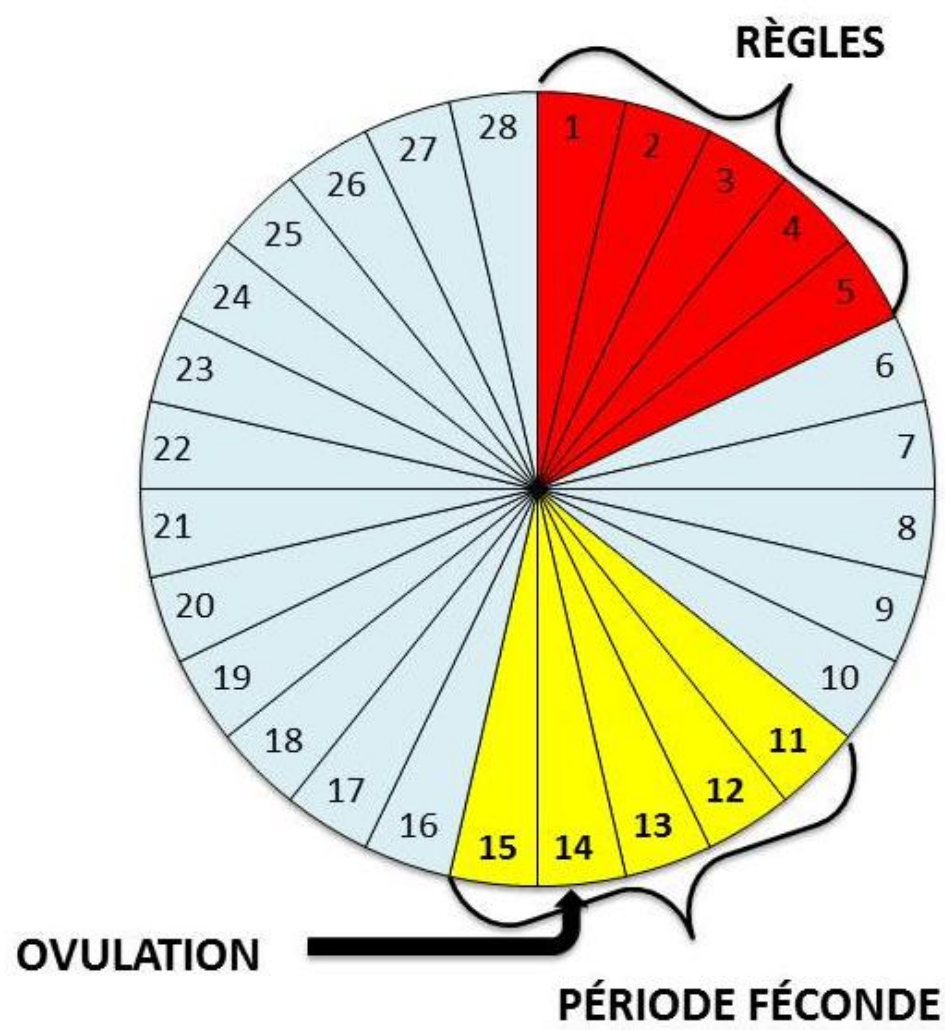

5. Expliquez l'importance de l'hygiène pendant les menstruations

"Le bain est important et il convient de laver la vulve à l'eau pour en éliminer les résidus de sang. Lorsque vous avez vos menstrues, votre corps est plus sensible aux maladies et aux infections, car le sang et les produits utilisés pour gérer le flux sanguin augmentent les chances pour les bactéries d'entrer dans votre vagin et de causer des problèmes comme les infections. Vous devriez nettoyer votre corps au moins deux fois par jour, surtout quand vous avez vos menstrues. Les médecins conseillent de n'utiliser que de l'eau pour nettoyer les zones privées, sans savon, parce que la peau est sensible et le savon peut l'irriter. "

- Les habits, papier hygiénique, serviettes ou tampons doivent être changés fréquemment (trois fois ou plus par jour en fonction du flux sanguin), chaque fois qu'ils sont partiellement ou totalement saturés. Les serviettes réutilisables doivent être soigneusement nettoyées et lavées avec du savon et de l'eau et bien séchées avant leur réutilisation.

- Si vos dessous ou vêtements se retrouvent tachés de sang, vous devriez les faire tremper dans de l'eau fraîche et légèrement salée. L'eau chaude permettra au sang de s'incruster et de rester comme une tache permanente. 
6. Encouragez les filles à poser toutes les questions qu'elles pourraient avoir et clarifiez tout malentendu. Si vous ne connaissez pas certaines réponses, écrivez les questions et demandez un appui au chargé du programme pour les clarifier. Répondez aux questions à la session prochaine.

\section{$\rightarrow$ Mythes et réalités sur la menstruation (15 minutes)}

1. Expliquez-leur qu'elles s'exerceront à un jeu pour aider à dissiper les mythes sur la menstruation. Demandez-leur si elles se rappellent de ce qu'est un mythe, et rappelez-leur qu'il s'agit d'une fausse déclaration, par opposition à une réalité. Alors les filles, "qui peut expliquer ce que c'est qu'un mythe?» Si les filles ont du mal à le décrire, vous pouvez expliquer ce que cela signifie.

2. Divisez les participants en deux groupes et demandez-leur de choisir des noms à leurs équipes. Écrivez les noms des équipes sur le flipchart.

3. Vous pourrez lire les déclarations ci-dessous une à une, en alternance entre les équipes et leur demander de déterminer s'il s'agit de réalités ou de mythes. Si elles répondent correctement, faites leur développer leurs idées. Si la réponse est incorrecte, expliquez pourquoi la réponse est fausse.

\section{Déclarations}

1. Quand une femme a ses menstrues, le sang qui sort signifie qu'elle est malade (mythe)

2. Si une femme n'a pas ses menstrues, cela signifie qu'elle est enceinte (mythe : elle peut avoir un cycle irrégulier, ou elle peut ne pas voir ses règles à cause du type de contraception qu'elle utilise)

3. Toutes les femmes ont leurs premières menstrues avant l'âge de 13 ans (mythe: certaines filles les auront avant ou après l'âge de 13 ans)

4. La période menstruelle d'une femme a habituellement lieu tous les 28 jours (réalité)

5. Les crampes menstruelles pendant une période indiquent que quelque chose va très mal (mythe)

6. La plupart des femmes trouvent que les malaises sont minimes et ne les empêchent pas de mener les activités régulières qu'elles aiment (réalité)

7. Les femmes qui ont leurs menstrues doivent rester au lit, ou éviter toute activité physique intense (mythe)

8. Les exercices peuvent aider à atténuer les symptômes; ils n'empireront pas la douleur (réalité)

9. Les femmes ne sont pas plus faibles au cours de leurs périodes menstruelles, sauf si elles ont une anémie, qui est causée par une perte anormale de sang pendant la menstruation. (réalité)

10. Pendant les premiers mois après qu'une fille ait eu ses menstrues, il est normal qu'elle ait un cycle irrégulier (réalité)

11. Il est normal que la période des menstrues d'une femme dure 1 à 6 jours (réalité)

12. Beaucoup de filles et femmes n'ont pas de problème lors de leurs menstruations. (réalité)

13. Les femmes qui ont leurs menstrues peuvent prendre facilement froid et doivent éviter l'eau froide ou les boissons glacées. (mythe) 
14. Les femmes sont toujours de mauvaise humeur et irrationnelles pendant la menstruation (mythe)

15. Avoir des rapports sexuels peut être un remède pour les règles douloureuses. (mythe)

4. Pour chaque bonne réponse, attribuez un point à cette équipe. Si elles sont en mesure de fournir plus d'informations, donnez à l'équipe, un autre point. Encouragez la discussion après chaque déclaration.

5. Passez de manière alternée d'une équipe à l'autre jusqu'à ce que toutes les déclarations aient été lues, en suivant les points inscrits sur le flipchart. L'équipe qui a le plus de points à la fin, est «le vainqueur».

\section{$\rightarrow$ Comment sont conçus les bébés? Comprendre le sexe et la fécondation (25 minutes)}

1. Réfléchir sur ce que les filles savent des rapports sexuels. De quoi s'agit-il?

2. Définir les rapports sexuels. Utilisez l'image sur les rapports sexuels pour aider à expliquer.

Rapports sexuels: le plus souvent, c'est quand le pénis pénètre dans le vagin et que l'homme éjacule son sperme. On utilise différentes expressions pour désigner les rapports sexuels, notamment « faire l'amour ". (Ces termes sont parfois utilisés aussi pour d'autres comportements sexuels.)

3. Demandez aux filles, "Connaissez-vous d'autres termes utilisés pour les rapports sexuels?» Demandez aux filles de répondre.

4. Vous devriez partager avec les filles le fait que chacun a le droit de dire non aux rapports sexuels. Au nombre des raisons pouvant être avancées pour refuser de s'engager dans les rapports sexuels, figurent: le fait de ne pas être prêt, les raisons religieuses, la volonté d'attendre jusqu'au mariage, ou le bon gars etc. Chacune a le droit de refuser les rapports sexuels sans se justifier, même si elle a déjà eu des rapports sexuels avec cette personne. Personne n'a le droit d'obliger une autre personne à avoir des rapports sexuels. Afin de sentir à l'aise maintenant, il est important que l'individu s'affirme, ait une bonne compréhension de ses valeurs et soit à même de lutter contre la pression des pairs.

5. Expliquez que la fécondation est la première étape de la grossesse:

Pour qu'une grossesse viable se produise, les conditions suivantes doivent être remplies :

- La femme doit être proche de la période de l'ovulation, plus ou moins deux semaines (11 15 jours) après le début de ses règles (mais c'est possible de tomber enceinte en dehors de cette période).

- L’homme doit avoir une érection et éjaculer dans le vagin de la femme ou à son entrée $\left(n^{\circ} 1\right)$.

- Le spermatozoïde de l'homme doit entrer en contact avec l'ovule de la femme ( $\left.n^{\circ} 2\right)$.

- Ensuite, si l'ovule est fécondé, il peut commencer à grandir et devient un fœutus dans l'utérus de la femme $\left(n^{\circ} 3\right)$. 
$\rightarrow$ Différences entre les femmes et les hommes (15 minutes)

1. Introduisez le jeu en disant: "Maintenant que vous savez comment les organes des filles fonctionnent différemment de ceux des garçons, passons à un jeu pour examiner ce dont nous avons discuté.»

2. Faites asseoir tout le monde dans un grand cercle. Puis bandez les yeux d'un volontaire et faites la se tenir debout au milieu du cercle.

3. Demandez aux autres filles dans le cercle de choisir une chanson courte pour chanter (la chanson ne devrait pas durer plus de 30 - 60 secondes). Pendant que les filles dans le cercle chantent, le volontaire dont les yeux ont été bandés, tourne lentement avec 1 bras tendu vers le cercle. Quand la chanson s'arrête, quel que soit la personne pointée par le volontaire, elle doit répondre à une question de révision.

4. Si la fille ne sait pas la réponse ou donne une réponse incorrecte, quelqu'un d'autre dans le groupe peut donner une réponse. Une fois la réponse correcte donnée, la fille qui a répondu correctement remplace la fille au milieu du cercle. Le jeu continue jusqu'à ce qu'il y ait eu des réponses correctes à toutes les questions de révision.

5. Terminez la session en demandant si les filles ont des questions et clarifiez toute fausse idée qu'elles peuvent avoir. Si vous ne connaissez pas certaines réponses, écrivez les questions et demandez un appui au chargé du programme pour les clarifier. Répondez aux questions à la session prochaine. 


\section{Questions de révision}

1. Comment appelle-t-on l'action où le pénis de l'homme pénètre dans le vagin d'une femme? [Les rapports sexuels]

2. Comment appelle-t-on les sacs qui stockent les ovules dans le corps de la femme? [Les ovaires]

3. De quelle partie du corps masculin sort le sperme? [Le pénis]

4. Quelle partie du corps féminin est située entre le vagin et l'utérus? [Le col de l'utérus]

5. Quel type de rapports sexuels peut entraîner une grossesse? [le sexe vaginal]

6. Comment appelle- $t$-on la période du mois où une femme perd du sang? [Menstruation]

7. Comment appelle-t-on le processus où un ovule est libéré de l'ovaire d'une femme et entre dans les trompes de Fallope? [Ovulation]

8. De quelle partie du corps féminin sortent les saignements mensuels? [Le vagin]

9. Si une femme a ses règles, est-ce qu'elle est enceinte? [non]

10. Qu'est-ce qui peut arriver quand les spermatozoïdes d'un homme s'unissent à l'ovule d'une femme dans le corps de la femme? [Grossesse]

11. Pendant combien de mois dure une grossesse? [9 mois]

12. Dans quelle partie du corps féminin se développe le bébé pendant la grossesse? [L'utérus]

13. Quel est l'organe sexuel dans le corps d'une femme qui peut être déchiré à la suite d'exercices réguliers ou de premier rapport sexuel? [L'hymen]

14. Quel est le nom utilisé pour décrire tous les organes génitaux externes visibles d'une femme? [La vulve]

15. Quelle est le période ou une femme a plus de chance de tomber enceinte? [environ 11 à 15 après le commence de ses règles]

16. Est-ce que une femme peut tomber enceinte en dehors de la période féconde (11-15 jours après le début de ses règles) ? [oui, c'est moins probable mais c'est possible]

17. Est-ce que une fille peut tomber enceinte la première fois qu'elle a des rapports sexuels? [oui] 


\section{Support : Rapports Sexuelles}

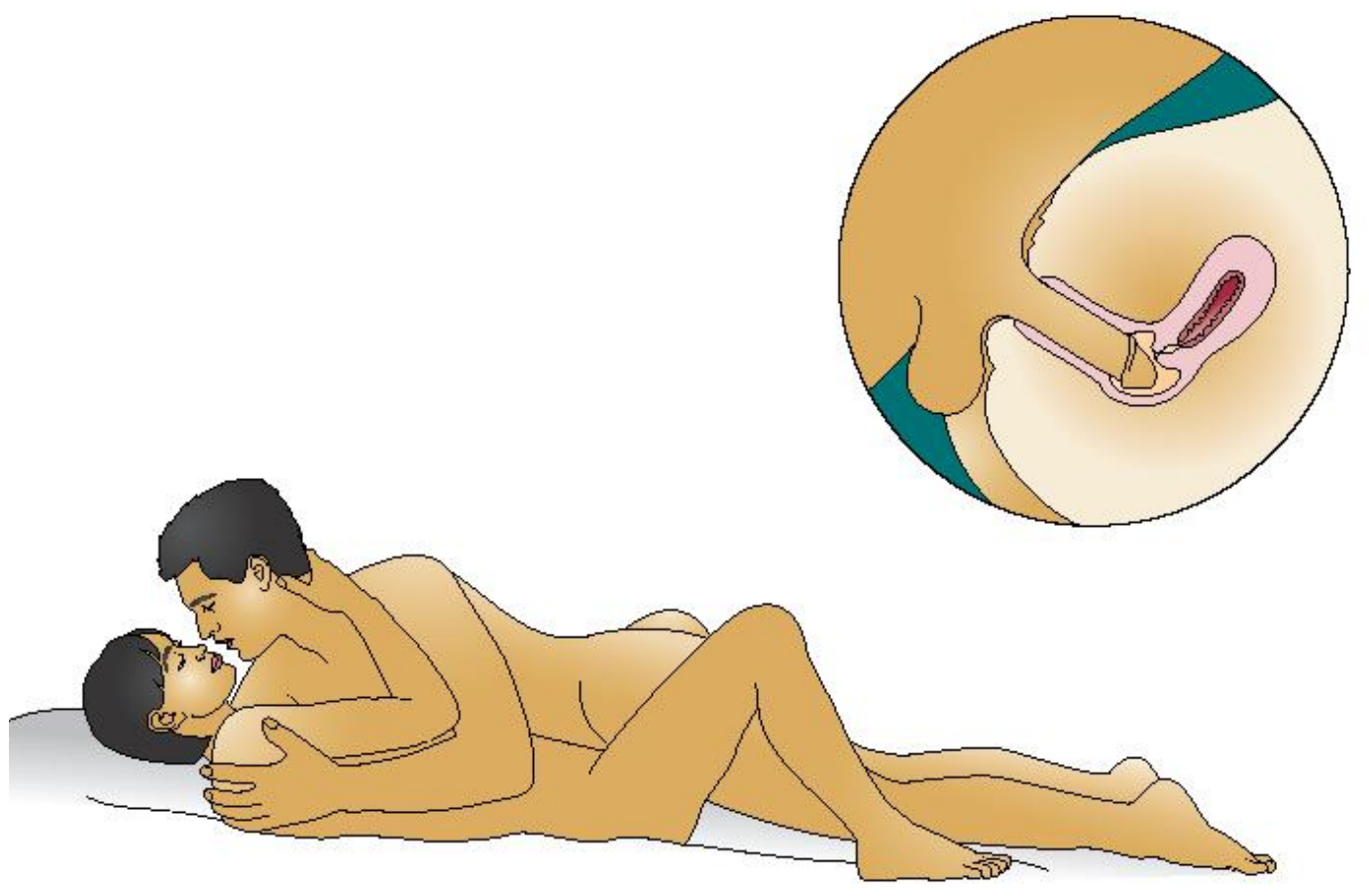

\section{Support : Fécondation et Grossesse}

\section{Comprendre la grossesse}

1

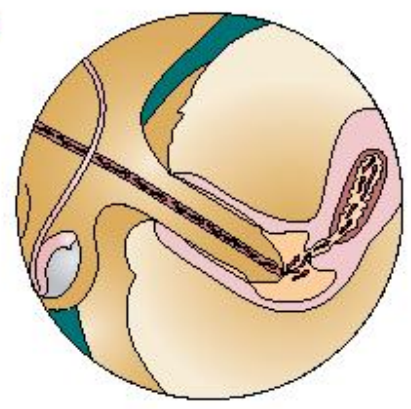

2

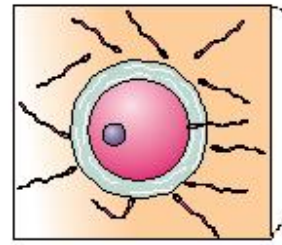

3

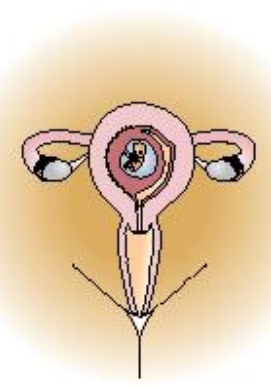

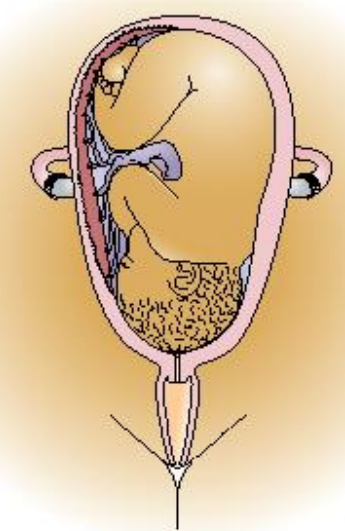

Images : Marie Stopes International. (2010). Le conseil en planification familiale. London, United Kingdom: Marie Stopes International. 


\section{Session 24: La planification familiale, la grossesse, et l'avortement}

\section{Objectifs de la session:}

À la fin de cette session, les filles seront capables de:

- Définir la contraception

- Identifier au moins quatre méthodes de planification familiale, en expliquant les avantages et les inconvénients de chacune d'elles

- Identifier les symptômes de la grossesse et comment assurer un bon suivi de la grossesse

- Identifier les facteurs associés à une grossesse saine

- Comprendre la nécessité et l'utilisation de la contraception d'urgence

- Définir l'avortement et décrire différentes méthodes utilisées pour l'avortement clandestin

\section{Matériel nécessaire:}

- Flipchart

- Marqueurs

- Supports ou dessins des différentes options de Planification Familiale

- Tous les échantillons de méthodes disponibles au Burkina Faso (l'injectable, le collier, préservatifs, stérilet, pilule, etc.)

\section{Plan de la session:}

- La Planification Familiale Crée des Options (10 minutes)

- Connaître les Différentes Méthodes de Planification Familiale (30 minutes)

- Comprendre la grossesse (20 minutes)

- Comprendre les Options avec les Grossesses Non Désirées (30 minutes)

Durée totale: 90 minutes

\section{AVANT LA SESSION:}

Présentez tous les échantillons des différentes méthodes de planification familiale.

\section{NOTES D'INFORMATION}

La discussion sur la grossesse et l'avortement peut amener des filles à faire cas de situations personnelles de contrainte (coercition) sexuelle. Apprêtez-vous à entendre les histoires des filles, et ayez à portée de main, des informations sur les lieux où référer les filles si des problèmes d'abus sexuels ou de grossesse sont posés. II peut être utile de laisser les filles connaître les cliniques où elles pourraient aller si elles soupçonnent qu'elles sont enceintes. Si une clinique dediée aux jeunes n'existe pas dans votre communauté, vous pourriez avoir à agir comme conseillère pour les filles. 
Il y a des préservatifs féminin et masculin. Les préservatifs masculins sont généralement moins chers et plus accessibles que les préservatifs féminins. Les préservatifs peuvent être achetés à la pharmacie sans ordonnance, dans les boutiques ou dans les alimentations, dans le centre de santé. Ils offrent une double protection contre la grossesse et les maladies sexuellement transmisibles. Les préservatifs doivent être portés, juste avant les rapports sexuels et enlevés après les rapports sexuels. Vous ne pouvez pas utiliser le même préservatif deux fois. Les inconvénients des préservatifs sont qu'ils peuvent se déchirer quelques fois, doivent être utilisés à chaque rapport sexuel, et certains utilisateurs disent qu'ils reduisent le plaisir. Le préservatif féminin et masculin ne doivent pas être utilisés à la fois, on ne doit pas aussi utiliser deux préservatifs à la fois, car ceci augment le risque qu'ils se déchirent et réduit l'éfficacité du préservatif.

Les pilules sont des petits médicaments que la femme prend tous les jours à la même heure et aussi longtemps qu'elle ne voudrait pas tomber enceinte. Certains avantages de la pilule sont qu'elles sont eficaces lorsqu'elles sont utilisées correctement, cela ne nécessite pas que la femme ou l'homme fasse quelque chose juste avant ou pendant les rapports sexuels. Egalement, elles peuvent réssoudre certains problèmes de santé, telles que la douleur au bas-ventre ou rendre régulier le cycle menstruel. Cependent, l'inconvénient est que la femme est obligée de prendre la pilule chaque jour à la même heure, et elle peut oublier d'en prendre. Les pilules ne protègent pas contre les maladies sexuellement transmissibles. Pour obtenir les pilules pour la première fois, la fille ou la femme doit aller dans un centre de santé ou de planification familiale.

L'injectable comme son nom l'indique est une injection que la femme fait tous les trois mois pour se protéger contre les grossesses. Elle peut l'obtenir dans une clinique, un centre de santé ou un centre de planification familiale. Les avantages de l'injectable sont: elle est éfficace, la femme n'est pas obligée de faire quelque chose tous les jours, et il ne nécessite pas que la femme ou l'homme fasse quelque chose avant ou pendant les rapports sexuels. Les inconvénients de l'injectable sont : elle ne protège pas contre les maladies sexuellement transmissibles, et elle a des effets sécondaires, tels que l'augmentation du poids chez la femme et la fréquence de cycle menstruel non régulier. Chez certaines femmes, les règles peuvent s'arrêtent complètement.

Le stérilet est un dispositif qu'un agent de santé insère dans l'utérus de la femme. Le stérilet est très éfficace, il a une protection de 5 à 10 ans selon le type de stérilet, et il peut être rétirer par un agent de santé à tout moment lorsque la femme veut tomber enceinte. Son utilisation est moins contraignante parce que lorsque la femme se fait insèrer le stérilet, elle n'est pas obligée de faire un contrôle régulier. II ne nécessite pas que la femme ou l'homme fasse quelque chose avant ou pendant les rapports sexuels. Les inconvénients du stérilet sont: il ne protège pas contre les maladies sexuellement transmissibles, et il a des effets sécondaires, comme les douleurs au basventre, un cycle non régulier, et il doit être rétirer par un agent de santé lorsque la fille ou la femme veut tomber enceinte.

La contraception d'urgence (CU) fait référence aux méthodes qui permettent d'éviter une grossesse après un rapport sexuel non protégé. Par exemple: après un échec contraceptif (rupture de préservatif), usage incorrect d'une méthode contraceptive, acte sexuel sans contraception ou viol. II y a deux types de contraception d'urgence. Le premier type c'est une pilule identique aux contraceptifs oraux, mais que la fille ou la femme doit prendre seulement en cas d'urgence, après avoir eu des rapports sexuels non protégés. Un autre type c'est le stérilet. Les deux types de 
contraception d'urgence permettent d'éviter une grossesse si une ou l'autre est prise ou pratiquée dans les cinq jours qui suivent le rapport non protégé. Son efficacité est d'autant plus grande qu'elle est prise ou pratiquée tôt durant cette période. La contraception d'urgence n'est pas un avortement. Si la fille ou la femme est déjà enceinte, la contraception d'urgence ne fera pas avorter sa grossesse.

Il existe plusieurs autres méthodes ici au Burkina Faso. Pour obtenir plus d'information, vous pouvez aller dans un centre de santé ou de planification familiale. Dans les semaines à venir, nous allons parler de la localisation de certaines cliniques et centres où vous pouvez trouver des méthodes contraceptives.

L'avortement est une procédure simple et sans trop de risque lorsqu'elle est pratiquée dans de bonnes conditions de sécurité : par un prestataire compétent, avec un équipement stérile approprié et avec accès thérapeutique rapide en cas de complications. L'avortement médicalisé et sûr est généralement plus probable lorsqu'il est légal. Au Burkina Faso, l'avortement n'est pas légal. Cependant, l'avortement peut être autorisé en cas de viol ou lorsque la vie de la mère est en danger. Certaines femmes pratiquent l'avortement clandestin qui est une pratique dangereuse car elle peut causer des infections graves, la stérilité ou même la mort de la femme.

\section{INSTRUCTIONS}

\section{$\rightarrow$ La planification familiale crée des options (10 minutes)}

1. Révision sur les rapports sexuels et le processus de fécondation qui ont été discutés au cours de la session précédente.

- Rapports sexuels: quand le pénis pénètre dans le vagin et que l'homme éjacule son sperme.

- Fécondation: Pour qu'une grossesse viable se produise, les conditions suivantes doivent être remplies :

- La femme doit être proche du moment de la période de l'ovulation, plus ou moins deux semaines après le début de ses règles.

- L'homme doit avoir une érection et éjaculer dans le vagin de la femme ou à son entrée.

- Le sperme de l'homme doit entrer en contact avec l'ovule de la femme.

2. Définir la contraception

La contraception peut être définie comme toute méthode servant à éviter la grossesse. Les méthodes s'utilisent de façons différentes à différents moments. La plupart des méthodes contraceptives sont utilisées par les femmes; seules quelques méthodes sont utilisées par les hommes. Il existe plusieurs méthodes.

3. Dites aux filles, "Aujourd'hui, nous allons étudiez toutes les méthodes contraceptives. Chaque personne a le droit à un consentement libre et éclairé concernant la méthode à utiliser. La contraception permet à de nombreuses personnes de profiter de leur vie sexuelle sans s'inquiéter du risque d'une grossesse non désirée. Le préservatif masculin ou féminin en plus d'être une méthode contraceptive protège aussi contre les infections sexuellement transmissibles. La contraception permet aux gens de mieux gérer leur corps, leurs relations et leur vie sociale et économique au sens large.» 


\section{$\rightarrow$ Connaître les différentes méthodes de planification familiale (30 minutes)}

1. Demandez aux filles: "Quelles méthodes de planification familiale connaissez-vous?» Réfléchissez sur les méthodes de planification connues des filles.

2. Dites aux filles, "La plupart des méthodes contraceptives sont destinées aux femmes; quelques unes seulement le sont aux hommes. Le choix de méthodes est vaste.»

3. Faites circuler des échantillons réels de méthodes de planification familiale et examinez les dessins des autres méthodes à court et à long termes. Expliquez aux filles qu'il existe plusieurs méthodes contraceptives modernes au Burkina Faso, telles que :

- Les pilules

- Les injectables

- Les préservatifs masculin et féminin

- Le stérilet

- Les implants (comme le Norplant)

- La ligature des trompes

- La vasectomie

(À partir des supports ci-dessous et des enchantillons)

4. Expliquez aux filles que, "Aucune méthode contraceptive n'est parfaite, et chacune présente ses propres caractéristiques. Certaines méthodes sont sujettes à des restrictions médicales».

- Deux méthodes seulement, le préservatif masculin et féminin, protègent contre le VIH et les IST.

- Certaines méthodes, mais pas toutes, peuvent affecter le plaisir ou la performance sexuelle.

- Certaines méthodes sont faciles à obtenir. D’autres requièrent une consultation ou même une visite médicale.

- Les méthodes varient dans leur efficacité de prévention de la grossesse.

- Certaines méthodes présentent des risques d'effets secondaires sur la santé de l'utilisatrice, mais les effets secondaires normalement ne sont pas trop graves.

- Certaines méthodes, mais pas toutes, peuvent être aisément interrompues ou reprises.

- Certaines méthodes conviennent mieux aux personnes dont les rapports sexuels sont peu fréquents.

- Le coût et la disponibilité des méthodes varient aussi.

- La seule méthode sure à $100 \%$ pour éviter une grossesse est l'abstinence sexuelle.

5. Expliquez aux filles que "Les méthodes les plus utilisés et accessibles au Burkina Faso sont les préservatifs, les pilules, les injectables, et les stérilets. " Expliquez ces méthodes en utilisant l'information dans « notes d'information. "

\section{Comprendre la grossesse (20 minutes)}

1. Demandez aux filles, "Connaissez-vous une personne qui a été enceinte? Quels ont été certains des symptômes expérimentés par cette femme lors de sa grossesse?» Réfléchissez aux symptômes de la 
grossesse chez les femmes. Si vous le souhaitez, écrivez les idées des filles sur le flipchart. Si les filles ont des difficultés à réfléchir aux symptômes (peut-être parce qu'elles n'ont pas abordé les symptômes de la grossesse avec quelqu'un), vous pouvez ajouter des exemples de symptômes à partir de cette liste:

- une absence de menstrues

- des seins sensibles ou gonflés

- des mamelons sensibles

- des mictions fréquentes

- une fatigue inhabituelle

- des nausées et vomissements

- des crampes

- des ballonnements

- des modifications de l'appétit

- une émotivité inhabituelle.

Rappelez aux filles que les premiers signes de la grossesse diffèrent d'une femme à une autre et d'une grossesse à l'autre. La grossesse peut être confirmée par un test de grossesse, qui peut être effectué par un prestataire de soins de santé ou acheté dans une pharmacie. Certaines femmes qui ont appris à détecter le moment où leur corps ovule peuvent prédire assez bien le jour où elles doivent voir leurs menstrues; elles peuvent donc soupçonner une grossesse dès qu'elles constatent un retard au niveau de leurs menstrues.

2. Expliquez comment vivre sainement avec une grossesse.

"Si une femme ou une fille choisit de garder sa grossesse, il est particulièrement important pour elle d'éviter de prendre des médicaments inutiles et surtout non prescrits par un médecin, de la drogue et de l'alcool. Prendre les vitamines et compléments minéraux recommandés (en particulier l'acide folique et de fer) est très important (y compris avant la grossesse, si possible). Elle doit également visiter un prestataire de soins prénataux, auprès de qui elle peut obtenir des examens médicaux et en savoir plus sur sa grossesse, les signes de danger potentiel, et l'accouchement, même si elle n'est pas malade. "

"Les femmes infectées par le VIH devraient prendre des antirétroviraux pour empêcher la transmission du virus au fœetus et préserver leur propre santé. Le traitement avec les antirétroviraux pendant le travail et l'accouchement est essentiel pour réduire le risque de transmission du VIH au bébé. »

3. Repérez les cartes d'image (voir support).

4. Dites aux filles: «je tiendrai une image de quelque chose qui pourrait être soit sain ou malsain pour une femme enceinte. Au fur et à mesure que je tiens les images, criez: "sain» ou "malsain». Sommesnous prêts?» Commencez l'activité. 


\section{$\rightarrow$ Comprendre les options avec les grossesses non désirées (30 minutes)}

1. Expliquez la contraception d'urgence en utilisant les informations dans « notes d'information. »

2. Demandez aux filles de se rappeler les informations de la dernière session sur les organes reproductifs des femmes, les rapports sexuels et le processus de fécondation. Décrivez ensuite comment fonctionne la contraception d'urgence :

La pilule contraceptive d'urgence c'est une manière de prévenir la grossesse. Elle n'est pas abortive, car elle ne fonctionne pas si la femme est déjà enceinte.

3. Demandez aux filles de partager ce qu'elles pensent de l'avortement et de réfléchir sur les raisons qui poussent les gens à avorter. Après que les filles aient fait une déclaration sur l'avortement, assurez-vous de clarifier les mythes ou idées fausses qu'elles peuvent avoir sur l'avortement en utilisant les informations dans « notes d'information. »

4. Dites aux filles «Les femmes et les filles se font avorter pour de nombreuses raisons. Par exemple :

- Elles n'ont pas les moyens ou la possibilité d'élever un enfant (qu'il s'agisse de leur premier enfant ou non).

- Elles ne désirent pas devenir mères au moment de la grossesse.

- Leur relation avec leur partenaire est difficile ou instable et elles ne désirent pas élever un enfant seules.

- Leur grossesse menace leur santé physique ou mentale.

- Leur grossesse est le résultat de rapports sexuels forcés ou contraints.»

5. Divisez les participants en trois groupes et demandez-leur de partager les méthodes dont elles ont entendu parler pour des avortements chez des femmes et ce qui leur ai arrivé.

Voici quelques exemples:

- Avortements avec des produits chimiques

- Surdosage de quinine (médicament antipaludéen)

- Herbes médicinales

- Méthodes mécaniques, y compris ceux consistant à percer l'utérus en utilisant des objets tranchants

- Prise de substances concentrées comme le quencher, le son de mil et les feuilles de thé.

- L'introduction des objets ou de produits nocifs dans le vagin pour provoquer la mort de fœtus

Toutes ces méthodes sont dangereuses car elles peuvent provoquer des infections graves, la stérilité, l'hémorragie ou la mort.

6. Dites aux filles de repenser à ce qu'elles ont étudié au cours de cette leçon. Animez un débat sur les sujets de la session. Voici des questions que vous pourriez poser:

- Quelles sont les méthodes de planification familiale qui seraient les plus faciles ou les plus commodes à utiliser? 
- Quelles sont les raisons principales de l'utilisation des méthodes de planification familiale? [Retarder ou espacer les grossesses, ou, en cas de préservatif, éviter les infections sexuellement transmissibles]

- Pourquoi pourrait-elle être utile ?

- Si vous tombez enceinte, que pensez-vous que vous feriez?

- Si vous voulez garder le bébé, quelles sont les actions saines que vous pourriez prendre pendant votre grossesse? [Dormir suffisamment, manger des fruits et légumes, aller régulièrement en visites médicales, etc.]

- Si vous avez eu des rapports sexuels non protégés, mais estimez que le temps n'est pas approprié pour garder le bébé, quelles seraient vos options? [Contraception d'urgence]

- Quels sont les raisons pour lesquelles une femme pourrait ne pas vouloir un bébé? [Voir les raisons ci-dessus pour le report de la maternité]

- Si vous ne voulez pas de bébé, que devriez-vous faire? [se protéger à chaque rapport sexuel]

7. Prévoyez suffisamment de temps pour discuter des autres questions que les filles peuvent avoir et clarifiez toute question ou fausse idée. Si vous ne connaissez pas certaines réponses, écrivez les questions et demandez un appui au chargé de programme pour les clarifier. Répondez aux questions à la session prochaine.

\section{TRAVAIL DE MAISON}

Demandez aux filles de vérifier avant de venir à la prochaine session combien d'argent elles ont reussi à épargner.

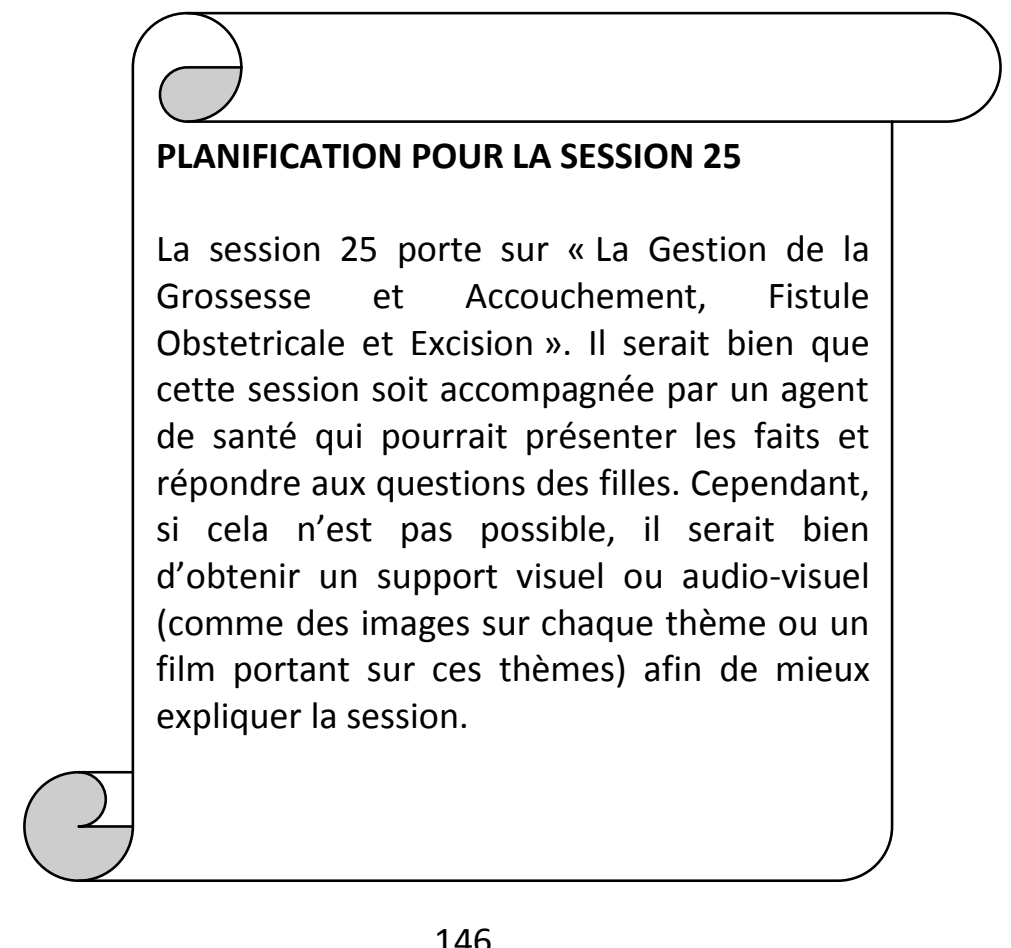




\section{Support: Méthodes contraceptives}

méthodes temporaires « contrôlées par l'utilisateur » qui empêchent les spermatozoïdes d'atteindre l'ovule

\begin{tabular}{|c|c|c|c|}
\hline MÉTHODE & Description & $\begin{array}{l}\text { Protection } \\
\text { anti-IST/VIH }\end{array}$ & Autres caractéristiques \\
\hline Préservatif masculin & $\begin{array}{l}\text { Fin capuchon en latex qu’on déroule sur le pénis en } \\
\text { érection pour empêcher le sperme de pénétrer dans } \\
\text { le vagin. }\end{array}$ & Oui & $\begin{array}{l}\text { Il s'agit de l'une des deux méthodes offrant une double protection, } \\
\text { contre la grossesse et l'infection. Il peut donc protéger aussi contre } \\
\text { le risque de stérilité et le cancer du col utérin. } \\
\text { Il protège l'homme ou le garçon ainsi que sa partenaire. } \\
\text { Il se procure aisément. } \\
\text { Il doit être mis en place lors de l'acte sexuel, avant la pénétration. } \\
\text { Certains trouvent qu'il réduit la sensation. } \\
\text { Il risque de fuir ou de se déchirer, surtout s'il est mal posé. }\end{array}$ \\
\hline Préservatif féminin & $\begin{array}{l}\text { Poche en plastique lubrifié à double anneau : le } \\
\text { premier reste à l'extérieur du vagin et recouvre une } \\
\text { partie des lèvres ; le second s'introduit dans le vagin, } \\
\text { où il recouvre le col de l'utérus. Le préservatif forme } \\
\text { une poche qui reçoit le sperme. }\end{array}$ & Oui & $\begin{array}{l}\text { Il peut être mis en place plusieurs heures avant l'activité sexuelle. } \\
\text { Il protège la femme ou la fille ainsi que son partenaire. } \\
\text { Il se remarque lors des rapports sexuels et son insertion peut } \\
\text { nécessiter une certaine pratique. } \\
\text { Il coûte cher par rapport au préservatif masculin. }\end{array}$ \\
\hline $\begin{array}{l}\text { Diaphragme ou } \\
\text { cape cervicale }\end{array}$ & $\begin{array}{l}\text { Diaphragme : Dôme peu profond en caoutchouc } \\
\text { souple qu'on remplit de spermicide et qu'on } \\
\text { introduit dans le vagin avant le rapport sexuel. Il } \\
\text { recouvre le col de l'utérus pour y empếcher l'entrée } \\
\text { du sperme, que le spermicide tue aussi. } \\
\text { Cape cervicale : Cupule en latex qu'on pose, dans } \\
\text { le vagin, comme un dé à coudre sur le col de } \\
\text { l'utérus, où il se maintient par succion et fait ainsi } \\
\text { barrière au sperme. Il convient de l'utiliser avec un } \\
\text { spermicide. }\end{array}$ & $\begin{array}{l}\text { Il n’a pas encore été } \\
\text { établi si la cape ou le } \\
\text { diaphragme assure une } \\
\text { protection contre les } \\
\text { infections. }\end{array}$ & $\begin{array}{l}\text { Il peut être mis en place avant le début de l'activité sexuelle. } \\
\text { Il ne se procure pas facilement. } \\
\text { Il risque de se déloger pendant le rapport. } \\
\text { Il doit être adapté par un prestataire de soins de santé. }\end{array}$ \\
\hline Spermicides & $\begin{array}{l}\text { Mousses chimiques, crèmes, gelées, films ou } \\
\text { suppositoires qu'on introduit dans le vagin avant } \\
\text { le rapport sexuel pour créer une barrière et tuer } \\
\text { le sperme. Le spermicide s'utilise seul ou avec une } \\
\text { méthode barrière telle que le préservatif, pour une } \\
\text { meilleure efficacité. }\end{array}$ & Non & $\begin{array}{l}\text { L’usage répété du spermicide nonoxinol-9 (N-9) peut provoquer des } \\
\text { lésions génitales et accroître ainsi le risque de transmission du VIH. } \\
\text { Les spermicides ne doivent pas être utilisés par les femmes qui } \\
\text { courent un haut risque de contraction du VIH. } \\
\text { Certains sont coulants et désagréables. }\end{array}$ \\
\hline
\end{tabular}

Remarque : Cette fiche accompagne le contenu de l'unité 7, pp. 210-213.

Pour plus de détails concernant les effets secondaires, l'efficacité et l'emploi, voir <www.who.int/reproductivehealth/publications/family_planning/9780978856304/fr/index.html> 


\section{méthodes durables internes au corps}

\begin{tabular}{|c|c|c|c|}
\hline MÉTHODE & Description & $\begin{array}{l}\text { Protection } \\
\text { anti-IST/VIH }\end{array}$ & Autres caractéristiques \\
\hline $\begin{array}{l}\text { Contraceptifs oraux } \\
\text { (1 pilule } ॥) \\
\frac{9000000}{\frac{.0000000}{.0000000}} \\
0000000\end{array}$ & $\begin{array}{l}\text { Petites pilules contenant des hormones synthétiques } \\
\text { (œstrogène et progestatif ou progestatif seul) qui } \\
\text { empêchent l'ovulation et gênent la migration du } \\
\text { sperme par épaississement de la glaire cervicale. La } \\
\text { femme avale une pilule chaque jour pendant } 21 \text { ou } \\
28 \text { jours suivant la marque et le type. }\end{array}$ & Non & $\begin{array}{l}\text { La femme ne doit rien introduire ou appliquer au moment des } \\
\text { rapports sexuels. } \\
\text { La pilule peut réduire les crampes menstruelles et le risque de } \\
\text { certains types de cancer, d'anémie, de problèmes de seins et } \\
\text { d'infection génitale haute. } \\
\text { La femme ne doit pas oublier de prendre sa pilule. } \\
\text { La fécondité se rétablit généralement rapidement quand la femme } \\
\text { arrête de prendre la pilule. }\end{array}$ \\
\hline Inject & $\begin{array}{l}\text { Injection administrée à intervalles réguliers, de } \\
\text { un ou trois mois généralement, contenant une } \\
\text { hormone synthétique progestative qui empêche } \\
\text { l'ovulation et épaissit la glaire cervicale. }\end{array}$ & Non & $\begin{array}{l}\text { La méthode peut être utilisée sans que d'autres le sachent. } \\
\text { La femme ne doit rien introduire ou appliquer au moment des } \\
\text { rapports sexuels. } \\
\text { L'injectable peut réduire le risque de certains types de cancer. } \\
\text { La fécondité se rétablit quelques mois après l'arrêt. }\end{array}$ \\
\hline Anneau vaginal & $\begin{array}{l}\text { Fin anneau souple que la femme introduit dans le } \\
\text { vagin et qui libère lentement un œstrogène et un } \\
\text { progestatif, pour arrêter l'ovulation et épaissir la } \\
\text { glaire cervicale. }\end{array}$ & Non & $\begin{array}{l}\text { La femme ne doit rien introduire ou appliquer au moment des } \\
\text { rapports sexuels. } \\
\text { La fécondité se rétablit immédiatement à l'arrêt de la méthode. }\end{array}$ \\
\hline Patch & $\begin{array}{l}\text { Petit carré adhésif appliqué sur la peau et qui libère } \\
\text { lentement un progestatif et un œstrogène à travers } \\
\text { la peau, pour empêcher l'ovulation et épaissir la } \\
\text { glaire cervicale. }\end{array}$ & Non & $\begin{array}{l}\text { La femme ne doit rien introduire ou appliquer au moment des } \\
\text { rapports sexuels. } \\
\text { Le patch est moins efficace pour les femmes pesant plus de } 90 \mathrm{~kg} \text {. } \\
\text { La fécondité se rétablit rapidement à l'arrêt de la méthode. }\end{array}$ \\
\hline Implants & $\begin{array}{l}\text { Simple ou double petit bâtonnet souple implanté } \\
\text { dans le haut du bras de la femme et qui libère une } \\
\text { faible dose progestative constante pendant trois à } \\
\text { cinq ans, pour épaissir la glaire cervicale et empêcher } \\
\text { l'ovulation. }\end{array}$ & Non & $\begin{array}{l}\text { Les implants peuvent être retirés à tout moment, mais ils doivent être } \\
\text { mis en place et retirés par un prestataire formé. } \\
\text { La femme ne doit rien introduire ou appliquer au moment des } \\
\text { rapports sexuels. } \\
\text { La fécondité se rétablit immédiatement après le retrait. }\end{array}$ \\
\hline
\end{tabular}




\begin{tabular}{|c|c|c|c|}
\hline Stérilet & $\begin{array}{l}\text { Petit dispositif, généralement en forme de T, introduit } \\
\text { dans l'utérus par un prestataire de soins. Certains } \\
\text { libèrent une hormone progestative et d'autres } \\
\text { contiennent du cuivre, aux effets contraceptifs. Le } \\
\text { stérilet empêche le sperme d'atteindre l'ovule. Certains } \\
\text { types restent efficaces pendant } 10 \text { ans. }\end{array}$ & Non & $\begin{array}{l}\text { Cette méthode, imperceptible, n'interrompt pas l'acte sexuel. } \\
\text { En cas d'infection présente au moment de l'insertion, ou si les } \\
\text { conditions de l'insertion ne sont pas stériles, une infection pelvienne } \\
\text { peut se développer et accroitre le risque de stérilité. } \\
\text { Le corps expulse parfois le stérilet. } \\
\text { Il doit être introduit et retiré par un prestataire compétent. }\end{array}$ \\
\hline
\end{tabular}

\section{« méthodes naturelles » - méthodes requérant des comportements spécifiques et une bonne compréhension de son corps}

\begin{tabular}{|c|c|c|c|}
\hline MÉTHODE & Description & $\begin{array}{l}\text { Protection } \\
\text { anti-IST/VIH }\end{array}$ & Autres caractéristiques \\
\hline $\begin{array}{l}\text { Méthode de } \\
\text { l'aménorrhée } \\
\text { lactationnelle }\end{array}$ & $\begin{array}{l}\text { Méthode réservée exclusivement aux femmes } \\
\text { qui allaitent. La lactation provoque dans le corps } \\
\text { la production d'hormones capables d'empêcher } \\
\text { l'ovulation. Pour la contraception, cette méthode } \\
\text { n'est efficace que pendant les six premiers mois } \\
\text { d'allaitement ou, s'il intervient plus tôt, jusqu'au } \\
\text { moment où la menstruation réapparait, et que } \\
\text { si l'enfant n'est nourri qu'au lait maternel et à la } \\
\text { demande. }\end{array}$ & Non & $\begin{array}{l}\text { Laallaitement maternel est gratuit et bénéfique à la santé de la mère et } \\
\text { de l'enfant. } \\
\text { La méthode de l'aménorrhée lactationnelle (MAMA) peut être } \\
\text { difficile pour les femmes qui doivent s'éloigner régulièrement de leur } \\
\text { enfant. }\end{array}$ \\
\hline Retrait & $\begin{array}{l}\text { Le retrait du pénis, hors et à distance du vagin avant } \\
\text { l'éjaculation, évite l'entrée du sperme dans le vagin. } \\
\text { Cette méthode peut être efficace si elle est utilisée } \\
\text { correctement et sans exception. }\end{array}$ & Non & $\begin{array}{l}\text { Le retrait est toujours disponible et gratuit. } \\
\text { Il est considérablement plus efficace que l'absence de retrait. } \\
\text { Il dépend de la maîtrise qu’a l'homme de son corps et de sa capacité } \\
\text { à prédire l'éjaculation ; les femmes n'ont aucun contrôle sur cette } \\
\text { méthode. } \\
\text { Il interrompt l'acte sexuel et peut amoindrir le plaisir. }\end{array}$ \\
\hline $\begin{array}{l}\text { Méthode de } \\
\text { conscience de la } \\
\text { fécondité - glaire } \\
\text { cervicale }\end{array}$ & $\begin{array}{l}\text { Le col de l'utérus sécrète une glaire observable } \\
\text { quand la femme s'essuie ou sur le fond de culotte. } \\
\text { Le type et la quantité de cette glaire change au cours } \\
\text { du cycle menstruel. La femme peut apprendre à } \\
\text { reconnaître le type de glaire qui indique qu'elle } \\
\text { est vraisemblablement féconde ou non. Pendant } \\
\text { la période féconde, elle peut utiliser une méthode } \\
\text { contraceptive barrière ou s'abstenir de tous rapports } \\
\text { sexuels (voir la fiche relative au cycle menstruel). }\end{array}$ & Non & $\begin{array}{l}\text { Cette méthode donne à la femme une meilleure conscience et } \\
\text { compréhension de son corps. } \\
\text { Elle lui permet de prédire le début de son prochain cycle menstruel. } \\
\text { Elle peut aussi aider les couples qui désirent concevoir à identifier } \\
\text { leurs jours les plus féconds. } \\
\text { Elle est acceptable aux groupes religieux opposés aux autres méthodes. } \\
\text { Elle demande un certain temps d'apprentissage, une discipline } \\
\text { d'observation journalière et la coopération du partenaire de la femme. }\end{array}$ \\
\hline
\end{tabular}




\section{SUPPORT: CARTES D'IMAGES:}

Dormir suffisamment - sain

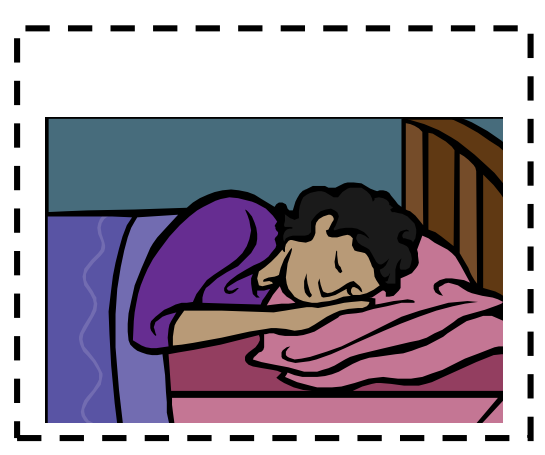

Fumer - malsain

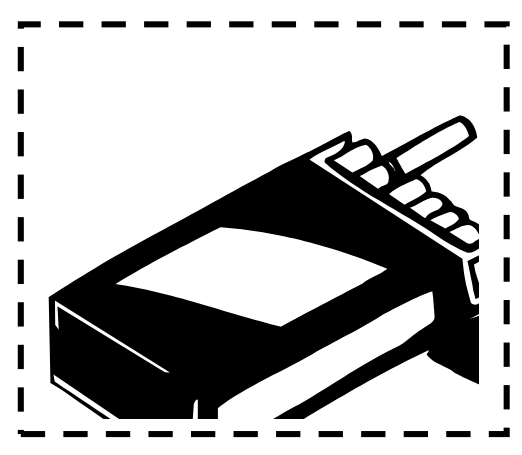

Manger des légumes propres - sain

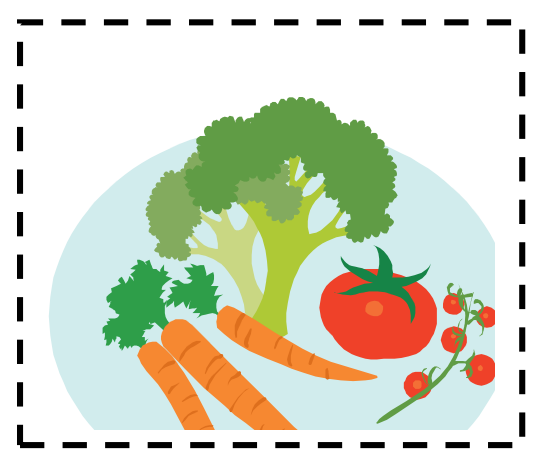

Visites régulières au centre

de santé - sain

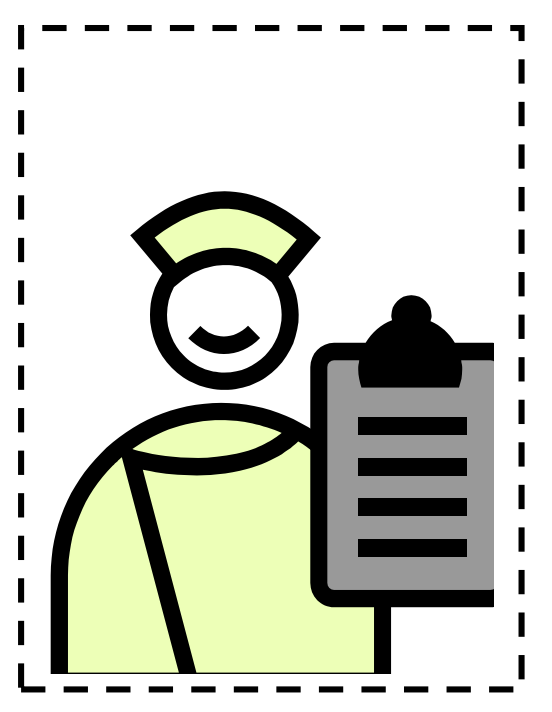

Boire de l'alcool - malsain

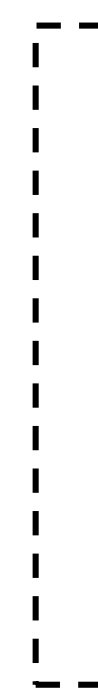

Manger des fruits- sain

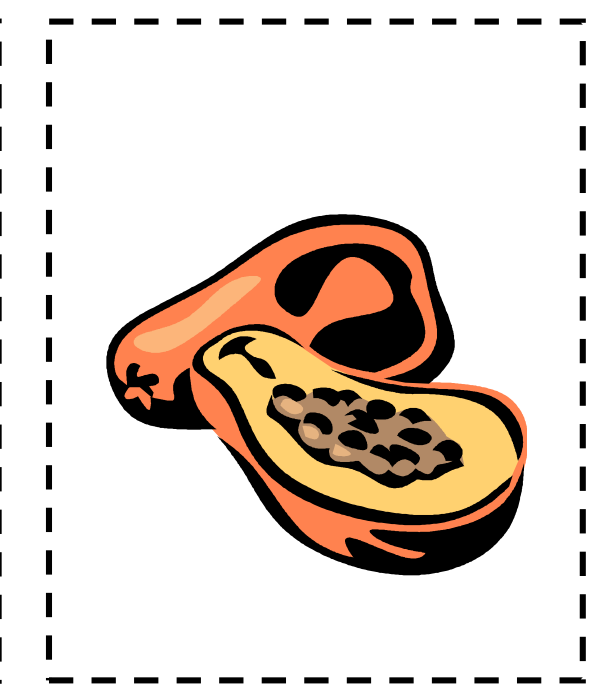

Prendre des vitamines - sain

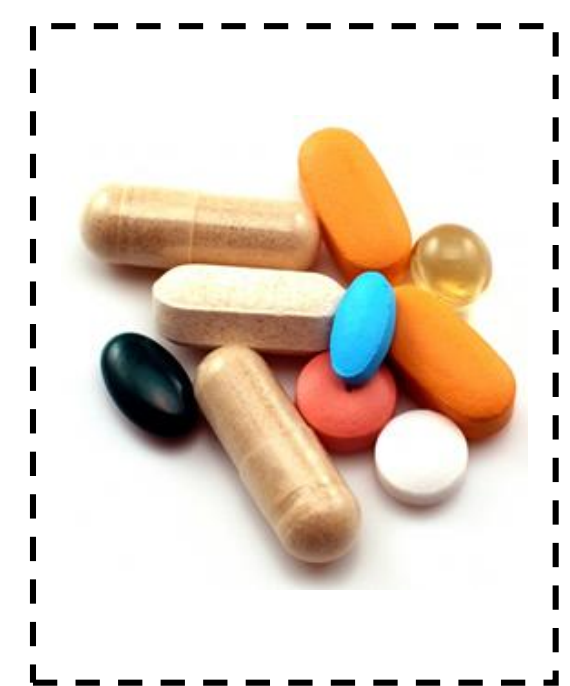




\section{Session 25: Gestion de la grossesse et accouchement, fistule obstétricale et excision}

Objectifs de la session:

À la fin de cette session, les filles seront capables:

- D'expliquer comment gérer la grossesse et l'accouchement

- De décrire les manifestations, causes, prévention de la fistule obstétricale

- De décrire l'excision, les raisons avancées pour justifier la pratique et les conséquences

\section{Matériel nécessaire:}

- Papier Flip-chart ou tableau

- Marqueurs ou craies

- Outil de suivi d'epargne

\section{Plan de la session:}

- Suivi des plans d'épargne (10 minutes)

- Jeu de rôle sur la gestion de la grossesse et l'accouchement (20 minutes)

- Jeu de rôle sur les manifestations, causes, prévention de la fistule obstétricale (20 minutes)

- L'excision, les raisons de la pratique et les conséquences (40 minutes)

Durée Totale: 90 minutes

AVANT LA SESSION: Lire attentivement la note d'information pour comprendre très bien les thèmes. Également, il faudrait examiner la façon dont vous allez instruire les filles sur chacune des parties (voir le début de section «Instructions»). Si l'accompagnement de cette session se fera avec un agent de la santé, présentez-lui la session, et décidez ensemble, de comment intégrer une ou plusieurs activités dans son exposé (le jeu de rôle par exemple). Si l'accompagnement d'un agent de santé n'a pas été obtenu pour cette session, il serait bien de s'approprier quelques images ou autres supports visuels (comme un film) qui pourraient faciliter la présentation de cette session. Le film pourrait être montré après l'activité de jeu de rôle par exemple.

\section{NOTES D'INFORMATION}

\section{Grossesse et accouchement}

Bien avant que leur ventre ne s'arrondisse, de nombreuses femmes peuvent percevoir les premiers signes de la grossesse. Le premier constant, celui qui donne presque toujours l'alerte, est, bien entendu, le retard de règles. Cependant, de nombreuses femmes ont des règles irrégulières, voire des périodes d'aménorrhée (arrêt spontané des règles), ce qui rend ce signe, en réalité, peu fiable, en début de grossesse. Par ailleurs des saignements peuvent se produire au moment où les règles auraient normalement dû avoir lieu. Bien que souvent moins abondants que les menstruations, ils peuvent néanmoins prêter à confusion. Bien d'autres symptômes évocateurs peuvent se produire au début de la grossesse, tous liés à la poussée de sécrétion des hormones sexuelles. Les seins gonflent, avec un bombement des mamelons, qui prennent une coloration plus foncée et se couvrent parfois de petites tuméfactions granuleuses, qui correspondent à des petites glandes. Ces changements de 
votre corps vous laissent penser que vous êtes enceinte. Les signes sont si nombreux et si variables d'une personne à une autre qu'il serait absurde de faire reposer sur eux le diagnostic de la grossesse. D'autant plus que de nombreuses femmes n'éprouvent aucun de ces symptômes. En révanche, la présence de l'une ou plusieurs de ces modifications peut attirer l'attention. Pour vérifier, rendez-vous à la pharmacie ou au laboratoire d'analyses pour faire un test de grossesse, et vous serez fixée.

Préparer son accouchement : Dès que vous avez la confirmation que vous êtes enceinte, consulter votre médecin ou votre sage-femme pour commencer les consultations prénatales pour le bon déroulement de la grossesse. Quatre consultations prénatales (CPN) sont recommandées mais si la femme enceinte a des malaises, elle doit immédiatement consulter la sage-femme ou le médecin. Au cours des séances de CPN, la sage femme vous expliquera dans le détail le déroulement de l'accouchement et vous aurez l'occasion d'exprimer vos préoccupations. Si la grossesse et l'accouchement sont des événements très naturels, ils n'en marquent pas moins une étape importante dans la vie d'une femme. Les changements corporels et psychiques alimentent de nombreuses angoisses ou questions. La préparation à l'accouchement permet à de nombreuses femmes de se rassurer et de se sentir moins seules.

\section{La fistule obstétricale}

La fistule obstétricale est une infirmité dévastatrice liée à la grossesse. C'est la constitution d'une communication anormale (une fistule) entre la vessie et le vagin (fistule vésico-vaginale) ou entre la vessie et le rectum (fistule vésico-rectale) survenant à la suite d'une grossesse compliquée. Elle survient généralement pendant un accouchement prolongé, quand une femme n'obtient pas la césarienne qui serait nécessaire ou quand c'est une jeune fille dont le corps n'est pas encore prêt pour l'accouchement. L'Organisation Mondiale de la Santé évalue à près de 2 millions le nombre actuel de femmes atteintes d'une fistule obstétricale.

Conséquences de la fistule : Incapables de rester sèches, beaucoup de femmes souffrent d'humiliation constante de dégager une odeur d'urine et/ou d'excréments. II peut aussi leur être difficile de marcher parce que les nerfs des membres inférieurs sont atteints. Elles sont souvent rejetées par leur époux ou leur partenaire, évitées par leur communauté et blâmées de leur état. Les femmes non soignées peuvent non seulement s'attendre à une vie de honte et d'isolement, mais risquent aussi de connaître une mort lente et prématurée pour cause d'infection et d'insuffisance rénale. La fistule obstétricale se soigne. Il est possible d'opérer la fistule dans la majorité des cas, même après plusieurs années. Si l'opération est correctement pratiquée, le taux de succès peut aller jusqu'à $90 \%$ et la femme peut généralement avoir d'autres enfants.

Pour éviter la fistule obstetricale et autres complications de l'accouchement, il faut se rendre le plus tôt possible dans un centre de santé lorsque le travail commence et se faire accoucher par un agent de santé qualifié. 


\section{L'excision}

Définition selon l'Organisation Mondiale de la Santé (OMS) : Les mutilations génitales féminines (MGF) recouvrent toutes les interventions incluant l'ablation partielle ou totale des organes génitaux externes de la femme et / ou la lésion des organes génitaux féminins pour des raisons culturelles ou toute autre raison non thérapeutique.

Les conséquences néfastes de l'excision : Les mutilations génitales féminines engendrent de multiples complications ayant des effets néfastes sur des femmes et sur leur enfant à l'accouchement.

Du point de vue de la santé sexuelle et reproductive donc, les mutilations génitales féminines sont un grave problème, car elles influencent négativement et parfois même définitivement, la vie de la fille/femme, et de la famille. C'est donc un phénomène de société.

En outre, en dehors de ces complications obstétricales, il faut relever des problèmes d'ordre gynécologique, urinaire, psychologique et social. Ce sont entre autres :

- Les MGF sont pratiquées dans la plupart des cas sans anesthésie, alors que le clitoris est très énervé, donc doublement sensible aux douleurs. C'est pourquoi la douleur très vive de l'excision peut même conduire à la mort.

- Le clitoris est très vascularisé; sa coupure provoque brutalement une hémorragie importante, difficile à maîtriser par les exciseuses.

- Elle est surtout favorisée par les différents chocs décrits plus haut. II peut même arriver que la fille perde la vie avant la fin de l'opération.

- Le microbe du tétanos peut être transmis aux filles excisées par l'intermédiaire des instruments souillés/rouillés utilisés au cours de l'opération et aussi pendant les pansements septiques. Les instruments traditionnellement utilisés pour l'excision dans certaines sociétés sont conservés dans des endroits très insalubres tels que les poulaillers.

- Le VIH-SIDA et le virus de I'Hépatique B sont des IST connues qui peuvent se transmettre par les mains et les instruments de l'exciseuse.

- L'accolement des lèvres qui réduit l'orifice vaginal peut empêcher les rapports sexuels ou rendre ces derniers douloureux, être à l'origine de la rétention du sang des règles.

- Les infections peuvent être localisées ou remontées au niveau interne et être causes de stérilité, ou de mort.

- Les cicatrices déforment la vulve et rendent les rapports sexuels difficiles.

- L'incontinence urinaire est provoquée par la lésion du muscle du sphincter urétral lors de l'excision. Elle marginalise les filles et femmes dans leur société et compromet leur avenir sexuel.

- La rétention prolongée de la tête fœtale pendant la période d'expulsion entraîne une souffrance fœtale qui se traduit plus tard par des séquelles neurologiques importantes (retard mental).

Remarque : L'incision du clitoris des nouveaux-nés est, selon l'opinion publique, très répandue au Burkina Faso, et fait cause de maintes plaintes. Cependant, aucune de ces plaintes n'ont été formelles, d'où la difficulté de déterminer si ce fait est un mythe ou une réalité. 


\section{INSTRUCTIONS}

\section{Suivi des plans d'épargne (10 minutes)}

1. Expliquez aux filles qu'il y a environ trois mois de cela, chaque fille avait fait un plan d'épargne et que maintenant nous allons voir les progrès individuels de vos plans.

2. Demandez aux filles une à une de dire combien elles ont reussi à épargner, et où est-ce que chacune garde son argent (chez elles, dans une caisse populaire, par l'employeur, etc). Notez sur votre outil de suivi la situation de chaque fille. Est-ce que quelqu'une a changé son but? Si oui, le mentor doit noter le nouveau but et plan dans l'outil de suivi.

3. Demandez aux filles de partager avec le groupe leurs défis à épargner. Encouragez les autres filles à donner des idées et suggestions. Si une fille se gène de parler de ses défis au groupe, le mentor doit l'encourager de lui en partager après la session.

\section{$\rightarrow$ Jeu de rôle sur la gestion de la grossesse et l'accouchement (20 minutes)}

1. Saluer les participantes et introduire la session du jour. Expliquer aux participantes que lors des sessions passées, vous avez abordé les thèmes sur les règles et la fécondation et qu'aujourd'hui, vous allez discuter sur la grossesse et l'accouchement qui sont des étapes qui succèdent la fécondation.

2. Lire le texte ci-dessous à haute voix et demander aux participantes d'écouter attentivement.

\section{Jeu de rôle}

Amina et Fatim sont des copines de longue date. Elles habitent la même ville et se voient presque tous les jours. Leur amitié est tellement forte à tel point qu'elles confient tout le temps leurs problèmes l'une à l'autre. Depuis un certain temps, Amina est inquiète car cela fait plus de deux semaines qu'elle n'a pas vu ses règles. Elle se confie donc à sa copine Fatim pour avoir des conseils. Si vous êtes à la place de Fatim qu'allez-vous faire ? Quels conseils, vous allez donner à votre amie Amina?

3. Donner la parole à un volontaire qui va s'identifier à Fatim et donner des conseils à Amina.

4. Donner la parole à 05 volontaires au moins.

5. Noter sur le papier flip-chart, les idées évoquées par les filles

6. Discuter les idées des filles en groupe et en se faisant guider par les questions:

\section{Questions}

- Est-ce que quelques jours de retard de règles signifient que la femme est enceinte ?

- Quels sont les signes annonciateurs de la grossesse ?

- Que faire pour s'assurer que vous êtes enceinte?

- Que faut-il faire si vous découvrez que vous êtes enceinte ? 
7. Faire la synthèse des réponses et compléter les idées s'il en existe.

8. Conclure cette partie et passer au point sur la fistule obstétricale

Les manifestations, causes, prévention de la fistule obstétricale (20 minutes)

1. Demander aux participantes d'écouter attentivement le texte qui sera lu car à la fin elles seront invitées à répondre à des questions.

2. Lire le texte au moins deux fois à haute voix.

Fatoumata Diallo la quarantaine, peut désormais affronter tous les regards. Elle revient de loin ; 20 ans de sa jeunesse passés dans la pénombre de l'exclusion, de l'errance et de l'isolement, parce qu'elle est " Natoudo ", la femme que l'accouchement a "gâtée » en fulfuldé. Fatoumata a porté comme un fardeau la plus handicapante des séquelles de l'accouchement. A quatorze ans lorsqu'elle allait découvrir sa féminité comme toute jeune fille de son âge, Fatoumata a dû connaître sa première expérience de maternité : "Le travail a été long ; j'ai passé au moins quatre jours à la maison. Quand tu es jeune, on trouve que tu es pressée, que la douleur n'est pas vive et à l'hôpital, on pouvait te retenir deux jours avant de t'évacuer à Ouagadougou, Dori ne disposant pas à l'époque de bloc opératoire ". Finalement, c'est à Ouagadougou que Fatoumata a accouché. Après l'accouchement, Fatoumata a eu une maladie grave.

3. Poser les questions une à une et noter toutes les réponses données par les participantes

\section{Questions:}

- Quelles sont les différents problèmes vécus par Fatoumata ?

- Pourquoi, Fatoumata a connu ses problèmes?

- Est-ce qu'elle pouvait éviter ces problèmes?

- Selon vous, quelle est la maladie que Fatoumata a eue?

- Est-ce qu'elle pouvait éviter cette maladie?

- Si oui, en quoi faisant?

4. Mener la discussion avec les participantes autour des points sur les causes, les manifestions et les conséquences de la fistule obstétricale et surtout comment l'éviter (en allant dans un centre de santé pour accoucher au lieu d'attendre que le travail dure longtemps).

5. Conclure cette partie et passer au point sur l'excision.

\section{$\rightarrow$ L'excision, les raisons de la pratique et les conséquences (40 minutes)}

1. Rappeler aux participantes qu'aux sessions précédentes, vous avez discuté sur les organes génitaux externes de la femme et leur fonctionnement. 
2. Faire un rappel afin de permettre aux participantes de mieux appréhender plus tard l'excision et les conséquences néfastes.

3. Entamer une discussion avec l'ensemble des participantes autour des questions suivantes:

- Selon vous, qu'est ce que c'est que l'excision ?

- Dans quelle partie du corps de la femme pratique-t-on l'excision ?

- Qu'est ce qu'on enlève exactement dans cette partie du corps ?

- Après cette question, utilisez le graphique des organes de l'appareil sexuel et génital féminin à la page 126 pour montrer et expliquer ce qu'on enlève

- Pourquoi selon vous, l'excision est pratiquée dans nos sociétés ?

- Quelles sont les raisons avancées pour maintenir la pratique ?

- Est ce que les raisons avancées par les gens sont fondées ?

- Ayant pris connaissance de la manière dont l'excision est pratiquée, quelles peuvent être selon vous, les conséquences néfastes de cette pratique sur les victimes, sur le plan sanitaire, social et psychologique?

4. Informer aux participantes que vous allez vous répartir en deux équipes (A et B) pour faire un jeu

5. Diviser le flip-chart en deux parties pour enregistrer les réponses de chaque équipe

6. Enregistrer toutes les réponses de chaque équipe (qu'elles soient vraies ou fausses) dans l'espace qui lui est réservé sur le flip-chart.

7. Dites aux participantes que certaines raisons sont évoquées par notre société pour justifier la pratique de l'excision. Un jour, vous vous êtes retrouvé en face qu'un groupe de parents qui croient toujours que l'excision est une bonne pratique. Voici quelques raisons qu'ils avancent. Maintenant que vous savez ce que c'est que l'excision, vous êtes interpeler à développer des arguments pour convaincre ces parents que l'excision n'est pas une bonne chose.

8. Lire une à une les raisons évoquées à la colonne une du tableau ci-dessous et enregistrer les arguments de chaque équipe.

Les principales motivations socioculturelles de la pratique de l'excision au Burkina Faso et les arguments pour les réfuter.

\begin{tabular}{|l|l|}
\hline \multicolumn{1}{|c|}{ Raisons évoquées } & \multicolumn{1}{c|}{ Argumentations pour les réfuter } \\
\hline $\begin{array}{l}\text { Le clitoris tue l'enfant } \\
\text { à la naissance }\end{array}$ & $\begin{array}{l}\text { Le clitoris ne peut pas tuer le bébé lors de l'accouchement. Au contraire, le } \\
\text { clitoris, grâce à son extensibilité contribue beaucoup à l'agrandissement de } \\
\text { l'orifice vulvaire et permet ainsi une sortie facile de l'enfant pendant } \\
\text { l'accouchement. }\end{array}$ \\
\hline $\begin{array}{l}\text { Le clitoris rend la } \\
\text { femme inféconde. }\end{array}$ & $\begin{array}{l}\text { Le clitoris n'a rien à voir avec la fécondité de la femme. Il est un organe } \\
\text { sexuel et ne fait pas partie des organes de reproduction de la femme. Les } \\
\text { ovaires donnent l'ovule qui est fécondé par les spermatozoïdes ; les } \\
\text { trompes permettent le passage des spermatozoïdes et de l'œuf; l'utérus } \\
\text { permet la nidation de l'œuf et le développement du fœtus. }\end{array}$ \\
\hline $\begin{array}{l}\text { L'excision purifie la } \\
\text { femme }\end{array}$ & $\begin{array}{l}\text { La femme ne naît pas impure, la femme et l'homme naissent tous purs. } \\
\text { L'excision n'est pas un acte de purification mais un acte de mutilation. } \\
\text { Aucune prescription divine n'en fait obligation. }\end{array}$ \\
\hline
\end{tabular}




\begin{tabular}{|c|c|}
\hline $\begin{array}{l}\text { L'excision est une } \\
\text { obligation religieuse }\end{array}$ & $\begin{array}{l}\text { Les écritures saintes (le coran et la bible) ne font aucune mention de } \\
\text { l'excision. Ce sont des interprétations erronées des textes religieux qui } \\
\text { induisent les fidèles en erreur. }\end{array}$ \\
\hline $\begin{array}{l}\text { Une femme non } \\
\text { excisée est infidèle et } \\
\text { insatiable sur le plan } \\
\text { sexuel }\end{array}$ & $\begin{array}{l}\text { La fidélité de la femme n'est pas liée à l'excision; elle dépend surtout de } \\
\text { l'éducation reçue, des facteurs socioéconomiques et de l'environnement } \\
\text { dans lequel la femme vie. } \\
\text { C'est par une bonne éducation et un encadrement décent qu'on peut } \\
\text { assurer un comportement sexuel responsable des hommes et des femmes. }\end{array}$ \\
\hline $\begin{array}{l}\text { L'excision préserve la } \\
\text { virginité de la fille }\end{array}$ & $\begin{array}{l}\text { L'excision n'est pas la solution pour préserver la virginité de la fille. C'est } \\
\text { plutôt une éducation saine de la fille et du garçon qui pourrait les amener à } \\
\text { assumer leur vie sexuelle de façon responsable. }\end{array}$ \\
\hline $\begin{array}{l}\text { Le clitoris contient des } \\
\text { vers }\end{array}$ & $\begin{array}{l}\text { Le clitoris est un organe vivant et sain. Il ne peut pas contenir des vers. Ce } \\
\text { sont des sécrétions vaginales blanchâtres normales qui s'y déposent. } \\
\text { Pendant l'excision ce sont les nerfs et les vaisseaux coupés ou des petits } \\
\text { vers placés exprès dans l'eau de la calebasse de l'excision que l'exciseuse } \\
\text { présente aux mères en leur faisant croire qu'il s'agit de vers sortis du sexe } \\
\text { de leur enfant. }\end{array}$ \\
\hline $\begin{array}{l}\text { Le clitoris rend } \\
\text { I'homme impuissant }\end{array}$ & $\begin{array}{l}\text { Le clitoris ne peut pas rendre un homme impuissant. Certaines } \\
\text { communautés ne pratiquent pas l'excision mais leurs hommes ne sont pas } \\
\text { impuissants. Le clitoris en contact avec le sexe de l'homme pendant les } \\
\text { rapports sexuels procure du plaisir à l'homme et à la femme. Il ne constitue } \\
\text { aucun danger pour le sexe de l'homme. }\end{array}$ \\
\hline $\begin{array}{l}\text { Le clitoris boit le sang } \\
\text { de la fille }\end{array}$ & $\begin{array}{l}\text { Le clitoris ne peut pas boire le sang de la fille; il est un organe comme les } \\
\text { autres. Ce sont plutôt des maladies telles que les parasitoses intestinales et } \\
\text { le paludisme qui peuvent provoquent l'anémie chez les filles. }\end{array}$ \\
\hline $\begin{array}{l}\text { L'excision éloigne les } \\
\text { mauvais génies de la } \\
\text { femme }\end{array}$ & $\begin{array}{l}\text { L'excision n'a aucune liaison avec une présence quelconque de génies, ce } \\
\text { sont des raisons avancées au-delà de toute explication rationnelle. }\end{array}$ \\
\hline $\begin{array}{l}\text { Une femme non } \\
\text { excisée accouche } \\
\text { difficilement }\end{array}$ & $\begin{array}{l}\text { Contrairement à ce que certaines personnes croient, le périnée de la } \\
\text { femme non excisée est très souple, se dilate facilement pour laisser passer } \\
\text { le bébé pendant l'accouchement. Alors que la cicatrisation de la plaie de } \\
\text { l'excision rétrécie l'orifice vulvaire et le rend moins extensible rendant la } \\
\text { sortie du bébé difficile. Dans certaines situations, l'agent de santé chargé } \\
\text { de faire l'accouchement est obligé de couper le périnée de la femme } \\
\text { excisée pour permettre la sortie de l'enfant (épisiotomie). Si cela n'est pas } \\
\text { fait à temps, l'expulsion du bébé est trop prolongée mettant sa vie et celle } \\
\text { de sa mère en danger : déchirures du périnée, fistules vésico-vaginales } \\
\text { ou/et recto-vaginales, mort, et bien d'autres complications. } \\
\text { La tête du bébé qui reste coincé pendant longtemps au cours de } \\
\text { l'accouchement peut avoir plus tard des problèmes d'encéphalopathies et } \\
\text { autres handicaps mentaux. }\end{array}$ \\
\hline $\begin{array}{l}\text { Le clitoris peut grandir } \\
\text { et trainer entre les } \\
\text { cuisses de la femme }\end{array}$ & $\begin{array}{l}\text { Si le clitoris devait se développer jusqu'à trainer entre les cuisses, le pénis } \\
\text { des hommes allait trainer par terre car il est extérieurement beaucoup plus } \\
\text { long que le clitoris. }\end{array}$ \\
\hline
\end{tabular}

9. Faire la synthèse et compléter s'il existe d'autres arguments en s'inspirant de la deuxième colonne du tableau en utilisant un marqueur de couleur différente.

10. Attribution des points aux bonnes réponses données par chacune des équipes et faire la sommation des notes obtenues pour déterminer l'équipe gagnante. 
11. Répondre aux questions des participantes s'il en existe.

12. Conclure la session et remercier les participantes. 


\section{Session 26 : Les IST, le VIH/SIDA, et le dépistage du VIH}

\section{Objectifs de la session:}

À la fin de cette session, les filles seront capables de:

- Décrire les Infections Sexuellement transmissibles (IST), y compris le VIH, et distinguer entre les mythes et réalités

- Discuter des IST et du VIH avec un partenaire sexuel

\section{Matériel nécessaire:}

- Flipchart

- Marqueurs

\section{Plan de la session:}

- Comprendre les IST (20 minutes)

- IST: Mythes et Réalités (20 minutes)

- Comprendre le VIH/SIDA (15 minutes)

- VIH/SIDA: Mythes et Réalités (20 minutes)

- Parler à un Partenaire Sexuel des IST et du VIH (20 minutes)

Durée totale: 95 minutes

\section{AVANT LA SESSION:}

Écrivez ces questions sur le flipchart.

1. Qu'est ce que le VIH?

2. Comment se transmet le VIH?

3. Comment se transforme le VIH en SIDA?

4. Comment prévenir le VIH?

\section{NOTES D'INFORMATION}

Les maladies sexuellement transmissibles, y compris le $\mathrm{VIH}$, sont des sujets difficiles et potentiellement sensibles. Rappelez aux filles que tous les sujets et discussions au cours des sessions, sont confidentiels.

\section{Infections sexuellement transmissibles}

Les infections sexuellement transmissibles sont des infections qui se propagent à travers l'activité sexuelle. Toutes sont évitables. Les IST sont des maladies transmissibles très répandues, notamment chez les jeunes de 15 à 29 ans. Certaines IST présentent des symptômes, mais ce n'est pas toujours le cas (surtout chez les femmes). Ces IST peuvent avoir de graves conséquences : VIH, PVH (verrues génitales), syphilis, blennorragie, chlamydia, trichomonas et herpès.

Il est possible d'attraper une IST, même après un seul rapport sexuel avec une personne infectée. Certaines IST sont traitables avec I'utilisation correcte des médicaments, mais d'autres ne disparaîtront jamais. 


\section{Qu'est ce que le VIH?}

Le VIH (virus de l'immunodéficience humaine) est un virus qui attaque et détruit le système immunitaire d'une personne. Le VIH affaiblit le corps et diminue la résistance du corps aux maladies. II survit dans les liquides corporels comme le sperme, les sécrétions vaginales et le sang. Une personne est dite séropositive lorsque le virus est détecté dans son sang. Une personne est dite séronégative lorsque le virus n'est pas détécté dans son sang.

\section{Comment se transmet le VIH?}

Le VIH est présent dans les liquides corporels des personnes infectées. Une personne séropositive peut transmettre le virus à travers son sperme (y compris le liquide pré-éjaculatoire), ses sécrétions vaginales, son lait ou son sang. Le virus se transmet le plus souvent lors de l'échange de sperme et de sécrétions vaginales durant l'acte sexuel. II peut se transmettre lors de rapports vaginaux ou anaux entre un homme et une femme, mais aussi lors de rapports anaux entre deux hommes. La présence d'une infection sexuellement transmissible peut accroître le risque de contraction ou de transmission sexuelle du VIH. Le virus se transmet aussi par transfusion de sang contaminé ou partage d'aiguilles contaminées pour l'injection de drogues ou de stéroïdes, le perçage ou le tatouage. II se transmet aussi par le partage de rasoir, par exemple pour l'excision ou pour faire les cicatrices raciales. Une mère séropositive peut transmettre le virus à son enfant pendant la grossesse, l'accouchement ou l'allaitement. Les relations buccogénitales (les rapports sexuels par voie orale) présentent aussi un risque de transmission.

\section{Comment se transforme le VIH en SIDA?}

Affaibli par le VIH, le corps ne peut plus se défendre contre la maladie et devient vulnérable à de graves infections, cancers, et maladies parfois mortelles, comme pour exemple la tuberculose. On parle alors de SIDA (syndrome d'immunodéficience acquise). Les personnes atteintes du VIH peuvent aussi recevoir le diagnostic du SIDA si leurs analyses de sang révèlent une insuffisance immunitaire.

\section{Comment prévenir le VIH ?}

Aucun vaccin ni cure n'existe actuellement contre le VIH. La prévention est donc essentielle.

La transmission sexuelle peut être prévenue par abstinence de rapports sexuels non protégés ou usage du préservatif masculin ou féminin à chaque rapport. Une autre approche consiste à se limiter à un(e) seul(e) partenaire sexuel(le) qui n'est pas infecté(e), en lui restant « fidèle ». Cette approche n'est valable que si les deux partenaires sont vraiment monogames et qu'ils sont tous deux séronégatifs. Beaucoup de personnes ignorent malheureusement qu'elles - ou leurs partenaires sont déjà infectées. Le seul moyen d'être certain de son état est de faire le test de dépistage du VIH. Personne ne peut de plus garantir que son ou sa partenaire n'en aura jamais d'autres. Aussi l'approche de la fidélité est-elle souvent risquée. Pour les hommes, la circoncision offre une certaine protection contre le $\mathrm{VIH}$, sans toutefois éliminer le risque. Pour les femmes, la circoncision masculine ne présente à ce jour aucun avantage direct connu, et l'excision augmente le risque de transmission parce que la femme excisée peut avoir des douleurs et des déchirures au moment des rapports sexuels. Le préservatif reste donc de rigueur. 
La transmission par les objets souillés peut aussi être prévenue moyennant l'usage d'un objet neuf ou stérilé à perçage de la peau. Cela inclus les aiguilles, les raisoirs, et tous autres objets qui entre en contact avec le sang.

Transmission mère-enfant: Il convient en tout cas de dépister les femmes enceintes. Celles séropositives peuvent prendre des médicaments préventifs pour réduire le risque de contamination de leur enfant pendant la grossesse et l'accouchement. La transmission du virus peut aussi survenir après l'accouchement, à travers le lait maternel. Les mères séropositives doivent obtenir l'avis d'un prestataire de santé pour prévenir la transmission pendant la grossesse et l'accouchement, et concernant aussi leurs options d'allaitement.

\section{INSTRUCTIONS}

\section{Comprendre les infections sexuellement transmissibles (IST) (20 minutes)}

1. Définir les IST en utilisant la définition dans « notes d'information ».

2. Montrez la liste des IST à partir du support ci-dessous. Expliquez les symptômes et traitements typiques des IST. Laissez les participants donner des noms locaux de chaque infection.

3. Expliquez pourquoi les filles sont plus à risque.

Les femmes sont plus exposées au risque d'IST que les hommes pour plusieurs raisons:

- Les différences dans le corps des femmes rendent la détection des IST plus difficile

- Pour quelques IST, l'infection a des conséquences plus graves sur les femmes que les hommes

- Le risque de transmission est supérieur de l'homme à la femme que de la femme à l'homme.

- Beaucoup de femmes ont peu de pouvoir pour se protéger dans des situations sexuelles

- Les liquides sexuels d'un homme (et l'infection s'il est malade) restent à l'intérieur du corps d'une femme après un rapport sexuel

- Les filles plus jeunes sont plus susceptibles de souffrir de déchirures du vagin pendant les rapports sexuels, ce qui favorise la transmission de l'infection.

4. Dites aux filles, «ll est important de s'abstenir de rapports sexuels si vous avez des symptômes d'une IST. Vous pouvez facilement propager I'IST si vous avez des plaies ouvertes. Si vous pensez que vous avez une IST, vous devriez voir un médecin et vous assurez de le dire à votre partenaire afin qu'il ne contracte pas l'infection également.»

\section{Les IST : Mythes et réalités (20 minutes)}

1. Expliquez aux filles qu'elles vont se prêter à un jeu de rôle pour mieux comprendre les IST. Divisez les filles en deux groupes et demandez à chaque groupe de choisir un nom. 
2. Lisez une question à partir de la "banque de questions» (ci-dessous) et demandez au premier groupe d'y répondre. Si la première équipe y répond en moins d'une minute, donnez-lui 10 points. Si le groupe désigné ne peut pas répondre, l'autre groupe peut essayer, mais gagnera seulement 5 points.

3. Écrivez les scores sur le tableau ou le flipchart. Montrez aux filles comment additionner les chiffres à mesure que vous jouez, pour renforcer les capacités en calcul.

4. Apportez des réponses correctes pour chaque question et expliquez davantage à travers les débats. Si le temps est compté, vous n'avez pas à poser toutes les questions.

5. L'équipe qui a le meilleur score gagne!

\section{Banque de questions sur les IST}

\section{Q1. Qu'est ce que les IST?}

A. Les IST sont des infections qui sont essentiellement transmises par contact sexuel. Le contact sexuel comprend les rapports sexuels et le contact corporel intime, surtout s'il y a contact avec les liquides corporels.

\section{Q2. Nommez 3 IST.}

A. Gonorrhée/Blennorragie, Syphilis, Herpès, VIH / SIDA, Chancre mou, Chlamydia; HPV

\section{Q3. Savez-vous toujours dans l'immédiat si vous avez une IST?}

A. Pas toujours. Vous pouvez avoir une IST pendant longtemps avant de le savoir. Par exemple, la gonorrhée/blennorragie et le VIH ne présentent pas immédiatement des symptômes. Pour les hommes, quelques fois il y a des symptômes plus clairs et donc, l'auto-détection précoce est possible dans certains cas. Mais le VIH ne présente pas immédiatement des symptômes pour les hommes ni pour les femmes.

\section{Q4. Quels sont des exemples de symptômes des IST?}

A. Sensation de brûlure lors des mictions, un écoulement clair ou crémeux du pénis ou des pertes blanches du vagin, des ampoules, des ulcères ou des œdèmes sur ou autour des organes génitaux. N'oubliez pas que pour certaines IST il n'y a pas de symptômes immédiats.

\section{Q5. Citez trois IST qui ont généralement des symptômes.}

A. Hépatite B (symptômes grippaux); herpès (lésions douloureuses sur les organes génitaux); Syphilis (commence par une ou plusieurs lésions non douloureuses sur les organes génitaux); trichomonase (les femmes peuvent avoir des pertes vaginales légères, de couleur jaunâtre verdâtre avec une forte odeur. Peut aussi causer des démangeaisons ou des malaises lors des rapports sexuels et mictions).

\section{Q6. Citez trois IST qui sont généralement SANS symptômes.}

A. Le chancre mou; Chlamydia; gonorrhée, VIH (initialement); HPV 


\section{Q7. Le VIH est-il une IST?}

A. Oui, quand elle est transmise sexuellement. Toutefois, le VIH peut également être contracté par contact non sexuel avec des liquides corporels ou par le sang d'une personne infectée.

Q8. Quelle est la première chose à faire lorsque vous soupçonnez une IST?

A. Consulter un médecin pour obtenir un diagnostic et un traitement appropriés. Informer votre partenaire sexuel.

\section{Q9. Devriez-vous avoir des rapports sexuels lorsque vous avez une IST?}

A. Non, vous pouvez infecter un partenaire, même pendant votre traitement.

\section{Q10. Quelles sont les IST NON soignables?}

A. L'herpès (bien que les symptômes puissent être maîtrisés grâce à un traitement); le VIH

\section{Q11. Comment est-ce que vous pouvez vous protéger des IST?}

A. En s'abstenant des rapports sexuels ou en utiliser toujours un preservatif (masculin ou feminin).

\section{$\rightarrow$ Comprendre le VIH/SIDA (15 minutes)}

1. Ensuite, dites aux filles qu'elles vont parler du VIH et du SIDA. Divisez les filles en 3 groupes.

2. Allez sur les questions que vous avez écrites sur le flipchart avant la session:

1. Qu'est ce que le VIH?

2. Comment se transmet le VIH?

3. Comment se transforme le VIH en SIDA?

4. Comment prévenir le VIH?

3. Dites aux filles de discuter de ces questions dans leurs groupes pendant 5 minutes.

4. Demandez aux filles de revenir ensemble dans le grand cercle. Répondez à chacune des quatre questions en demandant aux filles de partager leurs idées avec le groupe élargi. Examinez les informations dans les «notes d'information" qui répondent à ces questions. Utilisez ces informations comme orientations pour la discussion.

\section{$\rightarrow$ VIH/SIDA: Mythes et réalités (20 minutes)}

1. Dites aux filles qu'elles vont maintenant passer à un jeu pour tester leur compréhension du VIH / SIDA.

2. Divisez les filles en 2 équipes. Demandez aux filles de choisir des noms d'équipe. Écrivez les noms des équipes sur le tableau ou le flipchart.

3. Lisez une des questions ci-dessous à l'intention d'une seule équipe. L'équipe a une minute pour décider si la déclaration est vraie ou fausse. Si elle choisit la bonne réponse, l'équipe gagne 5 points. Si elle arrive à donner plus d'informations, donnez à l'équipe 5 points supplémentaires. Si l'équipe 
n'a pas été à mesure de répondre correctement, demandez à l'autre équipe de donner les informations relatives à la déclaration. Si elle arrive à le faire, donnez-lui 5 points.

4. Passez d'un groupe à l'autre jusqu'à épuiser toutes les questions. Suivez les scores des équipes sur le tableau ou l'affiche. L'équipe qui a le score le plus élevé gagne.

\section{Vous n'aurez pas le VIH si votre partenaire est propre et soucieux de l'hygiène. Faux.}

Avoir une bonne hygiène (bains réguliers, port de vêtements propres, etc.) n'a rien à voir avec le statut sérologique d'une personne. Une personne séropositive qui est propre et soucieuse de l'hygiène peut toujours transmettre le virus du VIH à un partenaire sexuel.

\section{Ce sont les femmes qui propagent le VIH. Faux.}

Les femmes comme les hommes peuvent avoir le VIH et peuvent le transmettre à leurs partenaires sexuels. Notre société accuse souvent les femmes comme seules responsables de la propagation des IST, mais les hommes sont tout également responsables.

\section{Les rapports sexuels avec une jeune fille vierge guérissent un homme du VIH. Faux.}

Cette pratique ne guérit pas le VIH. Avoir des relations sexuelles avec une vierge expose la fille au risque d'infection, mais ne guérira pas l'homme.

\section{Si vous avez le VIH, vous en mourrez. Cela peut être vrai ou faux.}

La plupart des personnes vivant avec le VIH (PV-VIH) mourront du SIDA, mais, comme tout le monde, elles meurent aussi d'autres causes. Par exemple, elles peuvent mourir d'une crise cardiaque ou d'un accident de voiture. Si une personne séropositive reçoit un traitement approprié, elle peut vivre pendant de nombreuses années et mener une vie productive.

5. Les personnes vivant avec le VIH ne devraient jamais avoir des relations sexuelles. Faux.

Avoir le VIH ne signifie pas que vous ne pouvez pas avoir une vie sexuelle, mais seulement que vous devez faire très attention et utiliser des préservatifs. Un préservatif protège les partenaires sexuels contre le VIH et protège la personne contre une réinfection par le virus, les grossesses, et d'autres IST.

\section{Est-il possible de reconnaître une personne qu'a le VIH à l'œil nu. Faux.}

Le VIH ne manifeste pas de symptomes dans l'immédiat. Une personne vivante avec le VIH peut avoir une bonne santé pendant de mois ou des années avant de developper des signes de la maladie. Même si une personne semble être en bonne santé, il est possible qu'elle ait le $\mathrm{VIH}$.

7. Les personnes vivant avec le VIH ne devraient pas avoir d'enfants. Faux.

Chacun a le droit d'avoir des enfants. Si de grandes précautions sont prises, une mère séropositive peut donner naissance à un enfant séronégatif. Cependant, sans soins médicaux, l'enfant peut contracter le VIH. Les soins futurs de l'enfant sont également à prendre en compte 


\section{Un enfant à naître contractera le VIH si la mère est séropositive. Faux.}

Si une mère séropositive prend les médicaments prescrits pendant la grossesse, le travail et après l'accouchement ainsi que pendant l'allaitement, elle ne transmettra pas nécessairement le virus à son bébé. Environ un sur trois bébés nés de mères séropositives qui n'ont pas pris de médicaments contractera le VIH. Si la mère prend les médicaments, c'est moins probable que le bébé naisse séropositif. La chose la plus importante est que la mère séropositive cherche des conseils médicaux dès qu'elle envisage de porter un enfant et continue d'être suivie jusqu'après son accouchement. Un agent de santé ou une sage-femme doit l'assister à la naissance.

9. Si vous avez des rapports sexuels non protégés avec une personne séropositive, vous serez certainement infectés. Faux.

Ce n'est pas tous ceux qui ont des rapports sexuels avec une personne séropositive qui contracteront la maladie. Certaines personnes peuvent avoir des rapports sexuels pendant longtemps avec une personne qui a le VIH sans contracter la maladie. D'autres sont infectées dès la première fois qu'ils ont des relations sexuelles avec une personne séropositive. Contracter le VIH est toujours un risque, mais il est important de savoir que le partenaire d'une personne séropositive n'est pas nécessairement séropositif.

10. Les préservatifs ne protègent que contre la grossesse et non le VIH parce que le virus du VIH est si petit qu'il peut passer à travers le préservatif. Faux.

Les préservatifs sont utiles dans la prévention de la grossesse, mais lorsqu'ils sont utilisés correctement et systématiquement, ils se sont aussi révélés très efficaces dans la protection contre le VIH et les IST pour les personnes sexuellement actives. Les préservatifs masculins sont le plus souvent disponibles sur le marché, mais il y a aussi des préservatifs féminins qui sont de plus en plus disponibles ces derniers temps.

11. Même si les deux partenaires sont séropositifs, ils ont encore besoin d'utiliser un préservatif. Vrai

Tout simplement parce que le fait que les deux partenaires soient séropositifs, ne signifie pas qu'ils ne devraient pas avoir une sexualité sans risques. Il est possible d'être réinfecté par une souche différente du virus, ou des autres IST. Dans ce cas, la progression du VIH vers le SIDA va considérablement s'accélérer et le traitement du VIH sera de plus en plus difficile.

\section{Le mariage protège contre le VIH ? Faux}

Le VIH ne se transmet pas uniquement par voie sexuelle. En plus, beaucoup de personnes ignorent qu'elles - ou leurs partenaires - sont déjà infectées. Le seul moyen d'être certain de son état est de faire le test de dépistage du VIH. Personne ne peut de plus garantir que son ou sa partenaire n'en aura jamais d'autres. Aussi l'approche de la fidélité est-elle souvent risquée. 
13. Est-ce que les gestes suivants peuvent être source de transmission du VIH/SIDA? (Répondre par vrai ou faux pour chaque élément de la liste ci-dessous)

- Le toucher Faux.

- Le fait de manger ensemble Faux

- Dormir dans le même lit Faux

- Rapports sexuels non protégés Vrai

- Utiliser les mêmes serviettes Faux

- Utiliser les mêmes couverts Faux

- Utiliser les objets souillés par le sang contaminé Vrai

- Piqûre de moustique Faux

- Allaitement maternel du bébé par la mère infectée Vrai

La transmission du VIH/SIDA se fait par rapports sexuels, de la mère à l'enfant, ou par voix sanguine. La transmission par voix sanguine veut dire que l'utilisation du même razoir peut par exemple transmettre le VIH/SIDA, si l'une des personnes utilisant le razoir est infectée. C'est également le cas pour la salive : si l'une des personnes est infectée et a une lésion dans la bouche, la transmission peut se faire de bouche à bouche (à travers la salive) si tous les deux ont une lésion buccale. Le VIH/SIDA n'est donc pas transmis par la simple cohabitation avec une personne infectée.

\section{$\rightarrow$ Parler à un partenaire sexuel des IST et du VIH (20 minutes)}

1. Ramenez les filles dans un grand groupe. Expliquez aux jeunes filles: «Nous avons beaucoup appris aujourd'hui sur les IST et le VIH / SIDA. Il est bon que chacun de nous ait ces informations, afin que nous puissions prévenir ces maladies et savoir si nous ou nos partenaires sont atteints de ces maladies. Mais que ferez-vous si vous pensez que votre partenaire a une IST ou le VIH? Voyons dans la pratique comment parler à nos partenaires à travers le jeu de rôle. Veuillez choisir un partenaire ".

2. Dites-leur qu'elles passeront maintenant à un jeu de rôle pour discuter de ce qui suit: "Que pourriez-vous faire ou dire, si vous remarquez que votre partenaire sexuel a des plaies ou un écoulement inhabituel ou des odeurs dans les parties génitales? ”

3. Dites aux filles qu'une d'entre elles va jouer le rôle de la "fille», et une autre fille prétendra être le «partenaire souffrant d'IST ». Donnez aux filles 3 minutes pour le jeu de rôle. Dites ensuite aux filles de changer de rôles, et demandez leur de rejouer 3 autres minutes. Puis ramenez le groupe ensemble pour discuter.

4. Animez un débat en posant les questions suivantes:

- Était-il difficile ou inconfortable de parler à votre «partenaire»? Même si ce n'est pas aisé de discuter avec votre partenaire, pourquoi est-il important de le faire?

- Quels sont les trois moyens les plus éfficaces d'éviter les IST?

- S'abstenir de tout rapport sexuel

- Utiliser des préservatifs pour chaque rapport sexuel 
- Être fidèle à un partenaire qui vous est également fidèle

- Quels sont les trois choses que vous devez faire si vous pensez avoir contracté une IST?

- Rechercher immédiatement un traitement médical approprié en se présentant dans un centre de santé pour obtenir un traitement médical approprié

- Informer votre ou vos partenaire(s) sexuel(s)

- S'abstenir de rapports sexuels jusqu'à ce qu'il n'y ait plus de signes d'infection et que vous ayez pris tous les médicaments. 


\section{Infections sexuellement transmissibles (IST)}

Remarque : L'information présentée ici peut changer en fonction de l'avance de la recherche, des tests et des approches de traitement. Pour toutes mises à jour et renseignements complémentaires voir <www.who.int/topics/sexually_transmitted_infections/fr/>

\begin{tabular}{|c|c|c|c|c|}
\hline IST & Symptômes féminins & Symptômes masculins & Guérissable? & Vaccin? \\
\hline Chancre mou & \multicolumn{2}{|c|}{$\begin{array}{l}\text { Plaies douloureuses au niveau des organes génitaux; ganglions gonflés dans l'aine. } \\
\text { Les femmes sont souvent asymptomatiques. }\end{array}$} & Oui & Non \\
\hline Chlamydia & $\begin{array}{l}\text { La plupart des femmes sont } \\
\text { asymptomatiques. } \\
\text { Les femmes qui ont des symptômes } \\
\text { peuvent avoir des pertes vaginales } \\
\text { anormales ou une sensation de brûlure } \\
\text { quand elles urinent. }\end{array}$ & $\begin{array}{l}\text { Souvent asymptomatique. Les } \\
\text { hommes qui ont des symptômes peuvent } \\
\text { observer un écoulement pénien purulent } \\
\text { ou avoir une sensation de brûlure quand ils } \\
\text { urinent. }\end{array}$ & $\begin{array}{l}\text { Oui. Non traitée, cette IST peut mener à } \\
\text { une infection génitale haute chez la femme, } \\
\text { susceptible de la rendre stérile. Les } \\
\text { complications sont rares chez l'homme. }\end{array}$ & Non \\
\hline Blennorragie & $\begin{array}{l}\text { La plupart des femmes sont } \\
\text { asymptomatiques. Sinon, écoulements } \\
\text { vaginaux anormaux et sensation de } \\
\text { brûlure quand elles urinent. }\end{array}$ & $\begin{array}{l}\text { Les hommes ont souvent un écoulement } \\
\text { anormal ou une sensation de brúlure quand } \\
\text { ils urinent. Certains n'ont pas de symptômes. }\end{array}$ & $\begin{array}{l}\text { Oui. Non traitée, cette IST peut mener à une } \\
\text { infection génitale haute chez la femme et } \\
\text { à la stérilité chez la femme comme chez } \\
\text { l'homme. }\end{array}$ & Non \\
\hline Hepatitis B & \multicolumn{2}{|c|}{$\begin{array}{l}\text { Certaines personnes ont des symptômes grippaux, la jaunisse et des urines foncées; } \\
\text { d'autres ne présentent aucun symptôme. }\end{array}$} & $\begin{array}{l}\text { Il n'existe à ce jour aucun médicament contre } \\
\text { l'hépatite B, mais le corps élimine souvent } \\
\text { l'infection de lui-même. Elle mène parfois à } \\
\text { une maladie chronique du foie. Les bébés et } \\
\text { les petits enfants courent un risque d'infection } \\
\text { chronique beaucoup plus grand. }\end{array}$ & Oui \\
\hline $\begin{array}{l}\text { Herpès (virus } \\
\text { herpès simplex) }\end{array}$ & \multicolumn{2}{|c|}{$\begin{array}{l}\text { Épisodes récurrents de lésions douloureuses au niveau des organes } \\
\text { génitaux ou de l'anus. }\end{array}$} & Non, mais les symptômes peuvent être traités. & Non \\
\hline $\begin{array}{l}\text { VIH (virus de } \\
\text { l'immunodéficience } \\
\text { humaine) }\end{array}$ & \multicolumn{2}{|c|}{$\begin{array}{l}\text { Le VIH ne présente généralement pas de symptômes dans les premiers temps. } \\
\text { Il mène généralement au sida. Les sidéens sont vulnérables à différentes infections, } \\
\text { cancers et autres affections graves. }\end{array}$} & $\begin{array}{l}\text { Non, le sida est une maladie chronique } \\
\text { mortelle, mais le traitement antirétroviral } \\
\text { en ralentit remarquablement la progression. }\end{array}$ & Non \\
\hline $\begin{array}{l}\text { Papillomavirus } \\
\text { (PVH ou HVP) }\end{array}$ & \multicolumn{2}{|c|}{$\begin{array}{l}\text { Peut être asymptomatique. Certaines souches sont la cause de verrues génitales, } \\
\text { d'autres de cancers : de la tête, du cou et de l'anus, du pénis chez l'homme et - le } \\
\text { plus souvent — du col utérin chez la femme. }\end{array}$} & $\begin{array}{l}\text { Non, mais les symptômes peuvent être } \\
\text { traités. Certaines cancers secondaires au } \\
\text { papillomavirus peuvent être soignés. }\end{array}$ & $\begin{array}{l}\text { Oui. Les vaccins } \\
\text { anti-PVH protègent } \\
\text { hommes et femmes } \\
\text { contre beaucoup des } \\
\text { souches du virus. }\end{array}$ \\
\hline Syphilis & \multicolumn{2}{|c|}{$\begin{array}{l}\text { Commence par une ou plusieurs lésions indolores au niveau des organes génitaux, du } \\
\text { rectum ou de la bouche. La deuxième phase peut présenter éruption cutanée, lésions } \\
\text { au niveau des muqueuses, fièvre et malaise. La phase latente commence quand ces } \\
\text { symptômes disparaissent. }\end{array}$} & $\begin{array}{l}\text { Oui, si traitée durant les premières phases. En } \\
\text { l'absence de traitement, l'infection reste dans le } \\
\text { corps. Le stade avancé de la syphilis attaque les } \\
\text { organes internes et peut être mortel. }\end{array}$ & Non \\
\hline Trichomonase & $\begin{array}{l}\text { Les femmes observent parfois des } \\
\text { pertes vaginales bulleuses de couleur } \\
\text { jaune verdâtre fort odorantes. Les } \\
\text { démangeaisons ou gênes sexuelles ou } \\
\text { urinaires sont aussi possibles. }\end{array}$ & $\begin{array}{l}\text { Les hommes sont généralement } \\
\text { asymptomatiques; il y a parfois un léger } \\
\text { écoulement pénien ou une légère brûlure au } \\
\text { passage de l'urine ou à l'éjaculation. }\end{array}$ & Oui & Non \\
\hline
\end{tabular}




\section{Session 27 : Le cancer du sein et le cancer du col de l'utérus}

\section{Objectifs de la session:}

À la fin de cette session, les filles seront capables de :

- Identifier les causes et l'importance de faire le dépistage du cancer du sein et celles du col de l'utérus

- De faire une auto-examination de son corps pour dépister un éventuel nodule.

\section{Matériel nécessaire :}

- Papier Flip-chart ou tableau

- Marqueurs ou craies

- Copies de l'auto examen du sein

\section{Plan de la session:}

- Identifier les causes et l'importance de faire le dépistage du cancer du sein et celui du col de l'utérus (40 minutes)

- Exercice pratique sur l'auto-examination de son corps pour dépister un éventuel nodule/cancer du sein (15 minutes)

Durée Totale: 65 minutes

AVANT LA SESSION : Lire attentivement les notes d'information pour comprendre très bien les maladies. Également, il faudrait examiner la façon dont vous allez instruire les filles sur chacune de ces maladies (voir le début de section «Instructions»).

\section{NOTES D'INFORMATION}

\section{Le cancer du col de l'utérus}

Le cancer du col de l'utérus est une maladie qui touche à l'appareil génital de la femme. C'est une maladie qui évolue par phases. Le malade peut ne pas percevoir les manifestations des symptômes lors de la phase initiale du cancer. Par la suite, les symptômes suivants peuvent apparaître chez la femme :

2. un saignement vaginal anormal ou un petit saignement entre les règles ;

3. de la douleur durant les rapports sexuels ou un saignement après les rapports sexuels ;

4. un écoulement vaginal séreux d'aspect clair ou nauséabond ;

5. une quantité accrue de pertes blanches.

Aux stades plus avancés, des symptômes peuvent se produire à mesure que les tumeurs grossissent ou envahissent d'autres organes :

- une douleur pelvienne ou dorsale ;

- des fuites d'urine (une incontinence) ou du sang dans l'urine;

- une perte de poids ;

- une perte de l'appétit ou anorexie ;

- un éssoufflement ;

- une anémie;

- du sang dans les selles ;

- de la constipation. 
D'autres états de santé peuvent déclencher des symptômes analogues à ceux d'un cancer du col de l'utérus. Seul l'agent de santé peut vous confirmer votre état de santé grâce aux examens médicaux minutieux qu'il vous demandera de faire.

Les causes sont multiples dont certaines sont liées à :

Activité sexuelle : Avoir de nombreux partenaires sexuels peut accroître la probabilité d'une infection par le VPH, et par conséquent le risque d'un cancer du col utérin.

Tabagisme : les personnes qui fument courent un plus grand risque de cancer du col utérin et d'autres cancers. La survenue du cancer du col utérin a aussi été associée au tabagisme et à l'exposition à la fumée secondaire (la fumée de tabac ambiante). Le risque augmente en fonction de la durée du tabagisme et du nombre de cigarettes fumées quotidiennement.

Le cancer du col utérin se détecte principalement au moyen du test de Pap. II permet de détecter un cancer ou des cellules précancéreuses pouvant mener à un cancer. Le test de Pap est un procédé rapide et simple qui ne cause habituellement pas de douleur.

Actuellement, on recommande à la population féminine âgée de 18 ans à 69 ans (ou de moins de 18 ans ayant une vie sexuelle active) d'effectuer le teste de depistage du cancer à chaque deux ou trois ans.

La plupart des cas de cancers du col utérin peuvent être prévenus ou guéris quand ils sont dépistés dans les phases initiales.

Les femmes peuvent réduire au minimum leur risque de cancer du col utérin en évitant de contracter une infection par le VPH. Le virus est plus souvent transmis par un contact sexuel et au cours de rapports sexuels. En vous abstenant de toucher les organes génitaux d'une personne infectée, et en utilisant un préservatif, vous réduirez le risque d'une infection par le VPH.

La vaccination est une autre façon de prévenir le cancer du col utérin. Le vaccin est actuellement disponible. Renseignez-vous auprès du centre de santé.

\section{Le cancer du sein}

Le cancer du sein est une de la glande mammaire. C'est une maladie qui peut survenir chez l'homme ou chez la femme. Cependant, il est beaucoup plus fréquent chez la femme que chez l'homme. II survient 200 fois moins souvent chez l'homme que chez la femme. Cinq 5 à $10 \%$ de ces cancers ont une origine génétique héréditaire; 85 à $90 \%$ des cas ont des origines environnementales.

L'auto-examen des seins peut permettre la découverte d'une anomalie. II est conseillé aux femmes surtout de le faire régulièrement, mais retenez qu'il ne faut pas se fier à $100 \%$ aux résultats de cette pratique. Un dépistage précoce améliore considérablement le pronostic du cancer du sein. L'autopalpation n'est pas un substitut à une mammographie (examen de détection du cancer du sein). Par conséquent, vous êtes invités à faire l'examen au moins une fois par an. Au Burkina Faso, certains hôpitaux ou cliniques font le test de dépistage 


\section{INSTRUCTIONS}

Les causes et l'importance de faire le dépistage du cancer du sein et celles du col de l'utérus (40 minutes)

1. Introduire la session : Aujourd'hui, nous allons discuter sur les cancers qui touchent surtout les femmes car ces maladies sont de plus en plus nombreuses dans notre pays. Nous allons particulièrement parler de deux types de cancer : le cancer du col de l'utérus et celui du sein.

2. Diviser le groupe en deux équipes (Equipe A et Equipe B)

3. Inviter les deux équipes à mener une compétition en répondant aux questions que vous aller poser et qu'à la fin du jeu, l'équipe gagnante sera celle qui enregistrera le plus de bonnes réponses.

4. Ecrire en grand caractère sur le côté droit du flip-chart "EQUIPE $A$ » et sur le côté gauche «EQUIPE B »

5. Poser les questions ci-dessous et inviter à chaque fois chacune des équipes à donner sa réponse.

\section{Questions}

- Qu'est ce que le cancer de façon générale ?

- Quels sont les types de cancer que vous connaissez ?

- Qu'est-ce que le cancer du col de l'utérus ?

- Comment la maladie se manifeste ? Citez quelques symptômes que vous connaissez.

- Que faire si vous découvrez que vous développez un de ces symptômes ?

- Est-ce que le cancer du col de l'utérus peut être soigné ?

- Comment réduire votre risque du cancer?

6. Enregistrer les réponses de chaque équipe dans l'espace qui leur est réservée sur le flip-chart.

7. Faire la synthèse en donnant les bonnes réponses.

8. Comptabiliser la note obtenue par chacune des équipes

9. Passer à l'exercice pratique.

Exercice pratique sur l'auto-examination de son corps pour dépister un éventuel nodule/cancer du sein (15 minutes)

1. Introduire par ces termes :

Les médecins ont toujours encouragé l'auto-examen des seins, y compris aux jeunes femmes. Pour eux, cette autopalpation peut participer à un dépistage précoce du cancer du sein, parallèlement à une mammographie régulière, ainsi qu'à un examen annuel chez le gynécologue. 
L'auto-examen des seins (ou AES) doit débuter par une inspection visuelle devant un miroir, dans quatre positions différentes: bras tombant le long du corps, mains posées sur les hanches, bras en l'air et buste légèrement penché vers l'avant. C'est là qu'il faut rechercher toute modification du sein, tant au niveau de sa taille que de sa forme, sans oublier l'aspect de la peau également. De plus, il faut examiner soigneusement le mamelon, afin de vérifier qu'il a bien sa forme habituelle, et enfin, il faut le pincer délicatement pour s'assurer qu'aucun liquide ne s'en écoule.

L'examen suivant peut être effectué au moment de la douche. Il convient de relever un bras, de le placer derrière la tête, et de palper, avec trois doigts, le sein qui se trouve du même côté que le bras relevé. Ensuite, on peut pratiquer le même examen, mais allongée sur le dos. Toutes ces palpations peuvent s'effectuer selon trois méthodes: celle du cercle, du quadrillage ou celle dite de l'horloge, dans laquelle il convient de palper les seins en agissant comme les aiguilles d'une horloge.

Sachez aussi que les seins de chaque femme sont différents, et que les seins peuvent changer pendant les règles. Pour certaines femmes, les seins deviennent plus grands, plus sensibles, ou plus dures pendant les règles. Ces changements sont normaux, mais, si vous sentez qu'il y a un nodule nouveau, une fossette dans la peau, ou un changement au mamelon, vous devrez consulter un médecin. Pour terminer, sachez que l'auto-examen des seins doit être pratiqué quelques jours après le début des règles, et, pour les femmes ménopausées, une fois par mois, à la même date. Un petit examen tout simple à faire et qui peut, dans certains cas, sauver bien des vies.

Notez cependant que la consultation d'un médecin s'avère indispensable, car ce dernier doit s'assurer que vous effectuez votre autopalpation de façon éfficace.

2. Donner la parole à celles qui ont des questions et donner des réponses appropriées

3. Demander aux filles de se mettre toutes en position débout et ensemble faites les mouvements indiqués dans le texte.

4. Répéter l'exercice deux ou trois fois et conclure en invitant les filles à le faire souvent suivant l'e calendrier indiqué. 
Auto-Examen du sein

Simple comme 1, 2, 3!

La sante des seins commence par une bonne connaissance de vos seins. Les tissus mammaires couvrent une assex. grande région ien hauteur jusqu' la clavicule et, en largeur, de $T$ aisselle jusqu'au milieu du sternum, au centre de la poitrine, Apprenez a reconnaitie ce qui est normal pour vous dans cette region, incluant les mamelons:

1 Debout

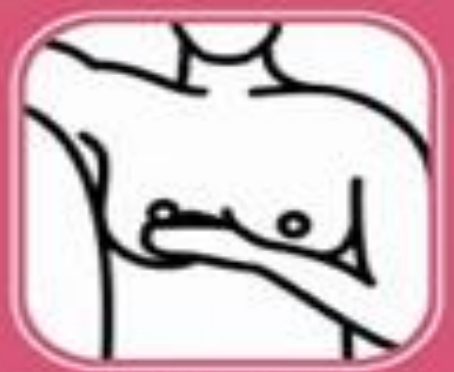

tever le bras et palper chacuesein.
2 Position couchée

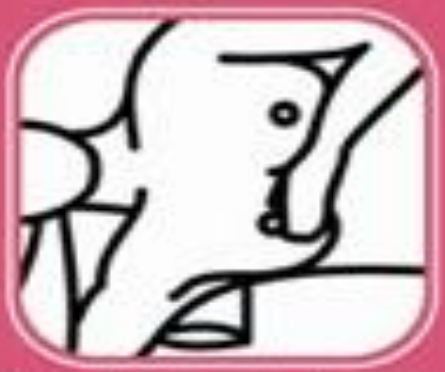

Installez un oreilier sous votre épaute et placer 1a main sous la tete, puis palpex chaque sein.

3 Devant le miroir

Observer vos seins dans le miroir et notez tout changement:

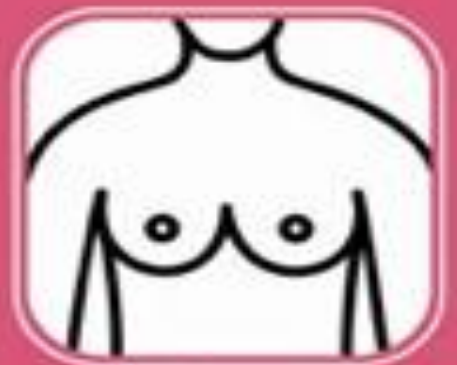

bras de chaque coté

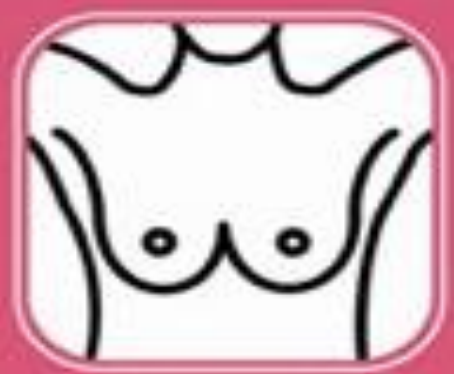

bras levés

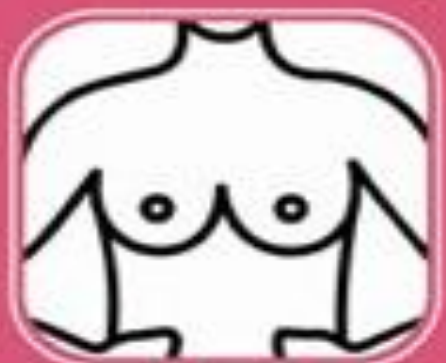

mains sur les hanches

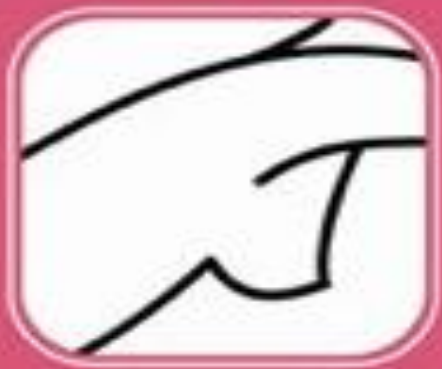

penchee vers I'avant 


\section{Session 28 : Information et communication sur la sexualité et sur la santé de la reproduction}

\section{Objectifs de la session:}

À la fin de cette session, les filles seront capables de:

- Communiquer avec leurs camarades sur la sexualité et la santé de la reproduction

- Recourir à des structures ou à des personnes appropriées pour les questions sur la sexualité et la santé de la reproduction

\section{Matériel nécessaire:}

- Papier Flip-chart ou tableau

- Marqueurs ou craies

Plan de la session:

- Jeu de rôle sur la communication sur la sexualité et la santé de la reproduction (35 minutes)

- Jeu de rôle sur le recours aux structures ou à des personnes appropriées pour les questions sur la sexualité et la santé de la reproduction (35 minutes)

Durée totale: 70 minutes

\section{INSTRUCTIONS}

\section{Jeu de rôle sur la communication sur la sexualité et la santé de la reproduction (30 minutes)}

1. Introduire la session par ceci: "Nous avons discuté dans les sessions précédentes, de la communication et son importance dans la vie en société. Aujourd'hui, nous allons surtout parler de la communication sur la sexualité et la santé de la reproduction. "Demandez aux filles de partager leurs expériences positives sur la communication avec les membres de leur famille et amis sur des sujets sensibles tels que la sexualité et la santé de la reproduction.

2. Diviser le groupe en petits groupes de cinq (5) personnes.

3. Demander à chaque groupe de discuter des thèmes suivants, à partir des exemples ou ce qu'elles ont entendu des expériences des autres filles. Ce n'est pas nécessaire de partager leurs propres expériences:

- La première fois qu'une fille a vu ses règles

- La première fois qu'une fille a eu des rapports sexuels

- La première fois qu'une fille a utilisé un condom avec un partenaire sexuel

- La première fois qu'une fille a utilisé une méthode contraceptive

4. Observez les groupes

- Est-ce qu'elles discutent sans gène ?

- $\quad$ Y a-t-il des blocages à s'exprimer ? 
- $\quad$ Est-ce que toutes les filles qui participent ?

5. Donner 10 minutes à chaque groupe pour discuter.

6. Inviter tout le monde à rejoindre sa place initiale.

7. Faciliter la discussion en posant les questions suivantes:

- Qu'avez-vous trouvé difficile de cette activité ?

- Est-ce que tout le monde a pu parler de son expérience sans se gêner ?

- Qu'est-ce qui fait que certaines d'entre vous n'ont pas pu parler de leur expérience ?

- Discutez-vous souvent des questions sur la sexualité ou la santé de la reproduction avec d'autres personnes?

- Si oui, qui sont le plus souvent ces personnes ?

- Pourquoi est-ce difficile de parler de sexualité avec ses parents, son petit ami, sa copine, l'agent de santé ?

- Comment s'y prendre pour discuter de ces sujets avec ces personnes ?

8. Faire une synthèse et conclure.

9. Passer à la deuxième suivante.

\section{$\rightarrow$ Jeu de rôle sur le recours aux structures ou à des personnes appropriées pour les questions sur la sexualité et la santé de la reproduction (30 minutes)}

1. Avant la session, identifier deux volontaires qui ont l'habitude de discuter de la sexualité avec leurs parents ou avec des personnes ressources dans leur communauté et demander les de faire un témoignage sur l'importance de communiquer sur la sexualité, comment elles procèdent généralement, avec qui elles communiquent souvent et qu'est ce qu'elles ont gagné en communiquant sur ces sujets. S'il n'y a pas de volontaire, demandez à deux filles de faire un jeu de rôle pour montrer pourquoi il est important de communiquer sur ce thème et quels sont les avantages qu'on peut tirer de cette situation.

2. Demander aux autres participantes de faire des commentaires sur ce qu'elles ont entendu.

3. Faire la synthèse en relevant le fait que dans notre entourage il y a des gens avec lesquels on peut discuter : les parents, les camarades, les amis, les enseignants, le personnel de santé, l'agent social, etc. et il est toujours important d'en parler car cela contribue à notre épanouissement et permet d'être averti sur différentes questions y afférentes.

\section{TRAVAIL DE MAISON}

A la fin de la session, demander à chacune des participantes de choisir un thème sur la sexualité ou sur la santé de la reproduction et d'identifier un interlocuteur (voisine, employeur, agent de santé, etc) avec qui elle ira en discuter. Demander à chacune de bien retenir le déroulement de la rencontre pour faire le feed-back à ses camarades à la prochaine session. Chacune des participantes doit insister sur les meilleures stratégies, les difficultés rencontrées, les leçons apprises pendant le compte rendu. 


\section{Session 29: Genre et les dynamiques de pouvoir}

\section{Objectifs de la session:}

À la fin de cette session, les filles seront capables de:

- Définir le genre

- Distinguer les caractéristiques attribuées aux hommes et aux femmes sur la base du sexe et du genre

- Comprendre les concepts de pouvoir et d'impuissance

- Étudier la dynamique de pouvoir entre les hommes et les femmes burkinabé et entre les travailleurs domestiques et leurs employeurs et leurs liens avec le contrôle des ressources

\section{Matériel nécessaire:}

- Flipchart et marqueurs

- Poster avec des images des ressources

- Lister ou utiliser le papier flipchart avec la liste des qualités des leaders que les filles ont fait pendant la session 10

\section{Plan de la session:}

- Comprendre le sexe et le genre (35 minutes)

- Pouvoir et impuissance (45 minutes)

- Vote pour les filles leaders (10 minutes)

Durée totale: 90 minutes

\section{AVANT LA SESSION}

Faites une affiche avec des dessins de chacune des ressources suivantes, ou servez-vous de la fiche d'images à la fin de la session, comprennant quelques uns des éléments suivants : animaux, semences, eau, transport, ustensiles de cuisine, formation professionnelle, école, crédit et micro-finance, logement pour l'activité intitulée «Pouvoir et Impuissance».

\section{NOTES D'INFORMATION}

Le concept de genre peut être très étranger aux filles de votre groupe, de sorte que votre travail est de faire une distinction claire entre sexe et genre. Préparez-vous à la session en affichant les posters sur les côtés opposés de la salle. Si cet exercice se déroule à l'extérieur, assurez-vous juste de placer les affiches assez loin.

Comprendre les définitions des concepts majeurs suivants est utile pour conceptualiser les questions de genre dans un contexte donné. II n'est pas nécessaire de couvrir toutes les définitions, mais elles peuvent servir de référence pour le reste de cette activité. Voici les définitions de "sexe " et " genre".

Le sexe renvoie aux différences biologiques entre les hommes et les femmes. II est généralement universel et ne peut changer avec le temps. 
Le genre renvoie aux rôles et responsabilités socialement conçus pour les femmes et les hommes. Cela signifie que les gens sont nés de sexe féminin ou masculin, mais apprennent à être des filles et des garçons et grandissent en agissant comme des femmes et des hommes. Les attitudes et comportements de genre sont appris et peuvent être modifiés.

Soulignez le fait que le genre est social et le sexe, biologique. Le sexe fait référence aux caractéristiques innées telles que les organes génitaux masculins ou féminins qui ne peuvent pas être modifiés mais les rôles de genre sont appris et peuvent être modifiés. Tout le monde est affecté par les normes de genre dans une certaine mesure; il est donc difficile pour une personne d'être $100 \%$ sensible au genre. En réalité, les femmes peuvent effectuer la plupart des mêmes tâches que les hommes et vice versa. Comprendre ces concepts permettra également de venir à bout des préjugés. Le genre inclu plusieurs aspects de la société. Par exemple, dans notre société, il y a une distinction claire entre les vêtements, le style de coiffure des cheveux, les bijoux, et les chaussures des hommes et des femmes. Les vêtements, le style de coiffure des cheveux les bijoux, et les chaussures qui sont normaux pour les hommes et pour les femmes sont charactéristiques de genre, et pas de sexe. Si un homme ne coupe pas ses cheveux, il est encore de sexe masculin. Si une femme n'utilise pas de jupe ou de pagne, elle est encore de sexe féminin.

De la même manière, il y a des grandes différences entre les rôles des hommes et des femmes dans notre société. Ce sont des femmes qui font normalement la cuisine et les tâches ménagères, cependent, l'homme est physiquement capable de faire les mêmes tâches. Un homme qui sait cuisiner est encore de sexe masculin. Au Burkina Faso, il y a plus de garçons que de filles qui sont à l'école et dans beaucoup de familles, l'éducation est plus valorisée pour les garçons que pour les filles. Mais, les garçons et les filles, ou les hommes et les femmes, sont également intélligents. Les femmes sont également capables de réussir à l'école et dans le travail intellectuel.

Toute formation sur les questions de genre est incomplète sans une discussion sur les différences de pouvoir entre hommes et femmes dans la société. Certains participants peuvent se sentir intimidés pour discuter des concepts de "pouvoir» et d'«impuissance». Utiliser les perceptions et expériences propres des participants sur ces concepts est un bon point de départ et peut aider à démystifier le sujet.

Si le groupe est prêt, vous pouvez mentionner les différents types de pouvoir. II y a un pouvoir qui supprime (où un seul parti est au pouvoir et l'autre est dominé); il y a un pouvoir coercitif (où quelqu'un utilise ses capacités pour amener les autres à servir ses intérêts). On peut aussi se sentir "habilité» quand on est en mesure de résoudre un problème ou apprendre un métier. Demandez aux participants les types de pouvoir les plus utilisés traditionnellement par les hommes et ceux qui sont traditionnellement utilisés par les femmes.

Pour expliquer ce que signifie "l'accès aux ressources et leur contrôle», examinez la situation des femmes rurales. Bien que les femmes rurales jouent un rôle central dans l'agriculture (notamment dans la phase post-récolte), elles ont moins accès aux ressources matérielles et financières (comme la terre, l'eau, le microcrédit) ainsi qu'aux services (tels que l'utilisation de la main-d'œuvre ou des animaux de trait) par rapport aux hommes. Les titres fonciers sont invariablement délivrés au nom du "chef de famille» qui est généralement un homme. Les femmes urbaines peuvent avoir un emploi rémunéré en dehors de leurs maisons et contribuer de manière significative aux revenus de 
la famille, mais leurs opinions sont souvent négligées quand il s'agit de prendre des décisions sur les ressources.

\section{INSTRUCTIONS}

\section{Comprendre le sexe et le genre (35 minutes)}

1. Donnez aux filles une brève introduction sur le sexe et le genre.

Demander aux filles de se servir de la fiche d'images à la fin de cette session pour attribuer chaque élément de la liste soit au genre masculin ou au genre féminin.

2. Divisez les filles en groupes de quatre ou cinq. Expliquez: "Aujourd'hui nous allons parler du "genre». Chaque groupe va imaginer des toiles de mots souvent associés au fait d'être un homme ou une femme. "Pour clarifier le concept de "toile de mots», donnez-en un exemple au tableau, sur un autre sujet. Voir l'exemple

\section{Note au mentor :}

Si les filles trouvent l'exercice des " toiles de mots" trop compliqué, vous pouvez modifier l'exercice et instruire simplement chaque groupe à réflechir en cinq ou six mots associés au fait d'être un homme ou une femme, et pas d'imaginer les toiles de mots. illustré ci-dessous pour le mot «bébé».

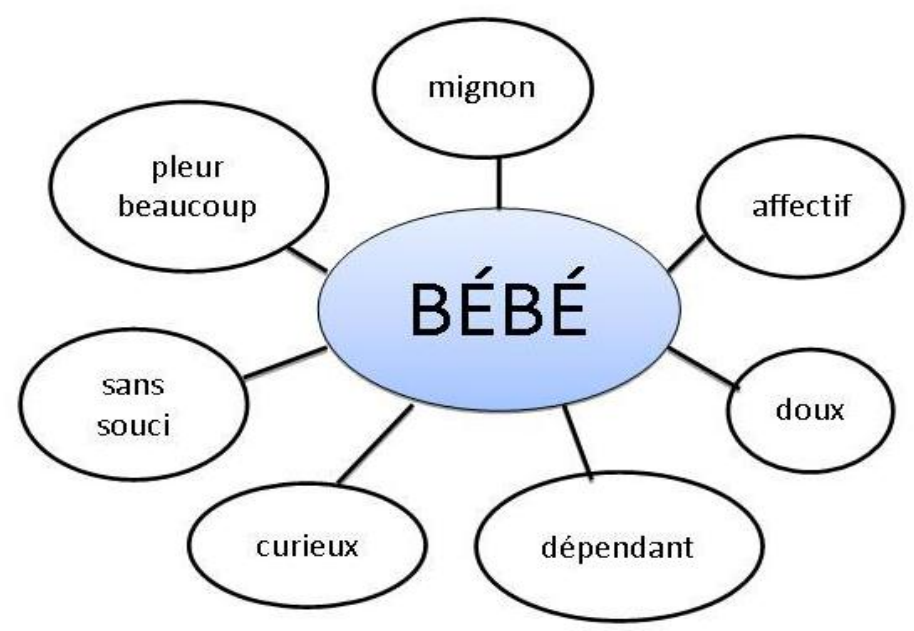

3. Donnez à chaque groupe deux à trois minutes pour réfléchir sur les mots associés aux hommes et des mots associés aux femmes.

4. Écrivez "Femme » et "Homme » au tableau et tracez sous chaque mot deux colonnes intitulées " Biologique » et « Social ». Commencez par un groupe et demandez :

- Donnez-moi une caractéristique que vous avez associée au mot «homme».

- S'agit-il d'une caractéristique " biologique " ou " sociale " ?

- Si les filles placent une caractéristique " sociale " dans la catégorie "biologique ", corrigez-les en demandant : si un garçon ou un homme ne possède pas cette caractéristique, est-il toujours de sexe masculin ?" 
5. Ajoutez une nouvelle caractéristique proposée par chaque groupe jusqu'à obtenir toutes celles qui définissent l'homme. Assurez-vous de la présence de beaucoup des mots suivants. (Au besoin, sondez pour obtenir les réponses voulues.). Exemples courants de caractéristiques associées à la masculinité :

- Force physique

- Absence d'expression affective

- Prédateur sexuel

- Hétérosexuel

- Réussite financière

- Chef de famille

- Décontracté

- Père

- Fier

- Puissant

- Athlétique

- Courageux

- Violent

- Plein d'humour

- Loyauté envers ses amis

6. Répétez l'approche pour les caractéristiques associées à la féminité. Exemples courants :

- Attentionnée

- Silencieuse

- Soumise

- Bavarde

- Bonne communicatrice

- Apparence soignée

- Psychologiquement forte

- Bien organisée/capable de faire plusieurs choses à la fois

- Pratique

- Non violente

- Modeste

- Bien équilibrée

- Physiquement faible par rapport à l'homme

- Aimante

- Mère

7. Réservez 10 minutes à la discussion au complet :

- Quelques caractéristiques masculines et féminines sont de nature biologique : le fait d'être père ou de pouvoir allaiter, par exemple.

- La plupart sont cependant déterminées par la société, sans fondement biologique.

- Les rôles masculins et féminins d'origine sociale sont des "rôles de genre ». Qui a déjà entendu cette expression? 
- Que pensez-vous des rôles de genre dans notre société? Êtes-vous d'accord avec tous les aspects de la façon dont les femmes sont censées agir et vivre ? Et les hommes?

- Que veut dire, selon vous, l'égalité de genre ?

- Dans chaque communauté et chaque société, certaines personnes ont des attitudes de genre et d'égalité non conventionnelles.

- L'évolution sociale, dans le temps et dans l'espace, s'accompagne de celle des attitudes à l'égard des rôles de genre.

\section{Pouvoir et impuissance (45 minutes)}

1. Expliquez que pendant cette activité, le groupe mettra l'accent sur la puissance et l'impuissance. Demandez-leur ce qu'elles savent sur ces termes, et expliquez que le pouvoir c'est quand une personne a le contrôle d'une situation et que l'impuissance, c'est quand elle en perd le contrôle.

2. Divisez les filles en petits groupes et demandez-leur de partager des exemples des moments où elles se sont senties puissantes ou impuissantes. Si les filles ont des problèmes, vous pouvez les pousser à réfléchir sur les situations avec les familles, les amis, les partenaires masculins, les employeurs.

3. Regroupez le groupe au complet et demandez à des filles de partager des exemples de situations où elles se sont senties puissantes ou impuissantes. Expliquez que le pouvoir est souvent lié au contrôle d'une personne sur les ressources.

4. Montrez aux filles l'affiche avec des images des différentes ressources.

5. Menez une discussion sur l'accès et le contrôle des ressources entre les hommes et les femmes dans leur société, en utilisant les questions à débattre suivantes:

\section{Questions à débattre}

- Quelles sont les ressources contrôlées par les femmes? Quelles sont celles contrôlées par les hommes?

- Comment les relations des femmes et des hommes affectent leur accès et leur contrôle sur les ressources?

- Est-ce les femmes, les hommes ou les deux qui prennent les décisions relatives aux ressources ou achats de grande valeur?

- Quels sont les liens entre le travail des femmes et leur utilisation et contrôle sur les ressources?

- Quels sont les liens entre le travail des hommes et leur utilisation et contrôle sur les ressources?

- Quel est l'impact de l'accès différent des hommes et des femmes aux ressources?

\section{Vote pour les filles « leaders » (10 minutes)}

1. Rappelez aux filles que pendant la session 10, elles ont discuté de ce que signifie être un leader. Lisez la liste des qualités que les filles ont faites pendant la session 10. Demandez aux filles si elles veulent ajouter ou changer des qualitiés. Si oui, ajoutez-les à la liste. 
2. Expliquez aux filles qu'on veut reconnaître deux filles qui ont démontré un leadership exceptionnel dans le programme, et que vous voulez que les filles elles-mêmes sélectionnent les filles leaders. Demandez aux filles de proposer des noms. Dites-leur q'une fille ne peut pas se proposer soi-même. Ecrivez les noms des filles sur le flipchart.

3. Demandez aux filles de bien réflechir et de choisir (sans rien dire) les deux filles qu'elles veulent voter. Expliquez aux filles qu'elles vont fermer les yeux et faire un vote silencieux en levant la main.

4. Demandez aux filles de fermer les yeux. Lisez les noms des filles qui ont été proposées par le groupe un à un. Lorsque vous dites le nom d'une fille, demandez à celles qui votent pour cette fille de lever la main. Pour chaque fille, comptez le nombre de votes pour elle et écrivez à côté de son nom. A la fin, demandez aux filles d'ouvrir les yeux et partagez les résultats du vote avec elle.

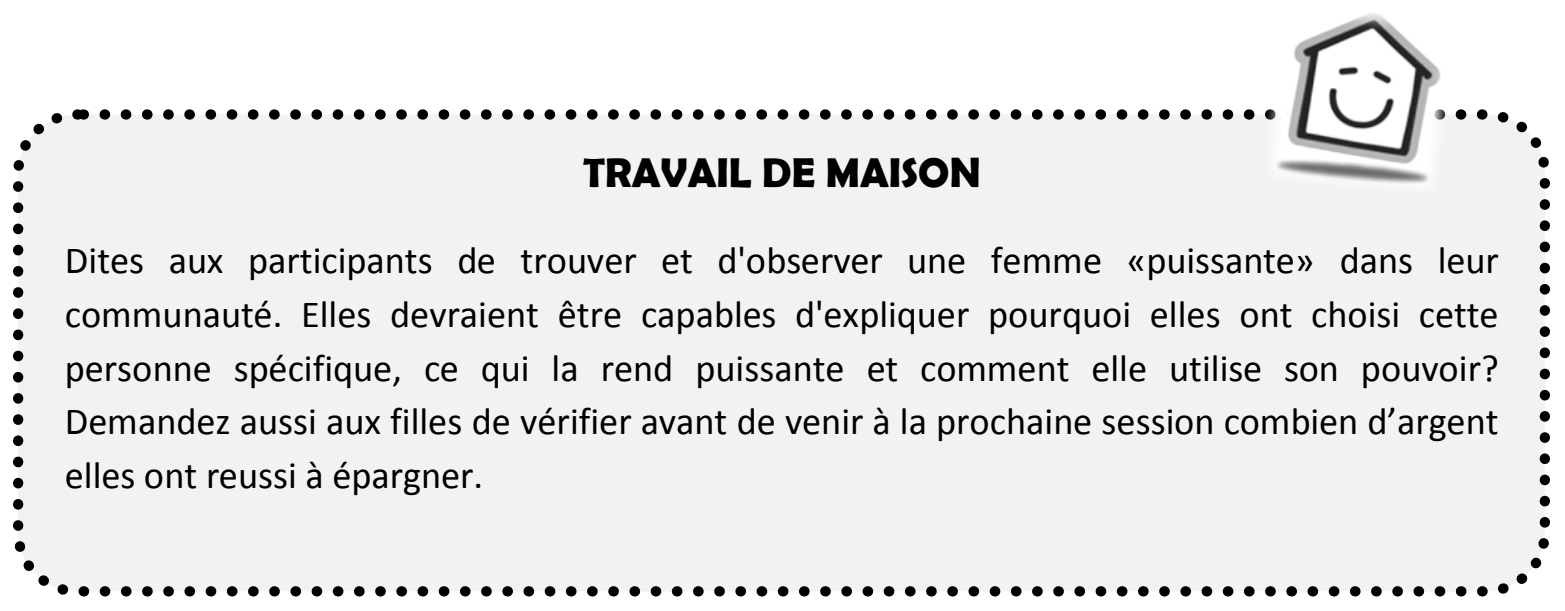




\section{SUPPORT: CARTES D'IMAGES:}

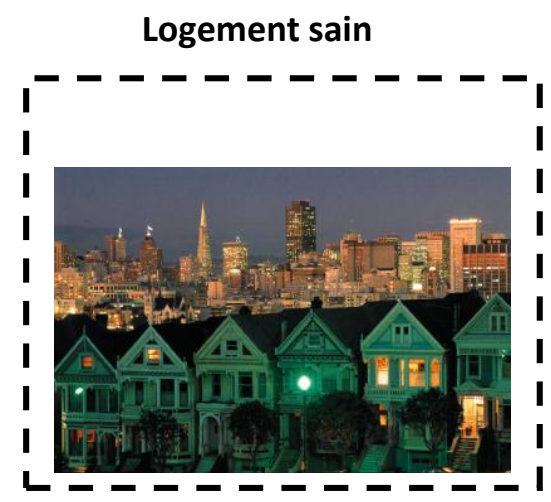

\section{Semence}

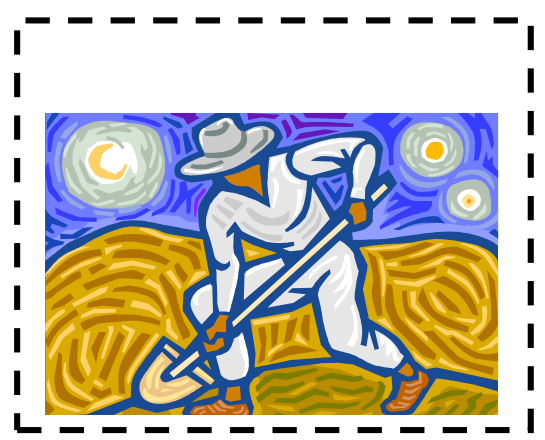

\section{Une Calebasse}

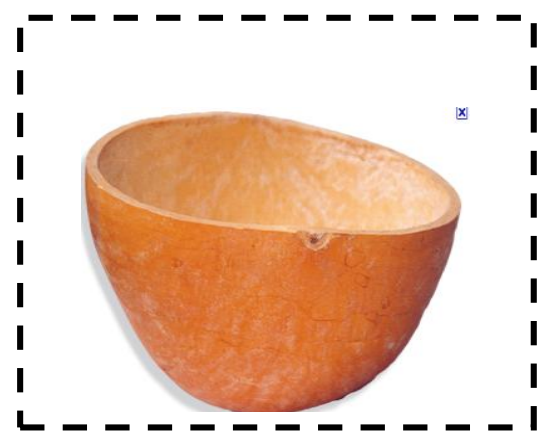

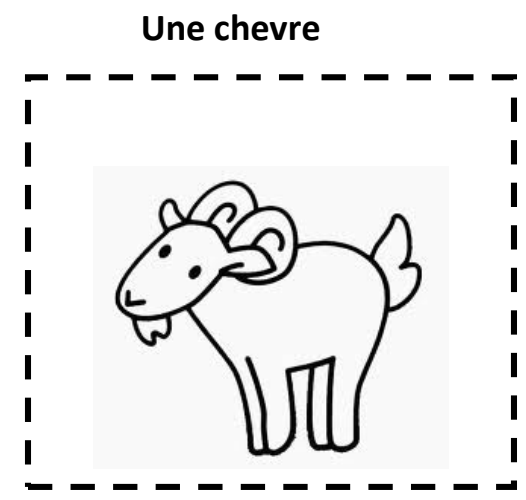

Ecole
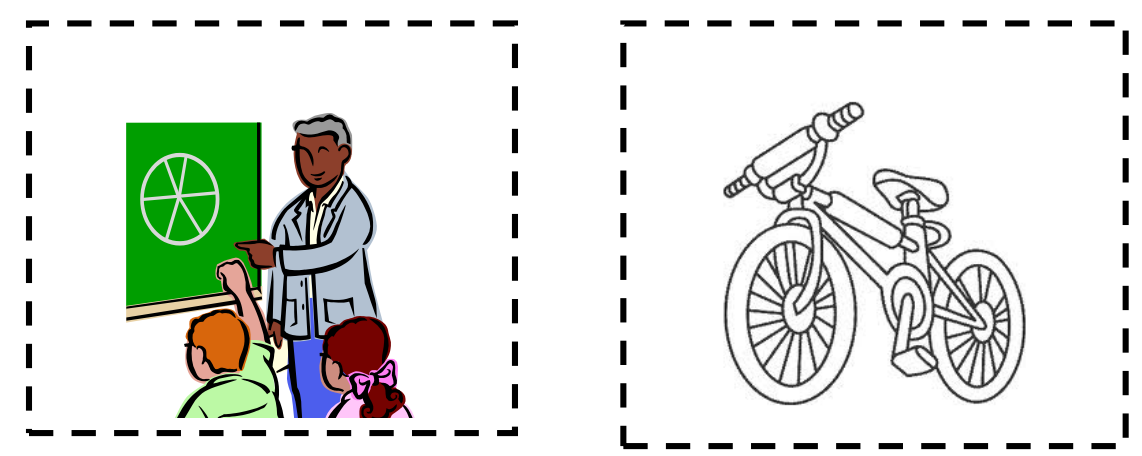

Une hache

Nourriture

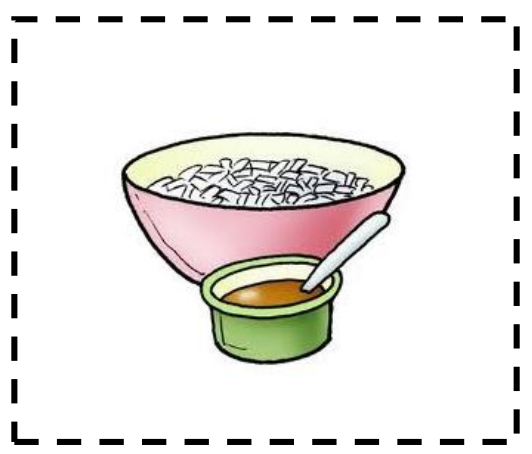

\section{Transport}

La semence

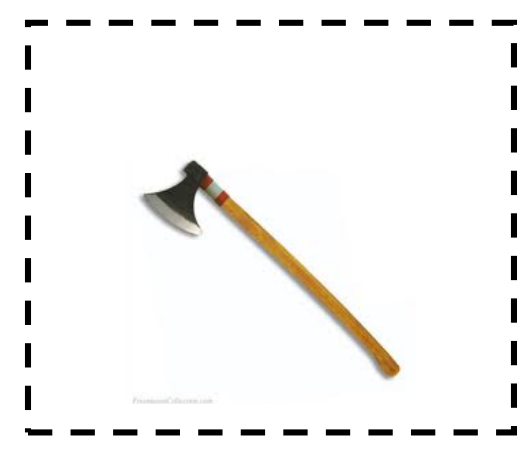




\section{Session 30 : Le harcèlement sexuel, la violence de genre et sexuelle, l'abus}

\section{Objectifs de la session:}

À la fin de cette session, les filles seront capables de:

- Élaborer des plans de sécurité

- Comprendre les différentes formes de violence de genre et les moyens dont les hommes et les femmes se maltraitent

- Identifier les services offerts aux victimes de violence

\section{Matériel nécessaire:}

- Outils d'évaluation de la sécurité

- Grille avec la liste des services antiviolence disponibles dans la communauté (médicaux, juridiques et psycho-sociaux)

\section{Plan de la session:}

- Suivi des plans d'epargne (10 minutes)

- Évaluations de la sécurité (30 minutes)

- La violence sexuelle et de genre (30 minutes)

- Réagir à la violence sexuelle et de genre (20 minutes)

Durée totale: 90 minutes

AVANT LA SESSION: Faites à l'avance, des copies des outils d'évaluation de la sécurité. Rassurez-vous que les informations collectées avant la première session concernant les services médicaux, juridiques, psycho-sociaux et foyers de refuge sécuritaires dans la communauté sont toujours d'actualité. Si non, il faut les mettre à jour avant la session. Faites des copies de la liste des services pour chaque fille. Le mentor doit reproduire le tableau "Sécurité en fonction du moment de la journée » et le tableau " Réseaux sociaux » sur deux fiches du flipchart.

\section{RECAPITULATIF DU TRAVAIL DE MAISON}

Demandez à quelques volontaires de partager les exemples de femmes puissantes qu'elles connaissent. Qu'est ce qui rend ces femmes puissantes? Ont-elles toujours été puissantes ou est-ce que cela est arrivé progressivement au fil du temps?

\section{NOTES D'INFORMATION}

La violence sexuelle est un acte sexuel commis sur un individu sans le consentement de ce dernier. Consentir, c'est accepter de faire quelque chose. Tout le monde a le droit d'accepter ou de refuser des rapports sexuels. La violence ou le harcèlement sexuel désigne tout acte sexuel subit par un individu sans son consentement. Cela inclut le fait de toucher les parties intimes d'un individu, de faire des commentaires sexuels, de montrer des images sexuelles à un individu, et d'avoir des rapports sexuels sans le consentement d'une personne. Le cas le plus extrême de la violence 
sexuelle est le viol. Le viol désigne l'utilisation ou la menace de coercition physique et/ou émotionnelle, afin de pénétrer une personne par voie vaginale, orale ou anale, contre son gré.

La violence sexuelle peut être commise sur n'importe qui, mais les adolescentes sont souvent les cibles. Les auteurs sont souvent connus de la cible (par exemple, les membres de la famille proche, les voisins, les amis, les employeurs, les amis, les partenaires, les ex-partenaires, les enseignants, ou toute autre connaissance) mais peuvent aussi être des étrangers.

La violence sexuelle est un crime et une violation des droits d'un individu. Elle provoque également des problèmes physiques, sociaux et psychologiques et de santé dont le VIH et les grossesses non désirées.

Répercussion de la violence sexuelle : La violence sexuelle peut être perpétrée sur les hommes et les femmes et au Burkina Faso, elle est essentiellement commise sur des enfants, des jeunes filles et des vieilles femmes. La violence sexuelle cause divers problèmes aux survivants.

- Problèmes psychologiques : Les filles qui subissent des violences sexuelles présentent différents problèmes émotionnels tels que l'hyperémotivité, la honte, le doute, l'angoisse, les troubles du sommeil, les cauchemars, la peur des hommes et de l'obscurité. Ces problèmes peuvent persister pendant une période courte ou longue. Les conseils peuvent généralement aider les filles à surmonter ces problèmes.

- Problèmes de santé : Les survivantes de violence sexuelle sont exposées à différents problèmes de santé tels que les ulcères vaginaux, la fistule, et les infections utérines. Elles peuvent tomber enceintes. Les victimes souffrent souvent de violences physiques dans le cadre de la violence sexuelle, lesquelles peuvent causer des fractures, des contusions et des blessures. Les filles qui ont été victimes de violence sexuelle peuvent être infectées par différentes IST, y compris le VIH / SIDA. Elles doivent faire l'objet d'examens immédiatement après l'incident violent et aussi après trois mois.

\section{Les mesures à prendre lorsque quelqu'un est confronté à la violence sexuelle ou au viol}

Appelez au secours : Une fille peut faire face à un violeur qui est soit connu d'elle ou un parfait inconnu. Dans les deux cas, elle devrait hurler et crier pour attirer l'attention des passants. Crier pourrait aussi effrayer l'agresseur et le faire partir de lui-même.

Intervention médicale : II est préférable d'obtenir un examen médical complet peu après un viol même si la femme ne veut pas porter plainte car il donne une preuve médicale qui peut être utilisée si elle change d'avis au sujet du dépôt d'une plainte à la police. La personne qui examine la victime s'occupera généralement des ses autres besoins de santé également.

- Prophylaxie post-exposition : Que les victimes de viol aillent ou non à la police, elles devraient évidemment rechercher une intervention médicale. Le gouvernement fournit des médicaments antirétroviraux pour la prophylaxie post-exposition (PPE) pour protéger les femmes contre le VIH ou d'autres IST après un viol. Cependant, le traitement n'est efficace 
que s'il est pris dans les 3 jours (72 heures) après le viol; le survivant doit donc y accéder dès que possible. Une vaccination contre le tétanos peut aussi être envisagée.

- Contraception d'urgence : Dans les services de santé publique, les pilules de contraception d'urgence (PCU), sont fournies pour éviter une grossesse non désirée. Les PCU peuvent permettre d'éviter une grossesse non désirée si elles sont prises dans les 72 heures suivant le viol. Selon I'OMS, les PCU fonctionnent en interrompant le cycle de reproduction d'une femme - en retardant ou en inhibant l'ovulation, en bloquant la fécondation ou empêchant l'implantation de l'ovule. Les PCU n'interrompent pas une grossesse et ne sont donc pas considérées comme une méthode d'avortement. , Un consentement éclairé est nécessaire avant de donner des PCU et des conseils devraient être offerts.

Signaler un viol ou une agression sexuelle à la police - Signaler un viol à la police est rare pour des raisons culturelles, mais est nécessaire pour l'application des lois afin d'identifier le violeur et d'éviter d'autres viols. Il est important de ne pas laver ou changer de vêtements après un viol, mais d'aller directement à la police ou à l'hôpital car il peut y avoir des empreintes digitales, des tissus biologiques, ou des liquides corporels sur le corps de la femme et les vêtements qui peuvent aider à identifier le violeur. Pour la santé de la femme et pour s'assurer que ce type de preuves est aussi précis que possible, le viol doit être signalé dans les plus brefs délais.

Quand un viol est signalé, la déclaration faite à la police et les autres détails de l'affaire doivent rester confidentiels. Un survivant peut apporter d'autres éléments à sa déclaration à tout moment et peut être accompagné d'un ami ou d'un membre de sa famille. Si des accusations sont portées, l'affaire peut être portée devant un tribunal et la victime sera probablement appelée à témoigner. Aucune victime ne devrait être poussée à porter plainte. Si une victime a peur des représailles de l'agresseur, elle devrait voir comment se protéger avant d'aller à la police. La police peut décider de qualifier la plainte d'agression sexuelle plutôt qu'un viol si l'agression ne correspond pas à la définition juridique du viol. Cela ne signifie cependant pas que l'agression sexuelle est un crime moindre.

Services de soins psycho-sociaux et de soutien : La plupart des victimes de viol ont besoin de services conseils d'urgence, en plus de services médicaux et juridiques. Elles devraient être référées à une organisation qui peut répondre à leurs besoins psychologiques ou devraient rechercher le soutien d'amis et de la famille si une telle organisation n'est pas disponible.

Les survivantes de violence sexuelle éprouvent souvent de la peur, de la culpabilité, de la honte et de la colère. Elles peuvent même développer des troubles de stress post-traumatique (TSPT), présenter des symptômes comme l'anxiété, la dépression, la peine ou des phobies. Dans les cas extrêmes, elles peuvent même devenir suicidaires. Les femmes plus jeunes et les adolescentes sont particulièrement vulnérables aux traumatismes et les prestataires de santé devraient prêter une attention particulière à leurs besoins psycho-sociaux.

Les membres de la famille, les amis ou les conseillers devraient aider les survivants à comprendre leur expérience et à réaliser qu'elles n'étaient nullement responsables et qu'elles peuvent compter sur leur soutien ou celui des professionnels pour les aider. 


\section{INSTRUCTIONS}

\section{Suivi des plans d'épargne (10 minutes)}

1. Expliquez aux filles qu'il y a 4 mois de cela, chaque fille avait fait un plan d'épargne et que maintenant nous allons voir les progrès individuels de vos plans.

2. Demandez aux filles une à une de dire combien elles ont reussi à épargner, et où est-ce que chacune garde son argent (chez elles, dans une caisse populaire, par l'employeur, etc). Notez sur votre outil de suivi la situation de chaque fille. Est-ce que quelqu'une a changé son but? Si oui, le mentor doit noter le nouveau but et plan dans l'outil de suivi.

3. Demandez aux filles de partager avec le groupe leurs défis à épargner. Encouragez les autres filles à donner des idées et suggestions. Si une fille se gène de parler de ses défis au groupe, le mentor doit l'encourager de lui en partager après la session.

\section{$\rightarrow$ Évaluations de la sécurité (30 minutes)}

1. Dites aux filles que la discussion d'aujourd'hui portera sur la violence, et qu'il sera important pour elles de se rappeler la règle de confidentialité du groupe. Expliquez que nous allons commencer la séance d'aujourd'hui avec une activité axée sur la sécurité des filles tout au long de la journée.

2. Demandez aux filles d'utiliser des marqueurs pour indiquer jusqu'à quel point elles se sentent en sécurité au cours des différents moments de la journée. Une croix dans la première colonne indique qu'elle ne se sent jamais en sécurité, une croix dans la deuxième colonne signifie qu'elle se sent quelques fois en sécurité, et une croix dans la troisième colonne signifie qu'elle se sent toujours en sécurité.

3. Ensuite, les filles utiliseront les marqueurs pour remplir les grilles sur les filets de sécurité. Assurez-vous de leur lire chaque ligne à haute voix et de leur demander de marquer la colonne que les concernant.

\section{Note au mentor :}

Si les filles trouvent l'exercice de mettre la croix dans la colonne correspondante trop compliqué, vous pouvez modifier l'exercice :

1. Lire chaque ligne à haute voix. Démandez à toutes les filles qui ne se sentent jamais en sécurité de lever le doigt.

2. Comptez les filles qui ont levé le doigt et marquez le nombre dans la colonne.

3. Repétez pour chaque catégorie.

4. Quand vous avez fini avec l'exercice de "sécurité en fonction du moment de la journée " vous devriez répéter le même exercice avec le tableau « Réseaux sociaux ».

4. À la fin, demandez à quelques volontaires de partager leur évaluation de la sécurité au fil du temps et leur analyse des réseaux sociaux. Assurez-vous de poser des questions d'orientation telles que «qu'est ce qui fait que vous vous sentez en sécurité et en insécurité»? Et "quelles mesures pouvez-vous prendre pour vous sentir plus en sécurité?» Et encouragez les filles à réfléchir aux autres petites mesures qu'elles peuvent prendre pour améliorer leur sécurité et les réseaux sociaux. 


\section{$\rightarrow$ La violence sexuelle et de genre (30 minutes)}

1. Expliquez le concept de la violence basée sur le genre.

La violence à l'encontre des femmes, des filles ou des personnes non conformes aux normes de genre dominantes est appelée «violence de genre».

- Les filles sont particulièrement vulnérables à la violence de personnes qu'elles connaissent, partenaires intimes compris.

- Cette violence peut être de nature sexuelle (attouchements ou rapports sexuels forcés). [Voir la section suivante sur la contrainte sexuelle.]

- Cette violence est d'intensité variable (coups, brûlure ou meurtre).

- Certaines personnes sont victimes de violences parce qu'elles sont perçues (à tort ou à raison) comme étant homosexuelles ou transsexuelles. La violence basée sur l'identité d'une personne est parfois appelée " crime haineux».

- Toutes les violences de genre constituent une violation des droits humains.

La violence de genre reflète et renforce les normes culturelles de masculinité et de contrôle et dominance masculine. Par exemple :

- Les filles sont souvent éduquées dans l'attente d'une faible maîtrise personnelle de leur propre corps.

- Les garçons sont souvent éduqués dans l'optique de la supériorité et de la domination de I'homme sur la femme.

- Beaucoup de filles sont éduquées pour accepter le droit de l'homme à la violence ou la violence comme une expression de l'amour de l'homme. Certains blâment la victime plutôt que de tenir l'homme responsable.

- Dans les communautés où la violence à l'encontre des personnes non conformes aux rôles de genre attendus (homosexuels, transsexuels et féministes déclarées dans les sociétés conservatrices), les «crimes haineux» deviennent parfois un aspect courant de la culture.

2. Expliquez le concept de la contrainte sexuelle.

La contrainte sexuelle est une forme de violence. Elle reflète et renforce l'inégalité de genre.

- Les hommes comme les femmes peuvent être contraints à avoir des rapports sexuels non désirés, mais les femmes en sont plus souvent victimes.

- Certaines communautés ou lois tolèrent la contrainte sexuelle, plutôt que d'y voir un type de violence.

La contrainte sexuelle revêt différentes formes : manipulation affective, duperie, force ou menace physique, insistance verbale, attentes culturelles ou incitation économique. La contrainte sexuelle s'exerce dans de nombreux contextes. Par exemple :

- Elle intervient souvent dans un contexte ou une situation habituellement considérée comme sûre : chez soi ou chez des amis ou parents, à l'école, dans un établissement de culte, au travail, avec un petit ami ou au sein du mariage. 
- Elle peut aussi se produire dans d'autres circonstances : avec un étranger, en échange d'argent ou de cadeaux (avec des pairs ou des partenaires plus âgés), dans les situations de guerre, en prison, etc.

3. Dites aux filles qu'elles vont maintenant former des groupes et dites leur qu'elles se prêteront à des jeux de rôles sur la violence sexuelle et de genre. Divisez-les en groupes de quatre ou cinq, et demandez à chaque groupe de préparer un jeu de rôle autour de ce qui suit:

- Un mari et sa femme discutent de la question d'avoir plus d'enfants

- Un homme et une femme discutent de l'utilisation du préservatif

- Une fille et son employeur discutent de la non-perception de son salaire

- Un homme se saoule et essaie de battre sa femme

- Un homme enlève une jeune fille alors qu'elle est allée chercher de l'eau

4. Demandez à chacun des groupes de jouer leur sketch devant les autres et de laisser le public discuter avec les acteurs (comme s'ils jouaient encore leur rôle) des questions suivantes:

- Qu'avez-vous ressenti lorsque l'homme est devenu violent, que ce soit physiquement ou par ses paroles?

- Pourquoi l'a-t-il fait? Comment pensez-vous qu'il s'est senti?

- Quelles compétences de communication pourriez-vous utiliser? (Rappelez aux filles de repenser aux sessions sur les compétences de vie courante)

- Qui a assisté à l'incident? Qui d'autre était impliqué? Comment pensez-vous qu'ils se sont sentis?

- Qu'avez-vous fait après l'incident? Pourquoi répondez-vous de cette façon?

- Que pensez-vous que les autres personnes feraient? Pourquoi agiraient-ils ainsi?

\section{$\rightarrow$ Réagir à la violence sexuelle et de genre (20 minutes)}

1. Réfléchissez aux conséquences de la violence sexuelle et de genre sur les femmes. Les réponses possibles pourraient inclure des problèmes de santé mentale/psychologique ainsi que des problèmes médicaux, y compris les grossesses et l'exposition au VIH. Reportez-vous à la section «informations générales» pour des exemples spécifiques de conséquences liées à la violence.

2. Expliquez aux filles les mesures à prendre lorsque quelqu'un est confronté à la violence sexuelle ou au viol en utilisant l'information dans « notes d'information ».

3. Partagez la liste des services disponibles pour les victimes de violence au cas où vous aurez intégrer de nouvelles informations. Assurez-vous de mentionner les services médicaux, juridiques, psycho-sociaux et les foyers de refuges sécuritaires. Donnez la fiche de contact actualisée afin que les participants aient des adresses et numéros de téléphone si elles-mêmes ou l'une de leurs connaissances ont besoin de services parallèles. 


\section{Outils d'evaluation de la securité}

(Activité: Plans de sécurité)

\section{Sécurité en fonction du moment de la journée}

\begin{tabular}{|c|c|c|c|}
\hline & $\begin{array}{l}\text { Je ne me sens jamais } \\
\text { en sécurité }\end{array}$ & $\begin{array}{l}\text { Je me sens } \\
\text { quelquefois en } \\
\text { sécurité }\end{array}$ & $\begin{array}{l}\text { Je me sens toujours en } \\
\text { sécurité }\end{array}$ \\
\hline \multicolumn{4}{|l|}{ Matin } \\
\hline \multicolumn{4}{|l|}{ Midi } \\
\hline \multicolumn{4}{|l|}{ Après-midi } \\
\hline \multicolumn{4}{|l|}{ Soir } \\
\hline Nuit & & & \\
\hline
\end{tabular}

\section{Réseaux sociaux}

\begin{tabular}{|l|l|l|l|}
\hline Dans une situation d'urgence ... & Oui & Non & Pas sûre \\
\hline $\begin{array}{l}\text { Avez-vous cinq amies en dehors de la } \\
\text { famille? }\end{array}$ & & & \\
\hline $\begin{array}{l}\text { Avez-vous un lieu où retrouver vos amies au } \\
\text { moins une fois par semaine? }\end{array}$ & & & \\
\hline $\begin{array}{l}\text { Avez-vous une personne vers laquelle vous } \\
\text { tourner en cas de problème personnel (pro- } \\
\text { blème vous concernant ou concernant une } \\
\text { autre personne)? }\end{array}$ & & & \\
\hline $\begin{array}{l}\text { Connaissez-vous une personne à qui vous } \\
\text { pouvez emprunter de l'argent ? }\end{array}$ & & & \\
\hline Avez-vous un lieu sûr où passer la nuit ? & & & \\
\hline $\begin{array}{l}\text { Avez-vous une personne vers laquelle vous } \\
\text { tourner en cas de problème de santé ? }\end{array}$ & & & \\
\hline $\begin{array}{l}\text { Avez-vous une personne vers laquelle vous } \\
\text { tourner en cas de problème } \\
\text { économique? }\end{array}$ & & & \\
\hline
\end{tabular}




\section{Clôture du programme}

\section{Objectifs de la session de clôture:}

- Les filles seront reconnues pour leurs efforts et leurs engagements dans le programme

- La communauté sera informée du bilan du programme

\section{Matériel nécessaire:}

- Des certificats de participation pour les filles qui ont participé à moins de 20 sessions

- Les certificats de participation et de mérite pour les filles qui ont participé à 20 sessions ou plus

- Des certificats de leadership pour les deux filles que le groupe aurait choisi

\section{Plan de la session:}

- Bilan du programme (45 minutes)

- Attribution des certificats de participation (20 minutes)

Durée totale: 65 minutes

AVANT LA SESSION COMMUNAUTAIRE: Comptez le nombre de présences de chaque fille durant les 8 mois du programme. Vérifiez votre tableau de présence pour voir combien de filles ont été présentes au moins à 20 sessions. Obtenez des certificats de participation pour les filles qui ont participé à moins de 20 sessions. Obtenez des certificats de participation et de mérite pour les filles qui ont participé à 20 sessions ou plus. Obtenez des certificats de leadership pour les deux filles que le groupe aurait choisi.

Choisiez deux pairs de filles qui vont faire des jeux de rôle pendant la session communautaire pour démontrer ce qu'elles ont appris dans le programme. Les mentors et les chargés de programme doivent encadrer les filles identifiées pour les jeux de rôle à bien se préparer pour la session communautaire. Encourager les filles à être créatives avec les jeux de rôle. Les jeux de rôle peuvent aborder quelques thèmes du programme - par exemple, les filles peuvent démontrer leurs connaissances et pratiques sur l'épargne, I'hygiène, les maladies, etc. Identifiez un ou deux employeurs qui sont très engagés dans le programme et leur demandez de faire un témoinage pendant la session communautaire pour parler de la fille et de l'importance du programme.

\section{NOTES D'INFORMATION}

Les mentors et les chargés de programme doivent organiser la troisième session communautaire une semaine après la fin du programme. Au cours de cette rencontre, il s'agira de donner les résultats atteints par le programme, reconnaître les efforts des filles, des employeurs, les leaders communautaires et les autres personnes ressources qui se sont engagés au cours du programme.

\section{$\rightarrow$ Bilan du programme (45 minutes)}

1. Expliquez à la communauté qu'on est arrivé à la fin du programme. Rappelez à la communauté que "Filles Eveillées » est un programme qui cible les filles migrantes, et qu'il consiste à créer un 
espace sûr pour une trentaine de filles, guidé par un mentor. Le programme dure 8 mois dont 30 sessions hebdomadaires ont été enseignées tous les dimanches. Notifiez les quatres thèmes que le programme a ciblés.

2. Demandez aux filles volontaires que vous avez choisi de venir devant la communauté et faire leurs jeux de rôles.

3. Demandez aux employeurs que vous avez choisi de faire leurs témoinages devant la communauté.

4. Invitez d'autres personnes de la communauté qui voudraient aussi s'exprimer sur le programme.

\section{$\rightarrow$ Attribution des certificats de participation, de mérite, et de leadership (20 minutes)}

1. Remerciez les filles pour leur participation au programme, et aux employeurs pour leur appui au programme. Si vous voulez, vous pouvez partager quelque chose que vous avez appris ou que vous avez aimé du programme.

2. Expliquez à la communauté que pour reconnaitre les efforts des filles qui ont participé au programme, on va leur remettre des certificats de participation. Appelez d'abord le nom de chaque fille qui ont participé à moins de 20 sessions et donnez le certificat de participation. Encouragez les filles et la communauté à applaudir.

3. Maintenant, expliquez qu'il y a des filles qui ont fait l'effort de participer au moins à 20 sessions. On considère que si une fille a participé au moins à 20 sessions, elle a aquis l'essentiel des compétences du programme. Appelez le nom de chaque fille et donnez le certificat de participation et de mérite. Encouragez les filles et la communauté à applaudir.

4. Expliquez à la communauté que l'ensemble des filles ont designé dans chaque groupe deux filles leaders pour leur dévouement au programme. Expliquez les critères que les filles ont retenus pendant la session. Appeler les deux filles choisies par le groupe et leur donner le certificat de leadership.

5. Invitez les filles ou les membres de la communauté qui veulent s'éxprimer avant de clôturer la session. 


\section{Annexe 1 : Liste des matériaux nécessaires}

Cette liste des matériaux est destinée aux mentors du programme "Filles Eveillées 》. Elle a été crée dans le but de servir de guide ou d'aide-mémoire aux mentors, afin de faciliter la préparation des sessions. La liste comprend deux parties : une première partie qui comprend la liste des éléments nécessaires pour la plupart des sessions (flipchart, marqueurs etc...), et une seconde partie qui comprend la liste des éléments qui requièrent un certain niveau de préparation (une liste d'images, une liste de services anti-violence etc...) que la mentor devrait soit créer elle même, ou identifier et photocopier avant la session.

Matériel nécessaire pour les sessions de ce Guide (pour chaque session se conférer au matériel nécessaire):

- Une balle

- Plusieurs papier flipcharts et paquets de marqueurs (ou un tableau et de la craie)

- Un appareil photo

- Des billets et pièces d'argent

- Une corde

- Feuilles de papier

- Outil de suivi de l'épargne des filles

- Deux seaux

- Eau propre

- Savon

- Gobelet

- Une serviette propre

- Une assiette ou un plateau propre

- Paillettes ou cendre

- Des brosses à dents (30)

- De la pâte dentifrice (30)

- Des petits gobelets ou des verres jetables (30)

- Copie en grand format du brossage des dents

- Morceaux de papier auto-collant

- Copies en grand format des appareils sexuels et reproductifs de la femme

- Copie en grand format des images du corps de l'homme et de la femme

- Copie en grand format du cycle menstruel

- Des échantillons des différentes méthodes contraceptives existant au Burkina Faso

\section{Eléments qui requièrent un certain niveau de préparation:}

- Carte d'identité individuelle

- Flipcharts et marqueurs pour le tableau intitule " a propos de moi et moi-même »

- Support : objectifs à court et a long termes

- Support : photo de l'équipe de football du Burkina Faso

- Une affiche énumérant les « six règles d'or » de l'affirmation de soi

- Un poster avec la liste des trois étapes de prise de décision (s'inspirer de la session 8 sur La Prise de Décision et la Resolution des Problèmes). 
- Des billets et pièces d'argent

- Matériel utilise par une femme lors des menstrues ('morceau de tissu', coton hygiénique, tampons)

- Copie des dessins des appareils sexuels et reproductifs

- Echantillons des méthodes de planification (préservatifs, stérilet, pilule, l'injectable, le collier)

- Supports ou dessins es différentes options de Planification Familiale

- Outil d'évaluation de la sécurité dans le flipchart

- Contact avec des personnes ressources (infirmières, agents de banque, etc)

- Grille avec la liste des services antiviolence disponibles dans la communauté (médicaux, juridiques et psycho-sociaux)

- Différents types de cartes d'images ; copies des images aux pages 62, 73, 169 


\section{Annexe 2 : Traduction des mots clés du curriculum en Mooré et en Dioula}

\begin{tabular}{|c|c|c|}
\hline Mot Clé en Français & Traduction en Mooré & Traduction en Dioula \\
\hline \multicolumn{3}{|c|}{ Module 1} \\
\hline affirmation de soi & $\begin{array}{l}\text { men-zĩnigri } \\
\text { zĩnig f menga }\end{array}$ & ka cogi don i yere la \\
\hline agressivité & $\begin{array}{l}\text { mo-gãgse } \\
\text { yãr-yãre }\end{array}$ & juguya ; benkanniko \\
\hline choix & yam-yãkre & nenata ; nenawoloma ; sugandi (li) \\
\hline compétence de vie courante & $\begin{array}{l}\text { beoog-beoog fãa vumã pvgẽ } \\
\text { tõogo } \\
\text { beoog-beoog fãa vumã pvgẽ } \\
\text { tovm-minim }\end{array}$ & ka se yeremina cogo ra dije na \\
\hline comportement & manesem & məgə kecogo ; məgə kewali \\
\hline connaissance de soi & men-bãngre/bãng m menga & yerelon \\
\hline conséquences & yel-watga/sẽn wat ne/yel-tũudi & nof kkow ; masubaw \\
\hline défi & $\begin{array}{l}\text { kall tı m tõog magbo } \\
\text { kall tı m tõog sardo }\end{array}$ & mon $\varepsilon$ korobəli \\
\hline développement de plans & bõn-daab tikri la magbo & yiriwalibaarabololaninw latigeli \\
\hline estime de soi & nandem-m-menga & lanaya ; y cr cla lanaya \\
\hline fixation d'objectifs & tik bõn-daabo la f mag n gãnege & magw entaw ni \\
\hline leader & taoor soaba & namøgo \\
\hline leadership & taoor louse & naməgəya \\
\hline plan & magbo & fecrew \\
\hline pression des pairs & weoogr sẽn yit $m$ taab nengẽ & tojogənw ka c esiri \\
\hline prise de décision & yik n yaas bũmb yĩnga & latigeli tali \\
\hline programme & Porogaraam/tovmd na-kẽndre & Baara jatemin $\varepsilon$ nin \\
\hline résolution des problèmes & zu-loees yidgri & $\begin{array}{l}\text { kunko janaboli } \\
\text { gw cl cyaw nanab oli }\end{array}$ \\
\hline sentiment & tagsgo & dusudiya walima dusugoya \\
\hline stress & zovbo & naminako ; jəronanko \\
\hline valeurs & $\begin{array}{l}\text { yõodo } \\
\text { piuugu }\end{array}$ & danbew \\
\hline \multicolumn{3}{|c|}{ Module 2} \\
\hline besoins & (bõn-) daabo/bõn-datse & makoyaw \\
\hline capacité financière & ligd tõogo & sebagaya ka taga wariko fanf $\varepsilon$ \\
\hline
\end{tabular}




\begin{tabular}{|c|c|c|}
\hline désirs & tolsem & diyanankow ; nanakow ; yaniyakow \\
\hline emprunter prudemment & n peng ne gũusgu & juruta ni hakili ye \\
\hline épargner & $\mathrm{n}$ kẽgse & ka wari mara \\
\hline examen de l'argent & ligdã gesgo & wari segescgeli \\
\hline façons de dépenser l'argent & ligd yiisg soaya & wariduncogo \\
\hline grosse somme d'argent & ligd (piuug) sẽn waooge & wariba \\
\hline lieu sécurisant pour l'argent & $\begin{array}{l}\text { ligd bĩngr zĩig bũmb sẽn kõn } \\
\text { maan-a }\end{array}$ & warimarayəro juman \\
\hline objectif d'épargne & kẽgsg yam gãnegre & warimarakun \\
\hline plan d'épargne & kẽgsg na-kẽndr gãnegre & warimara fecrew \\
\hline $\begin{array}{l}\text { résolution des conflits } \\
\text { relatifs à l'argent }\end{array}$ & $\begin{array}{l}\text { ligd sẽn wat ne zu-loees nins } \\
\text { yidgri }\end{array}$ & $\begin{array}{l}\mathrm{b} \text { enbaliyaw nanaboli ka taga wariko } \\
\text { fanfe, wariko benbaliyaw nanaboli }\end{array}$ \\
\hline \multicolumn{3}{|c|}{ Module 3} \\
\hline abus de l'alcool & rãmb rikre (tı looge) & doro min kojugu \\
\hline carie & yeené baancé & gnin so' \\
\hline choléra & $\begin{array}{l}\text { kolera } \\
\text { (sãad la wobdẽ) }\end{array}$ & tonkan ; kunfilanintu ; kunfilatu \\
\hline coqueluche & kõs-leo-leo & $\begin{array}{l}\text { kalosabasəgəsəgo ; keteketenin ; } \\
\text { ketekete }\end{array}$ \\
\hline drogues & dorok & drôgui \\
\hline fièvre typhoïde & 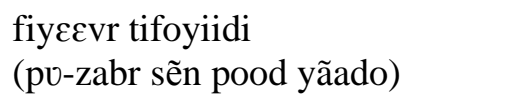 & nugusogobana \\
\hline $\begin{array}{l}\text { fréquentation des services } \\
\text { de santé par les } \\
\text { adolescentes }\end{array}$ & $\begin{array}{l}\text { kom-bub sẽn kẽnd laafi baoob } \\
\text { zussẽ }\end{array}$ & $\begin{array}{l}\text { soun gouronniw ka } \\
\text { dotorosso taga }\end{array}$ \\
\hline gencive & yeené nemdo & gni bougou \\
\hline hépatite $B$ & epatiti & biyenbana \\
\hline hygiène corporelle & $\begin{array}{l}\text { laafı sẽn kẽed ne yĩng yılgemd } \\
\text { wع\&ngẽ }\end{array}$ & fari bescya ; fari saniya \\
\hline hygiène dentaire & $\begin{array}{l}\text { laafi sen keed ne yééné yilgemd } \\
\text { weengen }\end{array}$ & $\begin{array}{l}\text { gni saniyali } \\
\text { gni saniya ko }\end{array}$ \\
\hline maladies & bãase & banaw \\
\hline mythes & $\begin{array}{l}\text { tags-vudo } \\
\text { tagsg sẽn pa tik fi }\end{array}$ & $\begin{array}{l}\text { koo min ti yere yere ye; kabakofenw; } \\
\text { dakamanakokorolenw }\end{array}$ \\
\hline paludisme & weoogo/koom/pali & sumaya \\
\hline pneumonie & $\begin{array}{l}\text { pinmoni } \\
\text { (fulfuud bãase) }\end{array}$ & n عncbana ; fogəfogəbana \\
\hline
\end{tabular}




\begin{tabular}{|c|c|c|}
\hline poliomyélite & kar-mendı bãaga & senfagabana ; murukubana \\
\hline rougeole & bi & fenmis $\varepsilon n$; misenmannin \\
\hline tétanos & tãntãnoose & tetanəsi ; sonbana \\
\hline tuberculose & kõs-kvdgo & sogəsəgəgwe \\
\hline vaccination & bogbo & boloci \\
\hline \multicolumn{3}{|c|}{ Module 4} \\
\hline abus & maan tı loog nugu & benkani \\
\hline accouchement & rogem & jigi ; wolo \\
\hline avortement & pog yiisgu & konətine \\
\hline blennorragie & belenorazi & sopisi \\
\hline canaux vaginaux & kınde/søzga & mouso ya sira \\
\hline cancer & kãnsєcre & kanscri ; duun \\
\hline cancer du col de l'utérus & rog-vak kãnsecre & wolonougou bana \\
\hline chancre mou & sãnkrrnu & bagabaga ; leminanpo \\
\hline changement émotionnel & yĩn-sidg wecngẽ tekre & haminankow yelemani \\
\hline changement psychologique & tags węngẽ tekre & hakililataw yelemani \\
\hline changements sociaux & duni teoongo & dinclatigekow yelemani \\
\hline chlamydia & klamidiya & bobo douma \\
\hline clitoris & zigri & biy ekise ; kere \\
\hline contraception d'urgence & $\begin{array}{l}\text { rogem gidgr ne yãgbo/ne } \\
\text { zaeegre }\end{array}$ & wololalofecre karabanin \\
\hline coton hygiénique & pekr lam-palse & kooli kunben kəori ; koton izeniki \\
\hline cycle menstruel & kiuug-kiuug pekre & coli wagati \\
\hline cycle mensuel & kiuug-kiuug pekre & kalo o kalo kooli \\
\hline dépistage SIDA & suda bãag biis baoobo & sidabana segesegeli \\
\hline diaphragme & fulfuud ne yãad sok nem-pıvoga & muso ka manan ; kalanin ; negenin \\
\hline excision & pagb bãongo & $\begin{array}{l}\text { bolokoli ; } \mathrm{k} \varepsilon \mathrm{n} \varepsilon \mathrm{k} \varepsilon \mathrm{n} \varepsilon \mathrm{li} ; \\
\text { siginegek or } っ\end{array}$ \\
\hline faire des cicatrices & poog wi/ kii- wi & ka wègnè kii \\
\hline fecondation & Paaga nee rao rog-biisi lagengo & $\begin{array}{l}\text { Kiè ni mousso ka wolo kissè } \\
\text { gnagamini }\end{array}$ \\
\hline fistule obstétricale & $\begin{array}{l}\text { rovd-kiuug ne poglem sẽn pãsg } \\
\text { n yek taaba }\end{array}$ & $\begin{array}{l}\text { p erenperenda min bi bo nuguden ni } \\
\text { wolonugu ce }\end{array}$ \\
\hline genre & pag bi raoa & 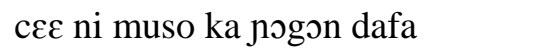 \\
\hline
\end{tabular}




\begin{tabular}{|c|c|c|}
\hline gestion de la grossesse & pvg zãabo & kənっ ladoncogo \\
\hline grossesse & poga & kono \\
\hline harcèlement sexuel & rat-m tı $\mathrm{m}$ pa rat-f manesem & $\begin{array}{l}\text { nint ooroko minw nasinnin be } \\
\text { cenimusoya ma }\end{array}$ \\
\hline herpès & $\varepsilon r p \varepsilon s$ & logo logoka tchi \\
\hline hymen & poglem limdi & $\begin{array}{l}\text { biy } \varepsilon \text { ding } \varepsilon \text { datugunan ; bogotigiya ; } \\
\text { sorosogolo }\end{array}$ \\
\hline identité & yalẽ/ned yalẽ & halalaya \\
\hline implant & $\begin{array}{l}\text { bũmb sẽn bok n ning yĩng pogẽ } \\
\text { n na n gidg rogem } \\
\text { kangẽ bãng sẽn gidgd rogem } \\
\text { nemsẽ bãng sẽn gidgd rogem }\end{array}$ & $\mathrm{n}$ oriplilan n'a jəgənnaw \\
\hline $\begin{array}{l}\text { infection sexuellement } \\
\text { transmissible }\end{array}$ & $\begin{array}{l}\text { bãas sẽn tũud ne pag la rao } \\
\text { lagem-n-taare }\end{array}$ & jenbanaw \\
\hline injectable (contraceptif) & piguure & pikiri mi bé kônô bali \\
\hline menstruation & pekre/kiuugu & kalobo ; kooli \\
\hline ovaire & $\begin{array}{l}\text { pag rog-biig gel-loabda } \\
\text { pag rogem biis gel-loabda }\end{array}$ & fandaga ; fanwoloba ; kis $\varepsilon w o l o b a$ \\
\hline ovule & $\begin{array}{l}\text { pag rog-bila } \\
\text { pag rogem bila }\end{array}$ & denfan \\
\hline pénis & raoolem & f oro ; сعya ; bolo \\
\hline $\begin{array}{l}\text { période de l'adolescence et } \\
\text { les règles }\end{array}$ & pog-sademd sasa la pekre & balikuya ni kooliw tuma na \\
\hline petites lèvres & poglem no-gãn-bãoonego & mousoya ka dagolo fitini \\
\hline pilule & tt-biis sẽn kvvd rog-biisi & pilili ; fura kise; furakiscnin \\
\hline planification familiale & rogem yaagre/rogem gũusgu & denbaya ladonko juman \\
\hline pouvoir et impuissance & tõog la yo-kunga (lar sẽn baage) & fanga ni dêsê \\
\hline préservatif féminin & souda siin foadg puglem & $\begin{array}{l}\text { mousso ka fougounan nafaman } \\
\text { mousso ka manani min bé do nièfèla } \\
\text { la }\end{array}$ \\
\hline préservatif masculin & souda siin foadg raolem & $\begin{array}{l}\text { kiè ka fougounan nafaman } \\
\text { kiè ka manani }\end{array}$ \\
\hline $\begin{array}{l}\text { prophylaxie poste- } \\
\text { exposition }\end{array}$ & $\begin{array}{l}\text { gibl-meng manesem, yell sã n } \\
\text { maan tı pa tũ ne gũusg poore }\end{array}$ & 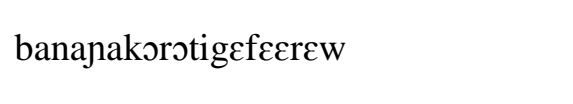 \\
\hline puberté & $\begin{array}{l}\text { bivongo } \\
\text { pagre/raoore } \\
\text { sẽn ta pag/rao ziiga }\end{array}$ & balikuyatuma \\
\hline règles & pekre/kiuugu & $\begin{array}{l}\text { kalo ; kalobo ; faniko ; t } \varepsilon g \varepsilon \text { be jii ra; } \\
\text { kalo ye }\end{array}$ \\
\hline
\end{tabular}




\begin{tabular}{|c|c|c|}
\hline $\begin{array}{l}\text { répercutions de la violence } \\
\text { sexuelle }\end{array}$ & $\begin{array}{l}\text { modr kẽed-n-taar zu- } \\
\text { loeese/modr kẽed-n-taar sẽn wat } \\
\text { ne zu-loees ninsi }\end{array}$ & benkani ka kasara \\
\hline reproduction & sẽn wat ne biiga & bangey ali \\
\hline réseaux sociaux & koong kibay kũun ne taaba & balima bolo ani sigui gnogon bolo \\
\hline santé de la reproduction & $\begin{array}{l}\text { manesem sẽn wat ne biig } \\
\text { weqngẽ laafı yelle }\end{array}$ & 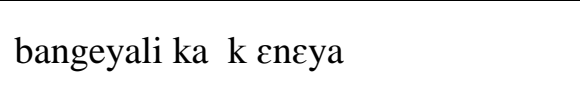 \\
\hline scrotum & lam-biis gãongo & b eleforoko; belekiliforoko \\
\hline sexe & pag bi raoa & ceya ni musoya/ nefela \\
\hline sexualité & poglem la raoolem wecngẽ yela & cenimusoya \\
\hline spermatozoïdes & $\begin{array}{l}\text { rao rog-biisi } \\
\text { rog rogem bila }\end{array}$ & lawakise \\
\hline sperme & $\operatorname{man} t$ & lawaji \\
\hline spermicide & tım sẽn kvvd rog-biisi & lawakise faganan \\
\hline stérilet & $\begin{array}{l}\text { poglem pvgẽ bãng sẽn gidgd } \\
\text { rogem }\end{array}$ & mana mimbi bla wolo nougou konon \\
\hline syphilis & sifilis & poronbana \\
\hline $\begin{array}{l}\text { systèmes reproductifs des } \\
\text { femmes }\end{array}$ & $\begin{array}{l}\text { pag yĩn-wils sẽn tõe } n \text { wa ne } \\
\text { biiga } \\
\text { pag yĩng pogẽ manesem sẽn tõe } \\
\text { n wa ne biiga }\end{array}$ & musow ka bangeminanw \\
\hline $\begin{array}{l}\text { systèmes reproductifs des } \\
\text { hommes }\end{array}$ & $\begin{array}{l}\text { rao yĩn-wils sẽn tõe } n \text { wa ne } \\
\text { biiga } \\
\text { rao yĩng pvgẽ manesem sẽn tõe } \\
n \text { wa ne biiga }\end{array}$ & $\mathrm{c} \varepsilon \varepsilon \mathrm{w}$ ka bangeminanw \\
\hline tampon & tãmpõ & tanpon \\
\hline testicule & lam-biisi & b elckili ; kayakili ; kili \\
\hline trichomonas & tirkomonaase & 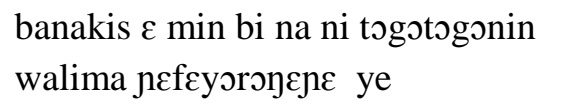 \\
\hline trompes & $\begin{array}{l}\text { pag rog-biis soaya } \\
\text { pag rogem biis soaya }\end{array}$ & fant $\varepsilon m \varepsilon s i r a$ \\
\hline urètre & raoolem pogẽ rovd-sore & negenetemesira \\
\hline utérus & $\begin{array}{l}\text { rog-vaka } \\
\text { rogse }\end{array}$ & wolonugu ; denso ; denforogo \\
\hline vagin & $\begin{array}{l}\text { kinde } \\
\text { secga }\end{array}$ & 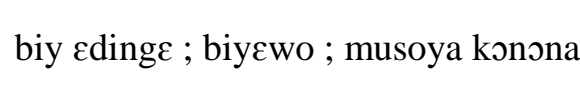 \\
\hline VIH/SIDA & suda & sidabana \\
\hline $\begin{array}{l}\text { violence de genre et } \\
\text { sexuelle }\end{array}$ & $\begin{array}{l}\text { modr kẽed-n-taare } \\
\text { kẽed-n-taar ne pãnga }\end{array}$ & 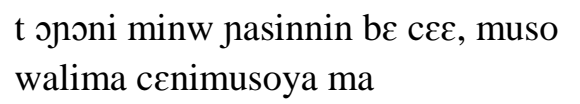 \\
\hline
\end{tabular}

